\title{
PRELIMINARY DESIGN STUDY OF THE TANDEM MIRROR REACTOR (TMR)
}

R. W. Moir, W. L. Barr, G. A. Carlson, W. L. Dexter,

J. N. Doggett, J. H. Fink, G. W. Hamilton, J. D. Lee,

B. G. Logan, W. S. Neef, Jr., M. A. Peterson, and M. E. Rensink

July 15, 1977

Work performed under the auspices of the U.S. Department of

Energy by the UCLLL under contract number W-7405-ENG-48.

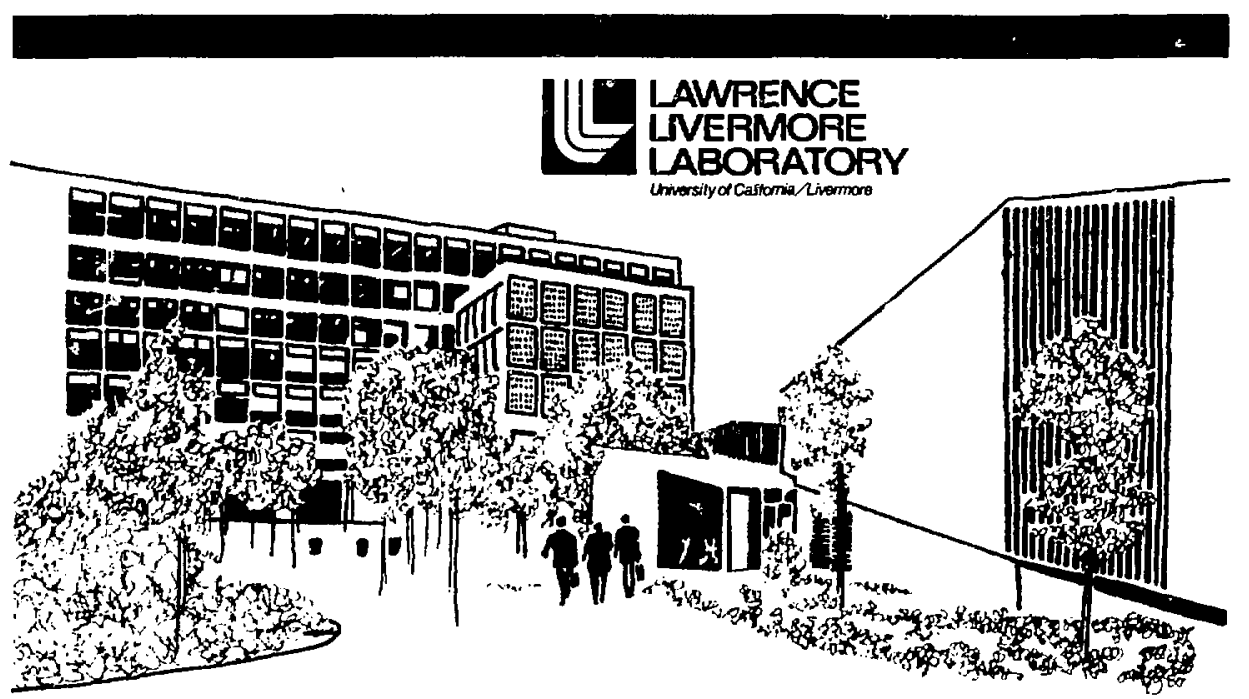

$+$

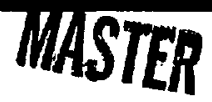




\section{!L \\ I_AWRENCE IIVEPMORE I_ABORATORY}

Unversily of Calitorme' tivermore Callornika 94550

\section{UCRL 52302 \\ PRELIMINARY DESIGN STUDY OF THE TANDEM MIRROR REACTOR (TM?)}

R. W. Moir. W. L. Barr, G. A. Carlson, W. L. Dexter.

J. N. Doggett. J. H. Fink, G. W. Hamilton, J. D. Lee.

B. (j. Logan. W. S. Neef. Jr.. M. A. Peterson, and M. E. Rensink

MS date: July 15. 1977

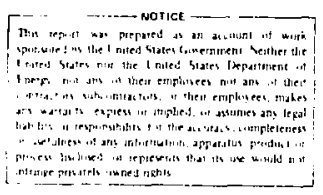




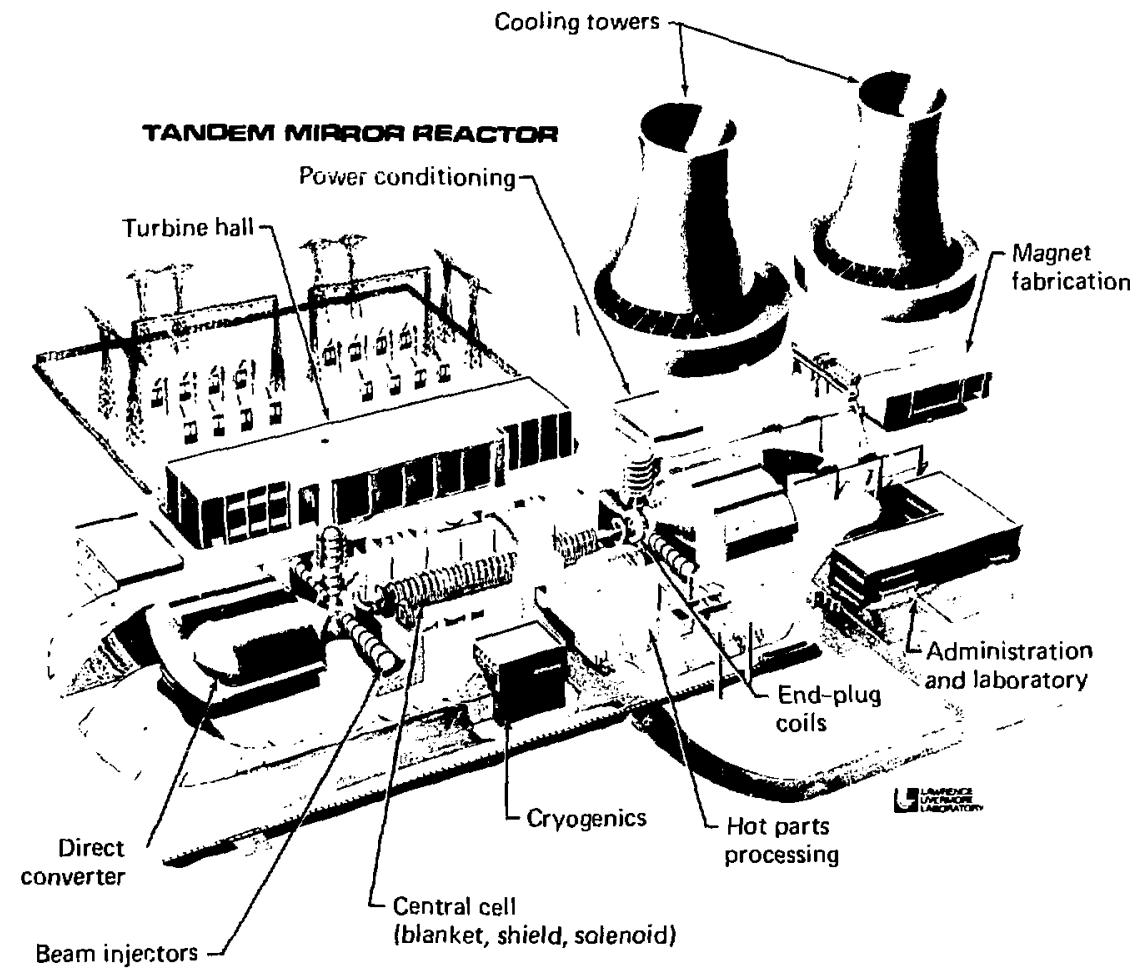




\section{CONTENTS}

Abstract . . . . . . . . . . . . . . . . . . . . . 1

Chapter 1. Intruduction . . . . . . . . . . . . . . . $3-4$

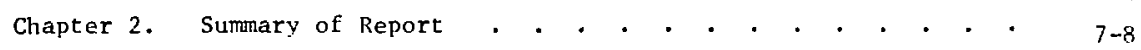

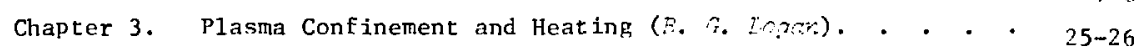

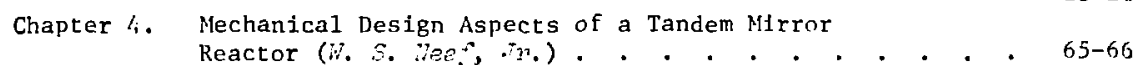

Chapter 5. Design of the Plug-Coil System ( $\because$. A. Peterson) . . . 83-84

Chapter 6. Nucleonics (. . D. Lee) . . . . . . . . . . . . 127-128

Chapter 7. Neutral-Beam Injector (.7. 7. Fi:n?,

ard J. i. ilamizton) . . . . . . . . . . . 143-144

Chapter B. Direct Energy Converter for the Tandem Mirror Reactor

(H. L. Bnrr) . . . . . . . . . . . . . . 167-168

Chapter 9. Power Supplies for the Tandem Nirror Reactor

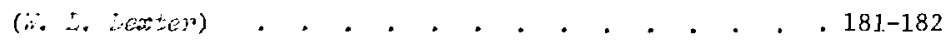

Chapter 10. Parametric Analysis (C. A. Cantaon) . . . . . . . 189-190

Chapter 11. Startup Scenario (B. G. Logan and R. W. Moip) . . . . 209-210

Chapter 12. Assessment of Needed Technology (R. W. Moin) . . . . 217-218 


\section{PRELIMINARY DESIGN STUDY OF THE TANDEM MIRROR REACTOR (TMR)}

\section{ABSTRACT}

The concept of tandem mirror confinement employs the positive electrostatic potential of two ordinary (standard) mirrors to plug the end losses from a long, power-producing solenoid. A proof-of-principle evaluation of the concept will be provided ty the Tandem Mirror Experiment (TMX), now under construction at Lawrence Livermore Laboratory (LLL).

This report describes work done in Fiscal Year 1977 by the Fusion Reactor Studies Group of LLL on the conceptual design of a 1000-MW(e) Tandem Mirror Reactor (TMR). The high Q (defined as the ratio of fusion power to injection power) predicted for the TMR ( $\sim 5)$ reduces the recirculating power to a nondominant problem and results in an attractive mirror fusion power plant.

The fusion plasma of the TMR is contained in the 100-m-1ong central cell where the magnetic field strength is a modest $2 \mathrm{~T}$. The blanket for neutron energy recovery and tritium breeding is cylindrical and, along with the solenoidal magnet, is divided into 3-m-long modules to facilitate maintenance. The central cell is fueled (but not heated) by the injection of low-energy neutral beams near its ends. Thus, the central cell is simple and of low technology. The end-cell plasmas must be of high density and high energy in order to plug and heat (via the electrons) the central-cell plasma. The present conceptual design uses 1,2-MeV neutral-beam injection for the end plugs and a cryogenic-aluminum, Yin-Yang magnet that produces an incremental field of about $1 \mathrm{~T}$ over a field of $16 \mathrm{~T}$ produced by a pair of $\mathrm{Nb}_{3} \mathrm{Sn}$ superconducting solenoids. Important design problems remain in both the neutral-beam injector and in the end-plug magnet. Also remaining are important physics questions such as alpha-beam particle transport and end-plug stability. These questions are discussed at length in the report and suggestions for future work are given. 
CHAPTER 1. INTRODUCTION 
The concept of the Tandem Mirror Reactor (TMR), as developed by Dimov et $a r^{1-1}$ and by Fowler and Logan, 1-2 employs the positive electrostatic potential of two ordinary (standard) mirrors to plug the loss of plasma from a long solenold. The combination results in $Q$ values of 5 or so (where $\mathrm{Q}=$ fusion power/injection power), whereas the standard mirror $Q$ is at most slightly more than 1 . The concept looks suffictantly interesting that a major experiment called the Tandem Mirror Experiment (TMX) has been initfated to check out and explore the underlying phystcs questions.

A reactur based on this concept that proiuces $1000 \mathrm{NW}(\mathrm{e})$ consists of a solenoidal magnet about $100 \mathrm{~m}$ long. A cylindrical blanket is used for energy recovery and tritium breeding. Thus, the reactor itself is simple and of low technology. The end plugs, however, are of high technology, having the high magnetic fields needed to confine the high-pressure plasma and the high injection energy $(\sim 1.2 \mathrm{MeV})$ needed to achieve good magnetic confinement. The plasma density in the plug $\left(\sim 8 \times 10^{14} \mathrm{~cm}^{-3}\right)$ is considerably higher than that in the central cell $\left(\sim 1 \times 10^{14} \mathrm{~cm}^{-3}\right)$ to provide a potential barrier at each end $\left[\phi=T_{e} \ln \left(n_{p l u g} / n_{\text {solenoid }}\right)\right]$. Be- cause the function of the end-plug plasma is to provide a potential barrier and not to produce plasma, only deuterium (or even hydrogen) need be injected. Therefore, neutron production in the end plugs is quite low. The end-plug magnets are very small [the size of the Mirror Fusion Test Facility (MFTF) coil] but of high field strength (17 T). Thus, what high technology is required for the TMR is concentrated in the end plugs.

This report describes how a 1000 MW(e) TMR would look based on our present understanding. However, because the design is based on physics and engineer Ing ideas that are rapidly evolving, this report is a preliminary description of a TMR; several design problems will be addressed by us in a later version of the design. For example,

- At the beginning of this study, we did not understand the problem of ash ( $\left.{ }^{4} \mathrm{He}\right)$ buildup; consequently, ash bulldup was ignored in most of the design. However, on the basis of. much new understanding of steadystate equ1l1brium concentrations of ash as discussed in the chapter on physics (Chapt. 3), we believe steady state may be possible from the ash buildup point of view. However, the design consequences are as yet unknown. 
- The high-field superconducting magnet, for example, is in principle feasible based on measured properties of superconductors; however, there is no experience with such large (3-m-diam), high-field (17-T) coils. As an example of evolving high-level technology, on the other hand, this report includes a description (Chapt. 7) of an Invention, the arc snubber, that allows us to hold high voltages over large areas, thereby making feasible 1-MeV injectors for the end plugs.

The report is organized Into chapters covering each major component or topic area; a Summary follows this Introduction.

\section{REFERENCES}

1-1. G. I. Dimov, V. V. Zakaidakov, and M. E. Kishinevsky, Fiz. Plasmy 2, 597 (1976); also
G. I. Dimov, V. V. Zakaidakov, and M. E. Kish1nevsky, "Open Trap with Ambipolar Mirrors," in Lros. 6th Inter. Conf. Plasma Physics and Controlled Nuclear Fusion Research, Berchtesgaden, lied. Rep. of Germany, 1976 (IAEA, in preparation), Paper C4. 1-2. T. K. Fowler and B. G. Logan, "The Tandem Mirror Reactor" Comments on Plasma Physics and controlied f'usion Research, 2, 167 (1977).

1-3. F. H. Coensgen, Project Leader, TMX Major Project Proposal, Lawrence Livermore Laboratory, Rept. LLL-Prop-148 (1977). 1-4. F. H. Coensgen, Project Leader, MX Major Project Proposal, Lawrence Livermore Laboratory, Rept. LLL-Prop-142 (1976). [Note: The "MX" designation was subsequentiy changed to "Mirror Fusion Test Facility" (MFTF) ] . 


\section{CHAPTER 2. SUMMARY OF REPORT}

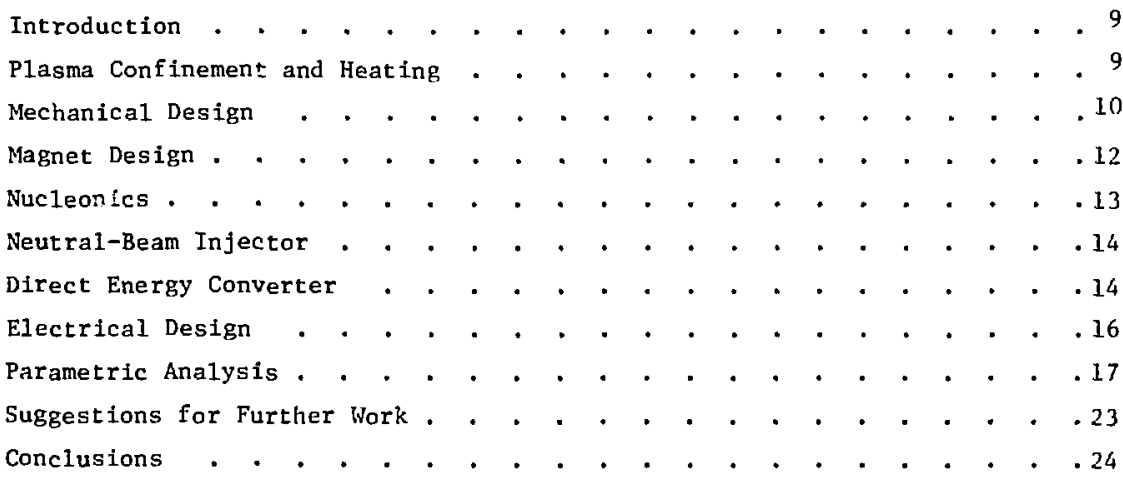




\section{INTRODUCTION}

This report describes the results of a 6-month study of a 1000-MW(e) fuston reactor based on the tandem mirror confinement concept. Our objective was to uncover the major problem areas in the design of a Tandem Mircor Reactor (TMR) as well as to determine the reasibflity of the concept. An artist's conception of an electric power plant based on TMR is shown in the frontispiece to this report; feneral parameters for the TMk analyzed in this study are given in I'able 2-1.

PLASMA CONFLNLMEN'] AND HEATINC;

In the TMR configurat ion shown in lig. 2-1, the plugs are assumed to
Table 2-1. General parameters for 1000-MW(e) Tandem Mirror Reactor.

\begin{tabular}{ll}
\hline Parameter & Value \\
\hline$P_{\text {net }}$ & $1000 \mathrm{MW}(\mathrm{e})$ \\
Recirculat ing power & 4.8 \\
Plant efriclency & $43 \%$ \\
Direct capital cost & $34 \%$ \\
Jength of solenold & $\$ 1.3 / \mathrm{W}(\mathrm{c})$ \\
Wall loading & $100 \mathrm{~m}$ \\
Fusion power density & $2 \mathrm{MW} \cdot \mathrm{m}^{-2}$ \\
\hline
\end{tabular}

be classical tnirror machines sustalned by the injection of high-energy neutral. beams. Ion losses from the central cell are replentshed by the injection of low-energy neutril beams, pellets, or gas at the thin plasma fans in the inner mirror throat. lihe design

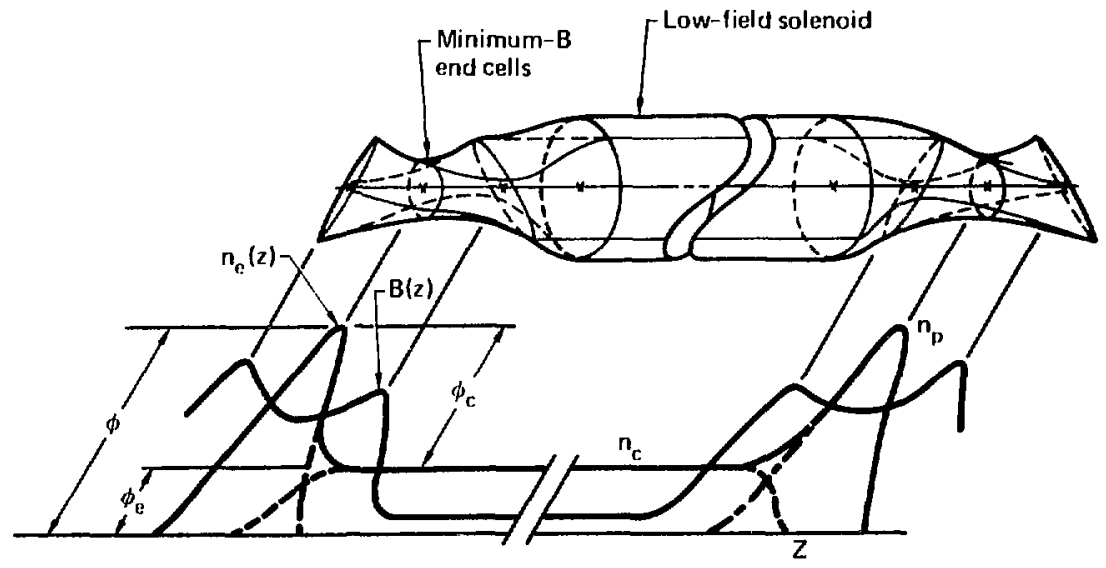

Fig. 2-1. Tandem mirror with ambipolar barriers at the ends. 
constderations giveis in Chapt. 3 lead to the parameters shown in Table 2-2. For these ralues, we assume that impurities and alpha particles do not accumulate; however, in Chapt. 3 we also present detailed calculations for the steady-state equilibrium alpha density and cross-field transport.
MECHANICAI, DESIG:

Table 2-3 lists some key mechanical design paramsters for the TMR. As shown in the Frontispiece, the reactor is composed of a power-producing central cell, end-plug magnets, $1.2-\mathrm{MeV} \mathrm{n}^{0}$ injectors to sustain the

Table 2-2. TMR physics parameters.

\begin{tabular}{|c|c|}
\hline Parameter & Value \\
\hline \multicolumn{2}{|l|}{ End Plug: } \\
\hline Injection energy & $1200 \mathrm{keV}$ \\
\hline Mean ion energy & $880 \mathrm{keV}$ \\
\hline Plasma density & $8.6 \times 10^{14} \mathrm{~cm}^{-3}$ \\
\hline Trapped current into each plug & $220 \mathrm{~A}$ \\
\hline Electron temperature & $42 \mathrm{keV}$ \\
\hline$\beta_{\text {plug }}\left(\beta \equiv \frac{-}{B_{\text {vac }} / 2 \mu_{0}}\right)$ & 1 \\
\hline Plasma radius & $0.5 \mathrm{~m}$ \\
\hline Bvac plug (midplane) & $16.5 \mathrm{~T}$ \\
\hline & 1.07 \\
\hline Potential at midplane & $350 \mathrm{keV}$ \\
\hline Particle $n \tau$ & $2.5 \times 10^{14} \mathrm{~s} \cdot \mathrm{cm}^{-3}$ \\
\hline \multicolumn{2}{|l|}{ Central Cel1: } \\
\hline Current injected & $1570 \mathrm{~A}$ \\
\hline$\beta$ & 0.7 \\
\hline Length & $100 \mathrm{~m}$ \\
\hline Plasma radius & $1.2 \mathrm{~m}$ \\
\hline$B_{\text {vac }}$ (midplane) & $2.4 \mathrm{~T}$ \\
\hline Electron temperature & $42 \mathrm{keV}$ \\
\hline Ion temperature & $30 \mathrm{keV}$ \\
\hline Plasma density & $1.1 \times 10^{14} \mathrm{~cm}^{-3}$ \\
\hline Particle nT & $7.7 \times 10^{14} \mathrm{~s} \cdot \mathrm{cm}^{-3}$ \\
\hline Potential of plasma & $260 \mathrm{keV}$ \\
\hline
\end{tabular}



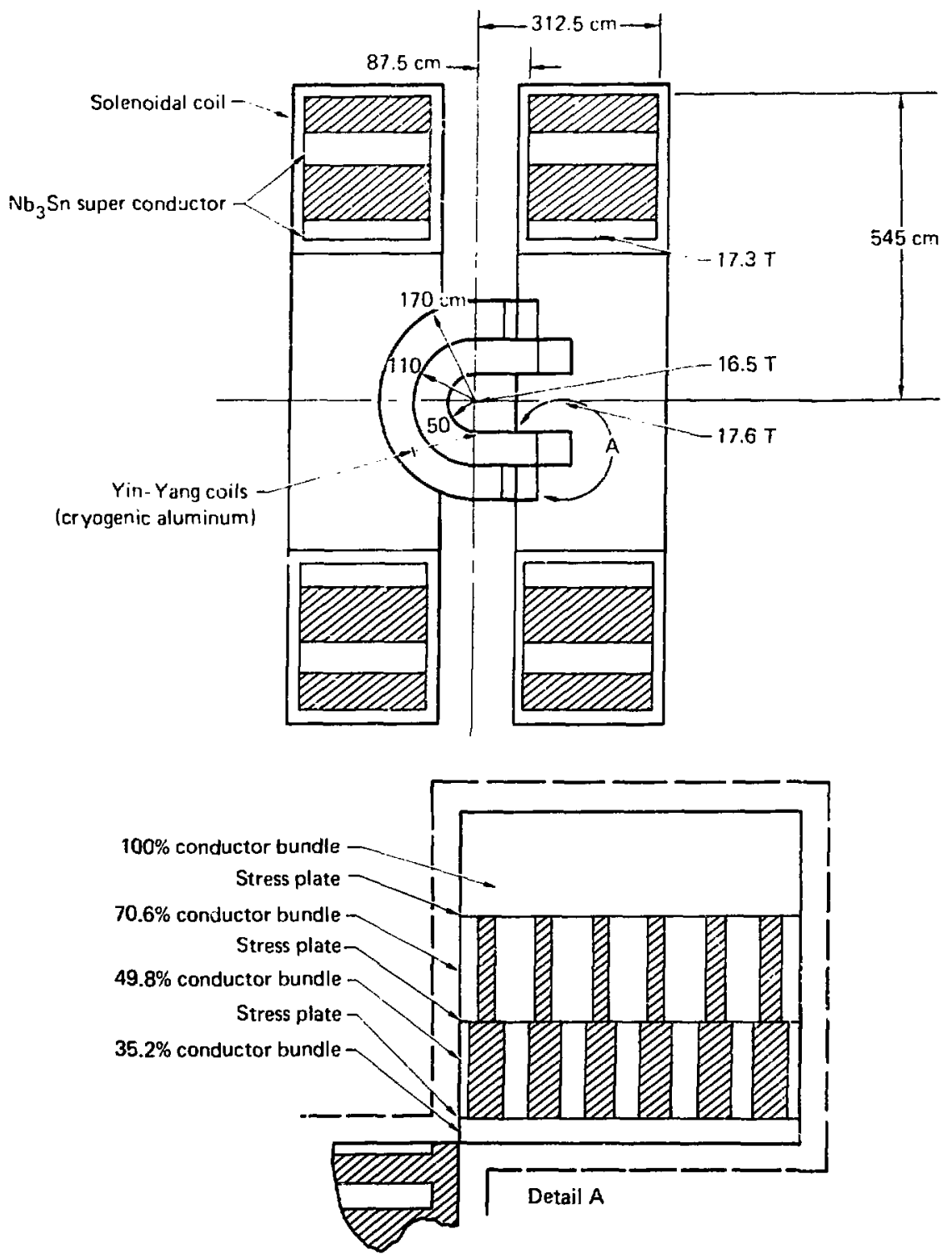

Fig. 2-2. Plug coll set (16.5 T). 
Table 2-3. Mechanical design parameters for the central cell.

\begin{tabular}{ll}
\hline \multicolumn{1}{c}{ Parameter } & \multicolumn{1}{c}{ Value } \\
\hline $\begin{array}{l}\text { First-wall radius } \\
\text { Length }\end{array}$ & $1.56 \mathrm{~m}$ \\
$\quad$ No. of modules & $100 \mathrm{~m}$ \\
No. of pa:allel heat-exchange loops & 36 \\
Magnetic field & 6 \\
Blanket coolant & $2.4 \mathrm{~T}$ \\
$\quad$ Inlet temperature & Helium \\
Exit temperature & $300^{\circ} \mathrm{C}$ \\
Inlet pressure & $530^{\circ} \mathrm{C}$ \\
Helium pressure drop & 50 atm \\
Blanket structure & 2 atm \\
Average power density into direct converter & Inconel 718 \\
\hline
\end{tabular}

end-plug plasma, and direct converters at each end to recover the charged particles that leak out the ends. The power-producing section is a 100-m-long cylinder. - The power production in the end plugs is low because they are not supplied with D-T ions, but rather only with $D$ ions. Thus, the energy-recovery blanket is in the cylindrical section, and only shielding is provided in the plug, region. The reactor is modular in construction, with sections of the solenoidal magnet, cylindrical blanket, and vacuum chanber all being of modest size. The blanket is helium cooled with a standard, high-temperature, gas-cooled, reactor power-conversion system. Waste heat is dumped to the atmosphere via wet cooling towers.
MAGNET DESIGN

The plug magnet shown in Fig. 2-2 is a hybrid superconducting and cryogenic magnet; its parameters are given in Table 2-4. The complex-shaped Yin-Yang magnet is about the size of the magnet for the Mirror Fusion Test Facility (MFTF) and produces an incremental field of about $1 \mathrm{~T}$ over the fleld of $15.5 \mathrm{~T}$ produced by the pair of $\mathrm{Nb}_{3} \mathrm{Sn}$ superconducting solenoids. The joule heating in the coil is about $0.5 \mathrm{MW}$ and cequires about $25 \mathrm{MW}$ of refrigeration power.

This hybrid magnet was initially thought to require a lower level of technology than would an al1-superconductor approach; however, we now conclude the reverse for two reasons: 
Center-cell solenoid:

$\begin{array}{ll}\text { Baxis } & 2.4 \mathrm{~T} \\ \text { Material } & \mathrm{Nb}-\mathrm{T} \mathrm{I} \\ \text { Bore } & 8.4 \mathrm{~m} \\ \text { Length } & 100 \mathrm{~m} \text { (36 segments) }\end{array}$

End-plug solenoidal pair:

Bore $5.75 \mathrm{~m}$

Baxis $16.5 \mathrm{~T}$

$\begin{array}{ll}\mathrm{B} \text { conductor } & 17.3 \mathrm{~T}\end{array}$

Material $\mathrm{Nb}_{3} \mathrm{Sn}$

End-Plug cryogenic Yin-Yang coil:

length

$2.8 \mathrm{~m}$ (mirror to mirror)

$B_{\text {mirror }}$

$17.6 \mathrm{~T}$

Material

$\mathrm{Al}$

R vac

1.07

Resistive power

$0.25 \mathrm{MW}$ (each plug)

- Our parametric analysis has shown that reducing the central field of the plug from $16.5 \mathrm{~T}$ to $15 \mathrm{~T}$ increases the plant unit cost by only 3 or $4 \%$, and a lower field considerably improves the usefulness of $\mathrm{Nb}_{3} \mathrm{Sn}$.

- The structural support for the cryogenic aluminum design was much more difficult than originally thought.

Because of our desire for a compact design, the shielding against neutrons is an important aspect of the design. We conclude in this study that the shielding in the present design is not adequate and that the magnet must be increased to allow for more shielding.

NUCLEONICS

\section{Blanket}

In our preliminary appraisal of TMR nucleonics, we conclude that the high $Q$ and favorable geometry of the central cell allow us to contemplate a blanket of modest performance. The high $Q$ eliminates the need for energy multiplication to achieve a favorable power balance; the very low area for neutron streaming (from the large 
length-to-dlameter rat lo of the cylindrical central cell) coupled with no requirement for energy multiplication leads to only a minimal requirement for neutron multiplication in the blanket. Thus, no bery 11 ium is needed in the blanket.

Our overall objective is to keep the blanket as simple and inexpensive as possible. In this 11ght, we are considering a liquid-11thium (natural) and stainless-steel blanket cooled by helium. The blanket is $84 \mathrm{~cm}$ thick, its tritium breeding ratio is 1.16 , and its energy mult 1plication is 1.20 .

\section{Shielding}

Between the blanket and the central-cell coils is $90-\mathrm{cm}$ thick steel- and lead-loaded concrete shieldirig. Our appraisal indicates that this shielding plus the blanket should provide more than enough shielding for the superconducting, centralcell coils.

Protecting the cryogenic-aluminum Yin-Yang coils is the major shielding challenge in this TMR design. The critical area appears to be at the inner mirror of the plug where $D-T$ plasma leaking from the central cell generates 14-MeV neutrons at a significant rate. According to preliminary calculations, 64-cm-thick, tungstenbased shielding is needed in the inner mirror region. Because the present plug design allows for on $1 y$ $15 \mathrm{~cm}$ of shieluing in this region, the magnet must be redesigned to provide for more shielding. With the possible exception of the outer mirror and the injection beam lines, the rest of the plug can use iron- and leadbased shielding.

NEUTRAL_-BEAM INJECTOR

In Fig. 2-3, we show a conceptual design of a high-current, 1.2-MeV $0^{0}$ Injector with an anticlpated operating efficlency of $70 \%$. Parameters for the injector design are given in Table 2-5. Al1 of the components in the proposed beam line are elaborations of physics experiments that have a1ready been reported in the literature. However, major aỏvances in all phases of neutral-beam technology are needed to meet the requirements of the TMR. These include a continuous source of negative ions, an efficient electronstripping cell, and the development of associated power conditioning and control equipment. We believe that the neutra1-beam requirements of the TMR provide a realistic goal for the not-too-distant future.

\section{DIRECI ENERGY CONVERTER}

Direct converters to recover power from the plasma lost from the ends 


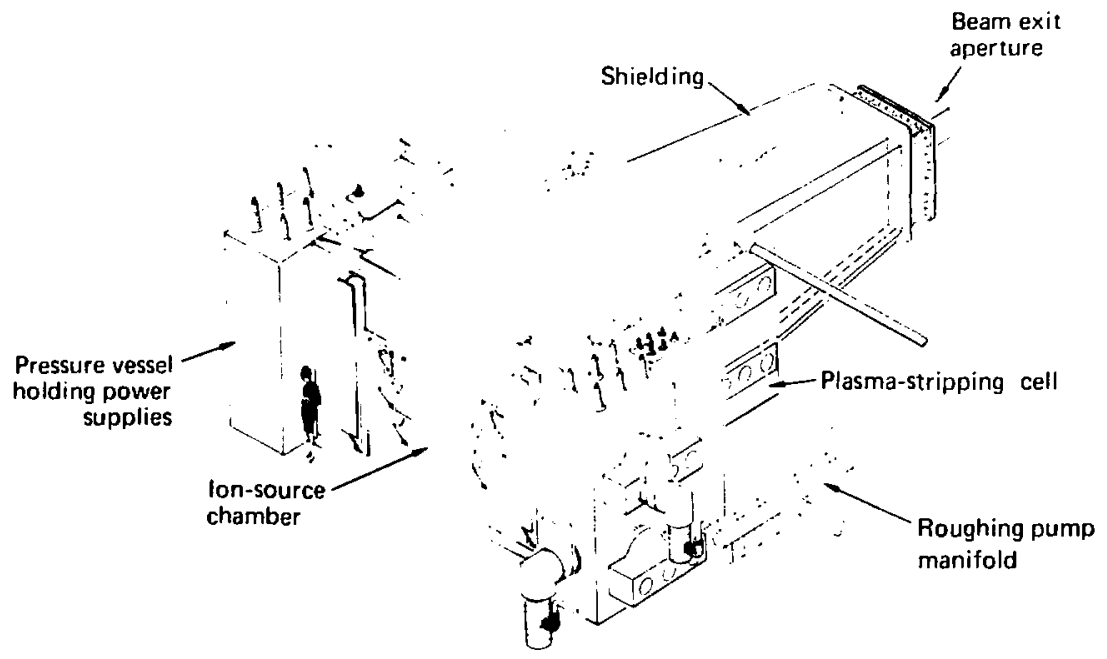

Fig. 2-3. A 1.2-MeV neutral-beam injector.

Table 2-5. Parameters for the neutral-beam injector.

\begin{tabular}{ll}
\hline \multicolumn{1}{c}{ Parameter } & \multicolumn{1}{c}{ Value } \\
\hline Beam energy & $1200 \mathrm{keV}$ \\
Equivalent $\mathrm{D}^{0}$ current (per injector) & $122.5 \mathrm{~A}$ \\
Total injected power ( 4 units) & $588 \mathrm{MW}$ \\
Operating mode & Continuous \\
Type of beam line & Negative Ions \\
Source of negative ions & Ce double charge- \\
& exchange cell \\
Type of stripping cell & Ce plasma \\
System efficiency & $80 \%$ \\
System cost & \\
\hline
\end{tabular}

a The values shown in this table are preliminary estimates used in the body of this study. Upon subsequent analyses, we estimated that the efficiency of the injector system would be $73 \%$ and the cost of the neutral-beam injector per kilowatt would be $\$ 320$ divided by the efficiency. This iteration results in an approximate increase of $13 \%$ in the direct cost of the electric kilowatt supplied by the TMR. 
of the TMR can be effective. The high ambipolar potential and the low Ion temperature result in good efficlency even with a single collector stage. Nbout $60 \%$ of the total efflux power (carried by escaping fuel lons, alpha particles, and electrons) can be directly recovered after allowing for losses due to incident electrons, grid Intercept: ion, and secondary and thermionle clectrons.

The two types of reglons in the TMR - the central cell and the end plugs - result in two distinct energy groups of lons and suggest a two-stage direct converter. The addition of a second collector stage in the direct converter ralses its efficiency to about $70 \%$. The direct converter would also control the recycling of cold electrons from the end walls. problems associated with space charge, voltage holding, and capacitively stored energy appear to be solvable. Figure 2-4 shows a cross section of the direct converter electrodes, and Table 2-6 gives some typical parameters.

\section{ELECTRICAL DESIGN}

The electrical aspects of the plant are divided into standard power plant equipment such as the generator and power-conditioning equipment for transmisston and the aspects unlque to this fusion reactor such as power supplies for the neutral-beam injector and power-conditioning equipment for the direct energy converter. About $43 \%$ of the gross electrical power is recirculated in the plant to power the injector; this aspect of the plant is thus very important. Over

1032-MW input:

438.5-A, 80?-keV $D^{4}$

1284-A, 380-keV, $D^{+}+T^{1}$

288-A, 731-keV He ${ }^{++}$

2011-A, 42-keV e-

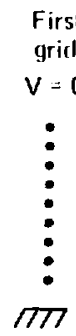

Ground connection
Second

gricl

$-170 \mathrm{kV}$

152-A input at $-170 \mathrm{kV}$ collector

$+350 \mathrm{kV}$

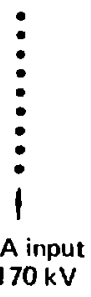

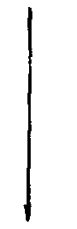

1853-A output at $+350 \mathrm{kV}$

FIg. 2-4. Power and current flow in a single-stage direct converter on the TMR, where $n_{D C}=\frac{(1853 \times 350)-(152 \times 170)}{1.032 \times 10^{6}}=0.603$. 
Table 2-6. Typical parameters for the direct energy convertar.

\begin{tabular}{lc} 
Mean ion energy & $470 \mathrm{keV}$ \\
Mean electron energy & $42 \mathrm{keV}$ \\
Power in ions & $950 \mathrm{MW}$ \\
Power density & $100 \mathrm{~W} / \mathrm{cm}^{-2}$ \\
Ifficiency (one-stage) & $60 \%$ \\
$\begin{array}{l}\text { Cost per kilowat of } \\
\text { incident power }\end{array}$ \\
\hline
\end{tabular}

$a_{\text {the energies quoted are at the direct }}$ converter.

three fourths of this recireulated power comes in the form of directcurrent power from the direct converter.

The startup electrical system uses power-conditioning equipment to bring power of the line during the brief time $(\sim 3 \mathrm{~s})$ during startup. After the approximately 3-s startup period, this equipment is gradually (during a 10- to 30-min period) switched over to use for putting power into the line.

\section{PARAMETRIC ANALYSIS}

The analytic model of the TMR used in the parametric study begins with a self-consistent description of tandem mirror physics. The physics model relates the densities, energies, and containment times of the fons and electrons in the plugs and central cell. We assume that the plugs are mirror mathines with classical end iusses sustained by high-energy, neutral-beam injection. The central cell is fueled by low-energy neutral beams of deucertum and trition. Electrons heated by the energetic ions in the plugs in curn heat the cold fons in the central cell. In the parametric study, the equations of the physics model are solved by specifylug the plug injection encrgy, the plug mitror ratio, the mirror ratio between the plugs and the plugs and in the central ce11, and the ion temperature of the central cell. The physics vutput conststs of the varlous energies, containment parameters (nit's), density rat los, and $Q$.

Next, the spectfication of a single magnetic [:eld strength (usually the central field of the plug) allows us to calculate al1 the plasma densities and the fusion power density in the central cell. Then, spectication of the blanket energy nultiplication factor $M$ and varius efriciencies (thermal conversion, direct conversion, and neutral-beam injection) allows calculation of power flows. At this point, the power quantities are unly relative because we have not yet selected an absolute power level.

Finally, speciflcation of a single power quantity (usually the net electric power) allows complete design of the reactor. The dimensions of 
the cyl indrlcal, centra]-cell plasma and Lhe approxtmale]y spherleal pluss

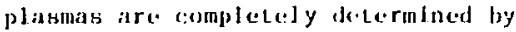
che contral acell-tomplugs volume rat 10, the fusfon power density of the central cell, the dosdred total lusjun power, and the requfrement for magnotic flux comservat fon thromphome

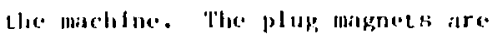
detilgnoed to provelate tha apecificel

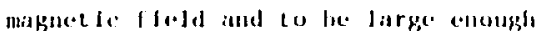
to contala the plup plasimas. Illes

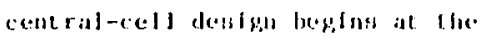
tyl Indrleal fIrut wisl (threa alpha riall l away from Llac plasmal and proceceds outward through Llice blambet, Hhleld, magnel, Hupport at rublur.,

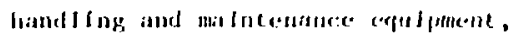

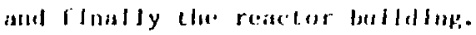

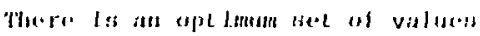
for play, Injecelom emersy, plup-to-

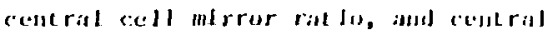

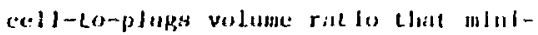
mines the ceste of prower. for a

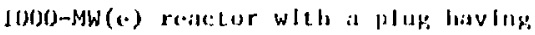

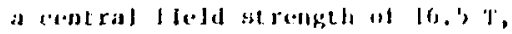
a p]ug vilculum mbror ratio ol 1.07 , and f: valuesis of 1.0 and 10.7 in the. plug and central cel! , roufectlvely, we liave foutid the opt Imam values lo be: plub JujeqL lon encrgy (deuterlum) a $1200 \mathrm{keV}$, plug-tocontral cell mieror raclo 07.0 , and central-cell Lon temperature - $30 \mathrm{keV}$. 'The blanket encrgy multiplicat ion factor for this case was 1.2 (no) bery 11 lum), and the efflelencles for
Lhermal converiaion, slmgle-slage. dleac converislon, and Inject fon were: $40 \%, 60 \%$, and $80 \%$, respecet ivily. The

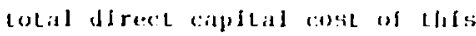

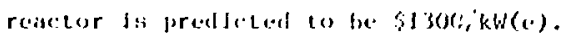

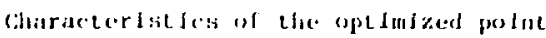

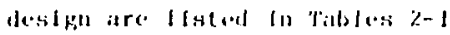
Ihrouph 2-6. The cast cist hate breakdown fa stvold la liabla $2-7$.

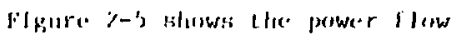

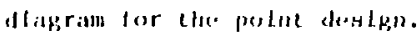

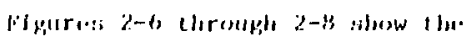

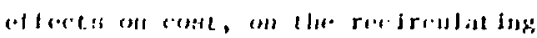

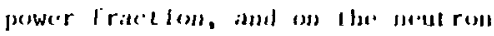

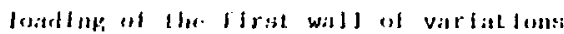

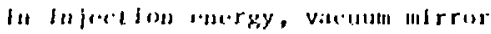

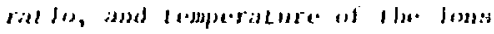
in the contral relle

Al lla begfunfag af libla study,

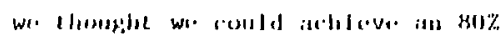

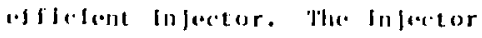

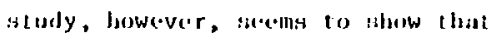

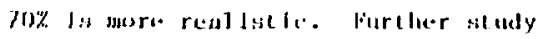

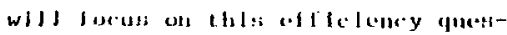
L $(1))$.

Wo. have illso thalled the al rect

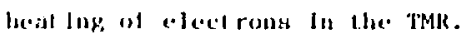
Ith In an atcractve Idea lor two remsulls:

- It mily ull Imately be more c.filclent and lews expensive than metet ralbealll lutal Lng, and

* The cost cat inale las not very uecurale and should b. Incerpreted in che conlext of the rcope of the study. 


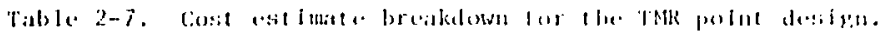

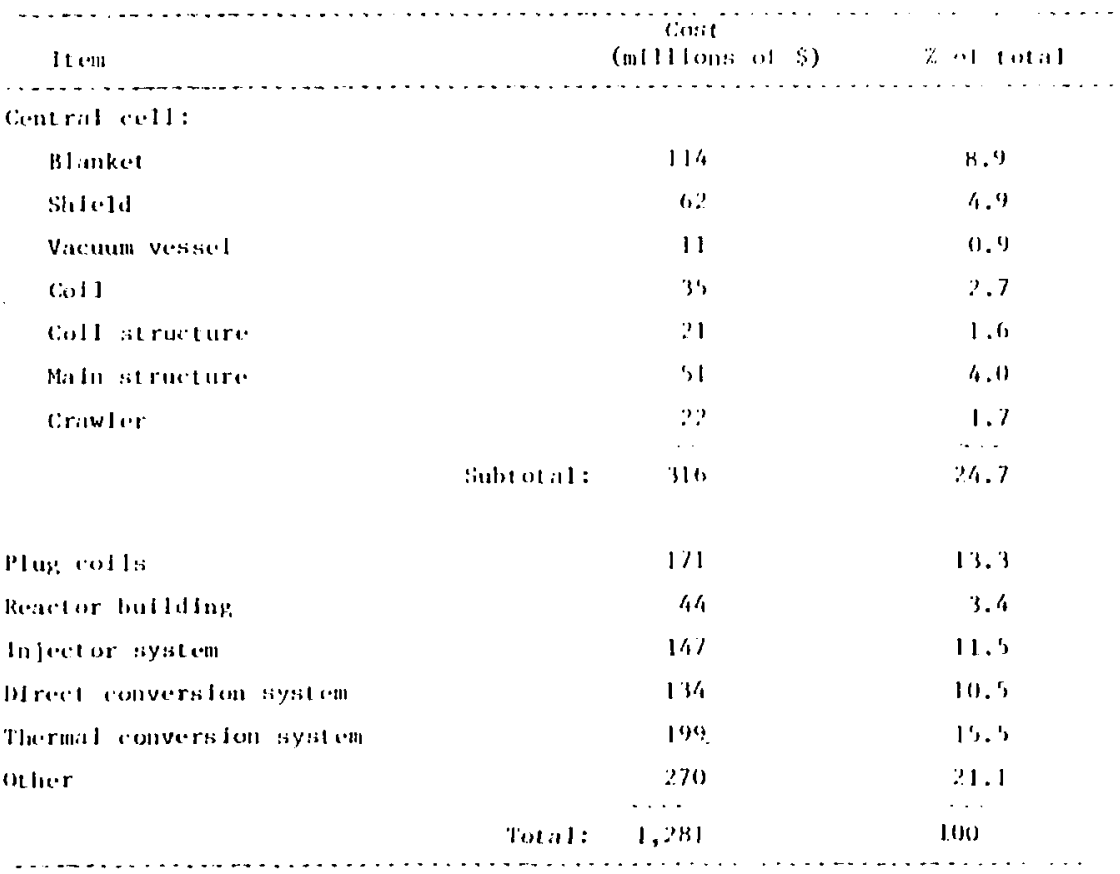

- Il may reduce clace rectufred

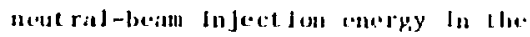
(*nd $[\cdot 11$.

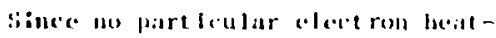

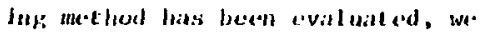

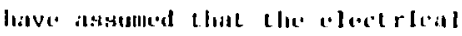
efflefens:y of such heate ing. che coupling efflefency to the platsmat, and its cost per unll power aro the Hanc das for the neutral-bean Injectors. Figure 2-9 showt the opt Imum neat ralbean energy and the predlcted cost of optinlazed $1000 \mathrm{MW}(\omega)$ reactory as fumel lous: at fF, the Iritet fon of the

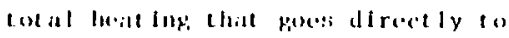

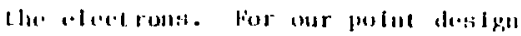

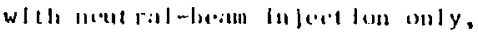

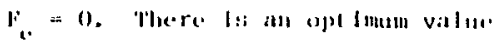
of li Mear 0.7) lor which the ressit

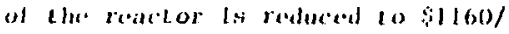
kW(a). Fla meat ral-besum in feret lon aterpy for this optelated reake or tis 500 ke.v.

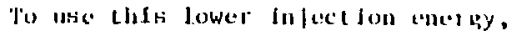

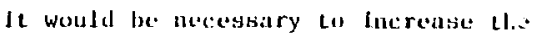
plus mirror ratio $k_{p}$ from 2 to 3 by 


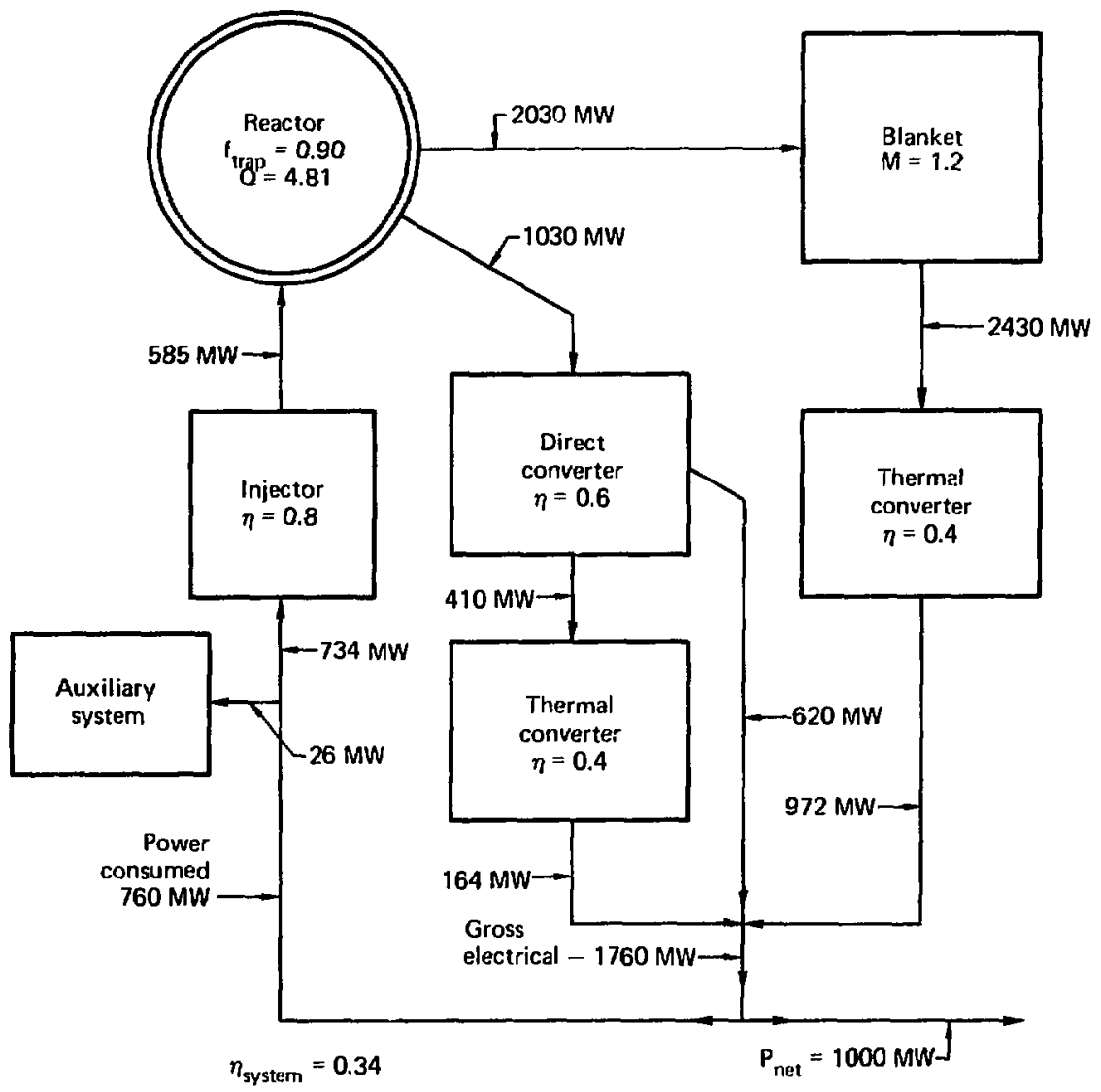

Recirculating power fraction $=\frac{\text { power consumed }}{\text { gross electrical }}=0.43$

Fig. 2-5. TMR power flow diagram.

a combination of higher $\beta_{p}$ and $R_{p}$ vac, gles in Chapt. 10.) Increasing $R_{p}$ so as to reduce the amblpolar cutoff should not entail a large increase energy $\left(\phi_{e}+\phi_{e}\right) /\left(R_{p}-1\right)$. (See in reactor cost, as indicated by arguments on minimum injection ener- Fig. 10-8. 

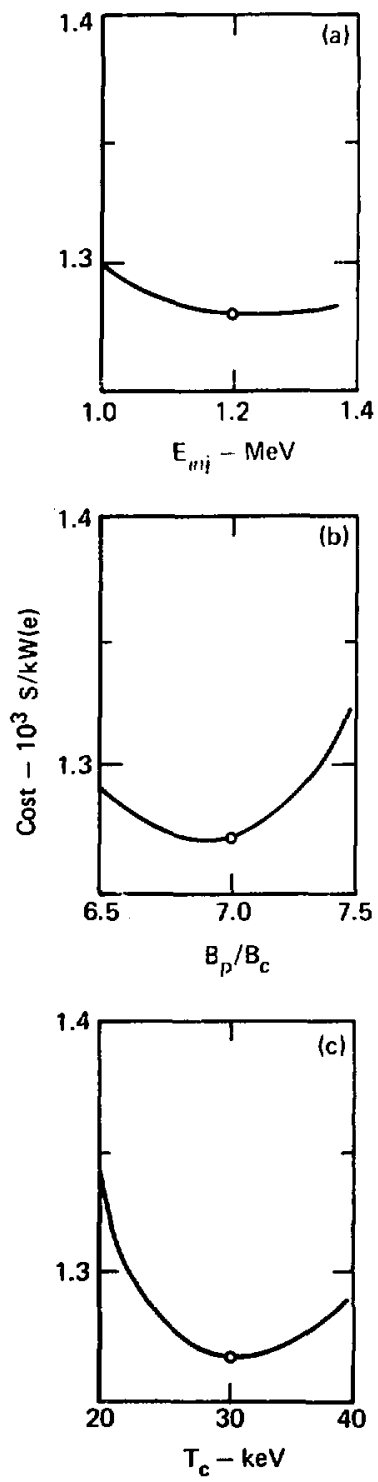

Fig. 2-6. Effect on cost of 1000-MeV(e) TMR's of variation in (a) injection energy $E_{\text {inf }}$, (b) vacuum mirror ratio between the center of the plug and the central cell $\mathrm{B} / \mathrm{B}$,
and (c) temperature of the lons $\mathrm{p}_{\text {in }} \mathrm{c}$, the central cell $\mathrm{T}_{\mathrm{C}}$. (Note: In Figs. 2-6 through 2-8, the data points identify the values seleated for the point design.) 

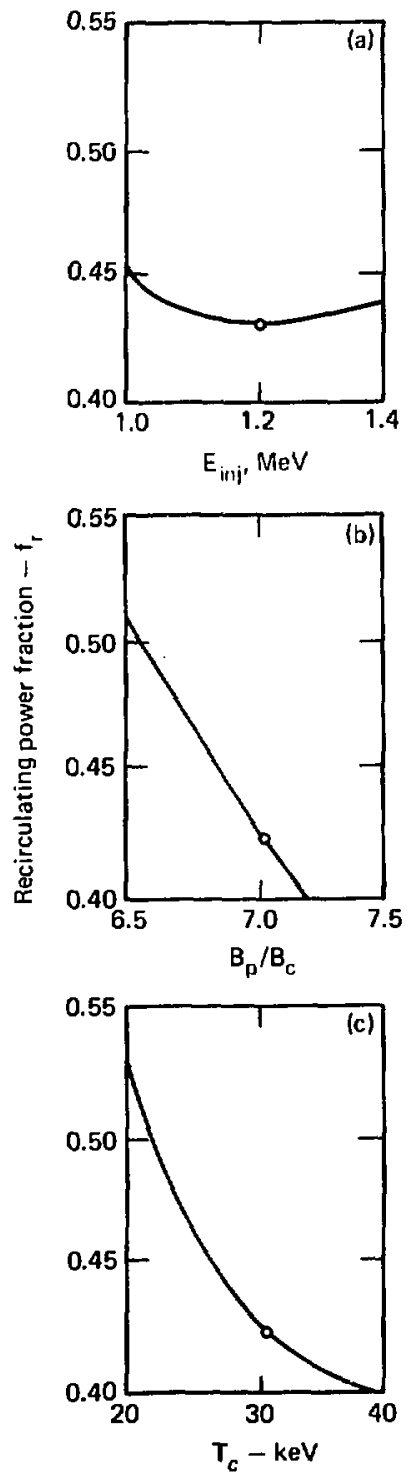

Fig. 2-7. Effect on recirculating power fraction $f_{r}$ in 1000-MW(e) TMR's of variation in the parameters defined in Fig. 2-6.
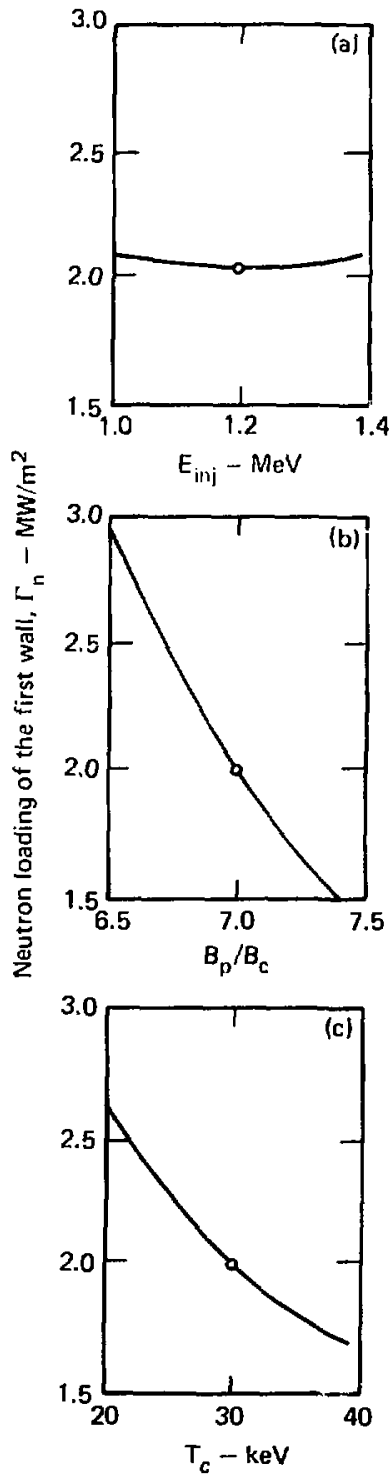

Fig. 2-8. Effect on the neutron loading of the first wall of 1000-MW(e) TMR's of variation in the parameters defined in $\mathrm{Fig}$. 2-6. 


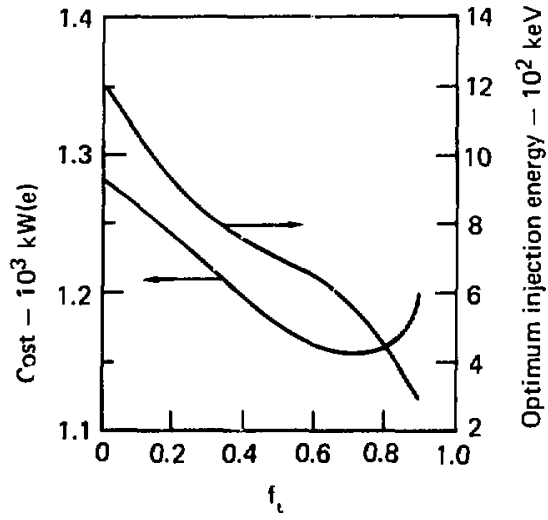

Fig. 2-9. Optimum neutral-beam injec$L$ ion energy and predicted cost of optimized 1000-MW(e) TMR's as functions of $f_{e}$, the fraction of the total heating that goes to the electrons.

SUGGESTIONS FOR FURTHEP. WORK

In the course of this work, the importance of ${ }^{4}$ He (ash) buildup became apparent. We had originally envisioned a periodic plasma flush; however, more detailed analysis (see discussion in Chapt. 3) indicates a possible steady-state mode of operation in which the ${ }^{4} \mathrm{He}$ concentration is only $4 \%$. Future work will focus on this question of impurity control and its implications to economics of the power cycle (i.e., a steady-state versus pulsed system).

Another area for further work is the increased size of the magnet to allow for more neutron shielding.
The most advanced component of the reactor is the $1.2-\mathrm{MeV}$ neutral-beam injector. Its design rests on the production of negative-ion beams, their acceleration to high voltages, and their passage through a plasma stripping cell to make the neutral atoms. The neutral-beam injector thus has a high priority for future work. The design at present is not self-consistent in a number of signilicant ways. For instance, the injector efficiency of $80 \%$ was used in the pulve balance, whereas $70 \%$ comes out of the injector design work. The end-plug magnet must be enlarged to allow room for more shielding. The steady-state ${ }^{4} \mathrm{He}$ concentration will increase center-cell losses and reduce the power density. Extra power is expected to maintain proper radial boundary conditions for stability and ${ }^{4}$ He removal. Each of these effects will increase the cust per unit net power and therefore neeis further study.

The beneficial aspect of injecting energetic neutral $\mathrm{D}-\mathrm{T}$ beams into the central cell is just beginning to be appreciated, and interesting reactors at smaller than 1 GW(e) with lower end-plug technology appear possible. Electron heating also appears promising if the efficiencies can approach that of the neutral-beam injector $(\sim 70$ to $80 \%)$. 


\section{CONCLUSIONS}

The IMR is a great improvement over the "standard" mirror reactor in a number of respects:

- The $Q(\sim 5)$ is about 5 times higher, thus greatly relieving the precarious power balance of the standard mirror.

- In large sizes $[\sim 1 \mathrm{GW}(\mathrm{e})]$, the cost per unit power $(\sim 1 / W$ direct cost) is ahout 5 times lower.

- The Lechnology of the reactor (the centra1-cell portion) is low by comparison to most other approaches to fuston in that low-field $\mathrm{Nb}-\mathrm{Ti}$ superconducting colls in simple cylindrical geometry are employed.

- The reactor is highly modular in construction, which allows each component to be produced in a factory and shipped to and assembled on the site.
One major consequence of the modular construction is that a small demonstration prototype reactor would differ from the full-size plant only in the length of the central cell. That is, more central-cell modules would be added to the prototype to make a full-size reactor. of course, sma1l modifications would still be necessary, e.g., current from the injectors and size of the conventional part of the plant.

The biggest uncertainty in the technology appears to be the $1.2-\mathrm{MeV}$ neutral infector. A number of physics uncertainties have been identifled and are being addressed in the Tandem Mirror Experiment (TMX) and by theoretical analysis.

The tandem mirror concept is quite new and appears promising; however, it needs much more study. 


\section{CHAPTER 3. PLASMA CONFINEMENT AND HEATING;}

\section{$\therefore \quad \therefore \quad \therefore i^{x}$}

Summary

General Description of Plasma Confinement, Heating, and

Stability in a TMR

Confinement in Potential Wells

Ion Cooling by Charge Exchange

Electron Heating.

Alpha-Particle Heating .

Plug Injection Energies.

MHD ability .

Plug Microstability .

Gradient Instabilities in the Solenold.

Physics Model

on Energy Balance

Plug Heating of Electrons

Electron Confining Potential

Electron Energy Balance.

Pressure Balance.

Plasma Dimensions.

Heating by 3.5-MeV Alpha Particles

Adiabatic Containment of Alpha Particles

Alpha Heating of Ions and Electrons

Hot-Alpha Pressure

Q Scaling in a TMR

Subignition Case

Condition for Ignition.

Radial Diffusion of Thermal Alpha Particles and Impurities Synchrotron Radiation Losses. References 
SLMLARY

The purpose of this chapecr is to develop a physics model for calculating plasma confinement and heating in the tandem mirror reactor (TMR). Solutions are to be obtalned from the physics model incorporated within the TMR cost-optimizer code, which includes the efficiencies and unit costs of the various energy-conversion systems external to the plasma (see Chapt. 10). Because there are numerous free parameters in the physics mode1, a wide, continuous spectrum of solutions for combined sulenoid and plug parameters is always possible. However, only those particular solutions evaluated by the yardstick of minimum power cost in the TMR code are desired. The twin basic requirements for low power cost per $\mathrm{kW}(\mathrm{e})$ net are high $Q$ (high $n \tau$ ) in order tu reduce the cost of parasitic recirculating power, and high neutron flux at the vacuum wall (high fusion power density) in order to reduce the blanket and other costs per $\mathrm{kW}$ of fusion power. The general discussion of physics in the following section shows that the plasma confinement properties inherent to the TMR make very high $Q$ and very high fuston power density mutually exclusive. The great value of including the reactor systems costs with solutions to the physics model in the TMR code is in finding the optimum trade-of $f$ between ? and wall loading for a minimum power cost at a given power out put .

The physics model is simplified as much as possible to faci]itale application of the TMR code over the widest range of parameter space. The goals of this [irrt study are to determine the broad limits of economical operation of a TMR and to assess the basic trends and sensitivities of reactor cost to the various input parameters. While searching for the optimum operation regimes, the conditions for validity of several simplifying assumptions made in the model may be strained, resulting in errors in some quantities as 1arge as $20 \%$. This is acceptable for the present purpose of finding the zero-order operating parameters for a TMR, from which refinements in the physics model and more detailed reactor designs can be made in the future.

Energetic (3.5-MeV) fusion alpha particles are expected to provide a major portion of the energy input required to sustain the solenold in a TMR. In the section on alpha heating, we discuss the containment and pressure of 3.5-MeV alpha particles and the partition of their energy to the plasma ions and electrons. The physics model is applied in the section on $Q$ scaling to determine how: the $Q$ of a TMR varles with soienold 
length and density unde: conditions in which the energy input to alpha particles is not sufficient to sustain the solenoid (subignition). Conditions to achieve ignition in the solenoid are determined. Two of. the most important simplifying assumptions made in the physics model are the neglect of thermalized alphas and the neglect of synchrotron radiation. Estimates of the radial transport of thermal alphis and power loss due to synchrotron radiation are made in the last two sections on radial alpha diffusion and synchrotron radiation.

GENERAL DESCRIPTION OF PLASMA CONFINEMENT, HEATING, AND STABILITY IN A TMR

\section{Confinement In Potential Wells}

In the tandem mirror configuration shown in Fig. 3-1, high-energy neutral beams sustain dense, mirror-ronfined plasmas in the minimum-B end cells, Neutral beans of generally larger current and lower energy replenish ion losses from the lower-density (but much larger-volume) central solenoid. The mirror plasmas in the end cells have the primary function of electrostatically plugging the solenoid via their positive ambipolar potentials. We assume the solenoid plasma is of much larger volume and produces much more fusion power than the plugs, and so we neglect the rusion power contributed by the plugs. We do include the neutral-beam power required to maintain the plugs as a primary power input to sustain the system.

In the solenoid as well as in the plugs, electrons tend to escape more rapidly than the lons, so that both the plugs and the solenoid charge up positive with respect to the end walls. Since electrons exchange rapidly between the plugs and solenoid during their lifetime, we can assume the electron temperature $T_{e}$ in the plugs to be the same as in the solenoid. To satisfy charge neutrality with the electron density $n_{p}$ in the plugs greater than the electron density $n_{c}$ in the central solenoid, the plugs must be more positive than the solenoid by an amount

$$
\phi_{c}=T_{e} \ln \left(n_{p} / n_{c}\right) .
$$

A larger potential drop $\phi_{c}+\phi_{e}$ from the plugs to the wall (Fig, 3-1) is set up to balance the electron loss rate with the combined ion loss rates from the solenoid and plugs (predominantly from the solenoid).

Since the plug ions see a larger outward potential drop $\phi_{c}+\phi_{e}$ than the Inward potential drop $\phi_{c}$, if the magnetic mirrors are of equal strength the loss boundary in velocity space (see Fig. 3-2) corresponding to the outward direction is closer to the 


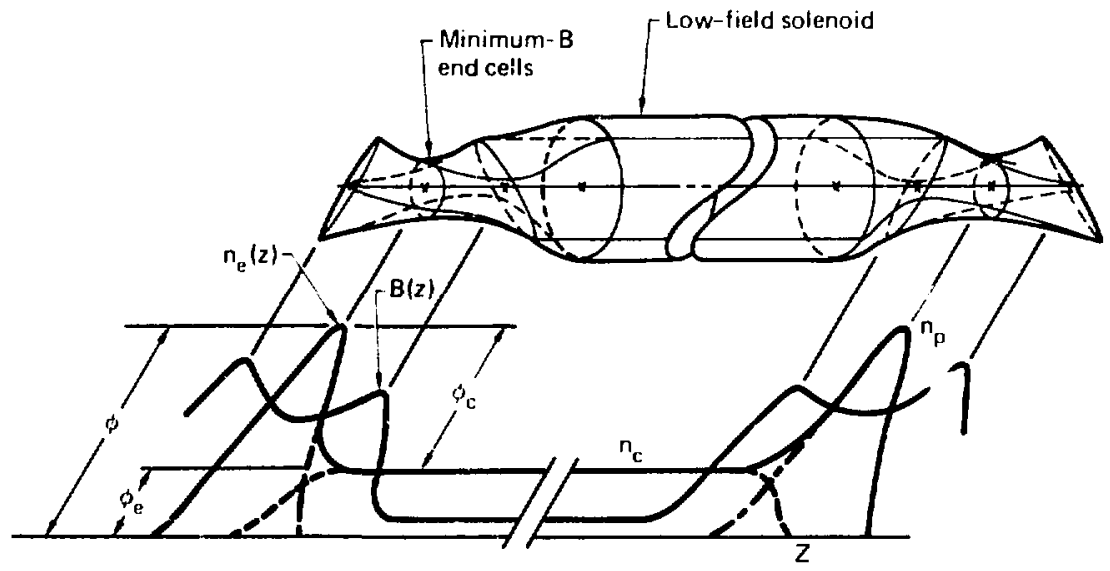

Fig. 3-1. Tandem mirror with ambipolar barriers at the ends.

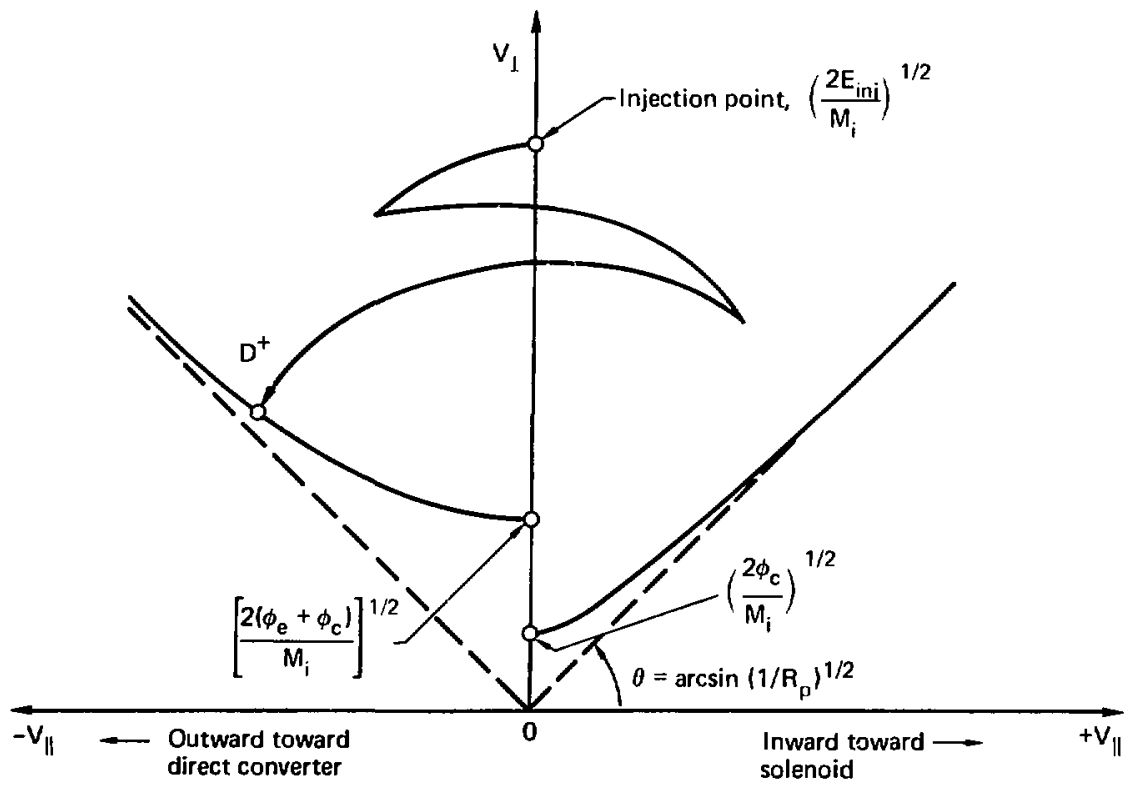

Fig. 3-2. Loss boundaries in velocfty space for plug ions, showing asymmetric ambipolar cutoffs and typical fon trajectory. 
injection point than to the loss boundary for inward motion. Since ions diffuse in small steps in velocity space, virtually all of the plug ions will exit away from the solenold. Thus, the steady-state density in the solenoid is controlled only by the neutral-beam injection current into the solenoid, balancing the loss rate of central ions that are diffusing upward in energy over the potential barrfer. The neutral-beam injection current in the plugs controls the plug density $n_{p}$ independently; $n_{p}$ together with $n_{c}$ determines the potential barrier helght $\phi_{c^{*}}$ By suitably controlling the injection rates in the solenoid and in the plugs, an arbitrary density ratio and potential barrier can be maintained in steady state.

With relatively deep potential wells $\phi_{c} \geq 3 T_{i}$, where $T_{i}$ is the central ion temperature, and with large central-cell mirror ratios $R_{c}=$ (internal plug field $\mathrm{B}_{\mathrm{pi}}$ /internal solenoid field $B_{c i}$ ) $>10$, the confined ion distribution in the solenoid can be nearly Maxwellian. Since the density and temperature are both lower in the solenoid than in the plugs by typically a factor of 10 (solenoid pressure $=10^{-2}$ plug pressure), the confining magnetic fields in the solenoid can be an order of magnttude smaller than the plug fields. With higher betas and dtamagnetic field reduction inside the solenoid than inside the plugs, central-cell mirror ratios $R_{c}$ as large as 20 to 40 are possible. A typlcal loss boundary in velocity space for central ions with $R_{c}=20$ and $\phi_{c}$ $=3 \mathrm{~T}_{i}$ is shown in Fig. 3-3. The dashed lines are the magnetic loss cones with angle $\theta_{c}=13$ degrees, and the solid line is the loss boundary with comblned magnetic mirrors and a potential barrier $\phi_{c}=3 T_{1}$. The circles are contours of constant $f_{i}(v, \theta)$ at $E_{1}=T_{i}, 2 T_{i}$, and $3 T_{i}$. Close to $90 \%$ of the ions in the distribution have energies less than $3 T_{i}$, the vertex of the loss hyperbolas. In addition, because a Eraction $\left(1-1 / R_{c}\right)^{1 / 2}$ of velocity space is occupled outside the magnetic loss-cone angle, more than $97 \%$ of the ions with energy above the poten'ial barrier are still trapped magnetically. In the original tandem mirror scheme proposed by Kelley, ${ }^{3-1}$ the central cell was a mirror machine with the ambipolar potential removed by having the outer cells at equal density with the center cell; therefore, the dashed lines in Fig. 3-3 became the loss boundary. We propose to go one step further by raising the density of the outer cell and imposing a potential barrier. With lons allowed to fill the loss cone below the potential barrier, the Ion distribution can become nearly isotropic, eliminating loss-cone instabilities. In addition, the classical 


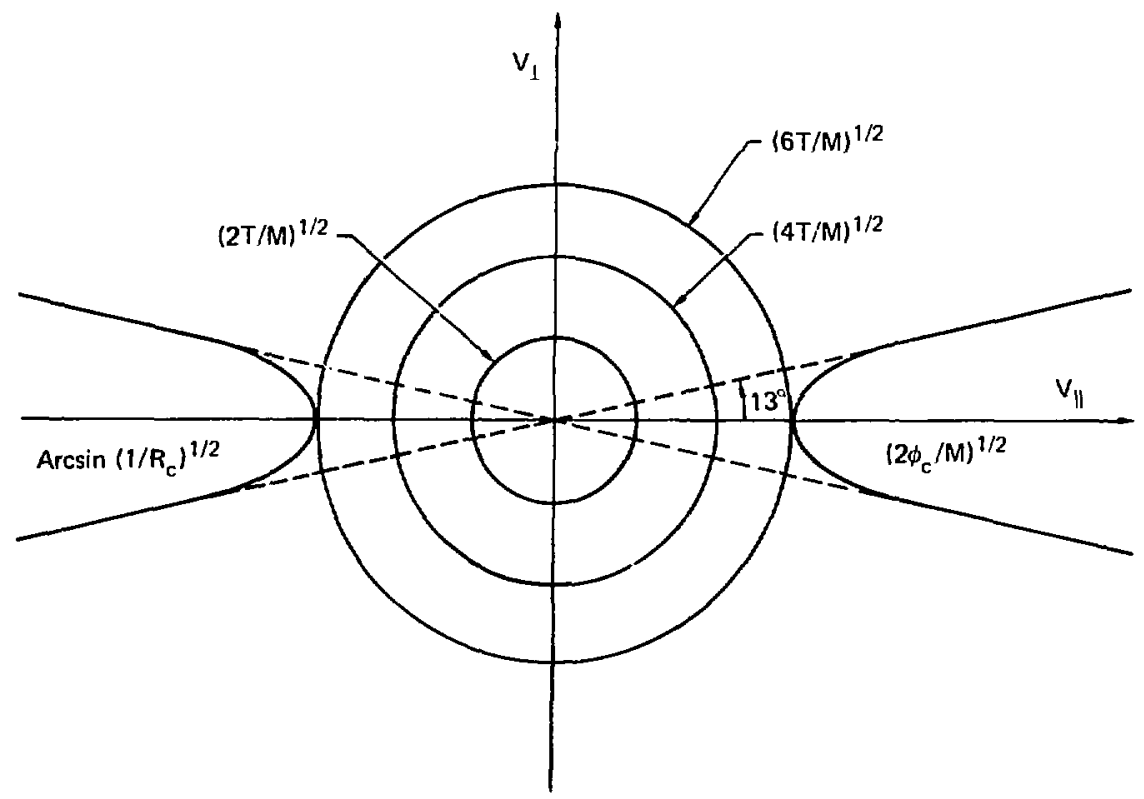

Fig, 3-3, Loss boundary in velocity space for solenoid ions for $\phi_{c}=3 \mathrm{~T}_{i}$ and $R_{c}=20$.

ion confinement time is greatly

enhanced by the addition of the potential well.

$$
(n \tau)_{i}=\left[\frac{\sqrt{M_{i}} T_{i}^{3 / 2}}{\sqrt{2 \pi} q^{4} \ln A_{i i}}\right]
$$

Depending on the ratio of potential barrier height $\phi_{c}$ to the central ion temperature $T_{i}$, the ion confinement time in the solenoid can be many collision times. For confinement of a single species of $Z=1$ ions in a relatively deep potential well $\left(\phi_{c} \geq 2 T_{i}\right)$ with magnetic mirrors, an approximate analytic formula by Pastukhov ${ }^{3-2}$ can be written:

$$
\text { - } g\left(\frac{R_{c}}{2}\right)\left(\frac{\phi_{c}}{T_{i}}\right) \exp \left(\frac{\phi_{c}}{T_{i}}\right) \text {, }
$$

where the quantity in brackets is the Spitzer self-collision time, and where $g(R)=\sqrt{\pi}(2 R+1) \ln (4 R$ $+2) / 4 R$ is a slow function of the central-cell mirror ratio $R_{c}$. For $R_{c}=20, g(10) \approx 3.5$. For typical 
ratios $\phi_{c} / T_{i} \approx 3$, Eq. (3-2) shows that the potential barrier together with

a large mirror ratio provides fon confinement for over 100 lon-ion calliston times. Also, the increase in $(n \tau)_{1}$ is much stronger than with the collision time factor $\propto \mathrm{T}_{i}{ }^{3 / 2}$. Thus, contrary to confinement with magnetic mirrors alone, confinement with a fixed potential barrier $\left(\phi>2 \mathrm{~T}_{i}\right)$ increases as the ion temperature decreases. Using Eq. (3-1) to eliminate $\phi_{c}$, and taking $M_{1}=2.5$ amu for DT ions and $\ln _{\mathrm{n}} \lambda_{\mathrm{i}}=22$, Eq. (3-2) can be written

$$
\begin{aligned}
(n \tau)_{i} & =8.7 \times 10^{10} T_{i}^{3 / 2}\left(\frac{T_{e}}{T_{i}}\right) \\
& =\ln \left(\frac{n_{p}}{n_{c}}\right)\left(\frac{n_{p}}{n_{c}}\right) T_{e} / T_{i},
\end{aligned}
$$

where $T_{i}$ is in units of $\mathrm{keV}$, and $(n \tau)_{i}$ is In $\mathrm{cm}^{-3} \cdot \mathrm{s}$. Given a practical upper limit on the plug density that can be confined by a maximum plug field, Eq. (3-3) shows that to increase (nt) $)_{i}$ for a given $\mathrm{T}_{\mathrm{e}} / \mathrm{T}_{\mathrm{i}}$ ratio, one must decrease the solenoid density ${ }_{c}$. However, the fusion power density in the solenoid then decreases as $n_{c}^{2}$. This fundamental tradeoff between confinement and power density in a TMR will be discussed again later.

\section{Ion Cooling by Charge Exchange}

At central ion temperatures $T_{i}=20$ to $40 \mathrm{keV}$, the probability for charge exchange of an injected neutral atom in the solenoid is several times greater than for ionization. Therefore, associated with the ionization rate needed to replace ion particle losses in the solenoid there is a charge-exchange energy loss per ion created of 3 to 10 times $T_{i}$, depending on $T_{1}$. Because of the scaling of electrostatic confinement of ventral-cell lons in a TMR, the improvement in ( $n t)_{1}$ from a larger value of $\mathrm{T}_{\mathrm{e}} / \mathrm{T}_{\mathrm{i}}$ can more than compensate for the lower reaction rate $\langle\pi v\rangle$ due to charge-exchange cooling. Thus, for ions in a deep potential well $\left(\phi_{c}>2 \mathrm{~T}_{\mathrm{i}}\right)$, chargu-cxchange cooling is often beneficial. This ion cooling mechanism can be realized by supplying the solenoid losises with very lowenergy bcams (L to $10 \mathrm{keV}$ ) injected inter the thin plasmil fans near the inner mirror throats. Since the potential barriers are co-located with the mirror-confined plug ions beyond the inner set of mirrors (see Fig. 3-1), the Maxwellian ions of the solenoid freely pass through the inner mirror fans at constant pressure. Therefore, with regard to confinement, creating an ion in the fan is as good as injecting the middle of the solenoid. Moreover, not only can the low-energy beams penetrate into the thin fans, but alsc the charge-exchange atoms can escape. 


\section{Electron Heating}

For the same reason that ion confinement can be improved by ion cooling, ion confinement can also be improved by electron heating. 3-3,4 Electrons are heated by hot ions in the plugs, by tons in the solenoid if $T_{i}>T_{e}$, by 3.5-MeV fusion al pha particles in the solenotd, and as options, either by direct auxillary heating such as with electron cyclotron resonance heating (ECKH) in the low-field solenoid or with intense relativistic electron beams injected from the ends. Increasing $T_{e} / T_{i}$ by electron heating can increased at the same $(n \tau)_{i}$ for a given density ratio $n_{p} / n_{c} ;$ alternately, the power density can be increased at the same $(n t)_{i}$ with a lower density ratio. In Eq. (3-3), for example, the same factor of enhancement in $(n t)_{i}$ is obtained with $\mathrm{T}_{\mathrm{e}}=3 \mathrm{~T}_{i}$ and $\mathrm{n}_{\mathrm{p}} / \mathrm{n}_{\mathrm{c}}$ of only 3 as with $T_{e}=T_{i}$ and $n_{p} / n_{c}=27$. The power density in the solenoid with the former case would be nearly two orders of magnitude greater if $T_{i}$ were kept constant and $\mathrm{T}_{\mathrm{e}}$ were increased by heating. Unfortunately, the projected tube efficiences (20\%) and the power output/unit (200 kW) of high-power microwave generators presently under development ${ }^{3-5}$ for ECRH heating of $10^{14} \mathrm{~cm}^{-3}$ density plasmas ( $f_{c}=100 \mathrm{GHz}, \lambda_{c}<3 \mathrm{~mm}$ required) do not approach the capability already achieved by neutral. beams ( $50 \%$ efficiency at $>1$ MW per madule on $2 \mathrm{X} 11 \mathrm{~B}$ ).

Whether microwave tube technology will ever catch up with neutral-beam development for fusion application is unclear. The situation with regard to intense relativistic electron beams is more hopeful; multi-megajoule pulses at production efflctencles comparable to or greater tha! neutral beams can probably be achieved with present technology. ${ }^{3-6}$ Efficient absorption ( $90 \%$ would be destred) of intense electron beams in $>10^{14} \mathrm{~cm}^{-3}$, fullyionized plasmas has yet to be demonst rated. However, extrapolation from theory $y^{3-7}$ as well as from experimental measurement ${ }^{3-8,9}$ of electron-beam absorption in short plasmas suggests that electron beams of 1 to $5 \mathrm{MeV}$ at current densities of only $1 \mathrm{kA} / \mathrm{cm}^{2}$ might be ai.sost totally absorbed in $100 \mathrm{~m}$ of $10^{14} \mathrm{~cm}^{-3}$ plasma in a TMR. Many small pulses within the 5- to 8-s plasma lifetime can be used, each pulse supplying a small fraction of the plasma energy. Thus, perturbations of $\mathrm{T}_{\mathrm{e}}, \mathrm{n}_{\mathrm{e}}$, and beta are kept small, and the electron-beam heating would appear almost quasi-steady.

The banefits of auxiliary electron heating in a l'MR are assessed in Chapt.10. However, since a detailed physics and engineering study of an electron-beam heating system has yet to be made for the IMR, such auxiliary electron heating is now considered only as an option. 


\section{Alpha-Particle Heat ing}

Fusion alpha particles can supply a substantia]. fraction of the encrgy input needed to sustain the solenoid plasma in a jMr. SInce the magnetic loss-cone angle is so small ( $\leqslant 18^{\circ}$ ) in the solenold, more than $95 \%$ of the alpha particles born Isotropically at $3.5 \mathrm{MeV}$ have veloctly vectors such that they are magnet feally trapped by the central mirrors. Depending on the design of the rield gradlent length at the ends of the solemold, a lraction $0.2 \leq t \leq 1$ of the alplass can be adiabatically conlined between the mLrrors of the central cell. for a suffletent Lithe to thermal toc, giving up their encergy to the central lons and electrons (sece "lleating by 3-5-M.V Apha Pareicles").

With $f_{1 /}$ near unlty and with sufftclent confincment (ni) ${ }_{1}$, alpla parLicles afone can encretcaliy sustain the central solenold (Ignition). An example of tgnition lis diseussed under "q) Scaling in a I'Mk". Unfortunately, as the alphas slow down, they heat the central lons as well as the clectruns, giving a larger fraction of their energy to the lons for ' $\mathrm{l}_{\mathrm{e}}>39 \mathrm{keV}$. thus at high ' $\mathrm{g}$ ', alpha heating tends to lower the rat to of $" \mathrm{te} / \mathrm{T}$, Increasing the density ratio $n_{p} / n_{c}$ requited for a given $(n t)_{1}$, if erfictent methods of heating electrons alone are available, such as via hot fons in the plugs or by auxiliary electron heating, it $i$. in ract desirable to reciuce alpha beatlog (by using nonadfabatleity, so that $\left.f_{\psi} \ll 1\right)$, and thereby to operate at smaller $n_{p} / n_{c}$ and higher power denslty. However, reduced alphia Input is an advantage only if the effictency of direct chectron heat ing is greater than about 50\%; otherwlse, the advantage of electron heating is whed out becallse corergy bilanec is recovered only at higher $(\mathrm{n} l)_{1}$ and $n_{p} / \mathrm{n}_{\mathrm{c}}$.

the alplase which do survive to slow duwn below $2 \phi_{e}$ encergy become electrostatically trapped and quickly thermalize to the temperature of the solenold ions. Thetr subsequent lifetime in a polential well of $2 \%$ is quLte long; inspection of Liq. (3-2) shows that the Lffetince of thermat alphe particless seatlering on IJT ions with

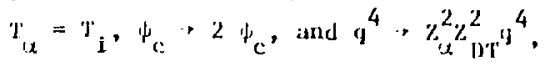
1.s Lunger chan the UT ton lifetime by a factor of $\sqrt{4 / 2.5} \%_{i l}^{-2} 2 \exp \left(\phi_{c} / 1_{1}\right)$. When (nt) Lis large due to $\phi_{c} \Rightarrow T_{i}$, (nt) $)_{1 e}$ ls very much liarger st 111 ; therefore, the thermal alphas accumulate to a large equilibriun fiaction $\left.{ }_{n_{i}} / \mathrm{n}_{i}=1\right)$ even though their source scrergth due to DI burnup is small compared to the IY Injection strength. Such large thermal alpha fractions would have a disastrous effect in reducing both $(\mathrm{nt})_{1}$ (enhanced scatterIng of $\mathrm{DT}$ ions by a factor of $\left(1+z_{u}^{2} n_{\alpha} / n_{1}\right)$ and power density (DT fuel density lower than the solenoid 
electron density by a fictent sf

$\left(1+\%_{i x} n_{i x} / n_{I}\right)$. Fortunatelv, it appears that the classical radial diflusion of thermal alphas can grcatly reduce thair caullibrium fractions $\left(n_{k} / n_{i} \therefore\right.$ $0.1)$, as suggested by pimov. $3-3$ Jhe equilibrium thermal alpha fractions can be reduced still further if $f_{a}<1$. due to nonadiabaticity; tha source serengtli of thernal alphas is proportional to $f_{\mu^{\circ}}$ llowever, the alpha energy input to the solenosd lis corresijoondingly reduced, lavorab]y or unlavorably, depending on whether there is efifelent electron leating to make up for the losis of alphis input.

\section{Plug Injection lincrgless}

fiur a 'IMR operating with high 'l', vory high reuteal injectioin energles $E_{\text {inj }}$ are requlred to minimfoe the neutral-beam power required to malntalu the plugs, In lifis. 3-2, the mintmum lon encerpy lis (min) Llat can bo concalued by the mirrors in the plugs is given by $\left(w_{c}+\psi_{c}\right) /\left(R_{p}-1\right)$. where $\psi_{e}+\psi_{e}$ is the total expelling potential as seen by the plug fons, and $R_{p}$ is the effective plug mlrror ratio enhanced by the dianagnetism of the plug. Higl-vacuum mirror ratios are impractical due to the engineering difficulties assoclated with producing high manetic fields In thr unfrors; also, the very large factors of reduction in the Incernal fleld of the plug caused by high beta are counterproduct ive becaluse the small magnelie flux linking the plug flves small cross-bection solenoids by conservation of flux, Thus, $R_{p}$ must always be modest: $R_{p}=2-3$. We shall. find that usually $\psi_{e} \geq 6 \mathrm{~T}_{\mathrm{c}}$ and $巾_{e} \geq 2 \mathrm{l}_{\mathrm{e}}$ as well, if ' $\mathrm{l}_{\mathrm{e}} \approx \mathrm{T}_{\mathbf{i}}$, such as with cicctron leating, $\dddot{i}$ must be a minlmam of 40 to $60 \mathrm{keV}$ if 'I is to be high enough for a prastical. fusion reatsifot rate. ditas, we ars Jed to minimum plup, fon energies

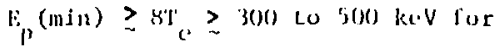
$\mathrm{k}_{\mathrm{f}}=2$, imel $\left.\mathrm{E}_{\mathrm{p}}(\mathrm{mi} 11) \geq \mathrm{I} 31\right) \mathrm{ta} 250 \mathrm{keV}$ for $k_{p}=3$. Of course, a plugk ion injectod with only the energy linj $=\operatorname{li}_{p}$ (min) would be lost inumediately. To have a dsiltul plug ion lifetine, the injection energy should be three Lo four Limes Llic amblpolar eutoft. Thls will Lypicilly requiro E inj $\because$ I. M.V in a IMR.

$\Lambda$ sccond reason for tigh injoction encergies til a TMR Is lo licit celcctrons. Jior ratios $\mathrm{E}_{\text {inj }} / \mathrm{T} \geq 15$, plug ions trimsler more cenergy lo clectrons than lis carried wat by the elcetrons accompanyling those ions over the biarricr $\psi_{L}+\psi_{e}$ In this way, a portiun of the neutral-beam power required to maintain the plugs can be "reused" to lieat the solenoid via electrons. The efliciency of heating electrons by the plugs increases with $\mathrm{E}_{\text {inj }} / \mathrm{T}$, exceeding $50 \%$ at $\mathrm{E}_{\text {in } \mathrm{j}} / \mathrm{T}=40$. his al reference case for the TMR, we issume that the solemoid is 


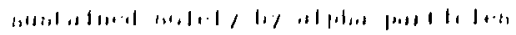

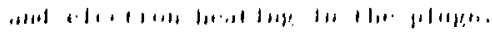

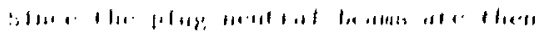

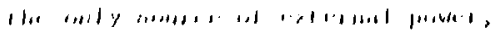

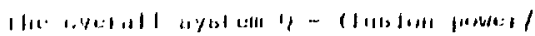

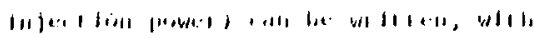
$11,-n_{1}-1,19$,

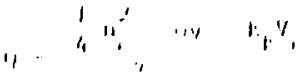

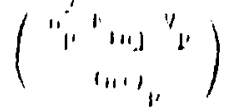$$
\text { i. }
$$

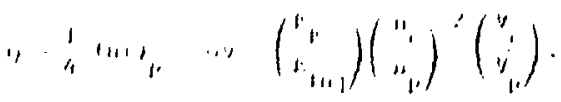

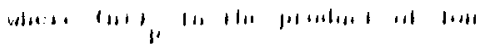

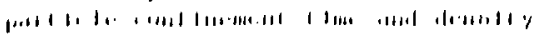

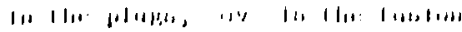

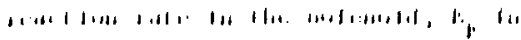

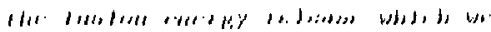

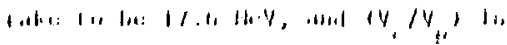

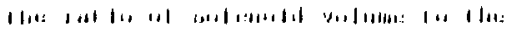

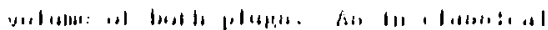

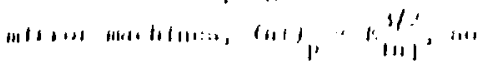

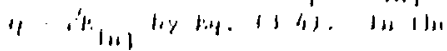

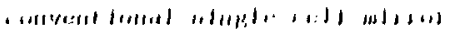

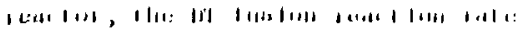

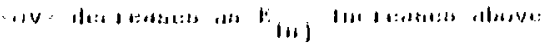

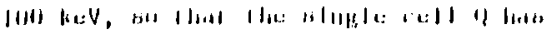

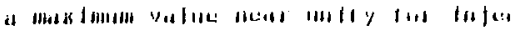

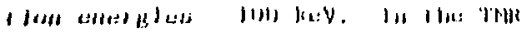

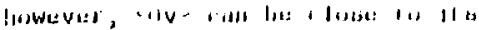

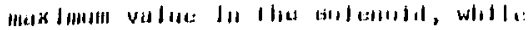

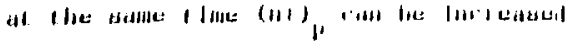

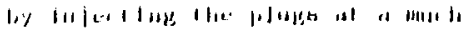

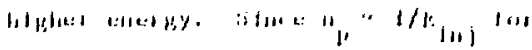

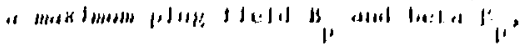
I Ja.

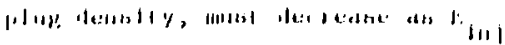

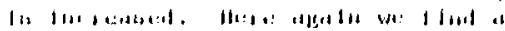

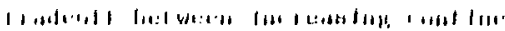

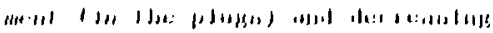

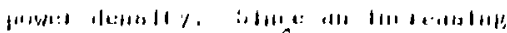

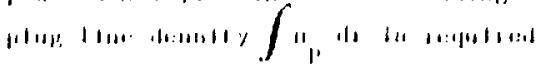

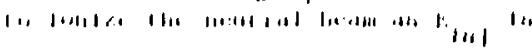

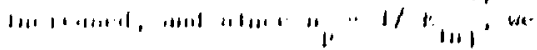

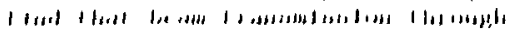

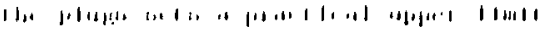

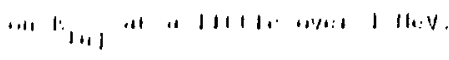

IIIt $: 1,11,1111$

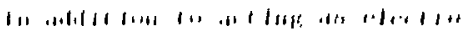

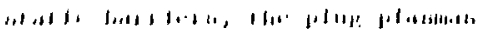

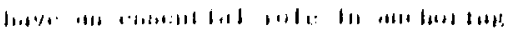

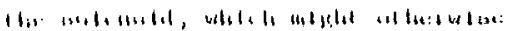

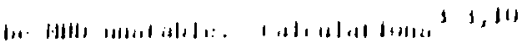

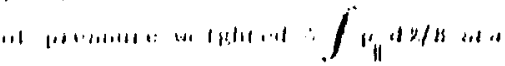

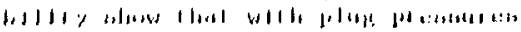

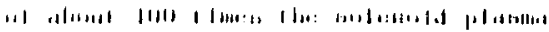
|4.

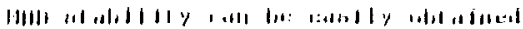

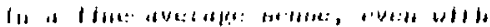

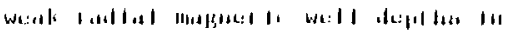

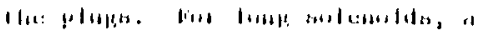

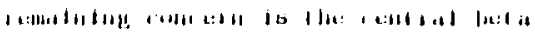

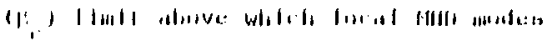

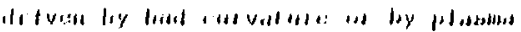

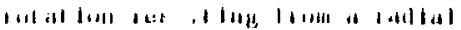

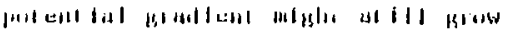

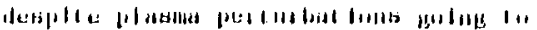

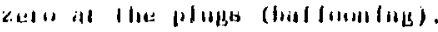




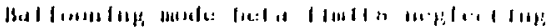

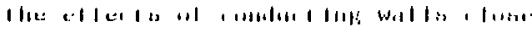

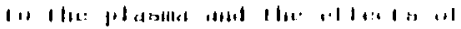

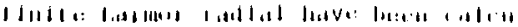

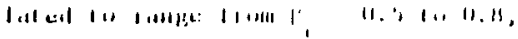

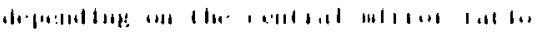

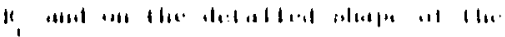

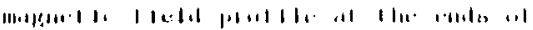

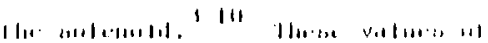

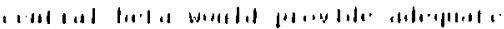

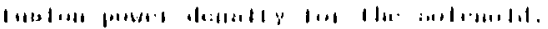

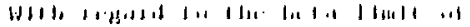

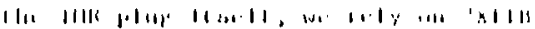

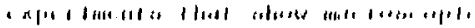

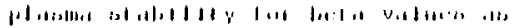

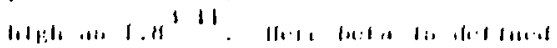

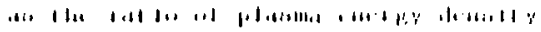

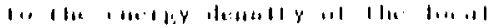

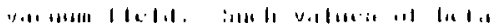

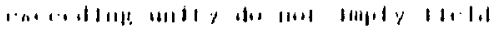

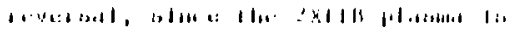

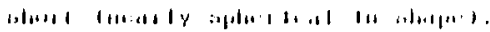

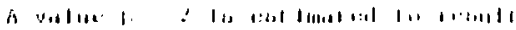

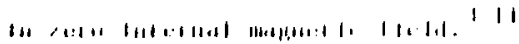

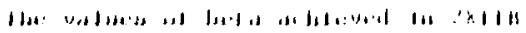

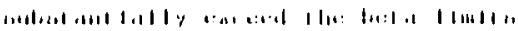

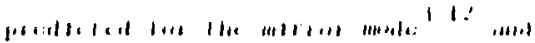

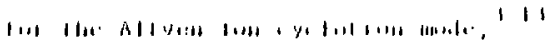

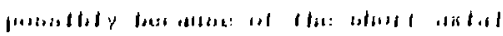

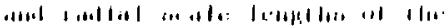

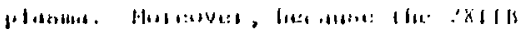

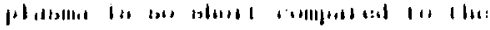

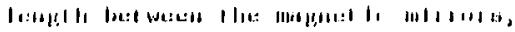

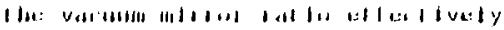

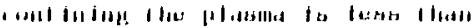

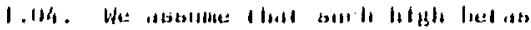

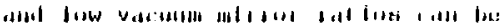

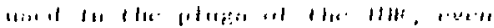

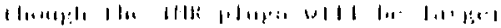

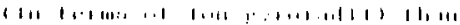

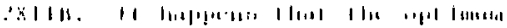

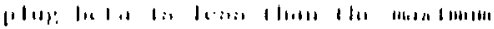

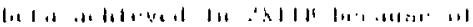

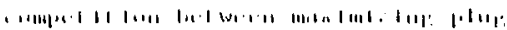

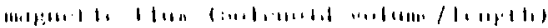

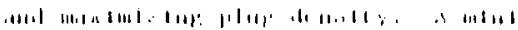

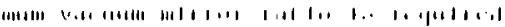

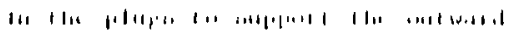

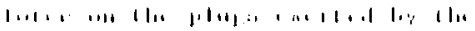

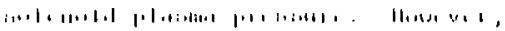

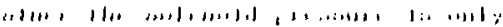

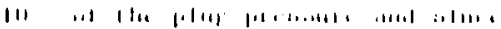

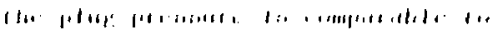

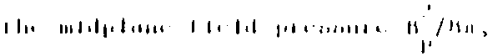

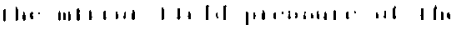

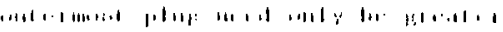

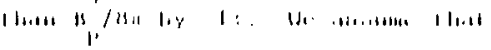

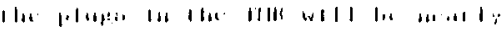

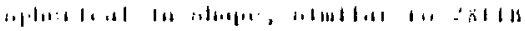

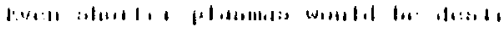

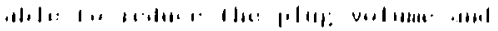

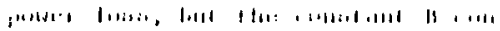

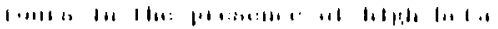

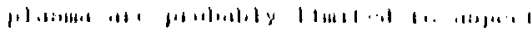
$1,41 \ldots, 1.1 \% 1, \quad 11111 \%$

H.14: $111,1 \ldots+1,41,1111$,

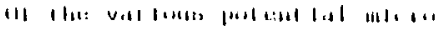

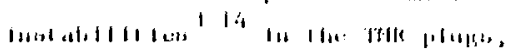

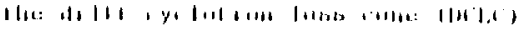

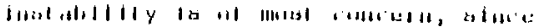

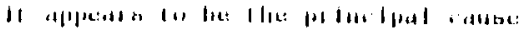

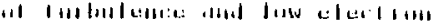


temperatures in the $2 X I I B$ experiment. ${ }^{3-15}$ An important parameter for the DClC mode is the scale length of the radial density gradient relative to the ion gyroradius $\Delta r_{p} / p_{i}$. At sma11 $\Delta x_{p} / \rho_{i} \approx 3$ as in 2 XIIB, marginal stability required that the loss cones be partially filled by low-energy ions streaming through the trapped lons, resulting in lower $T_{e}$ and lower $(n \tau)_{p}$ by electron drag. ${ }^{3-15,16}$ As $\Delta \mathrm{r}_{\mathrm{p}} / \rho_{1}$ is increased, the drive for the DCLC mode is weakened so that the streaming plasma required for marginal stability diminishes to insignificance for scale lengths $\Delta r_{p} / \rho_{i} \approx 40$, Such a scale length is comparable to the radial size of the plugs in a typical TMR of $1000 \mathrm{MW}(\mathrm{e})$ output.

Precise conditions for DCLC stability in the TMR plugs must be determined by further theoretical and experimental investigation in the upcoming TMX experiments (plug-solenoid -un overlap effects) and in the MFTF experiments (scaling to larger $\Delta \mathrm{r}_{p} / \rho_{i}$ ). For the present study, we assume classical loss as a reference case for the reactor. Should microinstabilities enhance loss rates in the plugs, the overall TMR $Q$ can be recovered by increasing the length of the solenoid (volume ratio) according to Eq. (3-4). The penalty is then an increase in reactor size for the same Q. However, practical reactor sizes will require that plug confine- ment not be degraded by large factors below classical.

Gradient Instabilities in the Solenoid

Although the uniform temperature and density region of the solenoid should be stable, a solenoid boundary layer of 2 to $4 p_{i}$ scale length is subject to instabilities driven by density and temperature gradient. At present, little research has been done on such instabilities and the enhanced radial transport they may cause. However, a few comments can be made in light of recent work $3-17,18$ on finite-beta effects in temperature and density gradient instabilities. With regard to low-frequency $\left(\omega \ll \omega_{c i}\right)$ drift waves, a fully electromagnetic treatment by Berk and Domingues $^{3-17}$ shows stability above modest critical beta values $\beta_{c} \geq 0.15$, depending on the gradients in temperature relative to gradients in density. Also for the lifgher frequency, lower-hybrid-drift instabllity $\left(\omega>>\omega_{c i}\right)$ Davidson et $a l .,^{3-18}$ find that finite-beta effects are stabilizing above critical beta values $\beta_{c} \geq 0.5$, depending on $T_{e} / T_{i}$ and $\Delta \mathrm{r}_{\mathrm{p}} / \rho_{i}$. of course, there will always be low-beta regions in the outer edges of the boundary layer which may be unstable. What result such instability in the outer fringes may have on bulk radial diffusion is unclear. We note that the hot-ion confinement 
near the boundary need only be one electron drag time. On time scales of the same order, there is no observable radial diffusion in the 2 XIIB experiment.

PHYSICS MODEL

In the following model of plasma confinement and heating in a THR, we assume that the solenold is energet1cally sustained primarily by $3.5-\mathrm{MeV}$ alpha-particle heating in the solenoid and by electron heating from hot ions in the plugs. As an option, we shall also consider dfrect auxiliary electron heating by including a general electron energy input term energy-balance equation, We assume that the neutral beams supplying the ion particle losses from the solenoid are of negligible energy, and include the effects of chargerexchange cooling of the solenoid ions off the lowenergy beam or gas neutrals supplying the solenoid. In the reference case, the neutral-beain power to the plugs is the only external power input to the system.

In taking credit for ion and electron heating by the fast alphas, we include their partial pressure in the solenoid when calculating the required confining field for the solenoid. However, since the equilibrium density of the hot alpha particles that are doing the heating is typically only $1 \%$ of $n_{e}$, their density is neglected. Also, in this model we assume (following Dimov ${ }^{3-3}$ ) that the radial diffusion of thermalized alphas will keep their density small compared to the density of the fuel ion. Thus, we set

$$
n_{e}=n_{i} \equiv n_{c}
$$

in the central solenoid and use Eq. (3-1) for the ton potential barrier $\phi_{c}$ and Eq. (3-3) for the DT ion confinement product $(n \tau)_{1}$, we assume that the fractional burnup in the solenoid is small and ignore the fact that the small portion of the injected fuel burned in the solenoid will exit radially in the form of $\mathrm{Z}=2$ alphas rather than as DT ions over the potential barrier. As it happens, the neglect of energy carried out by the thermal alphas $\left(\approx 3 / 2 T_{\alpha} \approx 3 / 2 T_{i}\right)$ is pessimistic since ion cooling by alpha loss would improve confinement just as does charge-exchange cooling. Also burnup itself cools the ions, since the average energy of reacting ions is several times $T_{i}$. However, the neglect of the alpha density is an optimistic assumption that of fsets the neglect of beneficial ion cooling by burnup and alpha loss.

The two ion spectes used for fuel in the solenold, deuterium and tritium, are treated as one ion spectes 
with an effective mass $=2.5$ amu. To ease shielding requirements for the end cells, we assume that the plugs consist of a single injected species - elther protons, deuterons, or tritons. Thus, contributions of fusion power from the plugs are neglected, whereas the plug injection power is included in determining $Q$ for the system. We take all mirror fields to be equal, so that few of the plug ions will exit into the center cell. The model then simplifies to one ton species in the center cell and one in the plugs, and one electron species throughout. The alphas then appear only as heating terms in the fon and electron energy-balance equations.

\section{Ion Energy Balance}

We assume that the low-energy neutral beams or gas feed maintain a constant average neutral density $n_{0}$ within the solenoid plasma. The ionization rate per $\mathrm{cm}^{-3} \mathrm{~J}_{i}$ required to replenish the DT-ion loss rate in steady state is given by

$J_{i}=n_{0} n_{c}\langle\sigma v\rangle_{i}=n_{c}^{2} /(n \tau)_{i}$,

where $\langle\sigma v\rangle_{1}$ is the sum of $\langle\sigma v\rangle_{e}\left(T_{e}\right)$, which is the rate coefficient for Ionization by electron impact, and $\langle\sigma v\rangle_{i}\left(T_{i}\right)$, which is the rate coefficlent for ionization by ion impact. These coefficients are given by the dotted and dashed curves, respectively,

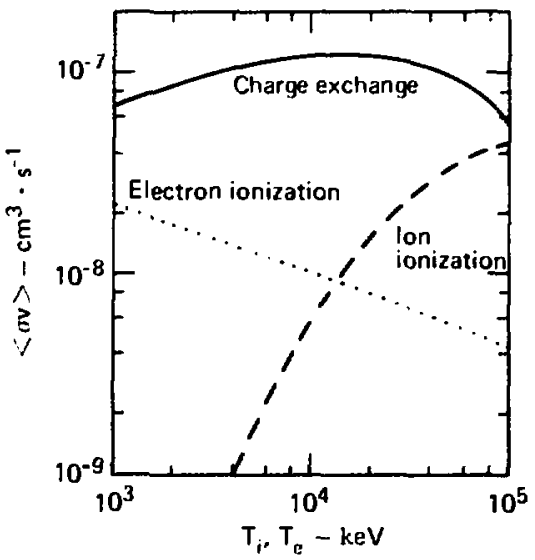

FIg. 3-4. Rate cuefficients for electron ionization as a function of $\mathrm{T}_{e}$ and for charge exchange and ionization by $D T$ lons as a fu.dction of $T_{i}$.

in Fig. 3-4. The rate of chargeexchange events per $\mathrm{cm}^{-3} \mathrm{~J}_{\mathrm{cx}}$ is correspondingly given by

$$
J_{c x}=n_{0} n_{c}\langle\sigma v\rangle_{c x},
$$

where $\langle\sigma v\rangle_{c x}\left(\mathrm{~T}_{i}\right)$ is the rate coefficient for charge exchange given by the solid curve in Fig. 3-4. Solving Eq. (3-6) for $n_{0}$ and substituting into Eq. (3-7), we can write

$$
J_{c x}=\frac{n_{c}^{2}}{(n \tau)_{i}} \quad \frac{\langle\sigma v\rangle_{c x}}{\langle\sigma v\rangle_{i}} .
$$

Pastukhov's calculation. ...td recent Fokker-Planck calculations $3-19,20$ show that the average energy carried out by ions escaping over the potential barrier is $\phi_{c}+T_{1}$ per lon lost. 
Assuming the injected neutral energy is small compared to the average ion energy, each charge-exchange event will result in approximately $3 / 2 T_{1}$ loss of energy, with no corresponding loss of Ion particles (charge exchange merely replaces a hot ion with a cold one). Thus, thr total energy lost per ion lost is given approximately by

$T_{i}\left(1+3 / 2 \frac{\langle j v\rangle}{\langle j v\rangle_{i}}\right)+110 T_{i}^{1 / 5}$,

for $T_{i}$ in $k e V,+5 \%$ in the range $10<\mathrm{T}_{i}<50 \mathrm{keV}$. We have used Fig. 3-4 in obtaining the fit given by Eq. (3-9), setting $\mathrm{T}_{\mathrm{e}}=\mathrm{T}_{\mathrm{i}}$. Since ionization by electrons is significantly less than ionization by ion impact, the errors incurred in $\mathrm{T}_{e}$ $\neq T_{i}$ are small, permitting Eq. (3-9) to be given as a function only of $T_{i}$. We can now express the ion energy balance in the solenoid as

$$
\begin{gathered}
\frac{n_{c}^{2}}{(n \tau)_{i}}\left[\Phi_{c}+T_{i}\left(1+\frac{3}{2} \frac{\langle\sigma v\rangle_{c x}}{\langle\sigma v\rangle_{i}}\right)\right] \\
=\frac{n_{c}^{2} \frac{3}{2}\left(T_{e}-T_{i}\right)}{(n \tau)_{e i}} \\
+\frac{1}{4} n_{c}^{2}\left\langle\sigma v{ }_{D T} E_{\alpha 0_{\alpha}} f_{i} .\right.
\end{gathered}
$$

In the right-hand side of Eq. (3-10), the first term is the energy transfer between lons and electrons by classical equilibration. The equilibra- tion time multiplied by the electron density $\left(\mathrm{ni}_{\mathrm{i}}\right)_{\mathrm{e}}$ is given by

$$
\text { (ni) } \mathrm{ei}=1.25 \cdot 10^{12} \mathrm{~T}_{\mathrm{e}}^{3 / 2} \mathrm{~cm}^{-3} \cdot \mathrm{s} \text {. }
$$

for $\mathrm{DT}$ ions of average mass $=2.5 \mathrm{amu}$, for $\therefore \mathrm{e}_{\mathrm{i}}=20$, and for $\mathrm{T}_{\mathrm{e}}$ in $\mathrm{keV}$. The second term in the right-hand side of Eq. (3-10) is the energy input per $\mathrm{cm}^{-3}$ given to ions by the fusion alphas: $\langle\mathrm{OV}\rangle_{D T}$ is the DT fusion-reaction rate, $E_{r_{x O}}=3520 \mathrm{keV}$ is the initial alpha energy, $f_{\alpha}$ is the fraction of alphas that are contained and thermalized, and $f_{i}$ is the fraction of $\mathrm{E}_{\alpha O}$ ennrgy given to ions by each alpha that thermalizes. According to subsequent discussion, $f_{\alpha}$ can be considered a parameter controlled by the design of the solenoid transition regions (adiabaticity control). The fraction $f_{i}$ is a function of $\mathrm{T}_{\mathrm{e}}$ as given in Fig. 3-5. An approximate formula for $F_{i}$ is given by

$$
f_{i} \approx 0.29 \ln \left(T_{e}\right)-0.5,
$$

for $\mathrm{T}_{\mathrm{e}}$ in $\mathrm{keV}, \pm 5 \%$ in the range $20 \leqslant \mathrm{~T}_{\mathrm{e}} \leqslant 60 \mathrm{keV}$. An approximate formula for $\left\langle\sigma v{ }_{D T}\right.$ is given by

$$
\langle\sigma v\rangle_{\mathrm{DT}} \approx 5.1 \times 10^{-16}\left[\ln \left(\mathrm{T}_{i}\right)-2.1\right]
$$

for $\mathrm{T}_{i}$ in $\mathrm{keV}, \pm 5 \%$ in the range $10<\mathrm{T}_{1}<50 \mathrm{keV}$. 


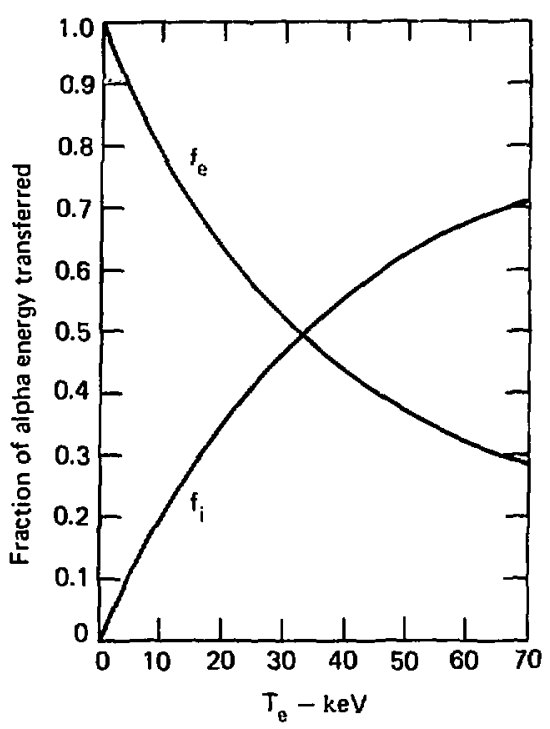

Fig. 3-5. Fraction of alpha energy transferred to electrons $f_{e}$ and to DT ions $f_{i}$ as a function of electron temperature.

\section{Plug Heating of Electrons}

Since electron heating beneficial in a TMR, the injection energy in the plugs is made as high as practical to allow a maximum fraction of the injected plug ion energy to be transferred to solenoid electrons by drag. For plug ion confinement dominated by electron drag, we use the approximate formula

$$
\begin{aligned}
(n \tau)_{F} \approx & 1.5 \times 10^{10} \mathrm{M}_{p} E_{p}^{3 / 2} \log _{10^{2}} \mathrm{R}_{\mathrm{p}} \\
& \cdot\left(\mathrm{cm}^{-3} \cdot \mathrm{s}\right),
\end{aligned}
$$

which is derived from Fokker-Planck calculations ${ }^{3-20}$ for plug injection energies $E_{\text {in }} \approx 30$ to $40 \mathrm{~T}_{e}$ and modest plug mirror ratios $R_{p}=2$ to 3 . We assume either protons, deuterons, or tritons, for the plug lons, for which $M_{p}$ is the appropriate mass number. The average plug ion energy in $\mathrm{keV} E_{p}$ is given by

$E_{p}=3.9\left(T_{e} E_{i n j}\right)^{1 / 2}$ (keV) ,

where $T_{e}$ and $E_{i n j}$ are in keV. For $\mathrm{T}_{\mathrm{e}} \approx \mathrm{E}_{\mathrm{inj}} / 15$ as in a conventional mirror machine, Eq. (3-15) gives $E_{p}=E_{\text {inj }}$. However, because for more drag-dominated plugs with lower $\mathrm{T}_{\mathrm{e}} / \mathrm{E}_{\text {inj }}$ the average plug ion energy is less than $E_{i n j}, E_{p}^{3 / 2}$ gives a better fit to ( $\mathrm{nT})_{\mathrm{p}}$ in Eq. (3-14) than the usual $E_{i n j}^{3 / 2}$. For the effective mirror ratio of short, 2XIIB-shaped plugs at high beta, we use an approximate empirical formula for $R_{p}$ given by

$$
R_{p}=R_{p-v a c} /\left[1-\left(\beta_{p} / 2\right)\right] .
$$

Data ${ }^{(3-18)}$ from 2 XIIB indicate that the diamagnetic reduction in plasma internal field $\Delta B$ is roughly linear with beta up to $\beta \approx 2$, hence the mirror ratio enhancement factor $\left[1-\left(\beta_{p} / 2\right)\right]$ in Eq. (3-16) rather than the usual $(1-\beta)^{1 / 2}$ factor for long, thin plasmas. For lower ratios of $E_{i n j} / T_{e}$ and lower mirror ratios, Eq. (3-14) will tend to overestimate 
(ni) ${ }_{P}$; at the lowest $E_{\text {in } j} / T_{e}=30$ and $R_{p}=2$, the error is $20 \%$. For most of the intended range of plug operation, however, Eg. (3-14) should give smaller errors. The rate at which hot plug ions of energy $E_{p} \gg T_{e}$ transfer energy to electrons per $\mathrm{cm}^{3}$ of plug volume is given by $n_{p}^{2} E_{p} /(n \tau)$ ep' where the product of plug density and equilibration time in the plugs is given by$$
(n T)_{\text {ep }}=5 \times 10^{11} \mathrm{M}_{\mathrm{p}} \mathrm{T}^{3 / 2}\left(\mathrm{~cm}^{-3} \cdot \mathrm{s}\right) \text {. }
$$

In Eq. (3-17), $M_{p}$ is the mass number For either protons, deuteron, or triton plug ions, $T_{e}$ is in keV, and we have assumed that $\ell_{\mathrm{n}} \Lambda_{\text {ep }}=20$. Each cold electron deposited with each neutral atom injected and ionized in the plugs escapes with an energy equal to the total plug potential $\phi_{e}+\phi_{c}$ (see Fig. 3-1) plus a transverse kinetic energy $\mathrm{T}_{\mathrm{e}}$. The fraction of plug ion esergy available to beat the solenoid electrons is therefore given by

$$
\begin{gathered}
f_{p}=\left[\frac{n_{p}^{2} E_{p}}{(n \tau)_{e p}}-\frac{n_{p}^{2}\left(\phi_{e}+\phi_{c}+T_{e}\right)}{(n \tau)_{p}}\right] \\
\text { or } \\
\cdot\left[\frac{n_{p}^{2} E_{i n j}}{(n \tau)_{p}}\right]^{-1 ;}
\end{gathered}
$$

$f_{p}=\left[\frac{(n \tau)_{p}}{(n \tau)_{e p}}\left(E_{p}-\phi_{e}-\phi_{c}-T_{e}\right)\right]\left(\frac{1}{E_{i n j}}\right)$.
The fraction $f_{p}$ can be considered as the efficiency by which high-energy neutral injection in the plugs heats the solenoid ions via electrons. Typically, $\dot{\tau}_{\mathrm{e}}=6 \mathrm{~T} \mathrm{e}$ and $\psi_{\mathrm{c}}=2 \mathrm{~T}_{\mathrm{e}}$ are required for adequate electron and ion confinement, respectively, in the solenoid. Using $\left(\hat{\psi}_{\mathrm{e}}+\hat{\psi}_{\mathrm{c}}+\mathrm{T}_{\mathrm{e}}\right)=9 \mathrm{~T}_{\mathrm{e}}$ $M_{p}=2, R_{p}=2$, and using Eqs. (3-14), $(3-15)$, and $(3-17)$,

$f_{p}=0.27\left(\frac{E_{i n j}}{T_{e}}\right)^{1 / 4}-9\left(\frac{T_{e}}{E_{i n j}}\right)$.

For a typical $\mathrm{T}_{\mathrm{e}}=40 \mathrm{keV}, \mathrm{f}_{\mathrm{p}}=0$ at $E_{\text {inj }}=660 \mathrm{keV}, 33 \%$ at $1.2 \mathrm{MeV}$, and $60 \%$ at $2.4 \mathrm{MeV}$.

\section{Electron Confining Potential}

We assume that the solenoid volume $v_{c}$ is sufficiently large that the total ion loss current from the solenoid is much larger than the ion loss current from the plugs, even though the solenoid ion confinement is better than ion confinement in the plug. In steady state, guasi-charge neutrality reguires the electron loss current $I_{\text {ec }}$ from the solenoid to equal the ion loss current Iic from the solenoid: $I_{\text {ec }}=I_{i c}$, or approximately,

$$
\frac{n_{e}^{2} v_{c}}{(n \tau)}=\frac{n_{c}^{2} v_{c}}{(n \tau)_{i}}
$$

where $(n \tau)_{e}$ is the product of electron density and electron confinement time for those electrons in the solenoid 
that see a confining potential of magnitude $\psi_{\mathrm{e}}$ (see Flg. 3-1). The electron confinement product (nt) e is given by a formula simflar to Eq. (3-2) for ions, with $\mathrm{M}_{\mathbf{i}} \rightarrow \mathrm{m}_{\mathrm{e}}, \mathrm{I}^{\prime}{ }_{\mathrm{L}} \rightarrow \mathrm{T}_{\mathrm{e}}$, $R_{c} \rightarrow R_{c}$, and $\phi_{c} \rightarrow \phi_{e}$. The electron collision time is reduced by a factor of 2 due to col1istons of electruns with plasma lons as well as selfcollisions. Using $9,12 h_{\text {ee }}=20$, and $g(R)=4$, we can write Eq. $(3-2)$ for electrons ats

$$
\begin{aligned}
& (n t)_{e}=9 \times 10^{8} \tau_{e}^{3 / 2}\left(\begin{array}{l}
\phi_{e} \\
r_{e}
\end{array}\right) \\
& . \exp \left(\frac{l_{e}}{r_{e}}\right)\left(\mathrm{cm}^{-3} \cdot s\right),
\end{aligned}
$$

where $T$ is in keV. Equation $(3-19)$ is only very roughly salisfied when the plug current Is comparable to the solenold cutrent, as sonctefmes occurs for small TMR's. The Inexactness of Eq. (3-20) is because the plug electrons see a larger confining potential. $\psi_{e}+\psi_{c}$ and become part of the solenold electron dentity (passing electrons between the plugs and solenold) before escaping to the ends. Nhus, the appropriate (n') to insure that the total electron loss equals the sum of plug and solenold ion currents is somewhat different from liq. (3-20). However, the magnftude of te that adjusts to ensure quasi-charge neutral1ty can be determined to suffirient accuracy (wtihin 5\% by substituting Iq. (3-20) into Eq. (3-19) and using $n_{e}=n_{c}$ from Eq. (3-5) to obtain

$$
\left(\frac{\psi_{e}}{T_{e}}\right)=\ln \left[\frac{(n \tau)}{9 \times 10^{8} \mathrm{~T}_{e}^{3 / 2}\left(\frac{{ }_{e}^{e}}{T_{e}}\right)}\right] \text {. }
$$

For all cases of interest, $\psi_{e} / \tau_{e}$ will be between 5 and 7 ; therefore, setting $\phi_{e} / \mathrm{T}_{e}=6$ within brackets of Eq. $(3-21)$ will suffice to give an accurate value of $\mathrm{p}_{e} / \mathrm{T}{ }_{e}$ as a function of $\mathrm{I} \mathrm{e}_{e}$ and $(\mathrm{nt})_{1}$.

\section{Electron Energy Balance}

liach electron tescaping froti the solenold carries out an energy equal to $\phi_{\text {e }}$ plus a transverse kinetic energy $\mathrm{T}_{\mathrm{e}}$. Correspondingly, each electron injected with a plug ton escapes with $\phi_{e}+t_{c}+\mathrm{l}_{\mathrm{e}}$ encrgy. The electron temperature is determined by this electron energy loss out tile ends by equillbration with lons, by the electron heating from hot plug lons and fusion alplas, and by arternal auxillary heat lng (it any). We neglect bremsstrahlung and synchrotron radiation loss as small (sce estimates at the end of this chapter). Using Eqs. (3-19) and (3-19), the electron energy balance can be expressed as

$$
\begin{aligned}
& \frac{n_{c}^{2}}{(n t)_{1}}\left(\phi_{e}+T_{e}\right)+\frac{n_{c}^{2}(3 / 2)\left(T_{e}-T_{1}\right)}{(n t)_{e i}} \\
& =\Gamma_{p}\left(\frac{n_{p}^{2} E_{i n j}}{(n \tau)}\right)\left(\begin{array}{c}
V_{p} \\
v_{c}
\end{array}\right) \\
& +\frac{1}{4} n_{c}^{2}<\sigma v>E_{\alpha o} f_{\alpha} F_{e}+P_{e-a u x}
\end{aligned}
$$


The first term on the left-hand side of lip. (3-22) is the electron power loss $/ \mathrm{cm}^{3}$ carried out by eiectrons accompanying the ions lost from the solenold; the second term on the lefthand side is the energy transfer rate $/ \mathrm{cm}^{3}$ to ions by equilibration when $\mathrm{I}_{2}>\mathrm{r}_{1}$. 'lihe first term on the right-hand side of liq. (3-22) is the energy linput to the solenofd via elsctrons heated by the plug ions. 'lihe volume ratio factor $v_{p} / V_{c}$ in this term normalfzes the heating of electrons in the plugs per un It of volume in the solenold. Note that the electron energy carried out by the electrons accompanying the plug fons is included in the definition of $f_{p}$ ' Eq. (3-18). The second terin on the right-hand side of Eq. (22) Is the power density of electron heating by fusion alphas. The fraction of alphas adiabatically contalned and thermalfzed is $f_{i x}$, and $f_{e}$ is the fraction or 3.5-MeV energy given to electrons by each alpha that thermalizes. 'l'he fraction $f_{e}$ is a function of $T_{e}$ als given in Fig. 3-5. An approximate formula for $f_{e}$ ls given by

$$
r_{e}=1.5-0.29 \ln \left({ }^{\prime}{ }_{e}\right) \text {, }
$$

for $\mathrm{T}_{\mathrm{e}}$ in $\mathrm{keV}, \pm 5 \%$ in the range $20<T_{\mathrm{e}}<60 \mathrm{keV}$. Recall that, by defintion, $\mathrm{f}_{\mathrm{e}}+\mathrm{f}_{1}=1$, for alphas which completely thermalize. As discussed later, sone alphas initially slow down on electrons and then scatter into the lo's cone before glving the remainder of their energy to fons. Therefore, eiectron heating by alphas is underestimated in $\mathrm{Eq}$. (3-22) using Eq. (3-23), while ion heat lng in liq. (3-10) is overestimited. Since confinement is sensitive to the rato 'l' $/ \mathrm{I}$ ', the approximat fon that alphas are elther lost with no energy transfer or else completely thermalize is a pessinlistlc approximation with regard to the effects of alpha heating on confinement. The last term on the right-hand slde of lig. (3-22) represents the power inpul to the electruas by external anxilfary beating fier $\mathrm{cm}^{3}$ of solenold volume. For a given value of $E_{\text {in }}, M_{p}, R_{p}, n_{i} / n_{c}$, $V_{c} / V_{p}, f_{i e}$ and $F_{e-a u x}$, and uslng Eq. (3-3) for (ni) ${ }_{i}$ In the solenold, Eq. $(3-14)$ for $(n t)_{p}$ in the plugs, $\mathrm{Eq} .(3-1)$ for $\psi_{c}$, and $\mathrm{kq} .(3-21)$ for 中e, the ion energy balance Bq. (3-10) and the eicetion energy balance Eq. (3-22) can be solved together to obtaln the fon temperature l', and the electron temperature 'l' $\mathrm{e}$.

Pressure Balance

To relate the densilies $n_{p}$ and $n_{c}$ to the fields $B_{p}$ and $B_{C}$ in the plugs and in the solenotd, respectively, we require pressure balance with the respective betas $\beta_{p}$ and $\beta_{c}$ as parameters. By definition, the plug beta 
is given by

$$
B_{p}=\frac{n_{p}\left(E_{p l}+T_{e}\right)}{\left(B_{p}^{2} / 8 \pi\right)},
$$

where $E_{P \perp}$ is the average perpendicular energy of the plug ions, and $B_{p}$ is the vacuum field in the centers of the plugs. The plug mirror field is then $B_{p-\max }=R_{\text {vac }} B_{p}$. Fokker-P lanck calculations show that for drag-dominated plugs $\left(E_{i r_{j} j} \gg T_{e}\right)$ and injection perpendicular to the fleld lines as in 2XIIB, $E_{P_{1}}=0.9 \mathrm{E}_{\mathrm{P}}$. That is, the plug pressure is anisotropic, peaked in the perpendicular direction. Then, neglecting $T_{e}$ compared to $E_{p}$, the plug density can be expressed as

$\mathrm{n}_{\mathrm{p}}=2.8 \times 10^{15} \frac{\beta_{\mathrm{p}} \mathrm{B}_{\mathrm{p}-\max }^{2}}{\mathrm{R}_{\mathrm{vac}}^{2} \mathrm{E}_{\mathrm{p}}} \mathrm{cm}^{-3}$,

where $B_{p-\max }$ is in teslas and $E_{p}$ is in keV. By definition, the central solenoid beta is given by

$\beta_{c}=\frac{n_{c}\left(T_{e}+T_{i}+p_{\alpha} / n_{c}\right)}{\left(B_{c}^{2} / 8 \pi\right)}$

where $\mathrm{p}_{\alpha} / \mathrm{n}_{c}$ is the perpendicular

alpha pressure per unit central density given by Eq. (3-58), and where $B_{C}$ is the external (vacuum) field in the central solenoid. Using Eq. (3-58) for $\mathrm{p}_{\alpha} / \mathrm{n}_{\mathrm{c}}$, the solenoid density can be expressed as

$$
\frac{n_{c}=2.5 \times 10^{15} \beta_{c} B_{c}^{2} .}{\left(T_{e}+T_{i}+10^{11} T_{e}^{3 / 2}<\sigma v>E_{\alpha 0} f_{\alpha} f_{e}\right)^{-1}},
$$

where $B_{c}$ is in teslas and $T_{e}, T_{i}$, and $E_{10}$ are in keV. Given the density ratio $n_{p} / n_{c}$, the betas $E_{p}$ and $e_{c}$, and either one of the fields $B_{P}$ or $B_{C}$, Eqs. (3-25) and (3-27) can be used to obtain the other field. Alternatively, given both fields, Fis. (3-25) and $(3-27)$ can be used to obtain the densities $n_{p}$ and $n_{c}$ and the density ratio $n_{p} / n_{c}$.

\section{Plasma Dimensions}

The dimensions of the plugs and the solenoid in a TMR are related by conservation of magnetic flux through the plugs and solenoid and by the volume ratio $V_{c} / V_{p}$. If we assume unfform plasma pressure across the cross sections of the plug midplanes and the solenoid, the condition for flux conservation can be written as

$$
\pi r_{c}^{2} B_{c i}=\pi r_{p}^{2}{ }_{p i},
$$

where $\mathrm{B}_{\mathrm{ci}}$ and $\mathrm{B}_{\mathrm{pi}}$ are the Fields inside the solenoid and plug plasmas, respectively, given by

$$
B_{c 1}=B_{c}\left(1-\beta_{c}\right)^{1 / 2}
$$

(the long, thin approximation for the solenoid) and

$$
\mathrm{B}_{\mathrm{p} i}=\mathrm{B}_{\mathrm{p}}\left[1-\left(\beta_{\mathrm{p}} / 2\right)\right]
$$

(the short, fat approxtmation for 2XIIB-1ike plugs). 
Using Eqs. (3-29) and (3-30) for $B_{c i}$ and $B_{p i}$, and solving Eqs. (3-27) and (3-25) for the external fields $B_{c}$ and $B_{p}$, respectively, Eq. (3-28) can be written

$$
\frac{r_{c}}{r_{p}}=\left[\frac{1-\left(\beta_{p} / 2\right)}{\left(1-\beta_{c}\right)^{1 / 2}}\right]^{1 / 2}\left[\left(\frac{\beta_{c}}{\beta_{p}}\right)\left(\frac{n_{p}}{n_{c}}\right)\right.
$$

- $\left.\left(\frac{0.9 \mathrm{E}_{\mathrm{p}}}{\mathrm{T}_{\mathrm{e}}+\mathrm{T}_{i}+10^{11} \mathrm{~T}_{\mathrm{e}}^{3 / 2}<\sigma v>\mathrm{E}_{\alpha \sigma_{0} \mathrm{f}_{\alpha} \mathrm{f}}}\right)\right]^{1 / 4}$.

Equation (31) relates the radif of the plugs and the solenoid when the densities and temperatures are known and when the plug and solenoid betas are specified.

We assume that the equivalent volume of each plug corresponds to a uniform sphere of radius $r_{p}$ at density $n_{p}$ at density $n_{p}$ and that the solenoid volume is that of a cylinder of radius $r_{c}$ and length $L_{c}$ :

$$
v_{p}=2\left(\pi \frac{4}{3} r_{p}^{3}\right)(\text { bath plugs)(3-32) }
$$

and

$$
V_{c}=\pi r_{c}^{2} L_{c} \quad \text { (solenoid) }
$$

Given the volume ratio $\mathrm{V}_{\mathrm{p}} / \mathrm{V}_{\mathrm{c}}$, the solenoid length can be determined from Eqs. (3-31) through (3-33) when either the radius of the flux tube in the plugs $\left(r_{p}\right)$ or the radius in the solenoid $\left(r_{c}\right)$ is spectfied:

$$
\begin{gathered}
L_{c}=\left(\frac{V_{c}}{V_{p}}\right)\left(\frac{8 r_{p}^{3}}{3 r_{c}^{2}}\right)=\left(\frac{V_{c}}{V_{p}}\right)\left(\frac{8}{3} r_{c}\right)\left(\frac{r_{c}}{r_{p}}\right)^{-3} \\
=\left(\frac{V_{c}}{V_{p}}\right)\left(\frac{8}{3} r_{p}\right)\left(\frac{r_{p}}{r_{c}}\right)^{2} \cdot
\end{gathered}
$$

The radius $r_{c}$ will be usually be determined by the economic requirement for sufficient solenoid fuston power per square metre of blanket (which scales with $r_{c}$ ), balanced with the requirement for sufficient $Q$ and a given total power output. Alternatively, depending on the injection energy $E_{i n j}$ and plug field $B_{p}$, the radius of the plug $r_{p}$ might be determined by the requirement for having a reasonable fraction of the plug neutral beams trapped in the plugs. The trapping function $f_{t}$ for the plug beam is given by

$$
\mathrm{f}_{t}=1-\mathrm{e}^{-\gamma},
$$

where the attenuation ratio $\gamma$ for a uniform density plug, using crosssection and energy distribution functions by Riviere, ${ }^{3-21}$ is given by

$\gamma=1.85 \times 10^{-14} n_{p_{p} r_{p}}\left(\frac{M}{E_{i n j}}\right)^{0.91}$

with $n_{p}$ in $\mathrm{cm}^{-3}, r_{p}$ in $\mathrm{cm}$, and $E_{\text {inj }}$ in keV. The competition between the need for high $E_{\text {inj }}$ and small plugs may sometimes lead to $f_{t}$ substantially 
less than unity. In all cases, the untrapped portion of the beam is assumed to be disposed of with no energy recovery, a circumstance which increases the recirculating power fraction and $\$ / \mathrm{kW}(\mathrm{e})$ net for a given Q. ( $Q$ is by definition the fusion power over injection power actually trapped in the plasma.) Nonrecovery of the untrapped beam is a pessimist ic assumption, since it may be costeffective to directly convert, or at least thermally convert, the unused portion of the beam. However, a design for such a beam direct converter has not yet been made. For the reference case (Table 10-2), 90\% of the bean is trapped; therefore, whatever is done with the untrapped porcion of the beam will not affect the energy balance more than $10 \%$, For the case of electron heating, the absorbed power $P_{e-a u x}$ in kq. (3-22) is assumed to be the same percentage of the injected electron power input as the trapped portion of the plug neutral beams is of the incident neutral beam.

HEATLNG BY 3.5-MeV ALPHA PARTICLES

\section{Adlabatic Containment of}

\section{Alpha Particles}

Since nearly all the 3.5-MeV alpha particles are born with pitch angles greater than the magnetic loss-cone angle In the solenoid, the fraction $\mathrm{f}_{\alpha}$ of contained $3.5-\mathrm{MeV}$ alpha part1- cles avallable to heat the plasma is determined mainly by adiabaticity. Adfabaticity is a function both of the particle energy and pitch angle, with alphas of greater pitch angle and lower energy being more adiabatic. The relative jumps in magnetic moment $\angle \mu / \mu$ that occur when the alphas reflect at the ends of the solenoid can be expressed as $3-22$

$$
\left(\frac{\Delta \mu}{\mu}\right)_{\mathrm{rms}}=\frac{\mathrm{A}_{0}}{2} \frac{\mathrm{V}}{\mathrm{V}_{1}} \exp (-\kappa / \varepsilon),
$$

where the amplitude $\Lambda_{0}=4$ for the majority of off-axis alphas $\left(A_{0}\right.$ is less for axis-encircling alphas). Assuming a quadratic field variation of the transition regions in the ends of solenoid,

$$
K=\frac{1}{2 \lambda^{2}}\left[\frac{1+\lambda^{2}}{2 \lambda} \quad \ln \left(\frac{1+\lambda}{1-\lambda}\right)-1\right] \text {, }
$$

where $\lambda=v_{1} / v$ in the uniform field region of the center of the solenoid. $K$ is an increasing function of $\lambda$ (pitch angle); $K=0.70$ for the more nonadiabatic alphas near the losscone angle $\theta=20^{\circ}(\lambda=0.342)$, and $\mathrm{k} \approx 2.0$ for alphas with $\theta=80^{\circ}$ $(\lambda=0.985)$. The quantity $\varepsilon$ is given by

$$
\varepsilon=\frac{\mathrm{v}}{\Omega_{0} \mathrm{~L}_{\|}} \text {, }
$$

where $\mathrm{v}$ is the alpha velocity.

$$
\Omega_{0}=\frac{2 q B_{c 1}}{M_{\alpha}}
$$


is the alpha cyclotron frequency at the field $B_{c i}=B_{c}\left(1-B_{c}\right)^{1 / 2}$ inside the solenoid plasma, and where $\mathrm{L}$ is the field gradient scale length in the transition (mirror) regions at the solenoid ends.

Since adiabaticity is strongly energy dependent through $\varepsilon$ in Eq. (3-37), the condition for alpha containment can be approximately expressed as

$$
\tau_{\alpha \beta} \geq \tau_{\alpha, e},
$$

where $\tau_{\alpha \theta}$ is the time for an alpha to diffuse in pitch angle by nonadiabaticity from its initial angle $\sigma_{a}$ to the loss-cone angle ${ }^{\prime} c$, and where $t_{y e}$ is the slowing-down time for an alpha by electron drag. Assuming an alpha makes a random (uncorrelated) pitch angle step of average magnitude

$$
\Delta 0_{a}=\Delta\left(v_{1} / v\right)=\left(\frac{\lambda}{2}\right)\left(\frac{\Delta \mu}{\mu}\right)_{\text {rms }}
$$

in each bounce time $\tau_{\text {bounce }} \equiv \mathrm{L}_{c} / \mathrm{v}_{n !}$, Eq. (3-41) can be expressed as

$$
\frac{\left(\theta_{a}-\theta_{c}\right)^{2}}{\left\langle\Delta \theta_{\alpha}\right\rangle^{2} / \tau_{\text {bounce }}} \geq j \times 10^{11} \mathrm{~T}_{\mathrm{e}}^{3 / 2} / \mathrm{n}_{\mathrm{c}} \text {, }
$$

where we have written the alpha drag time $\tau_{\alpha e}$ in terms of $T_{e}$ in $\mathrm{keV}$ and electron density $\mathrm{n}_{e}=\mathrm{n}_{\mathrm{c}}$. Using Eq. (3-42) then, the condition for adiabaticity is

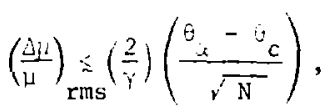

where $N \equiv \tau_{\text {Ge }} / \tau_{\text {bounce }}$ is the number of longitudinal bounces an alpha makes in the solenoid in one slowing down time. Using Eq. $(3-37)$ for $(\Delta \mu / \mu)_{\mathrm{rms}}$ in Eq. (3-44), we obtain

$$
K / \varepsilon \geq \ln \left(\frac{\sqrt{2 N}}{\theta_{u}-\theta_{c}}\right)
$$

for adiabaicity. Using Eq. (3-39) and $(3-40)$, this can be written

$$
B_{c i} L_{\|} \geq v\left(\frac{M \alpha}{2 q}\right)\left(\frac{1}{k}\right) \ln \left(\frac{\sqrt{2 N}}{\theta_{\alpha}-\theta_{c}}\right) \text {, }
$$

or

$B_{c} L_{\|}\left(1-\beta_{c}\right)^{1 / 2} \gtrsim \frac{0.27}{k(\theta)} \ln \left(\frac{\sqrt{2 N}}{\theta_{\alpha}-\theta_{c}}\right)$,

for $3.5-\mathrm{MeV}$ alphas $\left(v=1.3 \times 10^{9} \mathrm{~cm} / \mathrm{s}\right)$, and where $B_{c}$ is in teslas, and $L_{\|}$is in metres. Consider the two cases $\theta_{\alpha}=20^{\circ}$ and $\theta_{\alpha}=80^{\circ}$, for which $k$ $=0.7$ and 2.0 , respectively. For the reference case parameters, $\mathrm{N}=1.7 \times 10^{5}$ bounces at $\theta_{\alpha}=20^{\circ}$ an 1 $3.2 \times 10^{4}$ bouncts for $\theta_{\alpha}=80^{\circ}$. If we take a typical value for the losscone angle $\theta_{c}=13^{\circ}$, Eq. (3-46) gives $B_{c} L_{\|}\left(1-\beta_{c}\right)^{1 / 2} \geq 3.2 \mathrm{~T} \cdot \mathrm{m}$ for containment of $20^{\circ}$ alphas, and $B_{c} I_{\|}\left(I-\beta_{c}\right)^{I / 2}$ $>0.7 \mathrm{~T} \cdot \mathrm{m}$ for containment of $80^{\circ}$ alphas. If we assume the reference case $B_{C}$ $=2.2 \mathrm{~T}$ and $\beta_{c}=0.7$, the required 
field gradient scale length $\mathrm{L}_{\|}$is $2.7 \mathrm{~m}$ for $\sigma_{\alpha}=20^{\circ}$ and $0.6 \mathrm{~m}$ for $\partial_{\gamma_{\alpha}}=80^{\circ}$. Since efther field gradient length could probably be designed for the solenoid transition reglons, the minimum alpha pitch angle $\theta_{\alpha m i n}$ for adiabatic confinement could be chosen anywhere between these limits, giving a Eraction of contained alphas $f_{p}$ $=\cos 0_{\alpha m i n}$ ranging from $94 \%$ to $17 \%$. In the absence of nonadiabatic effects, Fokker-Planck calculations ${ }^{3-20}$ indicate that $70 \%$ of the alphas thermalize for a mirror ratio $\mathrm{R}_{\mathrm{c}}=10\left(0_{\mathrm{c}}=18^{\circ}\right)$. The $30 \%$ alpha particle loss is due to Coulomb scattering on plasma ions after most of the alpha energy has been lost to electrons and ions by drag. Most of those alphas lost would have been those born near the 1osscone angle. For $\mathrm{f}_{\alpha}<1$ due to nonadiabaticily, alpha loss by Coulomb scattering will be less important. For the present physics mode1, we assume that all adiabatically contalned 3.5-MeV alphas $\left(\theta_{\alpha}>\theta_{\text {amin }}\right)$ completely thermalize; i.e., we neglect Coulomb loss during thermalization of those alphas. Since the ion heating will thereby be overestimated compared to electron heating (an unfavorable effect), we may sometimes try to offset some of the disadvantage of this simplifying assumption by taking $\mathrm{f}_{\alpha}=1$ even though $f_{\alpha} \lesssim 0.95$.
Alpha Heating of Ions and Electrons

Assuming that those alpha particles that are adiabatically contained survive to thermalize completely, we wish to determine the fractions $\mathrm{f}_{\mathrm{e}}$ and $f_{i}$ of the initial alpha energy $\mathrm{E}_{a 0}$ that are transferred to electrons and DT Lons, respectively. By definitfon, then,

$$
E_{e}+E_{i}=1
$$

Following a treatment by Rose, ${ }^{3-23}$ we can determine the functions $\mathrm{f}_{\mathrm{e}}$ and $f_{i}$ from the drag rates of alphas on electrons and ions. If we assume that $E_{c x} \gg T_{e}, T_{i}$, the decay of alpha energy is glven by

$$
\frac{\mathrm{dE}_{\alpha}}{\mathrm{dt}}=-\frac{\mathrm{E}_{\alpha}}{\tau_{\alpha e}}-\frac{\mathrm{E}_{\alpha}}{\tau_{\alpha i}} \text {, }
$$

where

$$
\tau_{\alpha \in}=5 \times 10^{11} \mathrm{~T}_{\mathrm{e}}^{3 / 2} / \mathrm{n}_{\mathrm{c}}
$$

is the drag time on electrons and where

$$
\tau_{\alpha i}=1.7 \times 10^{9} \mathrm{E}_{\alpha}^{3 / 2} / \mathrm{n}_{\mathrm{c}}
$$

is the drag time on DT ions in the solenold. (All energies are in keV; $\left.\ln \Lambda_{\alpha e}=\ln \Lambda_{\alpha i}=20.\right)$ Equation (3-48) can be expressed as

$$
\frac{d E_{\alpha}}{d t}=-\frac{E_{\alpha}}{\tau_{\alpha e}}\left[1+k\left(\frac{E_{\alpha 0}}{E_{\alpha}}\right)^{3 / 2}\right],(3-51)
$$


where

$$
k=1.43 \times 10^{-3} \mathrm{~T}_{\mathrm{e}}^{3 / 2},
$$

and where $E_{20}=3500 \mathrm{keV}$ is the initial alpha energy. Note that as long as $E_{l} \gg T_{e}$, $T_{i}$, the rate of alpha energy loss depends only on $\mathrm{T}_{e}$ and $E_{i}$. The ion temperature $T_{i}$ does not matter until the alpha velocity approaches the ion velocity, by which time the alpha has lost nearly all its energy. The alpha energy decay is inftially exponential with a time constant $\tau_{\alpha e}$, but when $E_{\dot{u}} \leqq 30 \mathrm{~T}_{\mathrm{e}}$, the ion drag term [the second term in brackets in Eq. $(3-51)]$ becomes dominant, and the alpha rapidly loses its remaining energy to the ions.

The solution to $\mathrm{Eq} .(3-51)$ for the alpha energy is given by

$$
E_{a}(t)=E_{a 0}\left[(k+1) e^{-t^{-}}-k\right]^{2 / 3},
$$

where

$$
t^{\prime} \equiv \frac{3 t}{2 \tau_{\alpha e}} .
$$

Note that the alpha completely thermalizes $\left(E_{\alpha} \rightarrow 0\right)$ when $t^{\circ}=\ln [(k+1) / k]$. The fraction of alpha energy transferred to electrons is then given by

$$
\begin{aligned}
f_{e}= & \frac{1}{E_{\alpha e}} \int\left(\frac{E_{\alpha}}{\tau_{\alpha e}}\right) d t=\frac{2}{3} \int_{0}^{\ln [(k+1) / k]} \\
& \cdot\left[(k+1) e^{-t^{-}}-k\right]^{2 / 3} d t^{-} \cdot(3-55)
\end{aligned}
$$

The fraction of alpha energy transferred to ions is correspondingly given by

$$
\begin{aligned}
& f_{i}=\frac{1}{E_{10}} \int \frac{E_{d i}}{\tau_{d i}} d t \\
& =\frac{2}{3} \int_{0}^{\ln [(k+1) / k]} \frac{k d t}{\left[(k+1) e^{-t}-k\right]^{I / 3}}
\end{aligned}
$$

$\triangle$ plot of $\mathrm{r}_{\mathrm{e}}$ and $\mathrm{f}_{\mathbf{i}}$ as a function of $T_{e}$ is shown in Fig. 3-5. Note that alpias transfer more energy to ions than to electrons for $\mathrm{T}_{\mathrm{e}}>33 \mathrm{keV}$. Ratios of $T_{e} / T_{i}>1$ improve electrostatic confinement in a TMR, a process hich requires more energy into electrons than ions. However, because alphas heat the electrons less than ions for $\mathrm{T}_{e} \geq 33 \mathrm{keV}$, ignition at such temperacures accurs only with $\mathrm{T}_{\mathrm{e}} /$ $T_{i} \lesssim 1$ and requires fairly large density ratios (see "Q Scaling in a TMR"). Additional electron energy input, either by plug ions or other external sources, is required to obtain $T_{e} / T_{1}>1$.

\section{Hot-Alpha Pressure}

$$
\text { Associated with the instantaneous }
$$
power input per $\mathrm{cm}^{3}$ to electrons from fast alphas is a required alpha pressure $\mathrm{p}_{\alpha}$ giving a stored energy density $=3 / 2 p_{\alpha}$ in the form of hot 
alphas slowing down. Assuming that the average energy of the slowingdown alphas 15 much greater than $T_{e}$, one can express power balance between fusion production of alpha energy and a'pha energy loss by drag from the electron component as

$\frac{\frac{3}{2} p_{c}}{\tau_{\alpha e}}=\frac{1}{4} n_{c}^{2}\left\langle\sigma v>E_{\alpha, 0} f_{\alpha \epsilon} f_{e}\right.$

where $\tau_{\alpha e}$ is given by Eq. (3-49), and $\mathrm{f}_{\mathrm{e}}$ is given either by Eq. (3-55) or more conveniently by Eq. (3-23). Using Eq. (3-49), 3q. (3-57) can be solved for the hot-alpha pressure per unit density in the solenoid:

$\frac{\mathrm{p}_{\alpha}}{\mathrm{n}_{\mathrm{c}}}=10^{11} \mathrm{~T}_{\mathrm{e}}^{3 / 2}\langle\sigma \mathrm{v}\rangle \mathrm{E}_{\alpha 0} \mathrm{f}_{\alpha} \mathrm{f}_{\mathrm{e}}$.

For the reference case parameters (Table 10-2), the ratio of alpha pressure to electron plus ion pressure $\mathrm{p}_{\alpha} /\left[\mathrm{n}_{\mathrm{c}}\left(\mathrm{T}_{\mathrm{e}}+\mathrm{T}_{\mathrm{i}}\right)\right] \approx 36 \%$.

\section{Q SCALING IN A TMR}

The $Q$ in a TMR depends on a number of independent plasma parameters $-\mathrm{E}_{1 \mathrm{inj}}$ $\mathrm{M}_{\mathrm{p}}, \mathrm{n}_{\mathrm{p}} / \mathrm{n}_{\mathrm{c}}, \mathrm{V}_{\mathrm{c}} / \mathrm{V}_{\mathrm{p}}$, and $\mathrm{f}_{\mathrm{a}}$ and also depends weakly on the plasma betas $\beta_{p}$ and $\beta_{c}$ insof ar as they affect the mirror ratios $R_{p}$ and $R_{c}$ seen by the plug and solenoid ions. For the case with auxillary electron heating, the
Q given by Eq. (3-4) can be generalized to include the electron heating power:

$$
Q=\frac{1}{4}(n i)_{p}\langle\sigma v\rangle\left(\frac{E_{F}}{E_{i n j}}\right)\left(\frac{{ }_{c}}{n_{p}}\right)^{2}
$$

$$
\cdot\left(\frac{v_{c}}{v_{p}}\right)\left(1-F_{e}\right) \text {, }
$$

where

$$
F_{e} \equiv \frac{P_{e-a u x} v_{c}}{\left(\frac{n_{p}^{2} E_{1 n j} v_{p}}{(n \tau)_{p}}\right)+P_{e-a u x} v_{c}}
$$

is the rat to of direct electron heating power to the total power (neutral beam plus electron) injected into the plasma. In the 1 imit $\mathrm{F}_{\mathrm{e}} \rightarrow 1$ (dominant electron heating), $Q \rightarrow \frac{1}{4} n_{c}{ }^{2}\langle\sigma v\rangle E_{f}$ $P_{\text {e-aux }}$, so that $Q$ no longer depends on the plug parameters or $\mathrm{V}_{\mathrm{c}} / \mathrm{v}_{\mathrm{p}}$.

For an economic TMR, the goal is not just to maximlze $Q$, but to minimize capital cost per kilowatt. If there were no restrictions on $n_{p} / n_{c}$ or $V_{c} V_{p}, Q$ could be made arbitrarily large according to Eq. (3-59). How$\epsilon$ ver, increasing $n_{c} / n_{c}$ generally increases blanket cost per $\mathrm{kW}$; higher $v_{c} / v_{p}$ generally requires larger reactor size and power. Nevertheless, a high $Q$ is necessary also to keep the recirculating power small. One ci the most uncertain reactor cost estimates at the time of this study 
is the cost of the MeV neutral-beam injectors for the plugs. Depending cn how large the $\$ / \mathrm{kW}$ of recirculating power by those beams is in the final analysis, Q may possibly need to be increased to ten or more for economic operation. In that event, it is desirable to know the various ways to scale up $Q$ in a TMR.

\section{Subignition Case}

Let us consider first the situation where alpha heating alone is not sufficient to energetically sustain the solenoid. The solenoid requires addicional energy input in steady state, preferably in electron heating of some form rather than in ion heating. In the referencc case, the extra energy comes from plug ions heating the electrons, parameterized by the fraction $f_{p}$ of neutral-beam power that is available to the solenoid electrons. Auxiliary direct heating of electrons is parametrized by the fraction $F_{e}$ of total injection power that is direct electron heating. The plug parameters are coupled to solenoid parameters though the electron entrgy balance Eq. (3-22). Equation (3-22) can be solved for the volume ratio, giving

$$
\frac{y_{c}}{y_{p}}=\left(\frac{n_{p}}{n_{c}}\right)^{\cdots} \frac{(n \tau)_{i}}{(n \tau)_{p}}\left(f_{p}+\frac{F_{e}}{I-F_{e}}\right)
$$

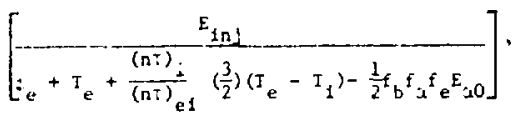

where $f_{b}=\frac{\frac{1}{2}(n t)_{i}\langle j v\rangle}{1+\frac{1}{2}(n \tau)_{i}\langle j v\rangle}$

is the burnup fraction. Substitution of Eq. (3-6i) into Eq. (3-59) then gives

$$
\begin{aligned}
& \text { i) }=\frac{1}{2}\left(\frac{r_{b}}{I-F_{b}}\right)\left[F_{p}\left(\downarrow-F_{e}+F_{e}\right]\right. \\
& {\left[\frac{E_{F}}{\left[e+T_{e}+\frac{(n t)}{(n T)_{e 1}}+\left(\frac{3}{2}\right)\left(T_{E}-T_{1}\right)-\frac{1}{2} f_{b} f_{a} f_{e} E_{d O}\right.}\right] \text {. }}
\end{aligned}
$$

Note that $Q$ is directly proportional to the burnup $\left(f_{b} / 1-f_{b}\right)$, hence proportional to (nt) $i$, a dependence not apparent in Eq. (3-59). When there is no auxiliary electron heating $\left(F_{e}=0\right), Q$ is directly proportional to the plug heating fraction $f_{p}$. The way to increase $Q$ with $f_{p}$ is to raise the injection energy $E_{\text {inj }}$ according to $\mathrm{Eq} .(3-18)$. However, raising $E_{i n j}$ at fixed $\beta_{p}$ and $B_{p}$ decreases plug density and solenoid fusion power density. When $E_{i n j} / T_{\circ}$ is such that $f_{p}=0$ by Eq. $(3-18), Q$ is directly proportional to $\mathrm{F}_{\mathrm{e}}$. 
Compared to the reference case with $f_{p} \approx 1 / 3$, a case with electron heating and $f_{p}=0$ would need $F_{e} \geq 1$ ij to do as well, assuming the generating and injection efficiency for electron heat ing were the same as the neutralbeam efficiency.

For the case of no electron heating $\left(F_{e}=0\right), F i g \cdot 3-6$ shows the variation of $Q, T_{e}$, and $T_{i}$ with volume ratio $v_{c} v_{p}$ (i.e., solenoid length) for a fixed plug injection power, a fixed injection energy $E_{\text {inj }}=1 \mathrm{MeV}$, and a fixed density ratio $n_{p} / n_{c}=10$. Deuterium plugs, $R_{p}=2.5$, and an alpha containment fraction $f_{\alpha}=1$ are assumed. As the volume ratio is increased, the power input per unit volume of solenoid from the plugs is decreased, so that the equilibrium electron and ion temperatures decrease monotonically with $v_{c} / v_{p}$. However,

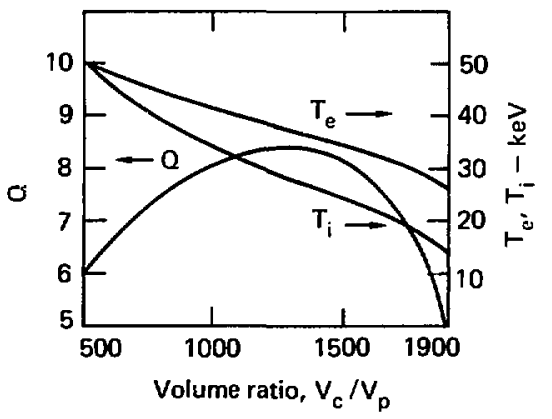

Fig. 3-6. Variation of $Q, T_{e}$, and $T_{i}$ with volume ratio $V_{c} V_{p}$ (subignition) for $n_{p} / n_{c}=10, E_{i n j}=1 \mathrm{MeV}, f_{\alpha}$ $=1.0$, and $F_{e}=0$. the cotal solenoid fusion power is increasing faster due to the volume increase than it is decreasing due to the decrease in $\mathrm{T}_{i}$ and rivi. Beyond a certain volume ratio, however, the rate of decline in s, with $T_{i}$ cannot be compensated for by inereases in volume, and (? decreases.

\section{Condition for lgnition}

The conditions for alpha heating alone to sustain the solenold (Ignition) can be expressed as

$$
\begin{gathered}
\left.\frac{1}{4} n_{c}^{2} \measuredangle 0 v\right\rangle E_{\alpha 0} f_{u} f_{e}=\frac{n_{c}^{2}}{(n \tau)}\left(t_{e}+T_{e}\right) \\
+\frac{n_{c}^{2}}{(n \tau)_{e i}}\left(\begin{array}{c}
3 \\
i
\end{array}\right)\left(t_{e}-T_{i}\right)
\end{gathered}
$$

and

$$
\begin{aligned}
\frac{1}{4} n_{c}^{2}\langle\sigma v\rangle E_{\alpha 0} f_{\alpha} f_{i}=\frac{n_{c}^{2}}{(n \tau)_{i}}\left(\phi_{c}+T_{i}\right) \\
-\frac{n_{c}^{2}}{(n \tau)_{e i}}\left(\frac{3}{2}\right)\left(T_{e}-T_{i}\right) \cdot(3-65)
\end{aligned}
$$

Adding Eq. (3-64) and (3-65) and using $f_{e}+f_{i}=1$ and $(n \tau)_{i}=(n \tau)_{e}$, we obtain

$$
\frac{1}{4} \mathrm{n}_{\mathrm{c}}^{2}<\sigma \mathrm{v}>\mathrm{E}_{\alpha 0} \mathrm{f}_{\alpha}
$$




$$
(n \tau)_{i}=\frac{4\left(\psi_{e}+\tau_{c}+I_{e}+T_{i}\right)}{\left\langle c v i E_{40} r_{i}\right.} \cdot(3-67)
$$

For ignition, $(n \tau)$, has a minimum $=7 \times 10^{14} \mathrm{~cm}^{-3}$ at $n_{p} / n_{c}=17$, $T_{e} \approx T_{i}=40 \mathrm{keV}, \mathrm{f}_{\lambda}=1$. The required $(n \tau)_{i}$ for ignition in a TMR is higher than in tokamaks because the energy carried out per ion-electron pair is greater than $\frac{3}{2}\left(\mathrm{~T}_{e}+\mathrm{T}_{i}\right)$ due to the potentials. On the other hand, the ions fall through the combined potential $t_{e}+t_{c}$ on escape, making efficient direct conversion possible in a simple one-stage direct converter with a collector potential at $\phi$ $+F_{C} \cdot$

Ideally, the plugs should not input any net electron energy to the solenoid under conditions of ignition; i.e., $f_{p}=0$. The solenoid parameters can then become uncoupled from those plugs; $\mathrm{T}_{e}$ and $\mathrm{T}_{i}$ become independent of $V_{c} V_{p}$. In Eqs. (3-61) and (3-62), this means that the denominators of the energy ratios in brackets go to zero, in accordance with Eq. (3-64). $V_{c} V_{p}$ and $Q$ can then assume any value. Although the effective $Q$ of the solenotd alone is infinite at ignition, a fixed neutral-beam power must always be injected to maintain the plugs. The tandem mirror system $Q$ according to Eq. (3-59) then scales up linearly with $V_{c} / V_{p}$, or solenoid length. have the attractive possibility of starting out at small power levels with a short solenoid, which could later be lengthened by simply adding solenoid modules to increase both? and power output without changing plus or solenoid parameters. As an example, Fig. (3-7) shows $Q$ as a function of volume ratio at a density ratio suffictent for ignition, $n_{p} / n_{c}=16.5$. All other parameters are the same as in Fig. 3-6. Q is seen to increase indefinitely with volume ratio. $\mathrm{T}_{\mathrm{e}}$ and $\mathrm{T}_{i}$ approach constant asymptotic values $=40 \mathrm{keV}$ at large volume ratios, so fusion power is also increasing proportional to volume. $\mathrm{T}_{\mathrm{e}}$ and $\mathrm{T}_{i}$ actually vary slowly with the smaller values of $v_{c} / v_{p}$ because the assumed injection

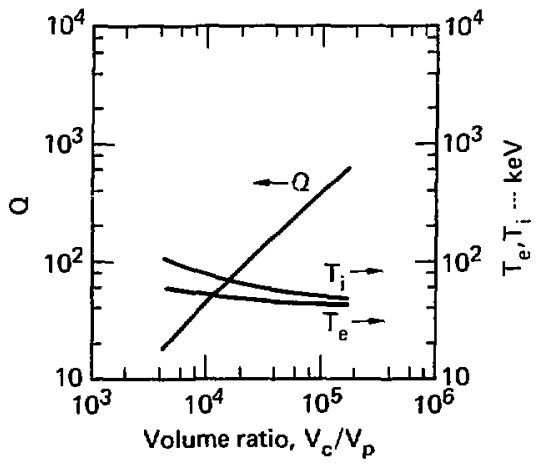

Fig. 3-7. Varlation of $Q, T_{e}$ and $T_{i}$ with volume ratio $V_{c} / V_{p}$ (ignition) for $n_{p} / n_{c}=16.5, E_{i n j}=1 \mathrm{MeV}$, $f_{\alpha}=1.0$, and $F_{e}=0$. 
energy $E_{\text {inj }}=1 \mathrm{MeV}$ is too high for $f_{p}$ to be exactly zero at the asymptotic ignition temperatures of $40 \mathrm{keV}$. Some unnecessary energy is being input by the plugs. The energy input is significant only at small solenoid volumes, at which $\mathrm{T}_{\mathrm{g}}$ heats up to approximately satis $\Gamma_{y} r_{p}-0$. An injection encrgy $E_{\text {in } j}: 660 \mathrm{keV}$ would allow the plugs to completely decouple.

Unfortunately, the constraint of a maximum plug density at practical plug magnetic fields makes the fusion power density in the solenoid uneconomically low at the density ratio $n_{p} / n_{c}=17$ required for ignition and at a total net power output of $1000 \mathrm{MW}(\mathrm{e})$. Ine plasma radius in the plugs and solenoid can be scaled up to achieve any desired wall loading on the blanket, but only at an increase in total power. The parametric analysis in Chapt. 10 shows that minimum reactor cost at a power level of $1000 \mathrm{MW}(\mathrm{e})$ occurs at $n_{p} / \mathrm{n}_{c}>9$, at which the power input to the solenoid from the plugs is comparable to the irput by alpha particles. The percentage of alpha heating increases asymptotically to $100 \%$ (ignition) as the reactor power is increased.

RADIAL DIFFUSION OF THERMAL ALPHA PARTICLES AND IMPURITTES

Here we consider the removal of thermal alpha particles and higher-Z impurities in a TMR by classical radial diffusion across the solenoid field, as suggested by Dimov. ${ }^{3-3}$ Such diffusion can occur by collisions between the iligher $-Z$ ions and the majority species of DT ions much more rapidly than the usual diffusion of ions by momentum-transfer collisions with electrons. For the moment, let us consider only thermal alphas as Impurities. We assume flat radiul density and temperature profiles in both the plugs and in the solenoid, as shown in Fig. 3-8. Thermal alphas generated by fusion reactions and couling down within the interior diffuse to the boundary, sustaining a negative radial density gradient of alphas $\mathrm{dn}_{\alpha} / \mathrm{dr}<0$. Let us assume there is some mechanism of removing thermal alphas preferentially from the boundary layer, so that the alpha density at the boundary is small, $\mathrm{n}_{\alpha}\left(\mathrm{r}_{\mathrm{c}}\right)=0$. One such mechanism is to injert high-energy neutral beams tangentially into the boundary layer, heating the ions $T_{i}, T_{, j}>t_{b}$, where $\phi_{b}$ is a small boundary layer potential barrier reduced by a lower $\mathrm{T}_{e}$ in the layer. The DT ions in the layer are contained for a collision time as in a high-temperature, $\hat{q}=1$ conventional - mirror machine. Alphas with $Z=2$ and higher- $z$ impurities are then preferentially expeiled from the layer because of their higher scattering rate. 


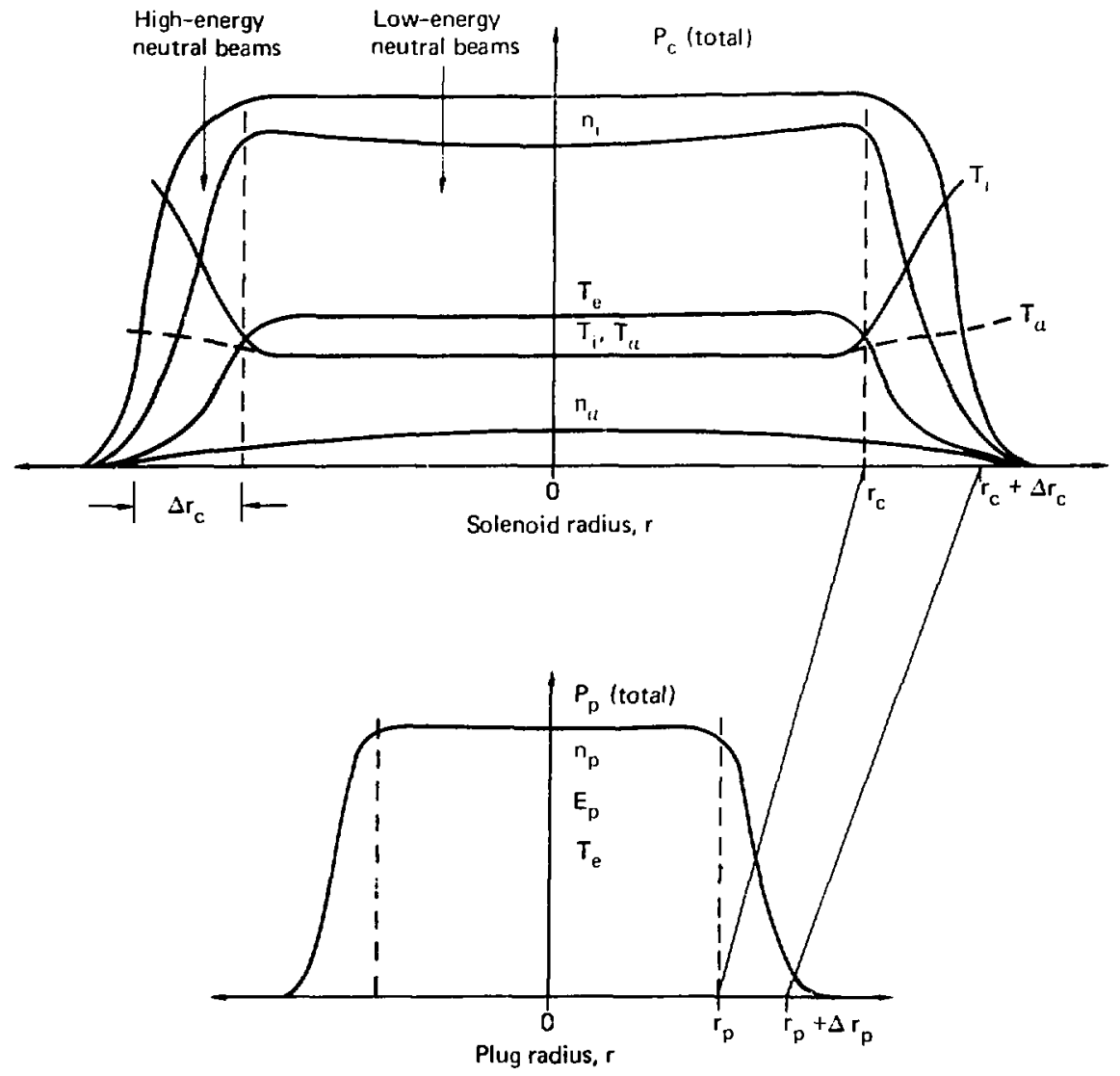

Fig. 3-8, Radial profiles of solenoid and plug.

For the case where there are no thermal gradients $(\partial \mathrm{T} / \partial \mathrm{r}=0)$, Longmire and Rosenbluth ${ }^{3-24}$ derive the $\Gamma_{12}=\frac{4}{3}\left(\frac{2 \pi M 2^{c^{2}}}{k T}\right)^{1 / 2} \frac{\mathrm{cq}_{2}^{2}}{B^{2}} \ln \Lambda_{12}$ flux $\Gamma_{12}$ of Species 1 due to the collisions with Species 2, which can be written for $\mathrm{T}_{1}=\mathrm{T}_{2}$ as

$$
\times\left(\frac{q_{1}}{q_{2}} n_{1} \frac{\partial n_{2}}{\partial r}-n_{2} \frac{\partial n_{1}}{\partial r}\right)
$$


where $M_{12}$ is the reduced mass. Equation 68 predicts that the net charge flux is zero

$$
\mathrm{q}_{1} \Gamma_{12}+\mathrm{q}_{2} \Gamma_{21}=0
$$

Rose $\mathrm{e}^{3-25}$ shows this to be a direct consequence of momentum conservation for guiding-center displacements due to individual collisions. Thus, no radial electron transport is required for charge neutralization of alphas diffusion outward on DT ions, since there is a flux of DT ions diffusing inward that is twice as large. This also means that in steady state, the diffusion of DT fuel into a local volume exactly balances the radial loss of thermal alpha from that volume. Thus, if most alphas thermalize, a local injection strength equal only to the unburned DT fuel loss is required, of course, the extra fuel diffusing inward must be supplied by injection in the plasma boundary to compensate for fuel loss by burnup in the plasma interior.

Letting Species 1 be thermal alphas and Species 2 be DT ions with an effective mass of $2.5 \mathrm{amu}$, the flux of alphas by Eq. (3-69), with $\ln \Lambda_{a i} \approx 22$, becomes

$$
\begin{aligned}
\Gamma_{\alpha i} & =\frac{6.1 \times 10^{-12}}{\sqrt{T_{i} B_{c i}^{2}}} \\
& \cdot\left(z_{\alpha} n_{\alpha} \frac{d n_{i}}{d r}-n_{i} \frac{d n}{d r}\right) .
\end{aligned}
$$

where $T_{i}=T_{\nu}$ is the ion temperature in $\mathrm{keV}$, and $\mathrm{B}_{\mathrm{cl}}$ is the field inside the plasma of the solenotd in teslas. Note that if the majority species of DT ions had a sufficlent negative radial gradient, the flux of alphas could be inward $I_{\alpha i}<0$ even though the alpha gradient were negative dn $/ \mathrm{d} r<0$. Thus, it is important to keep $\mathrm{dn}_{\underline{i}} / \mathrm{dr}$ zero or positive, as in the central zone in Fig. 3-8.

If there were no axtal loss of the majority DT fuel ion species, crossFleld diffusion of DT ions diffusing on electrons and on the alphas would proceed irreversibly to a negative DT Lon density gradient $\mathrm{dn}_{1} / \mathrm{dr}<0$. The outward diffusion of alphas would then be shut off until the alphas built up in the center to a point where the alpha density gradient term $n_{i} \partial n_{\alpha} / \partial r$ in Eq. $(3->0)$ exceeded

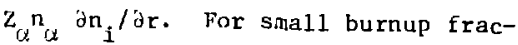
tions $\mathrm{f}_{b}=0$, the net alpha flux would be small, so that in steady state

$$
z_{\alpha} n_{\alpha} \frac{\partial n_{i}}{\partial r}-n_{i} \frac{\partial n_{\alpha}}{\partial r}=0 \cdot(3-71)
$$

Equation (3-71) can be integrated to give

$$
\ln \left(\frac{a_{\alpha 0}}{n_{\alpha b}}\right)=z_{\alpha} \ln \left(\frac{n_{10}}{n_{1 b}}\right)
$$

or

$$
\frac{n_{\alpha 0}}{n_{\alpha b}}=\left(\frac{n_{10}}{n_{i b}}\right)^{2}
$$


where $\mathrm{n}_{r_{\ell} 0}, \mathrm{n}_{\mathrm{iO}}$ are the alpha and $\left.D^{\prime}\right]^{\mathrm{T}}$ ion densities at $r=0$, and $n_{a b}, n_{i b}$ are the corresponding densities at the plasma boundary $r=r_{c}$. I.f the DT ion density decreased by a ratio of 10 from the center to the boundary, and the alpha fraction was $1 \%$ at the boundary, the resulting alpha fraction in the center would be unity by

Eq. (3 -72). Higher-Z impurities would concentrate even more. Only because the dominant loss of DT ions is axial is ic possible to preserve $\mathrm{dn}_{\mathrm{i}} / \mathrm{dr} \geq 0$ by an appropriate distribution of reutral injection in the solenoid, giving rapid outward diffusion of slphas and impurities.

We now wish to calculate the steadystate alpha fraction $C_{\alpha}=n_{d} / n_{i}$ at $\mathbf{r}=0$ using Eq. $(3-70)$ under conditions if a constant radial pressure profile as in Fig. (3-8), such that the internal field $B_{c i}=B_{c}\left(1-B_{c}\right)^{1 / 2}$ is uniform in radius. The condition that the total solenoid pressure $p_{c}$ be constarit can be written

$$
\begin{aligned}
P_{c} & \equiv n_{i} T_{i}+n_{\alpha_{\alpha}} T_{a}+n_{e} T_{e}\left(1+\frac{p_{\alpha}}{n_{e} T_{e}}\right) \\
& \equiv \text { constant }\left(r<r_{c}\right),
\end{aligned}
$$

where $\mathrm{p}_{\alpha}$ is defined in Eq. (3-57). Since equilibration between thermal alphas and DT ions is rapid, we can take $\mathrm{T}_{\alpha}=\mathrm{T}_{i}=$ constant. We assume nearly uniform $(n \tau)_{i}$ in radius, so we can also approximate $\mathrm{T}_{\mathrm{e}} \approx$ constant, with radius. Assuming $\mathrm{T}_{\mathrm{e}}=40 \mathrm{keV}$ and $T_{i}=30 \mathrm{keV}$ (reference case) and using Eq. (3-58) for $\mathrm{p}_{\mathrm{s}} / \mathrm{n}_{\mathrm{e}}$, we can write Fq. (3-7j)

$$
\begin{gathered}
n_{i}+n_{i}+\left(n_{i}+2 n_{i}\right)(1.33) \\
\cdot\left[1+\frac{0.58 n_{i}^{2}}{\left(n_{i}+2 n_{i}\right)^{2}}\right]=\text { constant. }
\end{gathered}
$$

Taking, the derivative of Eq. (3-74)

with respect to $r$ and assuming

$c: \cdots 1$, we obtain

$$
\frac{d n}{d r}=-0.68 \frac{d n}{d r},
$$

to first order in $C_{\alpha}$. By substituting Eq. (3-75) into Eq. (3-70), the alpha flux can be written

$$
\begin{aligned}
I_{\alpha i}= & -D_{\alpha} \frac{\mathrm{dn}}{\mathrm{dr}} \frac{\alpha}{\mathrm{cm}^{2} \cdot \mathrm{s}}, \\
& \left(\mathrm{r}<r_{c}\right),
\end{aligned}
$$

where the diffusion coefficient $D_{\alpha}$ is given by

$\mathrm{D}_{\alpha}$

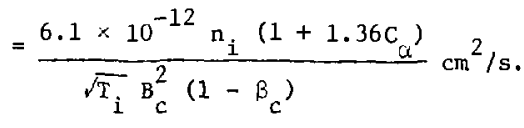

In Eq. (3-77) we have used $B_{c i}^{2}=B_{c}^{2}$ $\left(1-\beta_{c}\right)$. Anticipating small alpha fractions $\mathrm{C}_{\alpha} \ll 1$ over $r \ll r_{c}$, and 
because the radial profile is kept at constant pressure by appropriate neutral-beam injection, we note that ${ }^{D_{\alpha}}$ is approximately constant with radius. We obtain the steady state alpha density proftle from the diffuston equation

$$
\mathrm{J}_{a,} \frac{\mathrm{d}^{2} \mathrm{n} a}{\mathrm{dr}^{2}}+\mathrm{J}_{\mathrm{a}}=0 \text {, }
$$

where

$$
\left.J_{\alpha}=\mathrm{f}_{\mu}\left(\frac{1}{4} \mathrm{n}_{1}^{2} \operatorname{cov}\right\rangle\right)
$$

is the source strength of the thermal alphas. For the same reasons noted above, $J_{d}$ is nearly constant with radius, so $d^{2} n_{\alpha} / d r^{2}=$ const. The solution to $\mathrm{Eq} .(3-78)$ is then

$$
\mathbf{n}_{\alpha}(\mathbf{r})=\mathrm{c}_{1} \mathbf{r}^{2}+\mathrm{c}_{2},
$$

where the constants $\mathrm{C}_{1}$ and $\mathrm{C}_{2}$ are determined by the boundary condition at $r=r_{c}$ on the total alpha flux; $-\left.D_{\alpha} \frac{\mathrm{dn}}{\mathrm{dr}}\right|_{r=r_{c}} \cdot 2 \pi r_{c} \ell=J_{\alpha} \pi r_{c}^{2} \ell$, or

$$
c_{1}=-\frac{J_{\alpha}}{4 D_{\alpha}}
$$

and by the boundary condition that the alpha density go to zero at $r=r_{c}$;

$$
\left.n_{\alpha}(r)\right|_{r=r_{c}}=0,
$$

or

$$
c_{2}=-\left(\frac{J_{\alpha}}{4 D_{\alpha}}\right) r_{c}^{2}
$$

Thus the density profile of the thermal alpha is

$$
n_{i}(r) \frac{J \alpha^{r^{2}} c}{4 D_{\alpha}}\left(1-\frac{r^{2}}{r_{c}^{2}}\right) \text {. }
$$

We are interested in the average alpha fraction over $0<r<r_{c}$ :

$$
\bar{c}_{a}=\frac{J_{\alpha} r^{2}}{8 D_{\alpha}{ }^{n} i}
$$

Using Eq. (3-77) for $\mathrm{D}_{u}$, assuming $\mathrm{C}_{d}$ in the range of $10 \%$, and using Eq. (3-79) Eor $J_{\alpha}$, we obtain

$$
\begin{aligned}
\overline{\mathrm{C}}_{\alpha}= & 4.5 \times 10^{9} \mathrm{C}_{\alpha}\langle\sigma v\rangle \\
& \cdot \sqrt{\mathrm{T}_{i}}\left(r_{c} \mathrm{~B}_{c}\right)^{2}\left(1-\beta_{c}\right) .
\end{aligned}
$$

For the reference case parameters at $\beta_{c}=0.7$ and taking $E_{\alpha}=0.7$ for the actual thermalization fraction (see "Alpha Heating of Ions and Electrons"), Eq. (3-85) gives $\bar{C}_{\alpha}=20 \%$. However, with the same parameters except for $\beta_{c}=0.95, \vec{C}_{\alpha}=3 \%$. Thus, high beta in the solenoid is tmportant for effirient alpha removal. At any beta, a re-optimization of power cost with a self-conslstent alpha fraction would probably result in lower values of $c_{\alpha}$ by compromising $f_{\alpha}, T_{1}$, and $r_{c}$. 
Probable values of $\bar{C}_{\alpha}$ in the neighborhood of $5 \%$, depending on $\beta_{c}$, would result in lower $(n \tau)_{i}$ by a factor of $\mathrm{z}_{\alpha}^{2} \overrightarrow{\mathrm{C}}_{\alpha}=20 \%$ due to enhanced $\mathrm{DT}$ in scattering on the alphas. However, as noted in previous discussion, favorable ion cooling effects by burnup and alpha loss have also been neglected as well as the thermal alpha fraction in this study.

Should higher-Z impurities somehow manage to get into the solenoid, Eq. (3-68) shows that the radial diffusion flux $\mathrm{r}_{2}$ and diffusion coefficient $\mathrm{D}_{2}$ for impurities increase proportionally to $Z$. In addition, the source strength of high- $Z$ impurities will likely be very much smaller than the DT Euel burnup rate (20\%), therefore, we may conclude that under conditions in which thermal alphas can diffuse out, higher-Z ions will do so also, at concentrations that will always be much smaller than alpha concentrations.

\section{SYNCHROTRON RADIATION LOSSES}

Since high electron temperatures are desirable in a TMR, synchrotron radiation losses would appear, at first sight, to be important. However, the plasma beta in the solenoid is also expected to be high, reducing the magnetic field in the plasma. Radiation in the plugs should not be dominant because although the density and field are higher there, the volume of the plugs is sufficiently small compared to the solenoid volume. Bremsetrahlung is ne jligible compared to the fusion power since the ion temperature in a TMR is always well above the bremsstralilung ignition temperature of $4.5 \mathrm{keV}$ for $D T$.

To evaluate synchrotron radiation loss, we make use of formulas by Trubnikov, ${ }^{3-26}$ using an effective plasma radius $r_{p} /\left(1-R_{w}\right)$ in the presence of conducting walls having reflectivity $R_{W}$, as suggested by Drummond and Rosenbluth, $3-27$ The synchrotron radiation loss per $\mathrm{cm}^{3}$ of plasma is

$$
\begin{aligned}
& \mathrm{P}_{\text {sync }}=6.2 \times 10^{-17} \mathrm{~B}_{\mathrm{i}}^{2} \mathrm{n}_{\mathrm{e}} \mathrm{T}_{\mathrm{e}} \\
& \frac{\mathrm{K}_{3}\left(\mathrm{mc}^{2} / \mathrm{T}_{\mathrm{e}}\right)}{\mathrm{K}_{2}\left(\mathrm{mc}^{2} / \mathrm{T}_{\mathrm{e}}\right)} \mathrm{K}_{\mathrm{L}}\left(\mathrm{w} \cdot \mathrm{cm}^{-3}\right),
\end{aligned}
$$

where $B_{i}$ is in teslas, $n_{c}$ is in $\mathrm{cm}^{-3}$, and $T_{e}$ is in keV. $K_{3}$ and $K_{2}$ are modified Bessel functions with arguments mc ${ }^{2} / T_{e}$, the electron rest mass energy over the electron temperature. The ratio $k_{3} / k_{2}$ can be expanded for large argument to give

$$
\frac{K_{3}\left(m c^{2} / T_{e}\right)}{K_{2\left(m c^{2} / T_{e}\right)}}=1+\frac{T_{e}}{204} . . .
$$

for $\mathrm{T}_{\mathrm{e}}$ in keV. The dimensionless coefficient $K_{L}$ for plasma reabsorption of radiation can be expressed by an approximate formula glven by Rose, 3-23 
which fits Trubnikov's exact calculations within $10 \%$ up to $\mathrm{T}_{e}=150 \mathrm{keV}$ :

$K_{\mathrm{L}}=2.1 \times 10^{-3} \mathrm{i}_{\mathrm{e}}^{7 / 4} / \sqrt{\mathscr{S}}$.

for $\mathrm{T}_{\mathrm{e}}$ in keV. Equation (3-88) is valid only for $k_{L} \ll 1$, or strong reabsorption, as is usually the case. The dimensionless plasma length $\mathscr{Q}$ with reflecting walls can be approximated by

$$
\mathscr{Q}=\left(\frac{r_{p}}{1-R_{w}}\right)\left(\frac{\omega_{p e}^{2}}{c \omega_{c e}}\right) .
$$

The internal field $B_{i}$ is determined by the plasma beta $\beta$ and pressure balance:

$\frac{\beta}{1-\beta}\left(\frac{\mathrm{B}_{i}^{2}}{8 \pi}\right)=\mathrm{n}_{\mathrm{e}} \mathrm{T}_{\mathrm{e}}+\mathrm{n}_{1} \mathrm{~T}_{i}$.

Assuming $\mathrm{n}_{e}=\mathrm{n}_{i}$ and $\mathrm{T}_{e}=\mathrm{T}_{i}$, Eq. can be written, using Eqs. (87)

through (90):

$P_{\text {sync }}=3.8 \times 10^{-37} \mathrm{n}_{\mathrm{e}}^{2} \mathrm{~T}_{\mathrm{e}}^{17 / 4}$

$\cdot\left(1+\frac{T_{e}}{204}\right)\left(\frac{1-R_{w}}{\left\langle r_{p} B\right.}\right)^{1 / 2}$

$$
\text { - }\left(\frac{1-\beta}{\beta}\right)^{3 / 2} \text {, }
$$

where $\left\langle r_{p} B\right\rangle \equiv \int_{0}^{r_{p}} B_{i}(r) d r$

is a quantity proportional to the number of ion gyroradii across the plasma (which may have some minimum value). For the solenoid, the effective wall reflection coefficient with holes at the ends for the low-energy neutral beams and connection to the plugs averages out to $R_{W}=0.99$. In the plugs, the end holes have relatively more area, so $R_{w}=0.90$. The product $\left\langle r_{p} B\right\rangle=1 \mathrm{~T} \cdot \mathrm{m}$ in the solenoid and $4 \mathrm{~T} \cdot \mathrm{m}$ in the plugs. For the reference TM" reactor parameters at $\mathrm{T}_{\mathrm{e}}=43 \mathrm{keV}, \mathrm{T}_{i}=30 \mathrm{kev}$, the ratio of fusion power to synchrotron radiation power $\mathrm{P}_{\text {fusion }} / \mathrm{P}$ sync $25 \times 10^{3}$ at $B_{c}=0.7$ in the solenoid. Thus, synchrotron radiation would be small even if $\mathrm{T}_{\mathrm{e}}$ were higher. In the plugs, the ratio of the neutral-beam power in the plug to synchrotron radiation $\left[\mathrm{n}_{\mathrm{p}}^{2} \mathrm{E}_{\text {inj }} /(\mathrm{nT})_{\mathrm{p}}\right] / \mathrm{P}_{\text {sync }} \gtrsim 40$, so radiation is small there also.

\section{REFERENCES}

3-1. G. G. Kelley, "Elimination of Ambipolar Potenrial-Enhanced Loss in a Magnetic Trap," plasma Fhys. 9, 503 (1967).

3-2. V. P. Pastukhov, "Collisional Losses of Electron from an Adlabatic Trap in a Plasma with a Positive Potential," Nucl. Fusion 14, 3 (1974). 3-3. G. I. Dimov, V. V. Zakaidakov, and M. E. Kishinevsky, Fiz. Flasmy 2, 597 (1976); also G. I. Dimov, V. V. Zakaidakov, 
and M. E. Kishinevsky, "Open

Trap with Ambipolar Mirrors,"

in Froa. Sth Inter. Cont.

Plasme inusice and Contioized

Muclear Fusion Fecearch,

Eerohtesjaden, Ied. Key. of

jermany, 1976 (IAEA, in prepa-

ration), Paper C4.

3-4. T. K. Fowler and B, G, Logan,

"The Tandem Mirror Reactor"

Comments on Plasma Finjsics and

Controlled Fusion Research, 2,

167 (1977).

3-5. R. A. Dandle, Research Frojrcm for piasma confinement and heating in Elmo Bumy Torus I'evices, Oak Ridge National Laboratory, Rept. ORNL-TM-4941, Appendix G (1975).

3-6. See discussion by S. Putnam et az., in Proc. of High Beta Worksher, Los Alamos Seientific Latoratom, 1975 (ERDA Rept. $76 / 108,1.975) 411$.

3-7. L. E. Thode, "Plasma Heating by Scattered Relativistic Electron Beams: Correlations Among Experiment, Simulation, and Theory," Phys. Fluids 19, 831 (1976).

3-8. D. Prono, B. Ecker, N. Bergstrom, and J. Benford, "Plasma-ReturnCurrent Heating by Relativistic Electron Beams with $v / \gamma \sim 10, "$ Phys. Rev. Lett. 35, $43 \dot{8}$ (1975).
3-9. (., C. Goldenbaum, W. F. Dove. K. A. Gerber and B. G. Logan "Plasma Heating by Intense, Relativistic Electron Beams," inus. Fev. ictt. 32, $830\left(19^{4}\right)$. 3-10. F. H. Coensgen, Project Lead r,

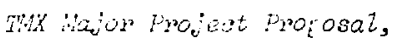
Lawrence Livermore Laboratory, Rept. Ll_l-Prop-148 (1977), Appendix A2, p. 47.

3 11. B. G. Logan, J. F. Clauser, F. H. Coensgen, D. L. Correl., W. F. Cummins, C. Gormezano, A. W. Molvik, W. E. Nexsen, T. C. Simonen, B. W. Stallar, and W. C. Turner, "High-B, Gas-Stabilized, Mirror-Confined Plasma," Ehys. Rev, Lett. 37. 1468 (1976).

3-12. L. S. Hall, "Magnetostatic Equilibria of Finite-Pressure Minimum-B Plasma Configurations," Priys. Fluids 15, (1972).

3-13. R. C. Davidson and J. M. Ogden, "Electromagnetic Ion Cyclotron Instability Driven by Ion Energy Anisotropy in High-Beta Plasmas," Phys. Fluids 18, 1045 (1975).

3-14. H. L. Berk, D. E. Bladwin, T. A. Culler, L. L. Lodestro, N. Maron, L. D. Pearlstein, T. D. Rognlien, J. J. Steriart, and D. C. Watson, "Theoretical Explanation of Present M_rror Experiments and Linear Stability 
of Larger Scaled Machines," in rroc. Wirtin Inter. Conf. Masma thyeice and controtler inolear Fusion Researih, Eerohtesgaten, Fed. hep. of fiemonis, 1976 (IAEA, in preparation), Paper $\mathrm{CN}-35 / \mathrm{C} 2$.

3-15. F. H. Coensgen, W. F. Cummins,

B. G. Logan, A. W. Molvik,

W. E. Nexsen, T. C. Simonen,

B. W. Stallard, and W.

C. Turner, "Stabilization of

a Neutra1-Beam-Sustained, Mirror-Confined Plasma," Physs. kev. Lett. 35, 1501 (1976).

3-16. D. E. Baldwin, H. L. Berk, and L. D. Pearlstein, "Tırbulent Lifetimes in Mirror Machines," Phys, Rev. Lett. ․ㅡ, 1051 (1976).

3-17. H. L. Berk and R. R. Dominguez, Variational Method for ilectromagnetic Waves in a MagnetoPlasma, Lawrence Livermore Laboratory, Rept. UCRL -78607 (1976).

3-18. R. C. Davidson, N. T, Gladd, C. S. Wu, and J. D. Huba, "Influence of Finlte-B Effects on the Lower-Hybrid-Drift Instability in Post-Impiasion $\theta$ Pinches," Phys. Rev. Lett. 37, 750 (1976).

3-19. R. H. Cohen, Lawrence Livermore
Laboratory, private communication (1977).

3-20. M. E. Rensiak, Lawrence Livermore Laboratory, private communication (1977).

3-21. A. C. Riviere, "Penetration of Fast Hydrogen Atoms into a Fusion Reactor Plasma," ifuel. Fusion 11, 363, (1971).

3-22. R. H. Cohen, G. Rowlands, and J. H. Foote, UCRL preprint 78889, (Dec. 1976).

3-23. D. J. Rose, Feasibility of lover by Mclexr Fusion, oak Ridge National Laboratory, Rept . ORNL-TM-2204 (1968).

3-24. C. L. Longmire and $M$. N. Rosenbluth, Ann. Pijs. (N.X.) 1, 120 (1957).

3-25. D. J. Rose and M. Clark, Plasmas and Controlzed Eusion Research, Wiley, N.Y. (1961), p. 221 .

3-26. B. A. Trubnikov and V. S. Kudryavtsev, "Plasma Radiation in a Magnetic Field," in Proc. 2nd U. S. Conference on Peaceful uses of Atomic Energy, Vol. 31, (United Nations, Geneva 1958), p. 93.

3-27. W. E. Drummond and M. N. Rosenbluth, "Cyclotron Radiation from a Hot Plasma," Phys. Fluids 3, 45 (1960). 


\section{CHAPTER 4. MECHANICAL. DESIGN ASPECTS OF A TANDEM MIRROR REACTOR}

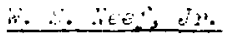

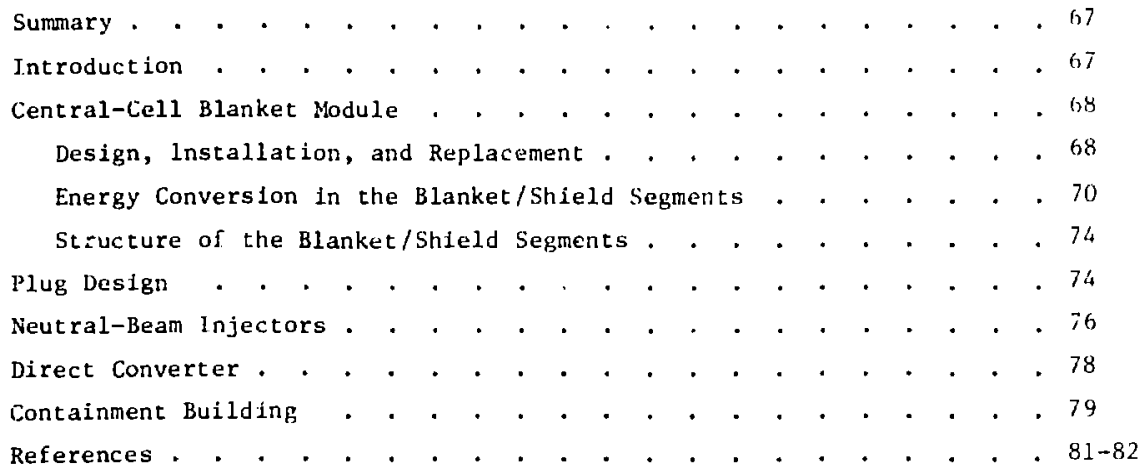


SUMMARY

T.Le new concept for a mirror fuiion power plant, the tandem mirror reaciur (TMR), calls for two plugs of dense plasma at either end of a central soleroid cell. A blanket design for the central cell is presented. Because of their linear, axisymmetric geometry, blanket modules can be permanently mounted on crawler tracks and serviced by remote welding and handling machines of very simple design. Three blanket designs are considered; the best, presented in some detail, has lithium as the breeder material and is heliumcooled.

The plug magnet must have high field strengths. A novel magnet composed of a simple mirror pair surrounding a small Yin-Yang pair satisfies the physics of the end plugs. Because 1,200-keV beam sources present special problems, methods of voltage standoff, arc damage control, and neutralization are discussed. New secondary containment ideas are presented that allow removable roof sections of balanced design.

\section{INTRODUCTION}

In a new concept for a mirror fusion reactor proposed by Fowler and Logan ${ }^{4-1}$ and Dimov et al., ${ }^{4-2}$ the power output comes from a central, axisymetric solenoidal cell of length appropriate to the desired total electrical power of the reactor. Losses frotn the ends of the central cell are prevented by a dense plasma plug at eách end.

Each pling requires a Yin-Yang or Baseball coil having a low mirror ratio but a field strength in the 16-T to 20-T range. Neutra1-beam injertion is required to maintain the plug plasma; our calculations indicate that the best injection energy is $1,200 \mathrm{keV}$. The ambipolar potential of each plug provides electrostatic stoppering for centralcell ions and allows reactor designs with large values of Q (fusion power/ injected power). The field strength of the central-cell solenoid is about one-tenth that of the plugs, well within today's superconducting-magnet technology .

Fusion reactor designs abound, The fusion community appears to agree that a demonstration reactor must be presented in about two decades. Any new approach to plasma containment must stand firm before the question, "Can a mechanically and operationally reasonable power reactor be designed using this physics concept?"

The Tandem Mirror Reactor stands up well to this engineering critique. The central-cell technology is largely state-of-the-art. Only in the consideration of first-wall life 
are we forced to admit that our projections are uncertain; however, we note that the wall loading of $2 \mathrm{MW} / \mathrm{m}^{2}$ is about the same as that in other fusion reactor designs. Only the construction of a reactor will allow design daca to be obtained. In all other areas of design, the construction and successful operation of similar equipment have been accomplished by others and/or ourselves. General Atomics has operated a reactor cooled by helium gas. Lawrence Livermore Laboratory (LLL) and other laboratories have aperated large superconducting coils in the $2-T$ regime. The Apollo space capsules were welded automaticaliy by the same methods proposed here. Remote assembly tools of greater complexity than needed here have seen service in several fission-power plants.

\section{CENTRAL-CELL BLANKET MODULE}

Design, Installation, and Replacement

This solenoidal, axisymmetric portion of the reactor is probably the simplest to construct and service of any fusion reactor design yet proposed. The total length is $100 \mathrm{~m}$, and that is composed of 36 blanket modules, each $2.78 \mathrm{~m}$ thick and weighing $\sim 620$ tonne.

Each blanket module has the following components:
- Vacuum wall cyilnder with weld flanges,

- Superconducting solenoid coil in its vacuum jacket,

- Support frame,

- Main helium supply and return ring-manifolds and distribution pipes, and

- Blanket/shield segments (24 per assembly).

All items except the blanket/shield segments can be assembled outside the main access door and conveyed into location on air pallets. The weight prior to blanket/shieid installation ts approximately 313 tonne. The assembly can then be completed inside the central-cell bay using the automatic tools described below.

Each module (see Fig. 4-1) is permanently mounted on a "crawler" transporter of the type now used to transport reactor pressure vessels and other heavy items. The motordriven crawler can move the blanket module about $12 \mathrm{~m}$ perpendicular to the cell axis after two circumferential welds joining the module to its neighbors have been ground off and the two helium mantfolds disconnected. A guide I-beam (part of the building structure) prevents the module from toppling while in the service position. The weld is removed and rejoined by a "skate" that is remotely and automatically driven around the cell circumference. A very similar 


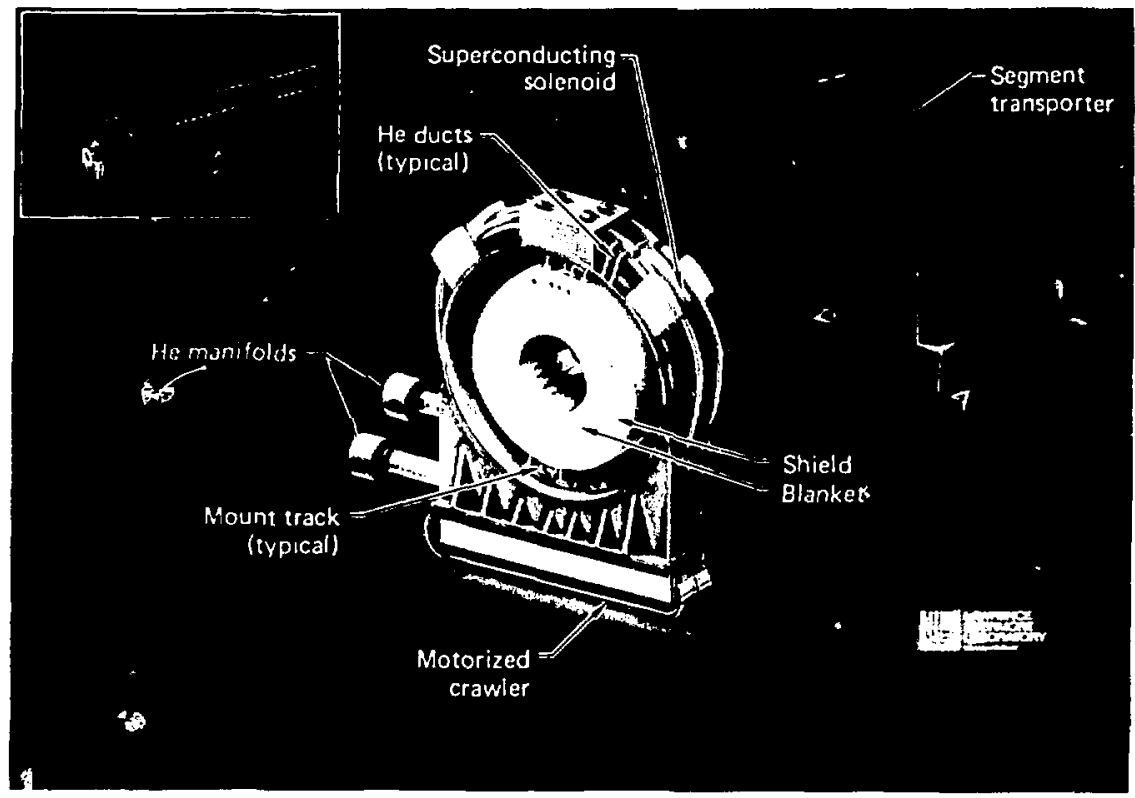

Fig. 4-1. Blanket module for the TMR.

system was used by Skiaky Bros. Inc. ${ }^{4-3}$ in welding the Apollo reentry capsule.

After being withdrawn from the solenoid, the blanket module is approached from each side by remote servicing machines. On one side, a machine removes helium manifold welds (and re-welds during re-assembly). On the other side, a rotating fork indexes to the particular blanket section being removed and withdraws it from the mounting slots fixed to the cylindrical vacuum wall.

The blanket module is divided into 24 identical, wedge-shaped blanket/shield segments. Removed blanket/shield segments are delivered by the fork assembly machine to a conveyor for transport to a hot-parts storage and processing area where blanket and shield can, in due time, be separated. The shield can be reused. Old blanket components are removed in special railroad cars for appropriate disposal.

An alternate method for replacing the blanket module, which will be considered in future refinements of this reactor, is replacement of a complete 620-tonne module. At this time, maneuvering such an unstable 
mass to an exit door and then reversing the process with a new module seems unnecessary and fraught with difficult design problems affecting what now is a simple building struc ture.

\section{Energy Conversion in the} Blanket/Shield Segments

There are many ways to build a blanket/shield for use in fusionneutron energy-conversion. The following simple and most obvious were selected for comparison:

- Liquid lithium circulated to a heat exchanger.

- Quasi-static liquid lithium slowly circulated only to remove bred tritium and cooled by helium carried in buried pipes.

- A static breeder - such as lithium aluminate, lithium beryllate, or liquid lithium - cooled by highpressure helium gas.

Circulated Liquid Lithium. We considered using liquid lithium circulated to a heat exchanger as one technique for converting fusion-neutron energy. Figure 4-2 shows a possible design. We found two major drawbacks to this technique:

- The electrical power required to drive the lithium-circulating pumps, and

- The required purging, special valves, and auxiliary heating systems.
The chief obstacle to flowing lithium results from the magnetuhydrodynamic (MHD) pressure drop required to force the conducting fluid across magnetic field lines. Every gram of lithium must flow twice across the solenoid flux. The space occupji-d by the coil is two-thirds of the module length; the weld flanges and welding skate take much of the remainfing space. The resulting diameter of the channel in which the lithium flows from the mantfold ring to the blanket segment is $15 \mathrm{~cm}$, and the resulting flow velocity is 0.24 $\mathrm{m} / \mathrm{s}$. Usiag this value, we evaluated the lithium circuit for MHD pressure drop:

$$
\angle P_{M H D}=\sigma_{q} L V B=\frac{c}{1+c} 235 \text { psi, }
$$

where

$$
\begin{aligned}
r_{2}= & 3.05(10) 6 \text { mhos } / \mathrm{m} \text { conductivity } \\
& \text { of } 1 \text { ithium } \\
\mathrm{L}= & \text { flow length, } \\
\mathrm{V}= & \text { [low velocity, } \\
\mathrm{B}_{\mathrm{c}}= & \text { magnetic field strength } \\
& \text { gerpendicular to flow, } \\
\mathrm{c}= & {[\text { owal1 } \times \text { (wal1 thickness) }] / } \\
& {\left[{ }_{1 i t h i u m} \times\right. \text { [radius of flow }} \\
& \text { channe1)] }
\end{aligned}
$$

When the MHD and hydraulic pressure drops are summed,

$$
\text { MHD } \triangle \mathrm{P} \quad 235 \text { psi }
$$

Hydraulic $\Delta \mathrm{P} \quad 50$ psi

Total circuit $\Delta \mathrm{P} \quad 285$ psi 


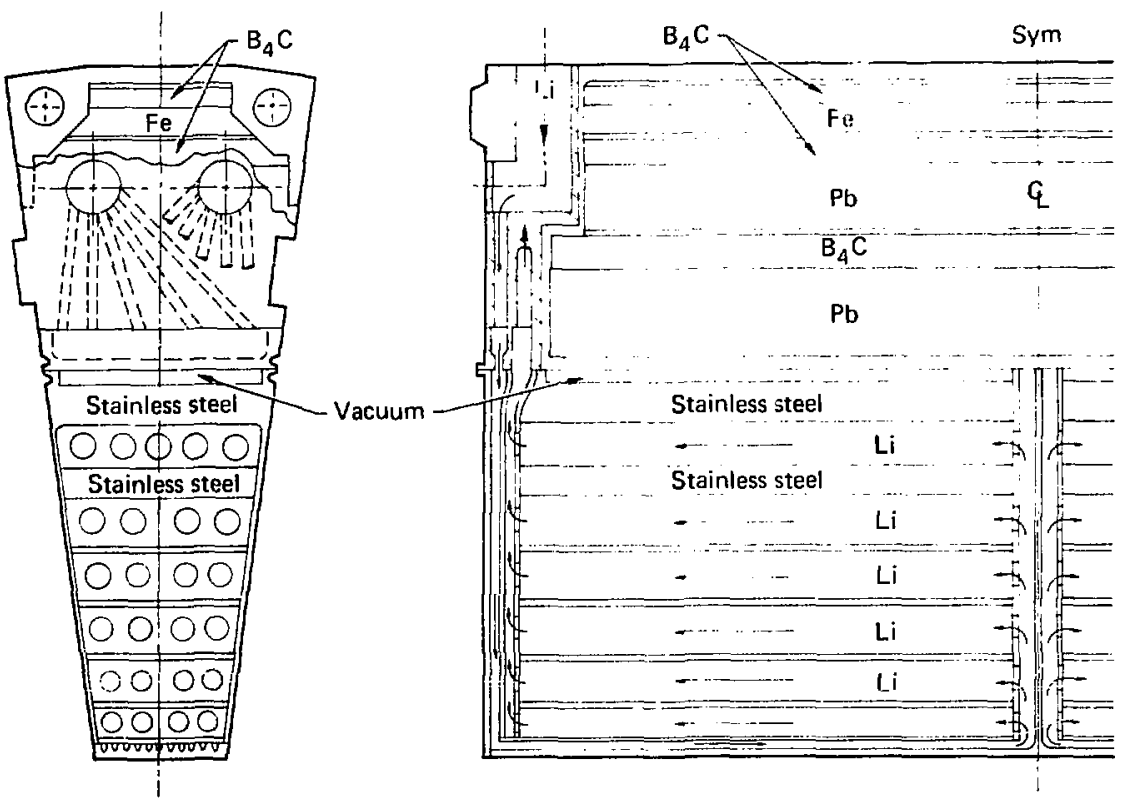

Fig. 4-2. Possible design for a circulating-lithium blanket/shield segment. Arrows show lithium flow.

the total is equivalent to about 15 MW of electrical power needed to drive the lithium circulating pumps, or $1.5 \%$ of the net electricity output of the plant.

Although large, that amount of power is not what caused us to choose another system. The main factor influencing the decision was the requirement for elaborate purging and valve systems and large auxiliary heater systems. These systems would be necessary for valving-of $f$ and subsequent decoupling of large lithium supply and return ducts, removing blanket segments, and prepar- ing for lithium eirculation after reassembiy, all procedures that require opening internal piping in the blanket module assembly.

Quasi-Static, Helium-Cooled Lithium. The second system considered was one in which slowly circulated, heliumcooled lithium would remove only bred tritium. Lt was reasoned that the plumbing problems could be greatly reduced by reducing line size and circulation rate to those necessary to hold the tritium inventory of the blanket to about $1 \mathrm{~kg}$. In this technique, a separate cooling circuit 
would be used to extract blanket energy. After considering a number of coolants such as Princeton's flibe (a molten salt mixture of F, Li, and Be),$^{4-4}$ a separate 1 ithium circuit, and various gases, we concluded that the most reasonable method would be helium gas at about $50 \mathrm{~atm}$.

We studied several mechanical blanket configurations. The most difficult thing to achieve was firstwall cooling with the coldest gas, then subsequent circulation of that gas to the rest of the blanket. Since energy deposition in the space behind the rirst wall varies with distance from the first wall, the spacing of coolant tubes (or their size) can be varied with distance from the first wall. An example of our calculated results is shown in Table 4-1. These results apply for "hot-spot" lithium temperature of $613^{\circ} \mathrm{C}$, a $15^{\circ} \mathrm{C}$ temperature drop across the tube wall, and a $48^{\circ} \mathrm{C}$ film temperature drop in the helium film,

Table 4-1. Variation of tube spacing with distance from first wall (2-in. o. d. $\times$ 0.040-in.-wall-thickness stainless-steel tubes).
Radial distance from first wall (cm) 10 25 10.5 40
Cooling tube spacing (cm)

\begin{tabular}{rr}
10 & 9 \\
25 & 10.5 \\
40 & 11.5 \\
\hline
\end{tabular}

Constructing blanket segments using gas-cooled lithium becomes a difficult and costly fabrication problem. Flow patterns are complex, and tube-support bulkheads almost eliminate access for welding. We sought a better solution.

Static, Gas-Cooled Breeder. J. D. Lee et $a l .,^{4-5}$ proposet the third approach to an energy-conversion blanket - use of a solld, trit lumbreeding material such as lithium aluminate or lithium beryllate contained in an envelope of thin alloy that would limit tritium permeation. In this design (Figs, 4-3 and 4-4), coolant gas is circulated past the envelope so that it contacts both the outer wall and the alloy tubes that run through the envelope at a spacing appropriate to good heat transfer. A blanket of this design appears reasonable to fabricate and easy to assemble and take apart, and permits simple extraction of the bred tritium.

However, an attempt to use pure lithlum aluminate showed that a sufficient breeding ratio could not be obtained. Even addition of a neutron multiplier such as lead did not make lithium aluminate acceptable. Although 1ithium beryllate would make a good blanket, we did not want beryllium in the design at this time because of limited availability and cost. Lithium alone, encapsulated in 


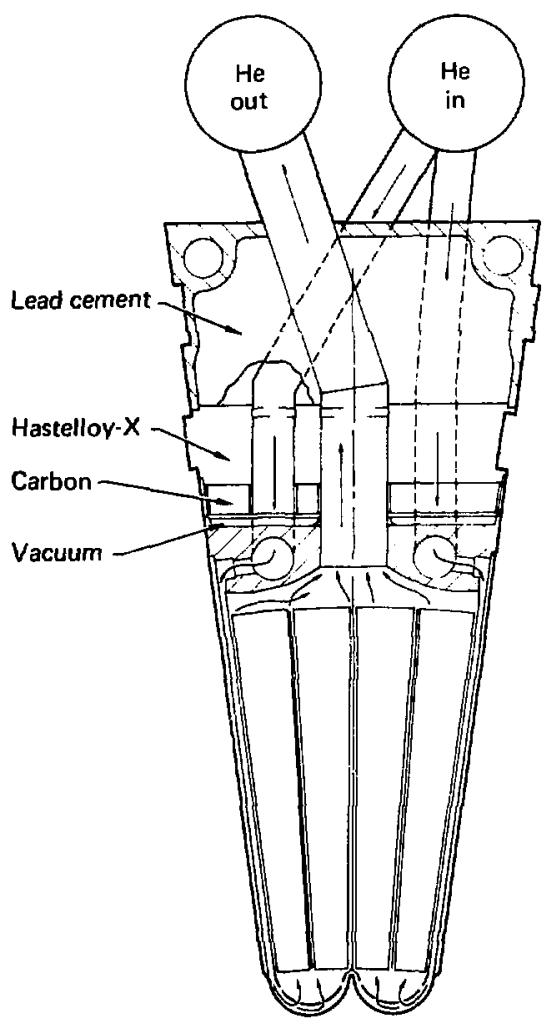

Fig. 4-3. Blanket/shield segment. Arrows show helium flow.

stainless-steel cans, provides an adequate breeding ratio.

of course, when the neutronics of 11thlum aluminate were proven poor and pure lithium was selected, the blanket was no longer "sol1d." However, the concept of a static blanket was retained with helium gas as the coolant for the envelopes in the breeding blanket. Tritium could be removed from such metal envelopes in several ways:

- By allowing tritium inventory to build up in the envelope until blanket replacement time and then processing the extracted breeder envelopes to remove accumulated eritium.

- By slowly circulat lng helium through captllary tubes contalned within the breeding envelope. The capillary tubes would be made of material that permits tritium permeation. As bred tritium permeates into the tubes, the separate helium flushing circuit sweeps it away.

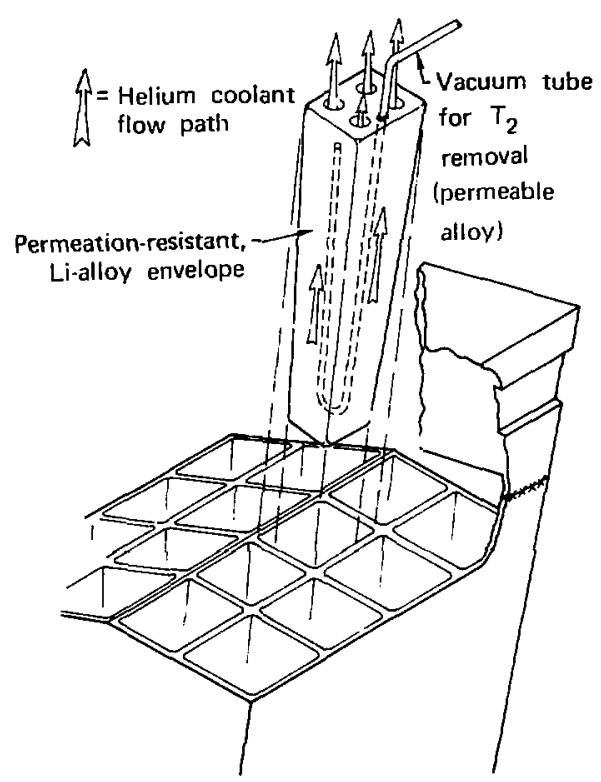

Fig. 4-4. Static 1ithium container in blanket for TMR. Arrows show flow path of helium coolant. 
- By using the permeable capillary tubes suggested above, but merely evacuating the tubes and processing the collected tritium from the auxiliary vacuum system.

The last method appears most attractive economically, but the vacuum conductance of small tubes may be so low that a penalty is paid in higher tritium blanket inventory than the helium flushing method.

Structure of the

\section{Blanket/Sh Leld Segments}

Our paramount objectives were simplicity of structure, ease of disassembly and change-over, and as a result, low cost of blanket/shield segments.

We plan'a vacuum-cast structure with an egg-crate cross section; to it will be welded a curved first-wall of $0.5-\mathrm{cm}-\mathrm{thick}$ Inconel 718 sheet and a shield structure enclosing Hastelloy-X plate and lead-cement. The whole assembly will be a pressure vessel for helium at $50-\mathrm{atm}$, and as such would be exhaustively radiographed around all perimeter walls anc welds. Each unit will be subjected to high-temperature pressurization tests at $150 \%$ design pressure before installation in a blanket module. Thus, the assembly of the segments to make a full circle does not imply that we would rely on side support from adjacent segments while under pressure.
PLUG DESIGN

The magnet used to contain the plug plasma is a more challenging design problem than the basic, lowfield solenoid employed by the central cell. The vacuum field required at the center of the plug is $16.5 \mathrm{~T}$, but the vacuum mirror ratio is a modest 1.07 . Superconducting materials have been found which, in laboratory samples, show promise of satisfactory performance at the required field strength. A small, 17.5-T coil has already been built.

Figure 4-5 shows the plug coil, a simple mirror pair surrounding a sma!l Yin-Yang coil pair. The total amount of superconducting material required is 5000 tonnes at each end of the TMR. It is not known at this time whether the small Yin-Yang should be superconducting or be made of cryogenic aluminum. Detailed field calculations will determine whether $\mathrm{Nb}_{3} \mathrm{Sn}$ wire could be safely operated here or whether the price of normal coil refrigeration should be paid to operate conventional conductors in very high-field regions of the Yin-Yang pair. This geometry looks comparatively attractive from the standpoint of fabrication cost.

In conjunction with this plug magnet, a transition coil will probably be needed to smooth the flux path between the solenoid and the 

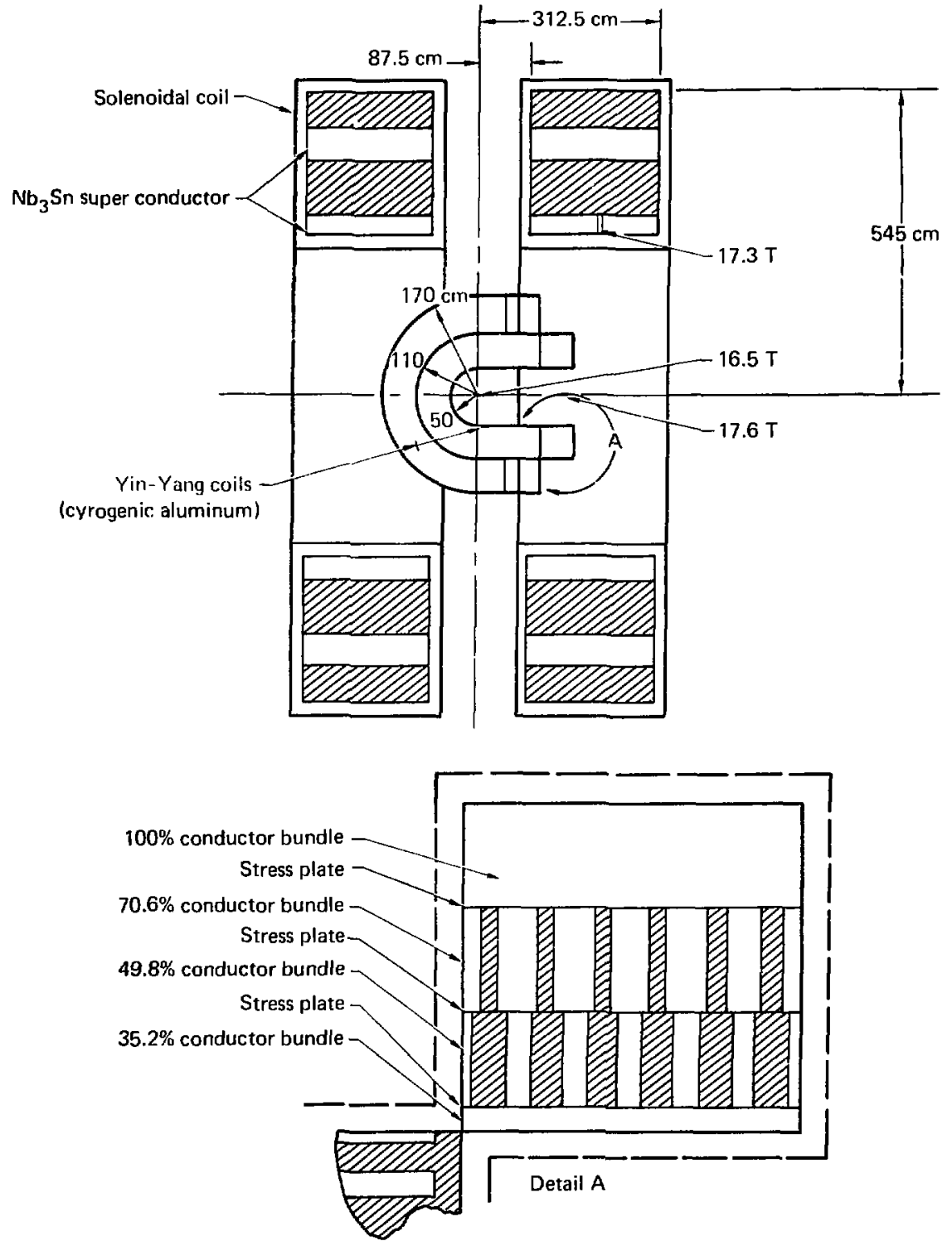

Fíg. 4-5. Plug coil set (16.5 T). 
plug. The flux bundle emerging from the plug is elliptical in cross section with an aspect ratio of 2.0 . The shape of this transition magnet has only been estimated. The flux leaving the plug and entering the direct convertor has this same elliptical aspect ratio (2.0). The orientation of the Yin-Yang pair about the long axis of the machine will be such as to make the long dimension of the exit fan parallel to the building floor at both ends. This has a dramatic effect on the design and cost of the direct convertor.

\section{NEUTRAL-BEAM INJECTOORS}

The plasma density of the plugs must be maintained by the continuous injection of deuterium ions. ${ }^{4-6} \mathrm{Mag}-$ net shielding requicements will be less severe if no tritium ions are injected into the plug. (There will be tritium present in the plugs, fugitive from the central cell.) The ambipolar property of the plug plasma can be achieved with 1,200-keV deuterium injectors supplying $490 \mathrm{~A}$ total into both plugs.

Lawrence Berkeley Laboratory (LBL) is developing sources for neutral-beam injectors for continuous operation at $120 \mathrm{keV}$. Fifty amperes of pulsed current has been obtained from an extraction grid area $10 \mathrm{~cm}$ by $35 \mathrm{~cm}$ at a few tens of kilovolts. When the extractor grid cooling problem is solved, we sha1l be left with only the voltage isolation and spark damage suppression problems. $\Lambda$ design for progressive shielding in steps of $200 \mathrm{kV}$ is being developed. Figure 4-6 shows the beam 1 ine arrangetlent with nested shiclds. Two of these souree arrays are planned for each plug. Three of the above described 50-A sources supply the current for earh injector.

Spark-down during initial operation of such high-vollage equipmont is incvitable. By cont rolling the energy in the spark it can be advantageous, smoothing out sharp points or edges, minimizing subsequent ares. To control the spark energy to about $10 . J$, the shield must be subdivided into arcas of a few square meters that must be electericaldy separated by large lossy elements such as transformer cores or resistors. Careful design will allow a sma 11 arc to occur and extinguish before current from adjacent panels can make it through the "choke" to compound the damage at the origina? arc site. Constant potential during normal operation is assured by electrical continuity.

'lo accomplish the $1,200-\mathrm{keV}$ ion acceleration, the positive-ion source Is held at $-600 \mathrm{kV}$ and the ions are 


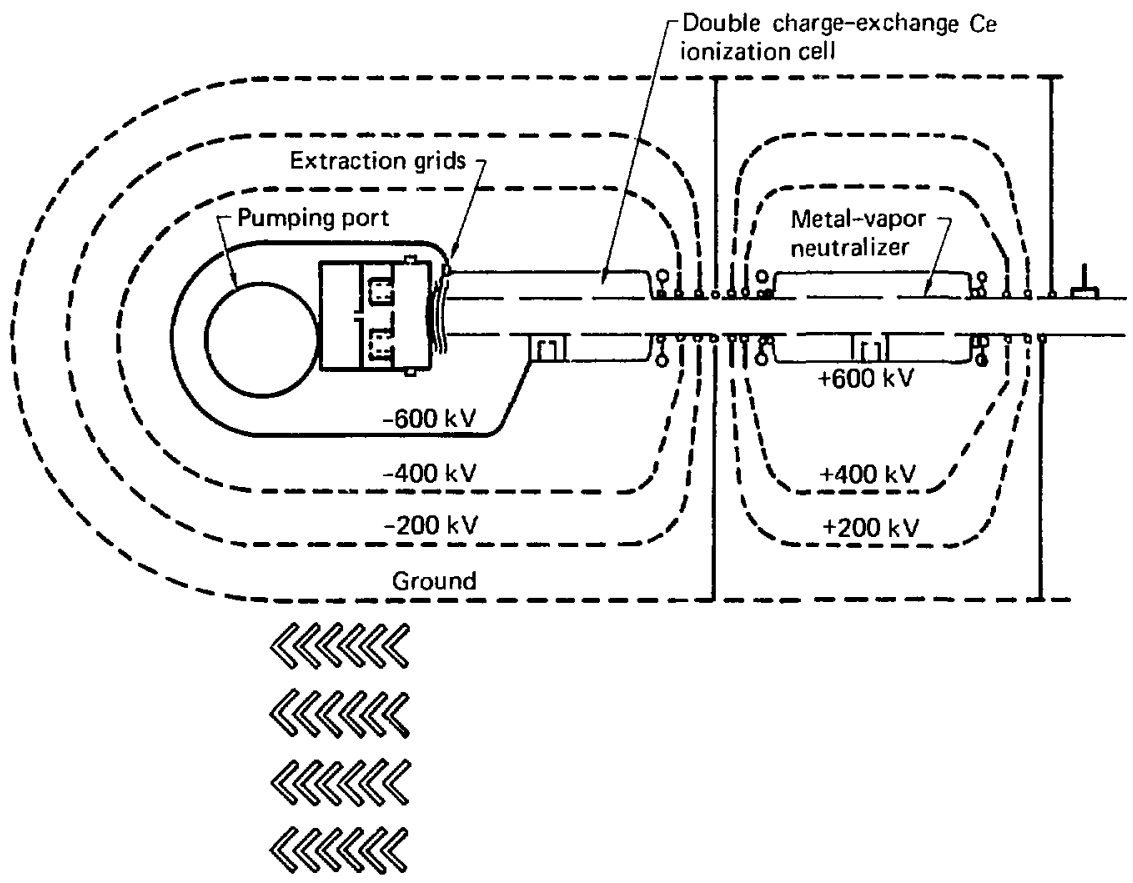

Fig. 4-6. 1,200-keV leutral-beam source.

neutralized in a stripping cell at +600 kV (see Fig. 4-6).

A cesiua cell will be used $t c$ double charge exchange the posit"ve ions from the source. The $\mathrm{D}^{-}$ions thus formed can be further accelerated and then neutralized by one of several techniques:

- By laser photodetachment with estimated efficiency about $95 \%$,

- By a metal vapor stri-pping cell with efficiency approximately $62 \%$, or
- By a high-density plasma-stripping cell using cesium ions with estimated efficiency of $82 \%$.

The laser-photodetachment technique has a serious drawback for this application: the length of a beam source. The cross section of the beam is such that a very large array of lasers and focusing lenses and also a lengthy (thick) photonreflection region would be required. The total length of a beam source 
thus becomes about $25 \mathrm{~m}$, and this has an undesirable effect on reactor and building size and cost. We are evaluating the other two methods, both of which occupy about the s.tme space and reduce the neutralizer length from $10 \mathrm{~m}$ to $2 \mathrm{~m}$.

The large pumping loads for a 125-A steady-state beam line can be met by cryopanels on both sides of and parallel to the beam line. Periodically, the panels must be warmed and evolved gas must be pumped out of the system. A bank of tubes, whose centerlines lie in the plane of a wal1, is allowed to protrude half into the beam line and half into the vacuum space on the far side of the bulkhead. When loaded with frozen deuterium, the tubes are rocaced 180 degrees on their centerlines and arc heated. The gas load represented by the frozen deuterium is released into the vacuum space, and the tube is then rotated back to its original position and cryogenically cooled. Conventional diffusion pumps evacuate the volume behind the pumping wall. The source extraction grid imposes a large gas load at the grid end of the beam line. Cryopumps are not used there because of space limitations. Through careful design of the insulator and shield, two large pumping apertures will be provided near the origin of the heaviest gas load, one opening above and one below the vertical column of beam sources.

\section{DIRECT CONVERTER}

Not all of the injected beam will be trapped by the plasma plug. It appears that a direct convertor on the far side of each beam line would substantially Improve the overall efficiency of the power plant. This convertor will be a single-stage device similar to the venetian-blind convertor proposed by Moir et al., 4-7 and the housing will include cryopump panels sufficient to continuously pump the expected residual beam. The plug plasma will thus have better vacuum environment, and the unavoidable need for a beam dump can be met by proper design of the thermal conversion elements in the direct converter.

When the TMR was first envisioned, we considered using anocher magnet outside the plug magnet set to recircularize the flux fan. We were motivated by the desirability of an economical cylindrical vacuum tank for the main direct converters. However, as the design for the plugs developed (particularly the 1,200-keV beam sources), another problem appeared that caused a-different design to be considered. As mentioned previously, the spark-down damage 
problem related to the capacitance of large electrostatic shield surfaces became a great concern. If the direct-convertor grids were subdivided into regions of acceptable capacitance (a few square metres) severe blockage of flux would occur. The structural frame supporting the grid would have to be convectively cooled, and any transformer or choke assembly used to electrically separate such regions would itself block much ion flux. This would further degrade convertor efficiency and create another severe cooling problem.

It seemed best to eliminate all blockage except the grid itself by confining all tensioners and chokes to the annular space around the flux bundle. One could design a circular direct converter to meet this objective, but the maximum length of a grid or vane is less if the flux bundle is elliptical and the length of the vane is parallel to the minor axis. Simply eliminating the outside circularizing magnet allows a flux bundle of elliptical cross section with an aspect ratio of about $2: 1$ to enter the direct converter. If the minor axis of the ellipse is vertical, and all vanes or grids run in the vertical direction, we can have the shortest, straightest grid structure (see Fig. 4-7).

One must design a vacuum tank to encompass such an elliptical grid arrangement. $\Lambda$ membrane of stainless steel periodically anchored to the heavy post-tenrioned concrete secondary containment structure can serve as the vacuur vessel. This membrane can also serve as the "form" for the concrete of the containment shell.

\section{CONTAINMENT BUILDING}

This TMR is long and relatively slim. The configuration of the containment building differs greatly from any previous power reactor concepts. In size, it approximates a drydock for a large passenger ship. The reactor fits its enclosure more efficiently than competitive designs. Roof spans are limited to about $40 \mathrm{~m}$, and portions of the secondary containment structure can be moved by a large gantry crane. (The same crane is used to install the plug magnets.) No large crane inside the building is required, hence, no lift-space and crane clearance. This is a blessing in reducing the building cost, but the smaller volume exacts a penalty: accident pressures in the building can be higher than designs with large containment she11s. We propose pressure relief diaphragms on the directconverter portion of the vacuun system. They must relieve inward to prevent excess pressurization resulting from a primary heat exchange loop accident. The entire reactur vacuum 


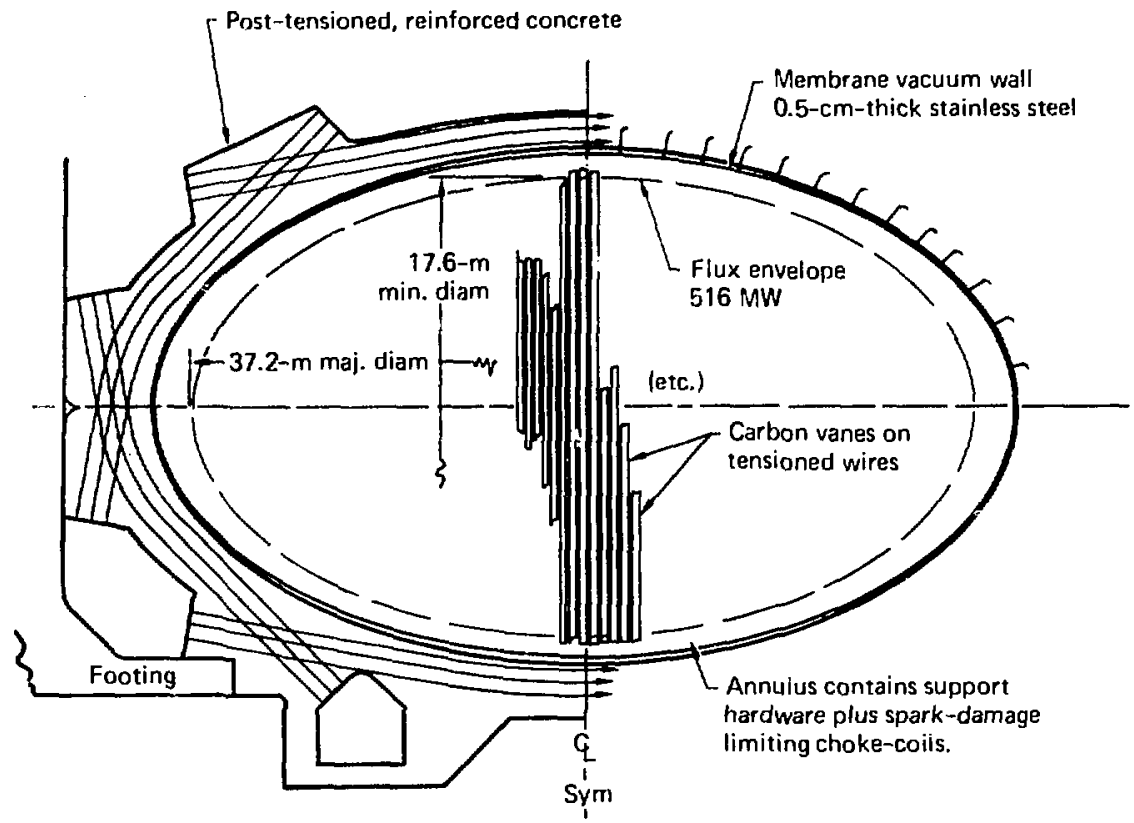

Fig. 4-7. Cross section of TMR at the direct converter. Detail $A$ shows variation of conductor percentage through thickness of coil.

tank then forms part of the containment volume, and the pressure Increase can be maintained below 2 atm. These relief diaphragms should be located on the ellipso-conical transitions between the plugs and the direct converters at both ends of the machine.

Any accidental releases of primary coolant must be confined within a secondary containment shell. It has been proposed by ORNL and by researchers in Europe that evacuation of the containment building offers some safety advantages at a negligible increase in cost. Plumbrook Station, ${ }^{4-8}$ near Lake Erie, which has been operated successfully by NASA as a test station for space power reactors, is an evacuated building of dimensions quite similar to those proposed for an Experimental Fusion Power Reactor.

An evacuated secondary containment shell presents one significant structural advantage. The side walls and roof of the TMR building are all basically flat plates (with the 
possible exception of a slightly

arched roor). They can be more

economically designed if the pressurt

differential varies from 1 atm

"inward" to 1 atm "outward" rather

than from zero to $2 \mathrm{~atm}$ in one direc-

tion. We plan to size the evacuated containment building so the pressure increase will in no accident circumstance exceed 2 atm. In the case of

a 2-atm pressure change, the wall

will experience a stress reversal.

A reinfurced concrete wall can be considerably thinncy if designed to meet the reversed luad condition. Calculations show that for the same weight oi reinforcing steel, only $60 \%$ as much wall thickness is required in the case of 1-atm pressure difference in either direction. On a concrete structure of this size, that represents an estimated $20 \%$ of the cost of the containment shell.

\section{REFERENCES}

4-1. T. K. Fowler and B. G. Logan, The Fandem lirror Reactor, Lawrence Livermore Laboratory, Rept, UCRL-78740 (1976).

4-2. G. I. Dimov, V. V. Zakaidakov, and M. E. Kishinevsky, Fiz.

Piasmi $\underline{2} 597$ (1976).
4-3. !'. Tasie, Bestern Rubion Represtentat ive of siaky Bros. Inc, l.os ingeles, Ch, private communicalion (1977).

4-4. $\quad \therefore \quad \therefore \quad \therefore \quad \therefore \quad \therefore \quad \therefore$,

R. (;. Hills, Fid, Princet on plasme Physicsi labaratory, Rept. Mit-1050 (1974).

4-5. 1. b. lees, w. 1.. Batmore, D. J. Bender, 3. N. Doggett, and J. K. Cialloway, ........"

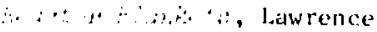
Livermore I aboratory, Rept. UCiD-17083, Rev. 1 (1976).

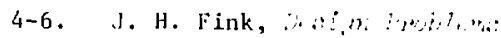

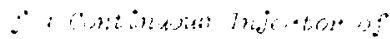

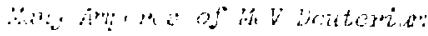
i.ctivati, lawrence livermore Iaboratory, Rept. UCID-17303 (1976).

4-7. W. L. Barr, R. J. Burleigh, W. L. Dexter, R. W. Moir, and R. R. Smith, A Jociminari Ensineering Desi, for a "Venetian Blind" Direct Enery: Convertor for Fusion Reastors, Lawrence Livermore Labcratory, Rept. UCRL-74636, Rev. 1 (1974).

4-8. Space Power Facility, Descmiption and Carabilities, NASA Lewis Research Center, Plum Brook Station, Sandusky, Ohio (1974). 


\section{CHAPTER 5. DESIGN OF THE COIL SYSTEM FOR THE TMR PLUG}

\section{A. Peterson}

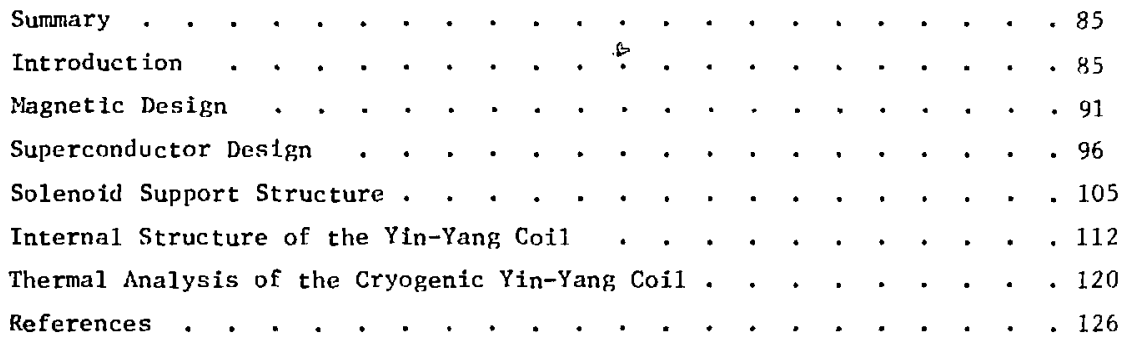


SURPLARY

Each plug coil in the Tandem Mirror Reactor (TMR) is a hybrid superconducting and cryogenic magnet set consisting of a cryogenic-aluminum Yin-Yang magnet placed within a niobiumtin solenoidal pair. The strength of the central vacuum magnetic field of the plug coil is $16.5 \mathrm{~T}$, and its vacuum mirror ratio is 1.07 . The niobium-tin superconducting solenoids have an inside diameter of $5.8 \mathrm{~m}$ and an outside diameter of $11 \mathrm{~m}$. The magnetic forces of these coils are restrained by periodic bands of stainless steel. The cryogenic-aluminum Yin-Yang magnet is about the size of the magnet for the Mirror Fusion Test facility (MFTF) and produces a field of about $1 \mathrm{~T}$ which adds to the field produced by the solenoids. The resistive heating in the Yin-Yang magnet is $0.25 \mathrm{MW}$, which requires about 12 MW of refrigeration power. Structural integrity of the Yin-Yang magnet requires a layered construction of pure-aluminum conductor plus aluminum-alloy columns and stress plates to transfer the magnetic forces to an external clamping structure.

\section{INTRODUCTION}

\section{General Description of}

\section{the Plug Coil Design}

Figure 5-1 shows the preliminary design of the TMR plug coil. In add- ition to the high-field design $\left|B_{0}\right|$ $=18$, design $\left(\left|\mathrm{B}_{0}\right|=18-\mathrm{T}\right)$ shown in Fig. 5-1, two lower-field cases $\left(\left|\mathrm{B}_{0}\right|=26.5 \mathrm{~T}\right.$ and $\left.\left|\mathrm{B}_{0}\right|=15 \mathrm{~T}\right)$ were developed from the high-field case by suitably scaling down the winding current. Although the intermediate - field strength $\left(\left|\mathrm{B}_{0}\right|=16.5 \mathrm{~T}\right)$ was eventually selected as the point value for the TMR reactor study, primary emphasis throughout the development of the preliminary plug coil design was placed on the high-field case $\left(\left|\mathrm{B}_{0}\right|=18 \mathrm{~T}\right)$ in order to define and explore the design problems that limit the atcainable field strength in the plug coil system.

The plug coil system uses a relatively small Yin-Yang coil pair with a square conductor cross section located inside two solenoid coils to generate a shallow minimum- $|B|$ well (mirror ratio $\mathrm{R}=1.07$ ). The solenoid coils are superconducting; the YinYang coil set carries about $12 \%$ of the total current in the plug coil system, while the superconducting solenoid windings carry the remaining $88 \%$ of the total current. The solenoid coil is separated into two winding layers, each with its own external, structurally independent support structure. This support structure carries the princlpal component of the magnetic force, which is directed radially outward, in tension. Depending on the stress and/or strain 


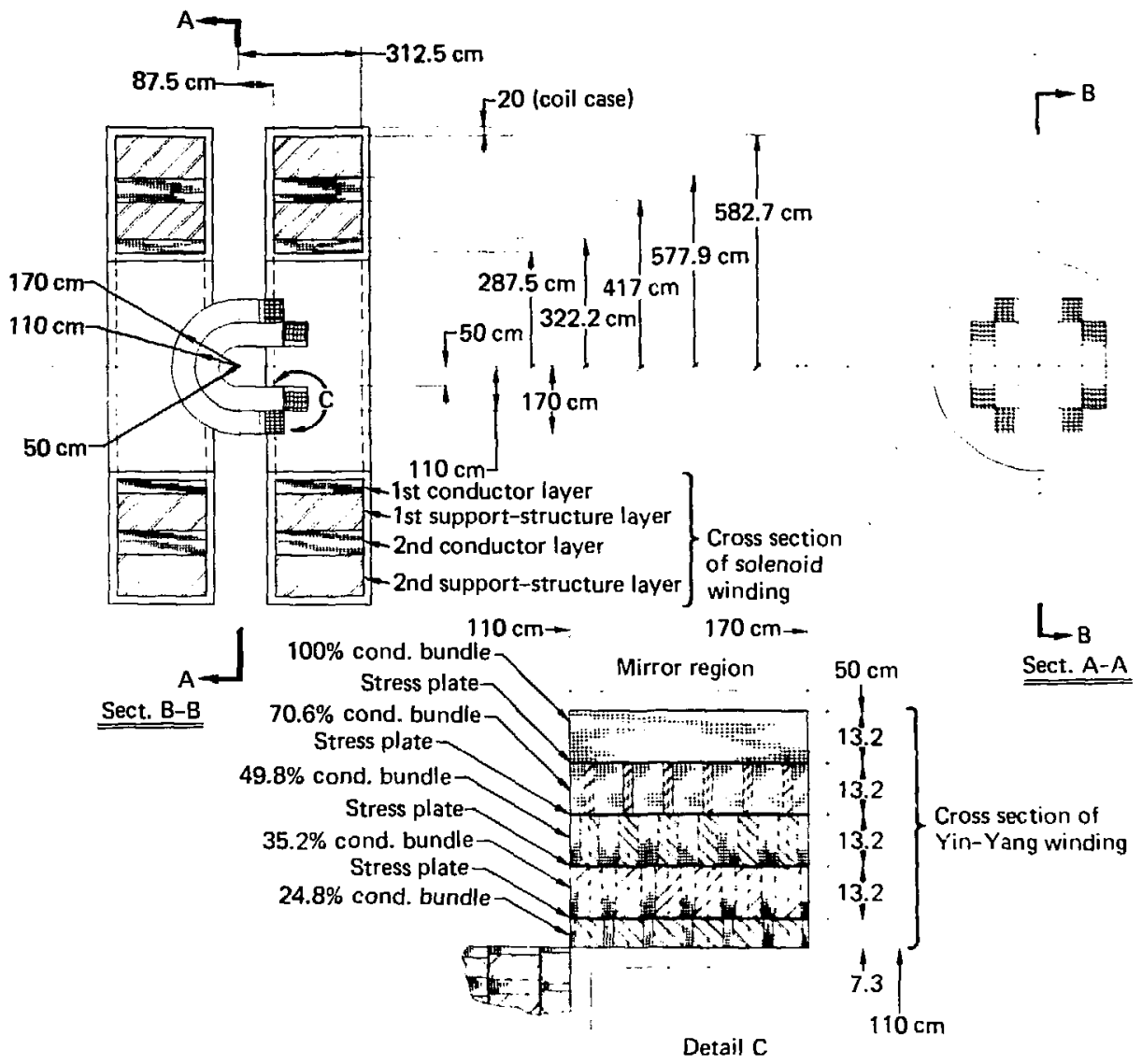

Fig. 5-1. Preliminary design of the 18-T coil bundle for the TMR plug cuil. 
limits of the copper-stabilized. Nin 3 ha superconductor, the inner suplurt st ructure may have to be presiressed. The aximum allowable current density in the winding of the superconduc ting solenojd is deterthined by requiring that cryostatic stability be mintilned locally throughout the winding. The detabled conductor configuration used in the cryostat ic stability analysts is based upon the condector desi in propused for the SFIF,

The Yin-yang coil ( $\mathrm{Fi}, ;-1$ ) incorporates an internal sipport structure that transmits to an external structure the mignetic forces distributed over tite conductors. The in. alal structure is recessary to 1 imit the compressive stress on the relatively weak, highpurity aluminum conductors. As discussed later in this chapter, in this report we do not consider the external structure supporting the Yin-Yang coil pair.

The cryogenic, high-purity-aluminum conductor is convectively cooled by gaseous helium pressurized to about 4 atm. Although it appears to present a formidable design challenge, the design of a manifolding system for the helium coolant has not been considered thus far in this preliminary study.

\section{Design Considerations}

Before beginning a detailed discusston of the design of the IMR coil

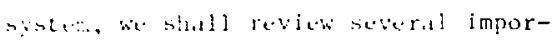

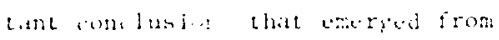

the iberotive search for a coil design.

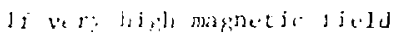
strontho are desired $(.20$ Th, coil systems inorpurating beth steperconduct ins and arogende-aluminum

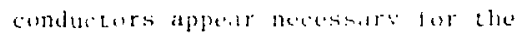
folluwing reisuns:

- Ihe critical aurent deasily al aval babe supercondue ingr materials

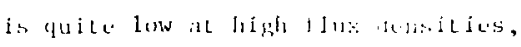
and

- Ihe reirigerilion jower for a coil system composed ent ir.]: a[ cryogenic aluminum is prohibitive.

Thus, if field strengle thuve about $20 \mathrm{~T}$ are specified, he coil windins would probahl: incorporate cryogenic aluminuri in the portion of the winding where the field strength was very high $(! b) \therefore 20 \mathrm{~T})$, whereas the remainder of the winding would be superconducting in order to minimize the refrigeration power required. Because of the extremely large magnetic forces generated by the high field strengths and the relatively low yield stresses of the conductor materials especially the high-purity aluminum used in the cryogenic-eluminum conductor $\left(\sigma_{y_{p}}=1 \times 10^{8} \mathrm{~N} / \mathrm{m}^{2}\right.$, $14.5 \mathrm{ksi}$ ) an internal structural system is required to transmit the magnetic forces through the winding itself to an external structure supporting the Yin-Yang coils. The choice of 
materials for the internal support structure is severely limited by the wide temperature range from the roomtemperature environment in which it is assembled to its cryogenic operating cemperature. Thus, the material from which the internal coil structure is constructed must be selected on the basis of having a thermal expansion coefficient compatible with the conductor material rather than for maximum strength. As with the conductor yield stress previously mentioned, this limitation on the matcrial used in the internal structure is much more serious for cyyogenic aluminum windings (aluminumalloy structure $\left(\sigma_{y p}=3.4 \times 10^{8} \mathrm{~N} / \mathrm{m}^{2}\right.$, $\approx 49.2 \mathrm{ksi}$ ) than for the copperstabilized superconducting windings (stainless-steel structure, $\sigma_{y_{p}}=6.9$ $\times 10^{8} \mathrm{~N} / \mathrm{m}^{2}=100 \mathrm{ksi}$ ).

When we sized the internal structure by the analysis described later in this chapter, and when we assumed reasonable current density values within the conductor itself, it became apyarent that the large amount of conductor displaced by the internal structure severely limited the average cirrent density [current density averaged over the cross section of the entire winding (conductor and internal structure)] that could be realized.

An economic analysis of the entire TMR reactor system ${ }^{5-2}$ indicates that the central field st rength must be maintained as high as possible if the relative cost $[\$ / \mathrm{kW}(\mathrm{e})]$ of the TMR system is to be reasonable. There is a clear economic incentive towards high central field strength and low mirror ratio in the plugs. Experiments in 2 XIIB suggest that a plasma can be confined by a mirror-ratio of

a few percent.

Although the preliminary design described in this report $(R \approx 1.07)$ certainly does not represent the highest possible mirror ratio design with adequate central field strength $\left(\left|\mathrm{B}_{0}\right| \geq 15 \mathrm{~T}\right)$, it should be emphasized that the increased conductor field strengths resulting from even relatively small increases in the mirror ratio will render the design of a viable coil system much more difficult.

The configuration of the internal structure and the local current density in each layer of the winding depend upon the magnetic field strength throughout the winding volume and upon the winding geometry. Since the magnetic field is itself dependent upon the geometry of the coil system, the configuration of the internal structure, and the local current densities within the winding, the development of a coil system design in which the average current densities used in the magnetic calculations are consistent with the local maximum current densitiss 1 imitations in the 
conductor is an iterative process. To develop the coil system design presented in this chapter, we first developed a "first-cut" coil geometry with suitable magnetic parameters based upon an assumed value of the average current density. Then, with the coil geometry and field strengths determined from the first-cut design, we calculated the actual value of the average current density from the local maximum allowable current density values in the conductor. If the assumed values of the average current densities were significantly different than the calculated achievable values based on local conductor limits, another iteration was made by altering the initial first-cut coil geometry.

The coil design presented in this chapter represents a preliminary design whose magnetic parameters fall within the magnetic design goals and whose bulk current densities closely approximate the maximum allowable current density values calculated from the preliminary analyses also described in this chapter. Thus, while further changes will probably be required when a more detailed analysis is made, the coil design presented here should provide a reasonably self-consistent picture of a viable TMR coil system.

In the remaining portion of this Introduction, we shall briefly discuss several key aspects of this preliminary
TMR coil design that requires more investigation.

Unfinished Business

Although the solenoid coil must be superconducting in order to limit the refrigeration power required, the relatively small share of the current carried by the Yin-Yang coil winding permits the use of cryogenic-aluminum conductors. Although cryogenicaluminum Yin-Yang conductors were initially chosen because of their capability for relatively high current densities at high field strengths, it may be feasible to use superconductors for both the Yin-Yang and solenoid ccils. However, the very strong, spatially uniform, magnetic fields present throughout the volume of the Yin-Yang coil windings limit the average current density achievable in a coil that incorporates superconducting conductors. Although achieving the desired current densities may be difficult with superconducting windings, their potential advantages - reduced refrigeration power requirements, reduction in the relative size of the internal structure (stronger conductor and st iuctural material), and a potentially simpler cooling system - provide a strong incentive for investigating their feasibility.

If further investigation eliminates the superconducting Yin-Yang option, a substantial design effort would be 
required to verify the feasibility of a cryogenic-aluminum, Yin-Yang coil system. Because of the limited time available, only the magnetic, structural, and internal thermal design of the aluminum Yin-Yang coil have been considered here. Since the thermal analysis (see subsequent discusrion under "Thermal Analysis of the Cryogenic Yin-Yang Coil") indicated that many relatively short coolant passages would be required, the development of a coolant manifold design that is compatible with structural, electrical, and constructional requirements may be quite difficult. To fully validate the feasibility of a cryogenic-aluminum, Yin-Yang coil option, we must develop a coil winding design, including electrical connections and coolant manifolds, that is compatible with the internal structure and coolant passage configurations described later in this chapter. Since the design of the electrical and coolant passages involves consideration of fine-scale, local aspects of the winding design, a fully feasible aluminum Yin-Yang coil design must be rather detailed, and thus requires a substantial design effort.

Thus far in this design study, we have not considered the external structure required to support the YinYang coil winding because, in contrast with past reactor coil systems, it does not appear to present a particularly difficult design challenge. Several different factors have contributed to the simplification of the coil support structure for the TMR reactor concept relative to past reactor designs. Because of the low IMR mirror ratio $(R=1.07)$, the nearly cylíndrical plasma volume (approximately defined by the mirrar-to-mirror extension of all the field lines passing through the last closed surface of constant $|B|)$ fills only a relatively small central portion of the mirror region of each Yin-Yang coil. Thus, a large portion of the major arcs (Fig. 5-1) of each Yin-Yang coil can be locally supported by a tension structure connecting the upper and lower coil winding. This contrasts with previous Yin-Yang designs in which structural material was excluded from a large portion of the mirror by the fan regions of the plasma volume. In addition to the large portion of the mirror region available Lis structure, the small size of the Yin-Yang coil winding relative to the solenoid winding surrounding it appears to allow ample space external to the Yin-Yang coil set for a supporting structure.

In any further design work on the TMR plug coil system, considerable emphasis should be placed on determining whether the solenoid coll structure requires prestressing, and 
if so, how to do it. To determine the need for prestressing the solenoid coil structure, its stress state must be more precisely defined through a more detailed structural analysis, and the maximum allowable conductor strain limits must be clarified from a wider range of experimental data. If prestressing is required, a preliminary structure design incorporating the desired amount of prestressing should be developed.

In the remaining sections of this chapter, the assumptions, design models, and calculations upon which this preliminary design is based are discussed in greater detail. First, we discuss the magnetic design of the TMR plug coil system shown in Fig. 5-1. Then we review the design of the superconducting solenoid winding conductor and its supporting structure. Finally, we discuss the design of the conductor and the internal support structure for the cryogenic-dluminum, Yin-Yang coil pair.

\section{MAGNETIC DESIGN}

The preliminary plug coil design developed to meet TMR magnetic design goals $\left(1.05 \leqslant R \leqslant 1.10 ;\left|\mathrm{B}_{0}\right| \geq 15 \mathrm{~T}\right)$ is shown in Fig. 5-1. This system utilizes a relatively small Yin-Yang coll set with a square conductor cross section located inside two solenoid colls to generate a shallow minimum-
|B| well. The solenoid coils are superconducting; the Yin-Yang coil sets uses cryogenic-aluminum conductors. The Yin-Yang coil set carries about $12 \%$ of the total current in the plug coil system, and the superconducting solenoid windings carry the remaining $88 \%$ of the total current.

The solenoid coils are separated into two Jayers of windings, each with its own external support structure.

Although it is not shown in Fig. 5-1, the solenoid windings are subdivided into five layers of conductor, each with a different current density and superconductor-stabilizer ratio (see Fig. 5-4, Table 5-2). The Yin-Yang coil (detail, Fig. 5-1) incorporates an internal support structure that transmits the magnetic forces distributed over the conductors to an external structure. The internal structure is necessary to limit the compressive stress on the relatively weak pure-aluminum conductors. As discussed later in this chapter, in this report we have not considered the external structure supporting the Yin-Yang coil pair.

The geometry and magnitude of the magnetic fields generaced by the plug coil design were evaluated with the computer code EFFI. To simplify the magnetic calculations, the Yin-Yang conductors shown in Fig. 5-1 were simulated by a number of circular arc 
conductors with the same external dimensions, but with the complex internal structure and coil bundles replaced by a homogeneously distributed, average zurrent density. Because the local value of the current density within the cryogenic-aluminum conductor is constant, and because the inner conductor layers (those nearest the mirror region) of the Yin-Yang winding have less conductor displaced by the internal structure, the constant current density approximation should tend to slightly underestimate both the mirror field strength and the mirror ratio.

The solenoid coils were modeled by constant current density conductors with the dimensions given in Fig. 5-1 for each conductor layer. Since in the actual solenoid winding the current density increases radially outward through the winding (lower field strength, higher critical current density) the constant current density approximation over-predicts the strengths of the mirror and central fields. This was confirmed, and we used a Djagnetic calculation performed with the correct current density distribution in the solenoid winding to determine that the error was less than $2 \%$. We found that the average current density values initially chosen for the solenotd ( $\mathrm{J}=3000 \mathrm{~A} / \mathrm{cm}^{2}$ ) and for the Yin-Yang coil ( $\mathrm{J}=2337$ $\mathrm{A} / \mathrm{cm}^{2}$ ) were in reasonable accord with the maximum allowable current density value determinations described later in this chapter. Thus, at least for a preliminary design study, no further iterations are necessary on the plug coil system design shown in Fig. 5-1. lable 5-1 lists the EFFI-compatible input data required to specify the geometrical configuration of the four circular loop conductors and the eight circular arc conductors used to simulate the plug coil systetr.

The magnitude of the axial magnetic field strength along the z-axis of the coil system as calculated by EFFI is displayed in Fig. 5-2 superimposed on the outline of the conductor cross sections in the $x z-p l a n e$ (from Fig. 5-1). From this plot, it may be seen that the central field strength is very close to $18 \mathrm{~T}$ and the mirror ratio is about 1.07 .

Since past experience with similiar geometries has shown that for such small mirror ratios the existence of a minimum- $|B|$ well cannot be taken for granted, we used EFFI to obtain a plot of contours of constant field strength in the central plasma region. From the contour plot shown in Fig. 5-3, it appears that a closed, minimum-|B| well does exist, although it is very small (radial mirror ratio $\leqslant 1.002)$. Since the solenold coil is superconducting, the magnitude of the field within the winding is of considerable Interest. Since (unlike 
Table 5-1. TMR plug coil system/EFFI input.
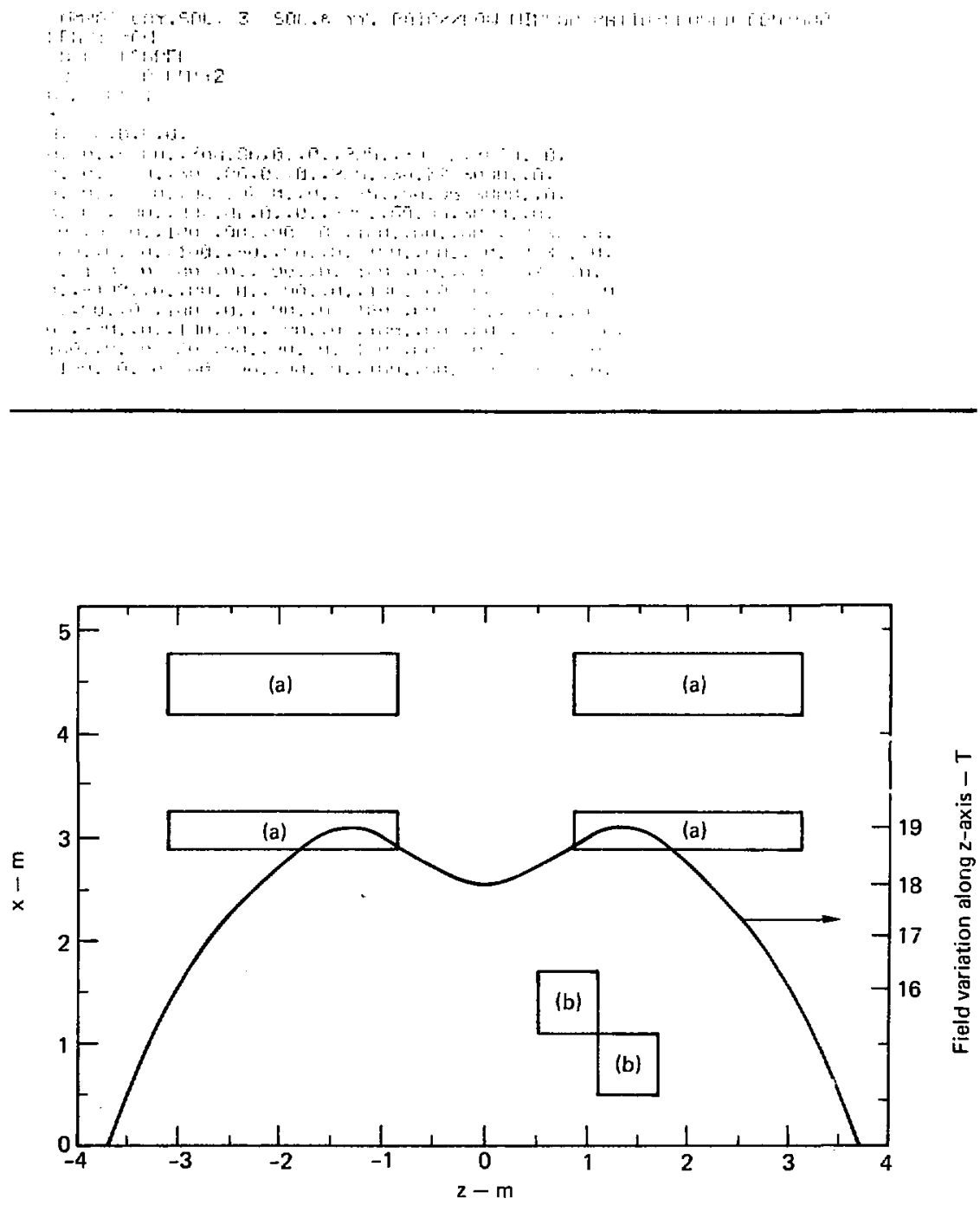

Fig. 5-2. Plot of on-axis magnetic field strength $|B|$. Items (a) are cross sections through the solenoid winding; items (b) are cross sections through the Yin-Yang winding. 
the fields in the central plasma region) the field strength within the solenoid winding itself is sensitive to the actual details of the current density distribution, we calculated the rield uslng the actual current density distribution determined later in this chapter.

The plot of constant field strength contours across the solenoid windingr, obtained with the actual current density distribution is shown in Fig. 5-4. From the values of the contours in Fig. 5-4, it can be seen that the peak field strength within the solenoid winding is actually less than the mirror field strength (17.8 T vs $\left.\left.\mid \mathrm{B}_{\mathrm{mp}}\right\rfloor=19.2 \mathrm{~T}\right)$ because the $\operatorname{mag}-$ netic flux vector components generated by the solenoid and by the YinYang coil are oppositely directed in the region of the solenoid.

To investigate the effects of Lowering the central rield strength while maintaining an approximately constant mirror ratio, we developed

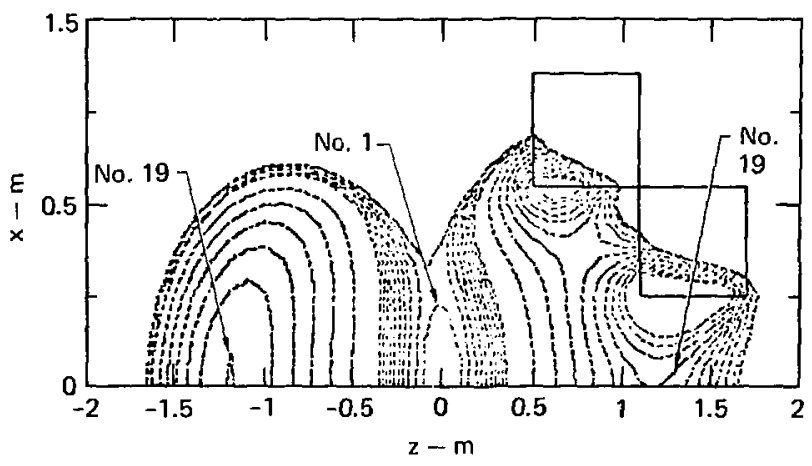

\begin{tabular}{|cc|}
\hline Contour No. & $\begin{array}{c}|\mathrm{B}| \text { value } \\
(\mathrm{T})\end{array}$ \\
\hline$\left|\mathrm{B}_{0}\right|$ & 12.036 \\
1 & 18.054 \\
2 & 18.072 \\
3 & 18.090 \\
4 & 18.108 \\
5 & 18.126 \\
6 & 18.144 \\
7 & 18.162 \\
8 & 18.180 \\
9 & 18.198 \\
10 & 18.216 \\
11 & 18.396 \\
12 & 18.577 \\
13 & 18.757 \\
14 & 18.937 \\
15 & 19.118 \\
16 & 19.298 \\
17 & 19.473 \\
18 & 19.659 \\
19 & 19.836 \\
\hline
\end{tabular}

Fig. 5-3. Constant field strongth contours of the minimum-|B|well. 
two additiona: design cases based upon the coil system shown in Fig. 5-1. In these two design cases, all the field strengths were reduced by scaling down the total current in the solenoids and in the Yin-yang coil set. In the first case, the currents were reduced by $20 \%$ to yield a central field strength of $16 \mathrm{~T}$; in the second case, a $10 \%$ reduction in the currents and fields yielded a central field strength of $16.5 \mathrm{~T}$.
Although this linear scaling of the field with the winding currents is strictly corruct only if the geomelry of the coil system is unaltered, the reduced currents in the solenoids were abtained by reducing the radial thickness of the solenoid winding rather than the current density. Thus, the magnetic parameters of these two additional cases as determined by lincar scaling from the original high field strength case are not exactly

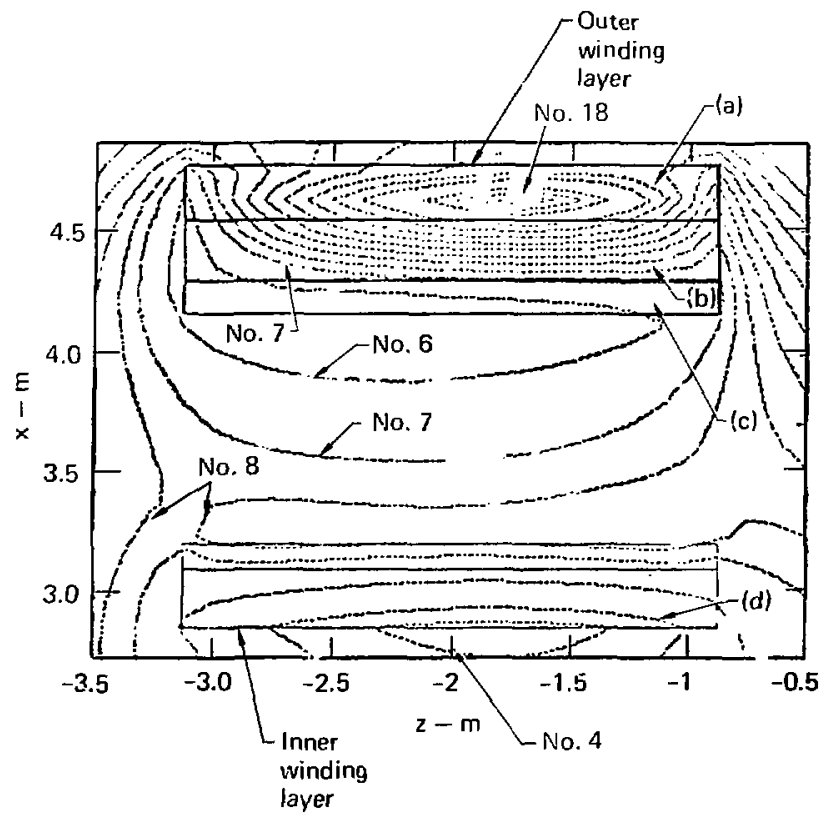

\begin{tabular}{|rc|}
\hline Contour No. & $\begin{array}{c}|\mathrm{B}| \text { value } \\
(\mathrm{T})\end{array}$ \\
\hline 2 & 19.961 \\
3 & 19.100 \\
4 & 18.060 \\
5 & 17.109 \\
6 & 14.258 \\
7 & 12.357 \\
8 & 11.406 \\
9 & 18.456 \\
10 & 95.050 \\
11 & 85.550 \\
12 & 76.040 \\
13 & 66.540 \\
14 & 57.030 \\
15 & 47.530 \\
16 & 28.520 \\
17 & 19.010 \\
18 & 95.000 \\
\hline
\end{tabular}

Fig. 5-4. Constant field-strength contours across the solenoid winding fci the actual current-density distribution. Item (a) is the conductor layer at $j_{4}$, item (b) the conductor layer at $j_{3}$, item (c) the conductor layer at $j_{2}$, and item (d) the conductor layer at $j_{1}$. 
correct. However, the small relative magnitude of the cross-sectional changes and the distant location of the solenoid winding from the central plasma region should cause the error resulting from the altered radial thickness of the solenold winding to be insignificant.

\section{SUPERCONDUCTOR DESIGN}

In the inttial destgn of the two identical solenotd colls used in each plug coil system (FIg. 5-1), we assumed that we could achieve a bulk average current density $J$ (averaged over the superconductor and copper stabilizing material for the entire cross sectlonal area of the winding) of approximately $3000 \mathrm{~A} / \mathrm{cm}^{2}$. This value was not based directly on any particular calculations, but rather represented a first guess of what should be possible using $\mathrm{Nb}_{3} \mathrm{Sn}$ superconductor at the contemplated field strengths.

For a particular desired value of

A the central fleld strength and a given superconductor, the bulk average current density that can actually be achieved depends upon the strength of the magnetic fleld throughout the entire conductor. Since the magnetic field strength can not be determined without specifying the geometrical configuration of the entire coil system and an assumed current density, an iterative process is necessary if the bulk average current density value initially assumed is much different than the actual allowable value. In addition, since the structural analysis of the solenoid coil is based on the initially assumed value of the average current density, a substantial change in that value would also render the structural analysis inconsistent. However, if the initially assumed current-density value can actually be achieved, the plug coll system shown in Fig. 5-1 will be capable of generating the calculated central field strength of $18 \mathrm{~T}$. Since the two lower field strengths cases considered in the magnetic design section $\left(\left|\mathrm{B}_{0}\right|=15 \mathrm{~T}\right.$ and $\left|\mathrm{B}_{0}\right|$ $=16.5 \mathrm{~T}$ ) were developed by reducing the radial thickniss of the solenoid winding while maintaining the current density used in the high-field case $\left(|\mathrm{B}|=18 \mathrm{~T}, \mathrm{~J}=3000 \mathrm{~A} / \mathrm{cm}^{2}\right)$, their viabillty will also be assured if the initially assumed current density can actually be achleved. Since the following analysis will indicate that the bulk current density value initially assumed is indeed viable, an Iterative redesign is not required, and the plug coil design shown in Fig. 5-1 is an acceptable preliminary design.

In this analysis, we assume that the bulk average current density of the superconducting solenoid is determined by the requirement that all the 
conductors in the winding be cryostatically stable. The cryostatic stability criterion requires that at any point along the conductor the natura] convective heat-transfer rate to the helium coolant must be sufficient to transfer the Joule dissipation power resulting from having current locally flow in the copper stabilizing material. Since this criterion applies locally at each point along the entire length of every conductar, we must begin the determination of its effect on the bulk average current density by locally examining a single conductor.

The cryostatic stability criterion can be formulated analytically in terms of a generalized conductor design (rectangular cross section defined by $d$ and $b$, Fig. 5-5) by imposing the requirement that the Joule dissipation $(\delta P)$ in an incremental length $(\delta \ell)$ of conductor be equivalent to the thermal power $\left(\delta P_{c}\right)$ removed from the conductor surface $[2 \mathrm{~d}(1+\mathrm{b}) \delta l]$ by the helium coolant. With the conductor geometry specified by the dimension of its largest side d, its aspect ratio $h$, and the fraction of its cross-sectional area occupied by each conductor component (copper stabilizer $f_{c u}$, superconductor $f_{s c}$, coolant $f_{h e}$ and insulation $f_{\text {in }}$, Fig. 5-5), the Joule dissipation induced by the entire conductor

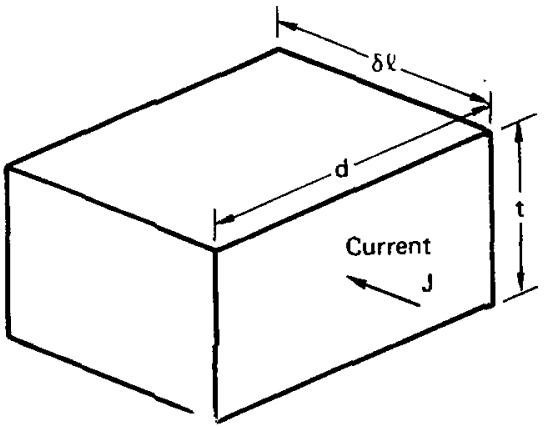

Fig. 5-5, Generalized conductor design, where

$\mathrm{b}=$ aspect ratio of cross section $=t / d$,

$\mathrm{d}=\mathrm{d}$ imension of largest side,

$\alpha=$ fraction of zonductor surface area interfaing with coolant,

$f_{s c}=$ fractional cross sectional area of superconditor $\equiv A_{s c} / A_{\text {tot }}$.

$\mathrm{f}_{\mathrm{cu}}=$ fractional $\mathrm{cr}$ ss sectional area of copper stabilizer $\equiv A_{c u} / A_{\text {tot }}$,

$f_{\text {in }}=$ fractional cross sectional area of insulator $\equiv A_{i n} / A_{\text {tot }}$,

$\mathrm{f}_{\mathrm{he}}=$ fractional cross sectional area of He coolant $\equiv A_{\text {he }} / A_{\text {tot }}$,

$\rho_{c u}=\rho(|B|, T)=$ resistivity of copper stabilizer

$j_{s c}=j(|\bar{B}|, T)=$ critical current

- density in super conductor,

$\bar{q}=$ average heat transfer rate per unit of coolant passageconductor contact area,

$A_{\text {tot }}=A_{\text {he }}+A_{s c}+A_{c u}+A_{\text {in }}$, and

$I=f_{h e}+f_{s c}+f_{c u}+f_{i n}$

current flowing in the copper stabilizer is given by the following expression: 


$$
\begin{aligned}
\delta P & =I^{2} \dot{\partial}=j_{s c}^{2}\left(\frac{\Lambda_{s c}^{2}}{A^{2}}\right)\left(\frac{\Lambda}{\Lambda_{c u}}\right) \sigma_{c u} A d \% \\
& =j_{s c}^{2}\left(\frac{f_{s c}^{2}}{f_{c u}}\right) \rho_{c u}\left(b d^{2}\right) d \%
\end{aligned}
$$

The power $\delta \mathrm{P}$ removed from the same incremental conductor by the coolant is given by the following relationship in terms of $\bar{q}$, the average heat transfer rate per unit of coolant passageconductor contact area and $\alpha$, the fraction of the conductor surface that interfaces with the coolant passage :

$$
\begin{aligned}
\delta P_{C} & =\bar{q} \alpha[(2 \mathrm{~d}+2 \mathrm{~T}) \delta \ell] \\
& =\bar{q} \alpha 2 \mathrm{~d}(1+\mathrm{b}) \delta \ell .
\end{aligned}
$$

Since the thermal power removed by the coolant is proportional to the conductor surface area and the Joule dissipation power is proportional to the conductor volume, cryostatic stability can in principle be achieved by reducing the conductor size $d$. However, pragmatic considerations asisociated with conductor fabrication and coil winding limit the conductor size to reasonakle levels $(\mathrm{d} \geqslant 1 \mathrm{~cm})$. When the cryostatic criterion is enforced by equating the disslpated power $\delta P$, Eq. (5-1) to the thernal power removed by the coolant $\delta \mathrm{P}_{\mathrm{c}}$, Eq. (5-2), the following relationshtp is obtained :

$$
\frac{f_{s c}^{2}}{f_{c u}}=\left[\frac{\bar{q}}{\rho_{c u} j_{s c}^{2}}\right]\left[\frac{\alpha}{d}\left(\frac{1+b}{b}\right)\right] .
$$

The terms inside the first brackets on the right-hand side of Eq. (5-3) are determined by physical properties of the helium coolant, the copper stabilizing material, and the superconducting material for a particular magnetic field strength and temperature. The geometrical terms inside the second set of brackets are determined by the detalled design configuration of the actual conductor. Thus, when we have chosen a particular conductor design $(\alpha, d, b)$ and determined the appropriate set of material properties $\left(\overline{\mathrm{f}}, \chi_{\mathrm{cu}}, j_{\mathrm{sc}}\right)$, the fractional area of the superconductor $f_{S c}$ and the fractional area of the copper stabilizer $f_{\text {cu }}$ must satisfy Eq. (5-3) if the cryostatic stability criterion is to be observed.

From the defintions of the fractional areas $(\mathrm{F} 1 \mathrm{~g} .5-5)$ we may use the following relationship to express the fractional area of the copper stabilizing materlal $\mathrm{f}_{\mathrm{cu}}$ in terms of the fractional areas of the helium coolant $\mathrm{f}_{\text {he }}$ and insulation $\mathrm{f}_{\text {in }}$ :

$f_{c u}=1-\left(f_{\text {in }}+f_{h e}\right)-f_{s c}$.

If we assume that the fractional areas required by the helium coolant and the Insulation are fixed for a 
particular conductor and winding desigr, we may use Eq. $(5-4)$ to eliminate the fractional area of the copper stabilizing material from the cryostatic stability criterion

[Eq. (5-3)]. Thus, for a set of material properties at a particular temperature and field strength and a particular conductor design, the maximum allowable fractional area of the superconductor $F_{s c}$ is locally set by the cryostatic stability criterion.

When Eq. (5-3) and (5-4) are combined and the quadratic rule invoked, the maximum allowable value of the fraction of conductor crosssectional area devoted to the superconductor is given by the following relationship :

$$
\begin{gathered}
F_{s c}=\left\{\left[\frac{\bar{q}}{\rho_{c u} j_{s c}^{2}}\right]\left[\frac{a(1+b)}{b d}\right]\right\} \\
\times\left(-1+\left\{1+2\left[\frac{\rho_{c u} j_{s c}^{2}}{\bar{q}}\right]\left[\frac{b d}{a(1+b)}\right]\right.\right. \\
\left.\left.\left(1-f_{\text {in }}-f_{h e}\right)\right\}_{(5-5)}\right\}_{(1 / 2)}
\end{gathered}
$$

The local value of the conductor current density $j$ at any point along the conductor is given by the product of the superconductor current density and the riximum allowable superconductor fractional area $\mathrm{F}_{\text {sc }}$ as set by the cryostatic criterion Eq. $(5-5)$ :

$$
j=j_{s c} F_{s c} .
$$

Having determined the allowable local current density in the conductor, we must consider the relationship of the conductor to the winding in order to determine the maximum achievable bulk current density $\mathrm{j}$.

Although the absolute maximum bulk current density would occur when the superconductor fractional area $f_{s c}$ is continuously varied to maintain all the conductors at the local maximum allowable current density value, the obvious constructional difficulties of such a design suggest that a discrete approximation to the continuously varying case provides a more realistic estimate of maximum achievable bulk current density, We develop this approximation by dividing the solenoid winding into a number of layers of conductors $\mathrm{N}$ in which the conductor current density $j$ is fixed throughout each layer at the lowest value of the allowable current density in the entire layer.

To apply this approximation to the solenoid winding design previously developed (Fig. 5-1), the total thickness in the radial direction of both the inner and outer windings of each solenoid $\left(\mathrm{T}_{\mathrm{t}}=0.987 \mathrm{~m}\right)$ is divided into four layers of equal thickness. 
[The second layer of constant current density conductors is split between the inner and outer winding layers (Fig. 5-4 and 5-9).] We assume that the magnetic field strength varies through the winding in a linear manner from the peak strength at the inner radial surface (the surface normal to the inside radius of the solenoid) to zero field strength at the outer radial surface of the winding. From the following relationsh1p, it may be seen that this linear variation of $|B|$ is based upon the distance $\beta$ through the winding from the Inner radial surface, with the region occupied by the inner support structure (Fig. 5-1) being neglected:

$$
|B|=\left|B_{\mathrm{mc}}\right|\left[1-\beta / T_{t}\right] \text {, }
$$

where

$$
\begin{aligned}
& B \equiv \text { the distance through the } \\
& \text { winding from the inner surface } \\
& \text { (neglecting the inner coil- } \\
& \text { support structure), and }
\end{aligned}
$$

$T_{t} \equiv$ the total winding thickness (neglecting the Inner coil-support structure).

Since the assumed linear variation of the magne:ic field inside the winding is correct only for a solenold of infinite axial length and uniform current density, it provides only a first-order approximation to the more complex spatial variation of the field within the finite-length, variable-izurrent-density solenolds in the plug coil. Because the maximum allowable current density decreases with increasing field strength, the lowest value of the maximum allowable current density in a particular layer of conductor occurs at the location of maximum fieid strength within that layer of conductor.

Thus, with the assumed field variation [Eq. (5-7)], the 11miting value of the maximum allowable current denstty for a given layer of conductor occurs at the inner radial surface of the conductor layer where the magnetic field strength is highest. Since the current density within a conductor layer is less than the maximum allowable value everywhere within that layer except at its innermost surface, the layered approximation tends to underestimate the value of maximur allowable bulk current density J. However, with a reasonable number of layers $(N \geq 3)$, it provides an adequate estimate of the maximum achlevable bulk current density, considering the preliminary nature of this analysis and the obvious constructional problems associated with a large number of conductor layers.

To estimate the maximum allowable bulk current density $J$ with the 
computational model discussed in the preceding test, we need a con'uctor design configuration. For the purposes of this analysis, we adopted the conductor design developed for the Mirror Fusion Test Facility (MFIF) experiment 5-1 (Fig. 5-6). To allow the relatively large superconductor fractional areas required by the high field strength levels inherent in the TMR concept, we modified MFTF conductor design by removing the restriction that the superconductor be confined to only one quadrant of the conductor (Fig, 5-6). We then evaluated the values of the parameters $d, b, \alpha$, and $f_{h e}$ describing the generalized conductor about which the preceding analysis was formulated for the MFTF conductor geometry (Fig. 5-6).

In addition to a conductor design, we must evaluate the material property

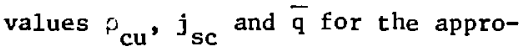
priate temperature $(\sim 4 \mathrm{~K})$ over the relevent range of magnetic field strengths $(0 \leq|\mathrm{B}| \leq 19 \mathrm{~T})$ in order to calculate the maximum allowable bulk current density from the model previously developed. For this analysis, we took the value of the average heat-transfer rate per unit of coolantpassage contact area used in Ref. 5-1: $\bar{q}=0.36 \mathrm{~W} / \mathrm{cm}^{2}$. Although the relatively low field strengths assoclated with the MFTF experiment allowed the utilization of a NbTi

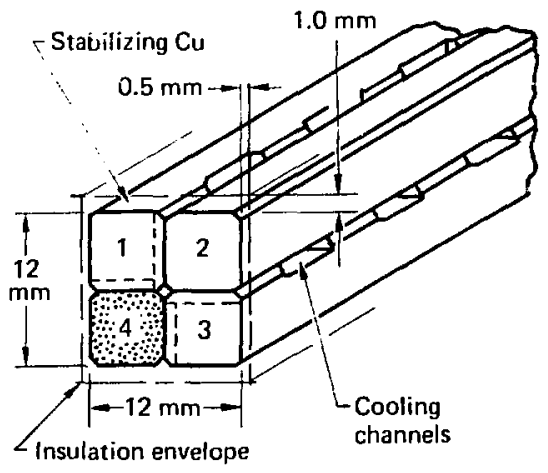

Fig. 5-6. Design of the MFTF conductor, where the variables defined in the caption to Fig. 5-5 have the following values:

$\overline{\mathbf{q}}=0.36 \mathrm{~W} / \mathrm{cm}^{2}$,

Coolant passage-conductor interface area/unit length $=53 \mathrm{~mm}^{2} / \mathrm{mm}$,

$d=12+1.0+1.0=14 \mathrm{~mm}$

$\mathrm{b}=\frac{12+0.5+0.5 \mathrm{~mm}}{14 \mathrm{~mm}}=0.93$,

$a=\frac{53 \mathrm{~mm}^{2} / \mathrm{mm}}{2(12+2)+2(12+1) \mathrm{mm}^{2} / \mathrm{mm}}=0.98$,

and

$\left.\begin{array}{l}f_{\text {in }}=0.15 \\ f_{\text {he }}=0.005\end{array}\right\}$ assumed values.

superconductor, the high field strengths required in the TMR concept necessitate the use of $\mathrm{Nb}_{3} \mathrm{Sn}$ superconductor. In estimating the allowable current density in the $\mathrm{Nb}_{3} \mathrm{Sn}$ superconductor, we used a plot of the critical current density for pure $\mathrm{Nb}_{3} \mathrm{Sn}$ as a function of magnet Ic field strength (Fig. 5-7) to provide the 


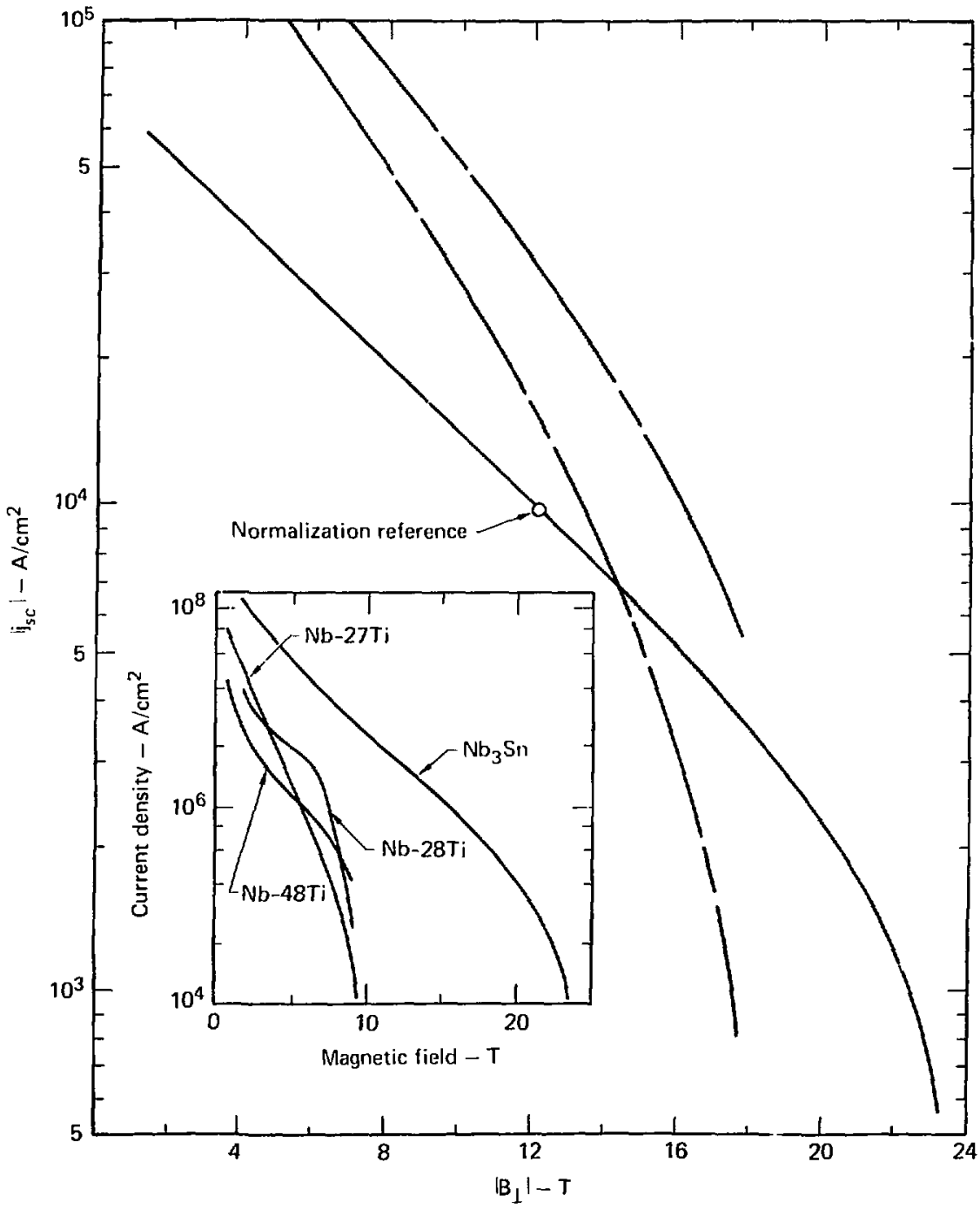

Fig. 5-7. Critical current density ror pure $\mathrm{Nb}_{3} \mathrm{Sn}$ superconductor as a function of magnetic field strength. The shaded area represents critical cur:ent density data from Ref. 5-3 for $\mathrm{Nb}_{3} \mathrm{Sn}$ multifilimentary conductors with different heat treatments. The sollid line is the normalized critical current density $j_{5 c}$. The normalization point, from $\operatorname{Ref}, 5-4$, is $j_{\mathrm{sc}}=1 \times 10^{4} \mathrm{~A} / \mathrm{cm}^{2}$ at $12 \mathrm{~T}$. Insert (taken from Ref. 5-5) shows un-normalized critical current density for three ductile alloys of $\mathrm{Nb}$ and $\mathrm{Ti}$ as well as for the $\mathrm{Nb}_{3} \mathrm{Sn}$. 
scaling of the critical current density with field strength. To include the various deleterious effects that reduce the critical current density of actual fabricated $\mathrm{Nb}_{3} \mathrm{Sn}$ superconductors, the critical field plot for pure $\mathrm{Nb}_{3} \mathrm{Sn}$ was normalized to a critical current density value representative of actual fabricated $\mathrm{Nb}_{3} \mathrm{Sn}$ superconductor $\left(j_{s c}=1 \times 10^{4} \mathrm{~A} / \mathrm{cm}^{2}\right.$ at $12 \mathrm{~T}$.

The substantial reduction in the critical current density for fabricated $\mathrm{Nb}_{3} \mathrm{Sn}$ superconductor relative to pure $\mathrm{Nb}_{3} \mathrm{Sn}$ (about an order of magnitude) results from several different factors associated with the diffusion process used to fabricate the $\mathrm{Nb}_{3} \mathrm{Sn}$ superconductor. This deterioration in critical current density for the $\mathrm{Nb}_{3} \mathrm{Sn}$ superconductor is not related to the current density limitations imposed on the complete conductor $\left(\mathrm{Nb}_{3} \mathrm{Sn}\right.$ conductor and copperstabilizing material) by the cryostatic stability criterion [Eq. (5-5)].

The resulting curve of the critical current density for a $\mathrm{Nb}_{3} \mathrm{Sn}$ conductor that was utilized throughout the remainder of this analysis is also given in Fig. 5-7. In addition, some more recent experimental data ${ }^{5-3}$ for $\mathrm{Nb}_{3} \mathrm{Sn}$ filamentary conductors are included in Fig. 5-7.

The electrical resistivity of copper is a function of both the temperature and magnetic field strength at cryogenic temperatures. The resistivity of copper immersed in a magnetic field $|B|$ at a particular temperature $\rho(|B|, T)$ may be related to its resistivity in the absence of a magnetic field $\mu(0, \mathrm{~T})$ by Kohler's law [Eq. (5-8)], which copper closely follows over a wide range of conditions: ${ }^{5-6}$

$$
\begin{aligned}
\Delta R & \equiv \frac{\rho(|B|, T)-\rho(0, T)}{\rho(0, T)} \\
& =\mathbb{E}\left(\frac{|B|}{\rho(0, T)}\right)
\end{aligned}
$$

From the definition of the magnetoresistance parameter $\Delta R$ used in Kohler's law we can develop the following relationship for the resistivity:

$$
\rho(|B|, T)=\rho(0,273)[\Delta R+1] / R
$$

where $\mathrm{R}$ is the resistance ratio,

$$
\mathbf{R} \equiv \rho(0,273 / \rho(0, T)
$$

With the magnetoresistance parameter evaluated from the appropriate plot for copper, ${ }^{5-6}$ we calculated the resistivity of copper $[\rho(|B|$, :): as a function of the magnetic field strength $|B|$ for several different resistance ratios $R$ and plotted it in Fig. 5-8. Although the resistance ratio for copper may be as high as 1400 under ideal laboratory conditions, large quantities of copper 


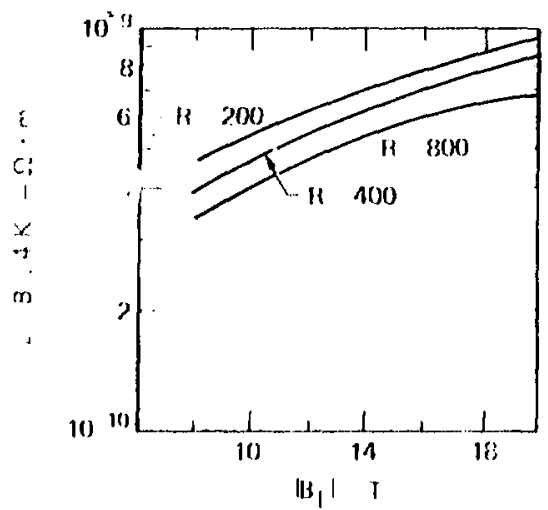

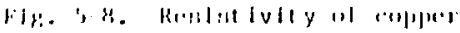
:itahillzing: mallertal, wharle

$$
\begin{aligned}
& \text { i.k } \quad \mathrm{H}(|\mathrm{H}|, \mathrm{T}), \mathrm{H}(\mathrm{l}), \mathrm{l}) \\
& \text { il(1), I') }
\end{aligned}
$$

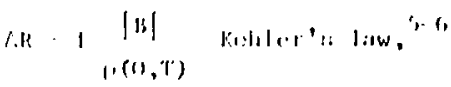

$$
\begin{aligned}
& \text { R } \quad 1(0,2,1, k) / 1,(0,4 k), \text {, } k 1,1
\end{aligned}
$$

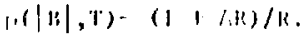

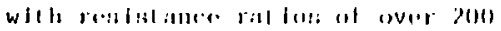

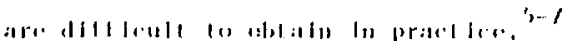

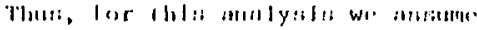

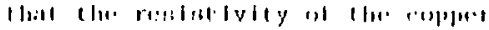

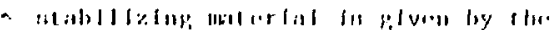

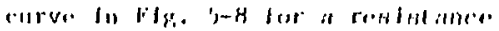
ral les is 200.

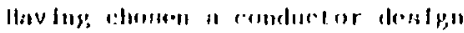

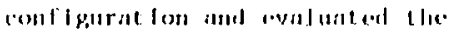

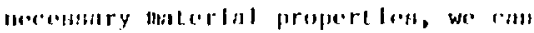

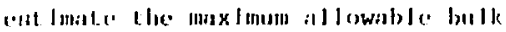
current demalty and compare to with

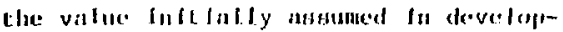

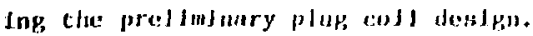
for this and ysla, we divide the cotal.

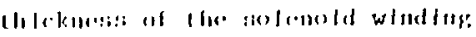

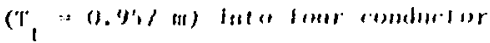
layers ol celual thlekmensi to (A:-

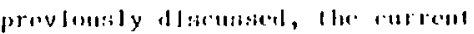

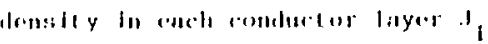

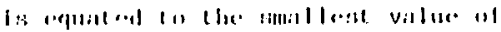

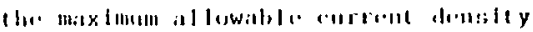

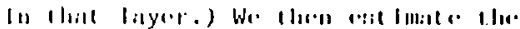

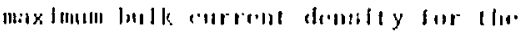

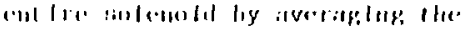

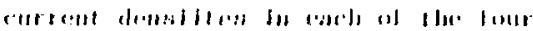

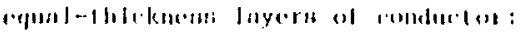

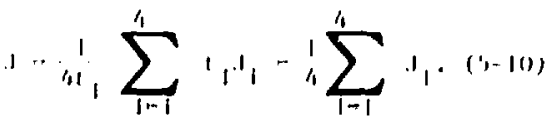

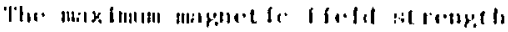

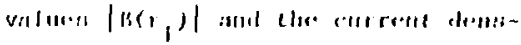

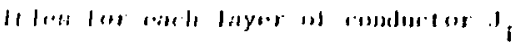

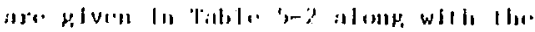

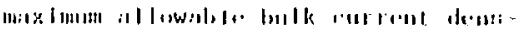

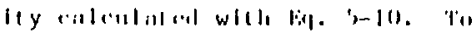

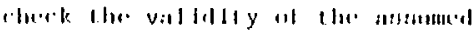

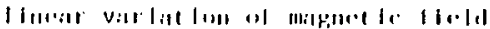

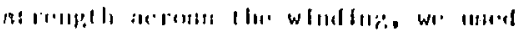

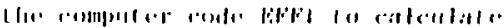

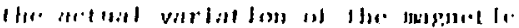

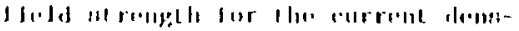

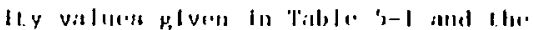

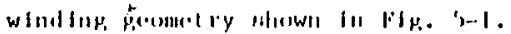

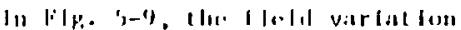

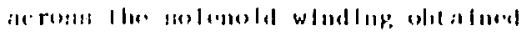

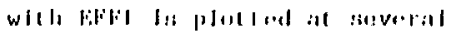

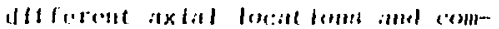

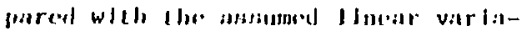

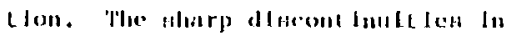
the ealenlated varlatelem of the fleld 


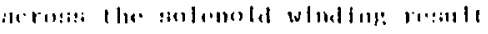

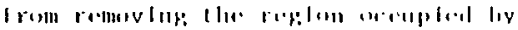

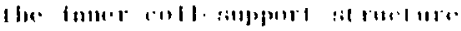

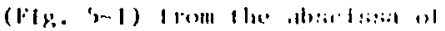

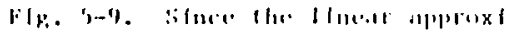

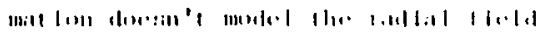

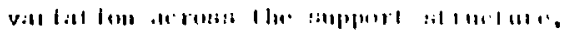

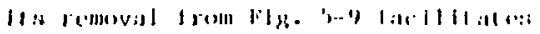

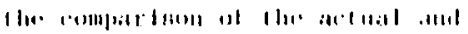
atu:a11med $\mid$ |r|al vilf fall lan.

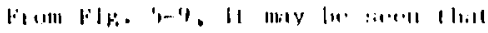

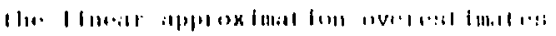

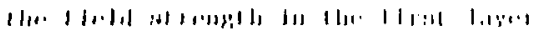

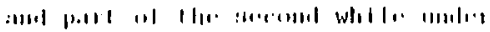

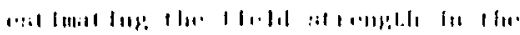

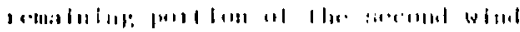

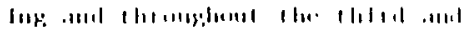

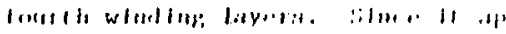

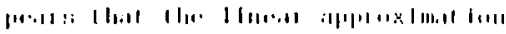

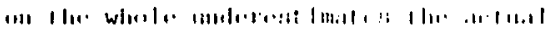

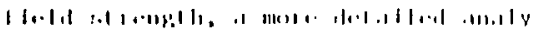

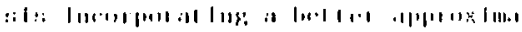

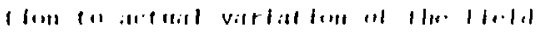

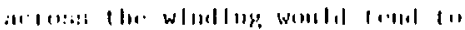

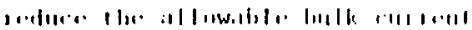

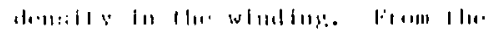

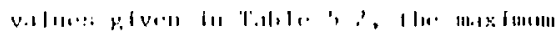

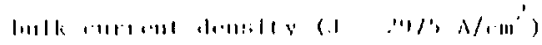

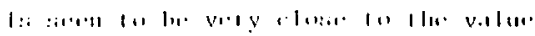

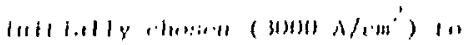

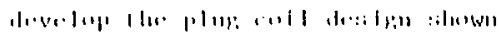

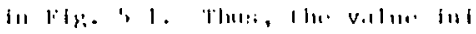

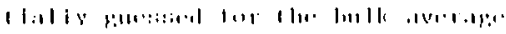

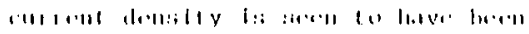

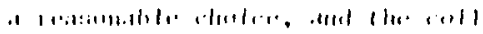

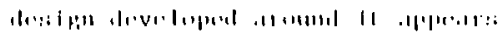

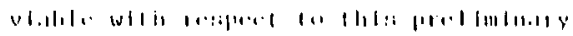

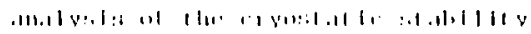
$1111,11114$.

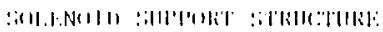

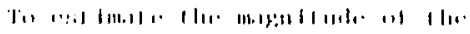

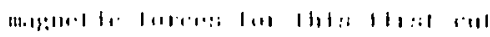

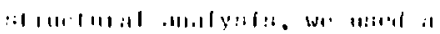

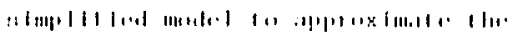

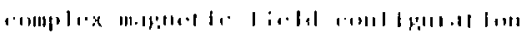

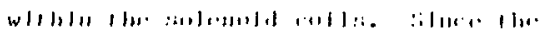

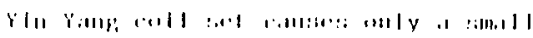

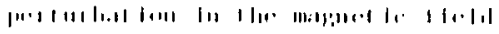

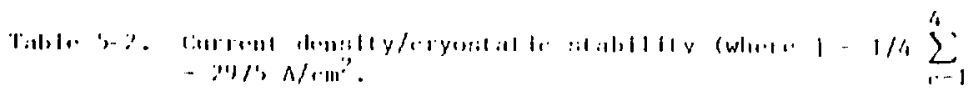

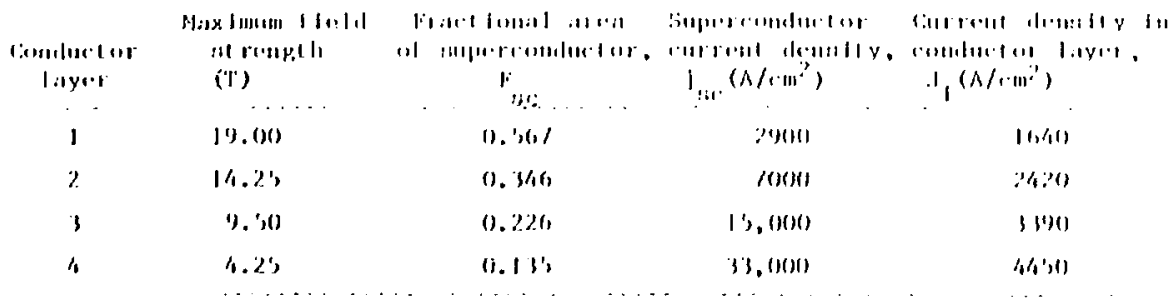




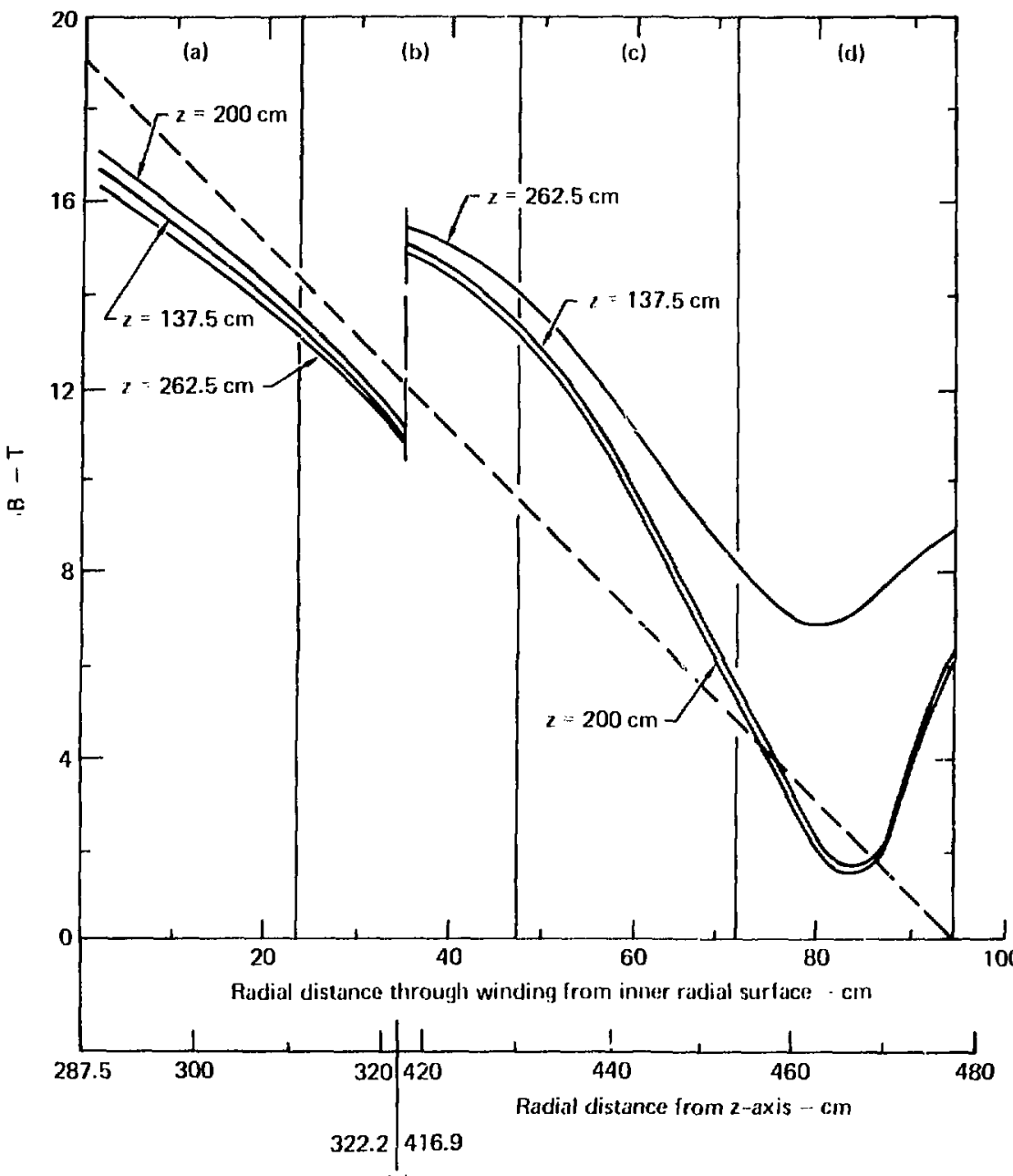

(e)

Fig. 5-9. Varlation in the magnetic field across the winding of the solenold colls in the plug coil system, where (a) is the flrst layer of conductors, $\mathrm{J}_{1}=1640 \mathrm{~A} / \mathrm{cm}^{2}$; (b) is the second layer, $\mathrm{J}_{2}=2420 \mathrm{~A} / \mathrm{cm}^{2}$; (c) is the third layer, $J_{3}=3390 \mathrm{~A} / \mathrm{cm}^{2}$; and (d) Ls the fourth layer $J_{4}=4450 \mathrm{~A} / \mathrm{cm}^{2}$. Ilhe solid lines are for calculated $|B|$ with varlable. I at three different axial locations. The lashed line is the Jnear approximation from Eq. 5-7. Line (e) marks the discontinuity resulting from the omission of the region occupled by the structure. 
genceraled by the solenuid coils, Ila. Inagnete ficta litay be ratismably approximated as axisymuetric (II) tangential component, fik. 5-1) about the 2 -axise In adaltion, L further simplily thjs anilysi:i and to be consistent with Lhe alproximi-

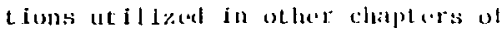

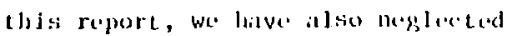

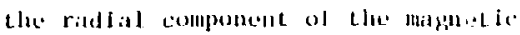

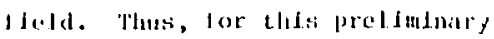

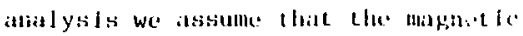
l lux delusily vectur is alwilys direcled along, the recourdinale direcel hat $|B-| \beta \mid \hat{k}]$. Io be eumbilitent with Lle eryostal to stabilfty erterion developed carliger in this chapler, we atsisume that the maghitule ol the

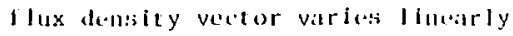
I roll a maxlmtet valule al the imare

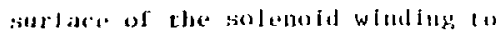
a null value at the meer surlace al Lhe. willing:

$$
|B|=B_{*}=\left(\left|B_{\text {me }}\right|\right)\left(1-1 ; / t_{t}\right)
$$

whicere

l: Lhe distince Lhrougih Llas winding from the finter surface, neglecting, the Inner coll-support structure, and

\footnotetext{
$t_{t}$ : the total wind ing thlekuest, neglecting the inner collsupport structure.
}

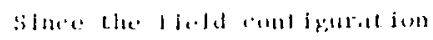

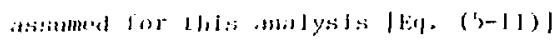

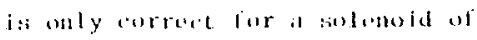

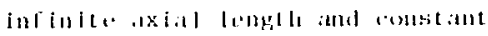

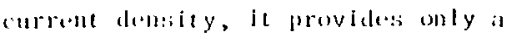

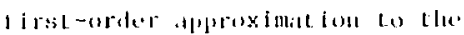

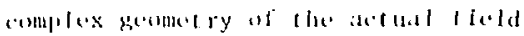
(1) i

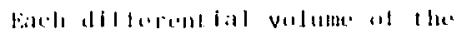

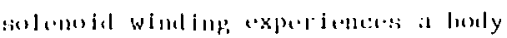

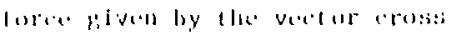

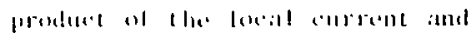

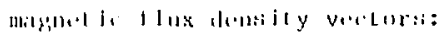

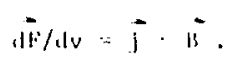

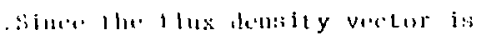

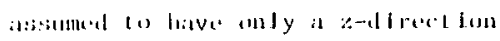

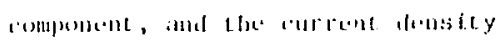
vectar iti alwaysi diratud alang the

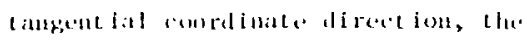

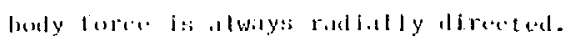

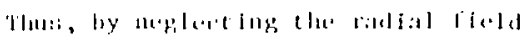

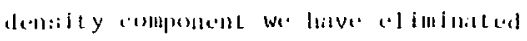

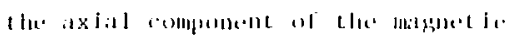

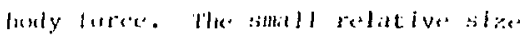

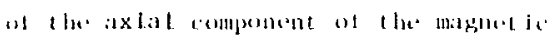

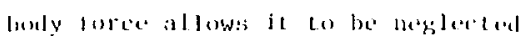

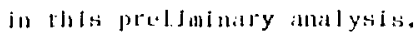

lhe radially di receted, miandele lualy forete is transmicted through the volume of each winding layer to the Ijterface of the winding layer and it:s assuciated supporting structuru. fiur a fiven current and fou-density distrlbut ion, the compressive st resti $a_{\text {ce }}$ on the Interface between clice 
windlug layer and the tupport st rueture tis determbned by the sum of all the contrlbut fons made by each different fal conductor layer across the ent lre thickness of the winding layer c. Thus, for a given max lomum allowable cumpressive stress limit

$$
r_{c c}=\int_{1}^{L}|\vec{j}| *|\vec{B}| d x,
$$

the llidkness of a particular wimlting

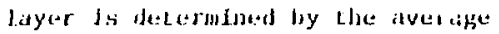
value of the frodiact of the current and the magnetic l lux dellsilles acrosti the winding layer.

With the current density values given in liable $5-1$ and the winding latyer thickness shown fin liff. 5-1, the maximu compressive stressi of the condwetor fts alsout $15 \mathrm{ks}$ l for the

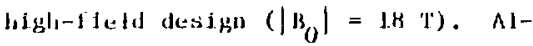
though thls peik stress level It probably is ightig above the yleid poline of fully annealed, high-purity copper (-J0 to ll ksi, lifi. 5-10), a very modest amount of strain hardenfing will raise the yleld polnt above $15 \mathrm{kst}$ (lig. 5-10). Since (as w111 be discussed short1y) the condurtor must be straln lardened by drawing in order for tit to wichstand the tensile loading along its axis, the compressive yteld stress transverse to the conductor may well exceed the fully annealed balue. If compressive stress levals of $15 \mathrm{ks} 1$ are

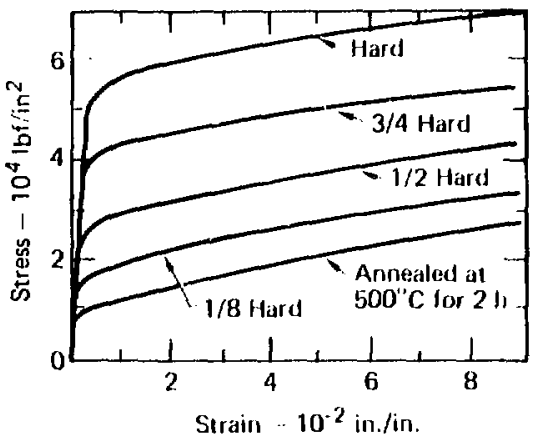

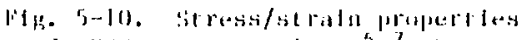
uf olill: copper at a $k, 5-7$ where $i_{4} k=17.2 \times 10^{6} 11,1 / 11^{2}$.

determined to be too high, they may lie reduced with little design penalty by dividing the solenolds into it Targer number of propurt iotially chinner combetors and is ruelure layers.

In addition to lle 1 ransiverse compressive stress exerted on the conductor, the deflect ton of its supporting structure under the mishnetic: loads will load the conductor in tension. Unlike the transverse compresslve stress previously ronsidered, It is nut clear that this axlal tensile stress an be substantially reduced by separating the solenold windings lato more layers. Since the cylindrfical structure supporting the second conductor layer can be made very thick, and since the magnetic forces are smaller in the second conductor layer, the maximum teusile stress expertenced by the 
conductor will atur in the illat

layer ul condustors.

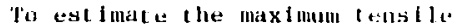
stress level in the first romiactor layer, we developtad two : Impl I I $1 \mathrm{tat}$ calculat ional models of the tirst combartor layer and its support strutule. IJ the fifit molel, we neglected the strength at the rondurtor

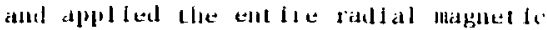

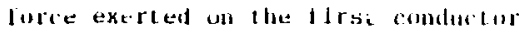
layer to the fanet siretace of the

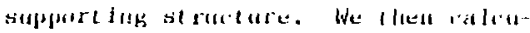

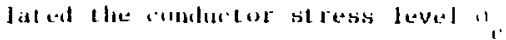

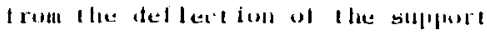
st ructure hy eqpad Ing the romductur lump strain , with the support strusIure Juop bt laill "s.

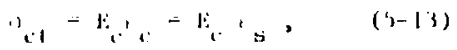

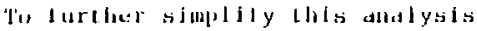

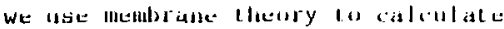

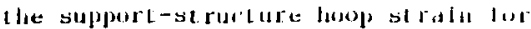
d rylindrlial pressure vessed. Thus, besides meglea' ing the strelighl wi the winding layer, hils sjuplet talcalatjon also neglecis lhe finile thidkfless at the shppore structure jtsell:

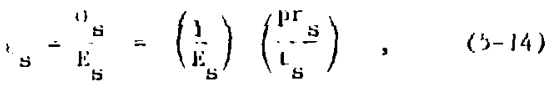

where

$$
\begin{aligned}
& \mathbf{r}_{B} \doteqdot \text { mean radlus of struclure, } \\
& p=\text { pressure on liner surface } \\
& \text { of structure }=a_{\text {ce }} \text {, and }
\end{aligned}
$$

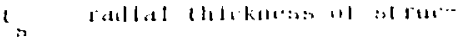

$$
\begin{aligned}
& \text { IUI: }
\end{aligned}
$$

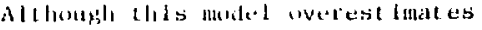

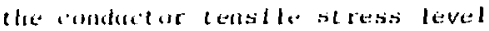
by neglecting the strellght af thes

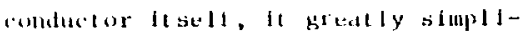
lies the stiultual raldulat limb by

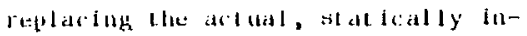
diterimbate cull strutetute with a slmplifilel, statlially detellalmate

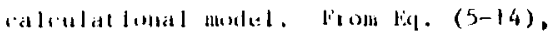

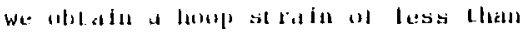

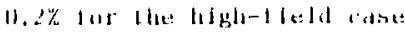

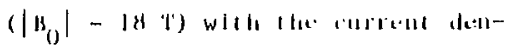

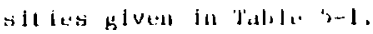

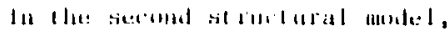

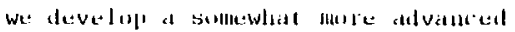

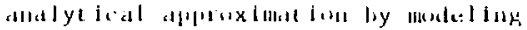

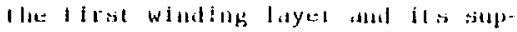

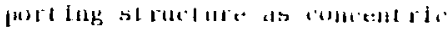

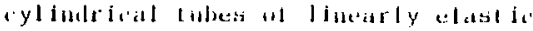

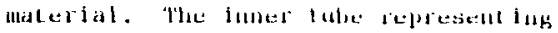
the I irsil whating layer is louded ill

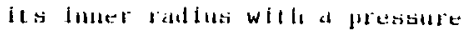

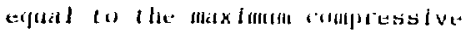

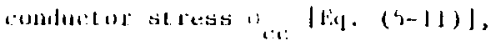
whife its unter ranius iti foaded will,

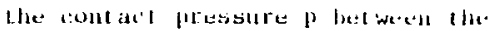
rombetor fayer and its smpporting

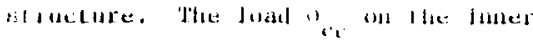

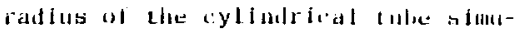
lating the condular layer model i the maghet lo budy force dist ribuled tiroughout libe conduclor volinme. since the structural streugth of the conductor has not been neglected in 
this model, the contact pressure between the structure and winding layer will be less than the maximum compresstue stress. How much less will depend on the relative stiffness of the winding layer and its support structure. The outer tube representing the support structure is loaded on its inner radius with the contact pressure between the winding layer and the support structure.

Although this model is more sophisticated than the preceding one, the replacement of the magnetic force distributed throughout the volume of the winding layer with an equivalent load applied to the inner surface of the winding layer appears to underestimate the deflection of the support structure and the conductor tensile stress level. Since the conductor and its support structure form a stat 1cally indeterminate structural system, the contact pressure between the winding layer and its supporting structure must be determined from an auxiliary condtion.

The contact pressure may be analytically determined by equating the relationships developed from the theory of elasticity for the displacement of the outer surface of the coil winding layer with the inner surface of the supporting structure: $\left[\left(\frac{m+1}{m-1}\right)+1\right]\left\{\left[\frac{G_{c}}{G_{s}}\right]\left[\frac{R_{c}^{2}-1}{R_{s}^{2}-1}\right]\left[\left(\frac{m-1}{m+1}\right)+R_{s}^{2}\right]\right.$

$$
\begin{aligned}
& \left.\left[\left(\frac{m-1}{m+1}\right) k_{c}^{2}+i\right]\right\}^{-1} \\
& =f\left(m, G_{s}, G_{c}, k_{s}, k_{c}\right),
\end{aligned}
$$

where

$$
\begin{aligned}
& R_{c} \because \frac{\text { outside radius of winding ? yer }}{\text { inside radius of vinding layer }}, \\
& R_{s} \text { outside radius of structure } \\
& \text { inside radius of structure }
\end{aligned}
$$

$i_{s}$ - shear modulus of structure,

; : shear modulus of winding layer, and

$$
m-\frac{1}{N v}=\frac{1}{\text { (Poisson's ratio) }} \text {. }
$$

With the contact pressure determined, the maxinum hoop strain in the winding layer may be analytically determined from the solutions of the equations of elasticity for a cylindrical pressure vessel

$$
\begin{gathered}
\varepsilon=\frac{\left[f\left(m, G_{s}, G_{c}, R_{s}, R_{e}\right) o_{c c}\right]}{E_{s}} \\
\cdot\left[\frac{1+R_{s}^{2}+\frac{1}{m}}{\left(R_{c}^{2}-1\right)}\right] .
\end{gathered}
$$

From Eq. (5-16), we determined that the hoop strain for the high-field case with the geometry given in ' Fig. 5-1 is approximately $0.14 \%$. 
As anticipated, the second structural model yields a loser conductor hoop strain thatn the first model. Since the hoop strains calculated with either the first or second structural model imply stress levels of about 25 co $35 \mathrm{ksi}$, far above the yield stress of annealed copper ( 11 to $12 \mathrm{ksi}$ ), either the copper stabilizer material must be work hardened or a method must be developed to prestress the coil support structure. Since work harciening the copper stabilizing material will substantially increase its electrical resistance at cryogenic temperatures (between 2 to 4 times, see Fig. 5-11), the maximum allowable current densities calculated carlier would decrease. Hlowever, since the increase in resiscance due to the magnetic field at high field strengths is much greacer $(\angle R \approx 10$ at $|B|=18 \mathrm{~T}$, Fig. 5-8) than the work-hardening effect, the redustion of the maximum

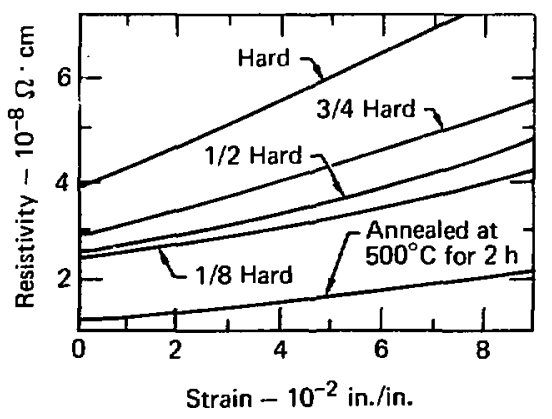

Fig. 5-11. Resistivity/strain properties of OFHC copper at $4 \mathrm{~K} .5-7$
1] luw.lble current thensity by work hardening will be more noticeable in the low-ficld regions of the solenoid winding.

Thus, when the work-hard ning resistance increasc is added to the magneto-resistance effect previously considered, the current density in the high flux density regions of the solenoid winding is not greaty affected. llowever, the maximum allowable current density in the low flux density regions of the solenotd winding is substantially reduced if the copper stabilizing matrial is work hardened. If we are to maintain the central field strength, a reduction in the solenoid current density necessitates an increase in the soletnoid winding cross section from the design illustrated in Fig. 5-1.

In addition to the strength of the copper stabilizing material, the brittle nature of the $\mathrm{Nb}_{3} \mathrm{Sn}$ superconductor material also imposes limitations on the conductor hoop strain. It was experimentally determined that multifilamentary conductors of $\mathrm{Nb}_{3} \mathrm{Sn}$ could withstand tensile strains of approximately $0.6 \%$ without degradation in the critical current density. The ability of the conductor to withstand such large strain values was attributed to an initial prestressing of the conductor resulting from the difference between the thermal expansion coefficients of the niobium filaments and 
the copper stabilizing material. Thus, it appears thit prestressing the suphort structure to reduce conductor strain is not necessary.

INTERNAL STRUCTURE OF TIE Y $2 N-Y A N C$ COLL

We shall now determine the maximum value of the average current density for the cryogente-aluminum Yin-Yang winding shown in Fig. 5-1 as a function of the maximum allowable value of the local current density. Jor a given maximum local current density and : magnetic field strength in the conductor, the average current denstiy is decermined by the fraction of the current-carrying conductor that is displaced by the noncurrent-carrying internal-support structure. From the structural analysis discussed here, the fraction of the Yin-Yang coil cross section that must be reserved for the internal structure is determined for all three of the magnetic designs, For the high-ficld case $\left(\left|\mathrm{B}_{0}\right|=18 \mathrm{~T}, \mathrm{Fig} .5-1\right)$, we consider the design of the internal structure in more detail in order to determine the thickness of the plates between adjacent layers of conductors. With the fractlor of the winding cross section occupled by the internal structure (average structural fraction f) determined from the analysis contained here and with the average currert density values initially ut llized to develop the magnetic design, we may determine $i$, the local value of the current density in the cryogenlc-aluminum conductor necessary to achleve the desired magnetic performance :

$$
j=\bar{j} / \bar{f} .
$$

After determining the therma] design implications (coolant passage length and arca fraction, pumping power, coolant pressure, etc.) of operating at the desiced conductor current density from the conductor thermal analysis described later under "Thermel Analys Is of the Cryogenic Y1n-Yang Col1," we can assess the feasibility of the magnetic design bassed on the init lally assumed average current density values.

Because it greatly simplifies this prelimlnary analysis and because it represents a reasonably valid approximation, we estimate the magnitude and direction of the magnetic forces acting on the conductors by assuming that they are immersed in a spatially uniform, axtal-direction ( $F 1 g$. 5-1) magnetic field at the field strength of the mirror point. This assumption neglects the perturbations in the magnetic fleld strength and geometry caused by the finite length of the solenoid windings and the Yin-Yang coils themselves. Since the magnetic force system exerted on the TMR YinYang coil differs conslderably from 
a conventional Yin-yang coil system, a sketch of the magnetic forcc systein is presented in Fig. 5-12. The sketeh was developed by applying the lorent: force law to the Yin-Yang coil winding immersed in the assumed uniform axial ficid.

To est Imate the averagc structural fraction for the Yin-Yang coll winding, we used the Intermal structure configuration for the winding cross section of the major are where the magnetic forces are strongest ( $x \%$ plane, Fig. 5-12) to size the intermal structure over the ent ire length of the coil winding, Slnce with this assumption the internal structure is sized by the maximum value of the magnelic forces, whereas in an actual design it may be possible to rexhece the size of the internal structure where the magnelic fories are smaller, this estimation process is prohably conservat lve. However, al more sophlsticated malysis of the alverage structural fraction would require a more detalled destgn of the internal structure involving consideration of che important and difficalt problems assuclated with fabrlcating and

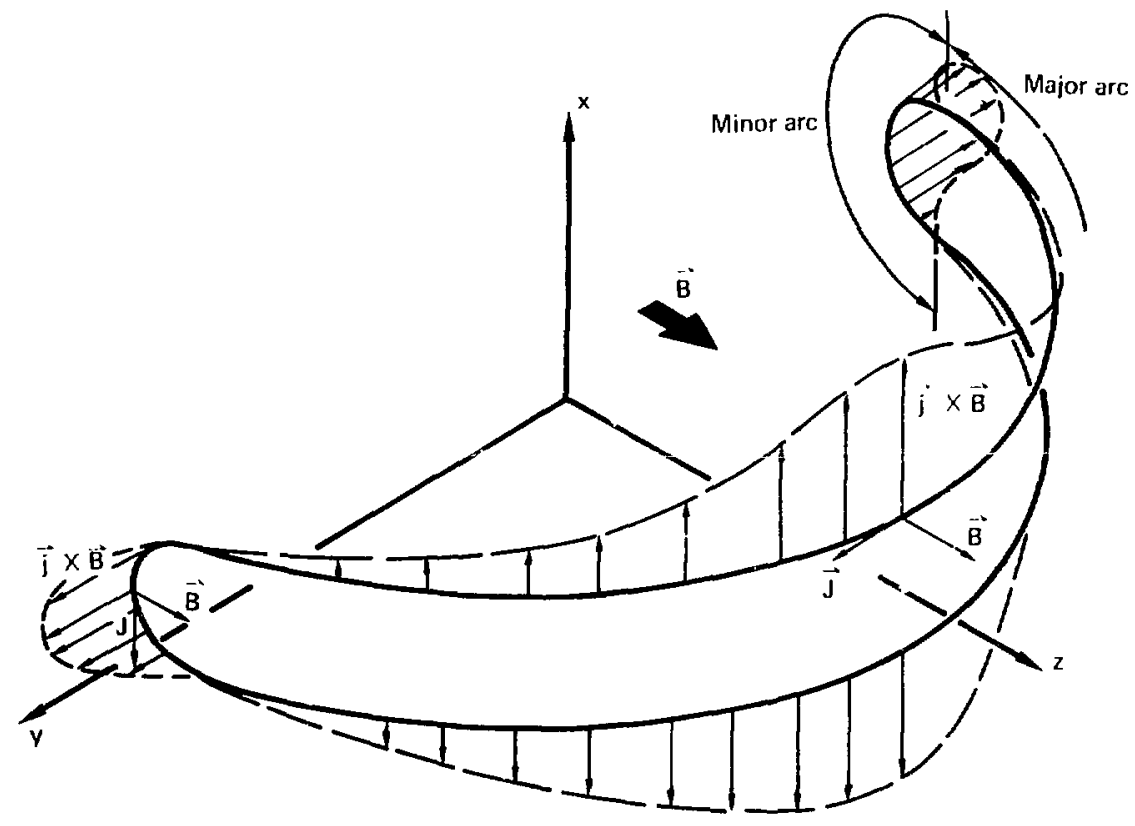

Fig. 5-12. Magnetic force syst in the TMR Yin-Yang coil. 
assemb]ing an actual winding. Such a design effort is beyond the scope of Lhis prejiminary design study. Another serlous desjgn problem neglected in this analysis it: ansur? by the abrupt change in the directional orjentation of the local manetic force with respect to the Yin-Yang winding cross section between the major and minor ares. If the colimms of the internal structure are orfented in the direction of the mignet is force along the major arc ( $x$-direction, Fig. 5-1), the magnet le are will be transversedy oriented to the columns of the internal structure alons the minor radius. 'lhus, either the ortentation of the internal structure columns relative to the wini ing tross section must be changed becween the major and ininor ares, or che plates scparating adjacent conductor layers must be redesigned to support the magnetic forces along the minor ares. Although this change in loading poscs a formiclable structural chatlenge, the very small maguitude of the magnetic forces in the transition region between the major and minor ares may allow the relative orlentation of the internal structure columns to be rotated along the direction of the magnetic forces.

We determined the average structural fraction for the Yin-Yang winding cross section in the $\mathrm{xz}$-plane. In this structural design, the winding conductors are divided inco a serles of layers ( $F i z$. S-l, detall $(\mathrm{C})$ whose thickness is chosen to limit the compressive stresis in the conductors. The magnetic forces distribuled over cach layer are transferred by the internal st ricture to an external structure. The internad structure In a layer of conductors consists of a series of compressively loaded columns that transfer the Lotal magnetie force destributed over all the proceeding conductor layers through Lhe condector layer under consideration. Since the columns do not contant the conductors in the layers they pass through, the conductors in each layer are subjected only to the magnetic forces dlstributed throughout their own volume. $A$ flat plate is used between each layer of conductors to transmlt to the columns the total magtec ic force distributed over the preceding layer of conductors.

After passing through the last layer of conductors, the columns transmit the load from the preceding conductor layers to the external. structure supporting the Yin-Yang coil winding. Since the columns are carrying the cumulative total of all the magnetic forces distributed over all the preceding layers of conductors, they must become larger and larger as they approach the external structure (1ig. 5-1). Thus, because of the increasing amount of current-carrying 
conductor displated from rach additional conductor layer by the intornal structure, each additional conduc:or layer lowers the average current density. In ajdition, as the winding thicknesis is increased by adding additlonal conductor layers, the internal structure eventually displaces the conductors, lius sezt ins an absolute limlt to the current-carrylng capacity of a conductor of 1 ixed width.

Iles thickness of ciath condutelor bayer $t$ is delermined by the requiter ment that the compresisfve stress on the outer surliace of the conductor layer be equal to the mixjmun allowible design stresis of the conductor "e" since the annealed, lofgh-purity aluminum used in the cryogenic-alumlnum conductor is very weak (o yp $\approx 2$ to $3 \mathrm{ksi}$ ), we treat it ils an incompresssible fluid that transfers the magnetic body forcesi to the internal structural system and the external case surrounding the coll winding. Thus, the maximum allowable conductor design stersis is decermined by the strength of the coolant passage ducts located inside each conductor rather than by the high-purity conductor material itself. In this analysis, we assume that the coolant passage ducts are con structed of high-strength, aluminumalloy tubes around which the lowstrength, higf-purity conductor material is extruded into a conductor of square cross section (as shown
Jata in Fis. :-1's). If we nosloct bucklins and atsitulu a ral to between

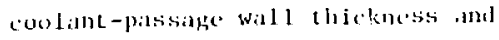
the coulant-pastage radius ol about $0.15,1$ he miximum al lowable conductor st ressis vilue is ahout $1.101^{8} \mathrm{~N} / \mathrm{m}^{2}$ (15 k:i ). With Lhe alisumed constant matgnetic $\mid$ ield strength $|B|=\left|B_{\text {mp }}\right|$ and with the loxal current density in the conductur comstint at the max Inum allowable valus j, the thickness uf cach layer of comductors is ebustisut inkl mity lo determined by the

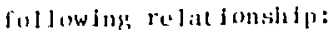

$$
\mathrm{L}=\mathrm{g} /(\mathrm{j} 13)
$$

'lite Itaction of each conductor laycer occupled by the internal strucLure (lowal struclural fract lon $i_{\mathrm{si}}$ ) may be decormined in terms of the locil struceural fraction of the precedlug layess by Lles following relat ionship:

$\left.r_{s i}=(1)_{i}(1){ }_{H}\right)\left[(i-1)-\sum_{i=1}^{i-1} i_{s i}\right]$. $(5-19)$

Gubition $(5-19)$ wiss derived by requiring that the internal structure in a conductor layer support the magnetle forces distributed over all the preceding layers without exceeding $o_{s}$, the maximun dusign stress of the struccural materlal. Since the structural fraction of the first layer 


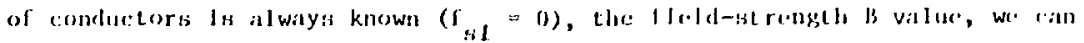
lid. (s-19) may be applled stecesess lvely begtunlag wels the first comductor layer tes determlare the st ructural fractions of each layer of conductors. The average structural f ract Ion of a Hiven windlikg de!tlg;n, whlch wlll mot in ginerad constist of an Integper mumber af equal-Lhleklassa windlup, Jayore $\mid L$, lig. (s-18) J, ls siven by

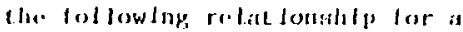

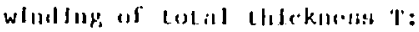

$$
\begin{aligned}
& 1 \quad T / 1=\left[\sum_{i=1}^{11^{*}}\left(1+1_{: 11}\right)\right] \\
& +\mid\left(11-11^{*}\right)\left(1-j_{: 11} k 1.1\right),
\end{aligned}
$$

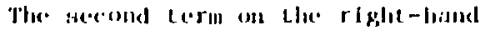
sicle of lig. ('x-20) repretientat l.he contrlbut fon to the average at rectural fract on from the liats couductor layer, which in porneral tes not nis thlek ass the preceding layers. When the atmultancous system of epuat tom formed by lias. $(5-18)$ and $(5-20)$ Is fecratively bolved with the approperinte material property values o ${ }, O_{H}$, athd 


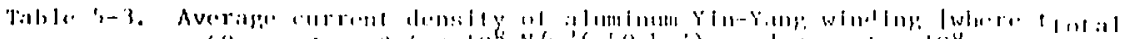

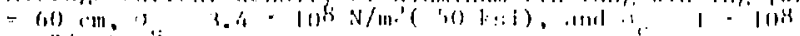
N/m? $P(1 ; 1 ; i) \mid$.

\begin{tabular}{|c|c|c|c|c|c|c|c|}
\hline 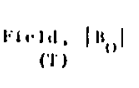 & 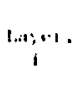 & 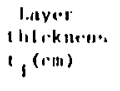 & 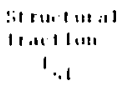 & 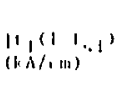 & $\begin{array}{c}1 / W \\
(H N / * \cdots)\end{array}$ & $\left(n / 1+m 0^{\prime}\right)$ & (Milmi) \\
\hline \multirow{3}{*}{15} & 1 & $\therefore .111$ & 0. & 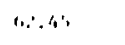 & \multirow{3}{*}{116.11} & \multirow{3}{*}{ וניויו } & \multirow{3}{*}{$\therefore 111$} \\
\hline & ' & $\therefore .10$ & 11..214 & and & & & \\
\hline & 1 & $11 .: 7$ & (1. : 'ו1) & $\{11.1\}$ & & & \\
\hline \multirow{4}{*}{ IA.' } & 1 & 14.14 & $(1.11111)$ & 'H. H' & \multirow{4}{*}{ t's." } & \multirow{4}{*}{$\therefore 1$} & \multirow{4}{*}{ แнแ" } \\
\hline & $\therefore$ & $14.11 / 4$ & (1..."I)/4 & (4.1: & & & \\
\hline & 1 & Ік."॥ & 11. '11: & $\therefore .111$ & & & \\
\hline & 4 & 1.111 & $13,6 t+B$ & 1111 & & & \\
\hline \multirow{5}{*}{ 1H } & 1 & 11.11 & 11.tunt & יו" & \multirow{5}{*}{$1 ; 1 . . . k$} & \multirow{5}{*}{$\therefore 14$} & \multirow{5}{*}{ Inin' } \\
\hline & $\therefore$ & 11.11 & 11.. & 11.11 & & & \\
\hline & 1 & 11.11 & 1). ',1)' & $\therefore 11 \%$ & & & \\
\hline & 4 & 11.11 & $11.1,4,4$ & 13.31 & & & \\
\hline & ', & I..', & 11. 12. & 1.111 & & & \\
\hline
\end{tabular}

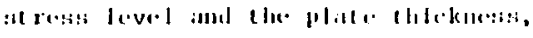

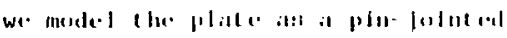

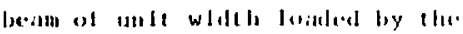

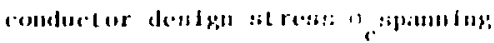

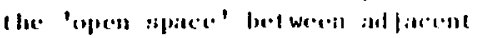

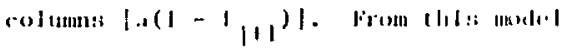

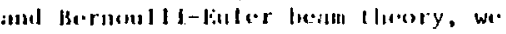
develoj l he lollowlap relal lombilit) for the requlted plited ladekmensi ol

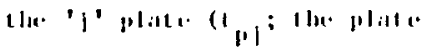
Hepitral lap, the 'f' and '| 1 ' (conductor Jiyeru):

$t_{p j}-\left(\begin{array}{c}\sqrt{3} \\ 2\end{array}\right)+\left(\begin{array}{l}11 \\ 1_{s p}^{c}\end{array}\right)^{1 / 2}\left(1-1_{1+1}\right)$

$(5-21)$

Thls relut fombla neplects the: elfeces of the plate geometry nat of

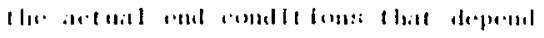

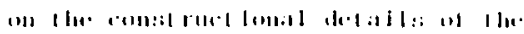

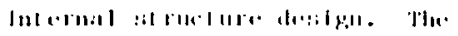

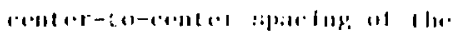

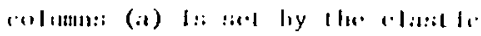

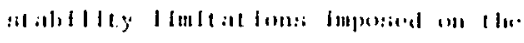

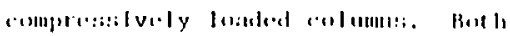

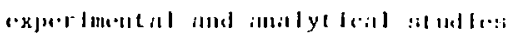

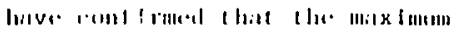

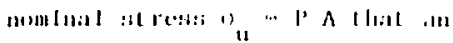

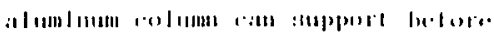

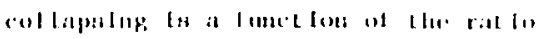

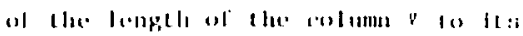

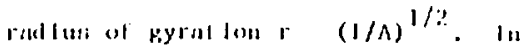

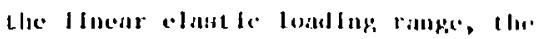

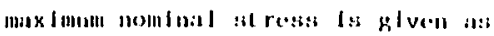
"f funce lon al the elast le modulus and

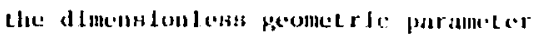
$\mathrm{k} v / \mathrm{r}$ by the liuler relatlonshl, 


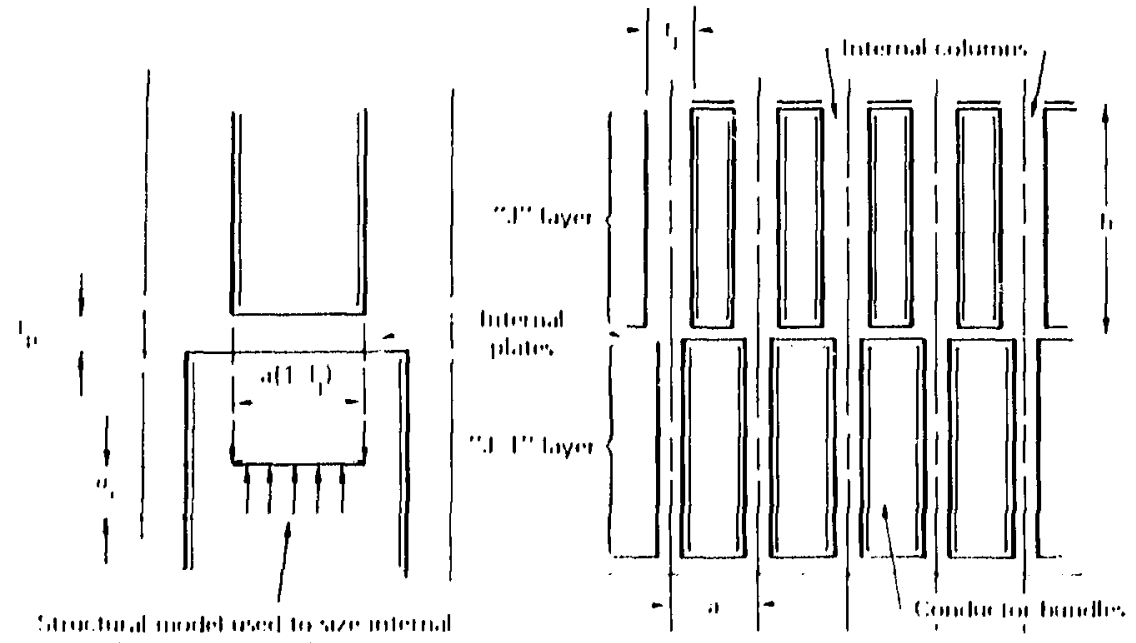

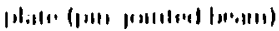

\begin{tabular}{|c|c|c|}
\hline $\begin{array}{c}\text { I ay:! } \\
\text { til!. }\end{array}$ & $1_{1}$ & $\begin{array}{c}1 \\
\mid 1 \\
1 \\
1\end{array}$ \\
\hline 1 & $(1.0(1)()$ & $N \wedge$. \\
\hline$\%$ & (1). & $1.1 \%$ \\
\hline 3 & $(1) !(1) ?$ & 2.21 \\
\hline 4 & ().Gin & 0.18 .1 \\
\hline ! & (0. & 3.10 \\
\hline
\end{tabular}

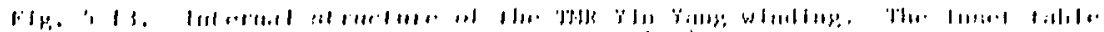

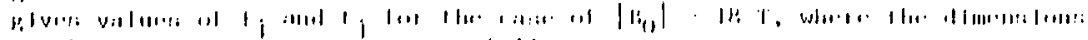

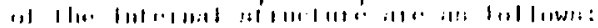

$$
\begin{aligned}
& n-4, \therefore, 2, \\
& 1-1.14 \text {.'ll, }
\end{aligned}
$$

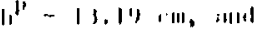

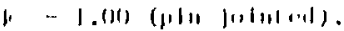

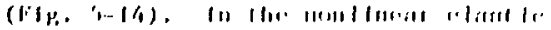

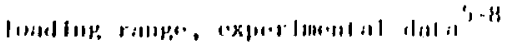

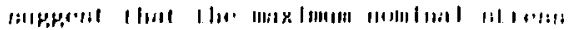

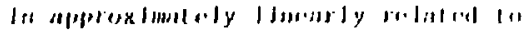

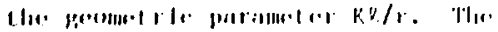

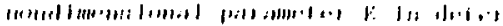

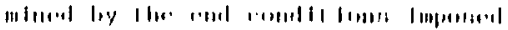

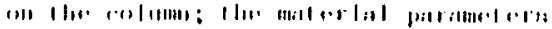
ll,

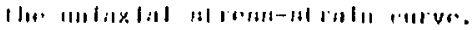



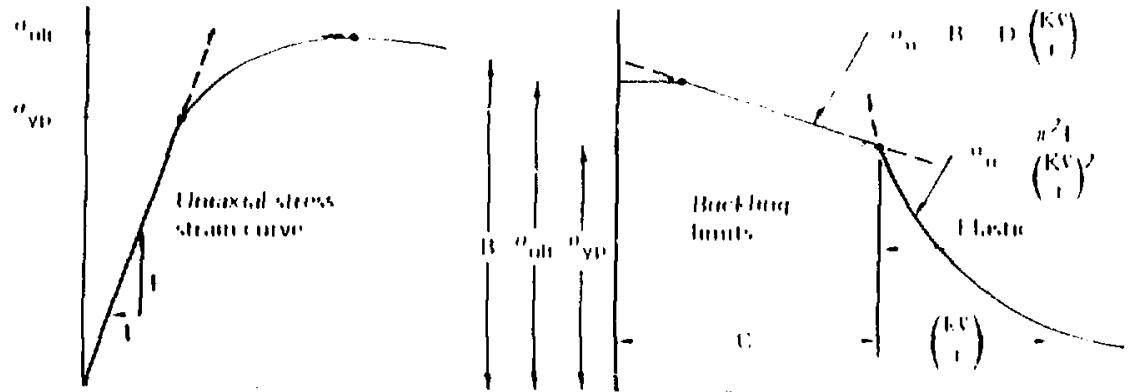

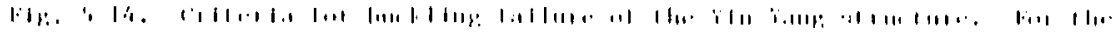

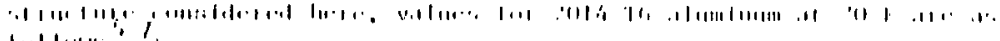
$1,11,1, \cdot 1$,

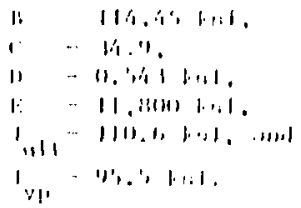

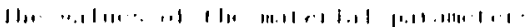

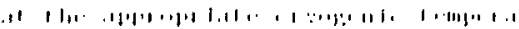

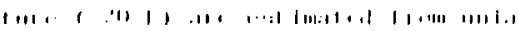

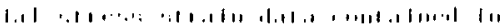

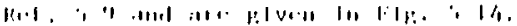

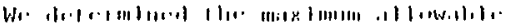

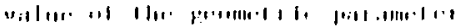

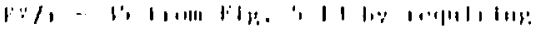

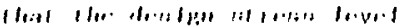

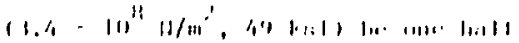

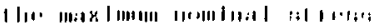

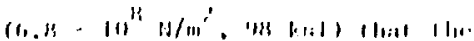

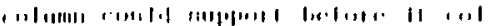

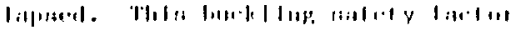

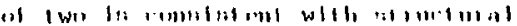

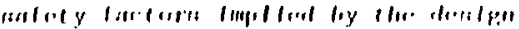

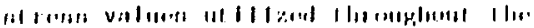

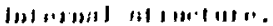

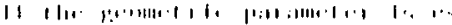

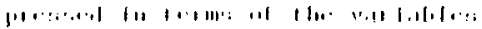

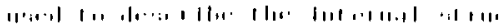

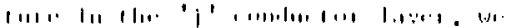

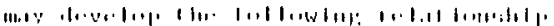

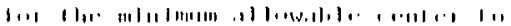

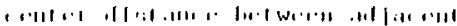
(1111111: 1.1, ):

$$
\therefore\left(\begin{array}{c}
\therefore 1 \\
i
\end{array}\right)\left(\begin{array}{l}
11 \\
1,
\end{array}\right), \quad(1, \therefore)
$$

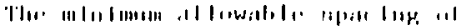

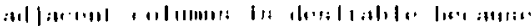

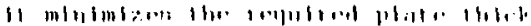
irita |lid $(1,, 1) \mid$.

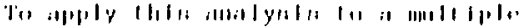

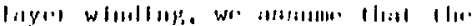


columns in each conductor layer are located on common centers (Fig. 5-i) whose spacing is set by the mintmum allowable spacing in the second conductor layer $\left[a_{s}, E q .(5-22)\right]$, With this arrangement, the second conductor layer is operating with a buckling safety factor of two, whereas the other conductor layers have buckling safety factors greater than two. The calculated dimensions of the internal structure components are tabularized In Fig. 5-13. From the plate thicknesses given there, it may be seen that the assumption that the plates did not significantly reduce the average current density is justified.

Next, we shall develop a thermal analysis of the cryogentc-aluminum conductor in order to determine the feasibility of the local current density values required to attain the average current density values used in the magnetic design.

THERMAL ANALYSIS OF THE CRYOGENTC YTN-YANG COIL

In this section, we shall evaluate feastbility of operating the cryogenic Yin-Yang coil at the desired local current density values (Table 5-2).

The feasibility of operating the coil at a particular current density level is primasily determined by the thermal design implications of the assoctated Joule dissipation power density. For a given current density, the Joule disstpation is determined by the electrical resistance of the aluminum conductor $\rho_{A l}$. Since for a given level of impurities, the resistance of the aluminum conductor material Increases very abruptly if the conductor temperature is raised above about $20 \mathrm{~K}$ (Fig. 5-15), the

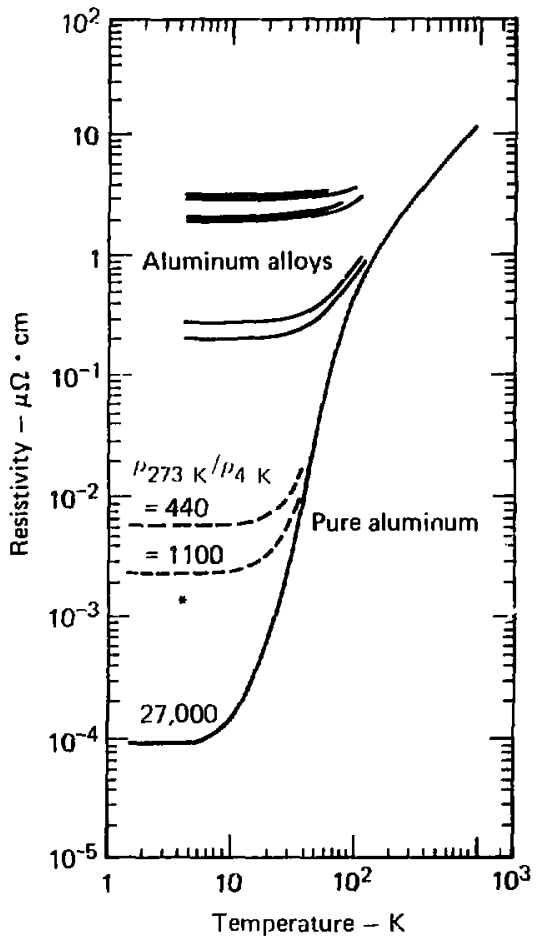

Fig. 5-15. Electrical resistivicy of pure aluminum and of aluminum alloys as a function of temperature (from Ref. 5-10). The asterisk narks the data point $[p(0,4) \approx 1.2$ $\left.\times 10^{-3} \mu \mathrm{A} \cdot \mathrm{cm}\right]$ used in preparing Fig. 5-17. 
out let temperature $\mathrm{T}_{0}$ of the helium coolant must not be over about $20 \mathrm{~K}$. The inlet temperature of the helium coolant is limited by the rapid degradation of the refrigerator coefficient of performance as the coolant temperature is Lowered. Because of this, the refrigerator power requirements appear to 1 imit $\mathrm{T}_{i}$, the inlet temperature of the hellum coolant, to temperatures disov about 12 to $15 \mathrm{~K}$. Thus, compared to many other more conventional heat-transfer systems, the cooling system for a cryogenic-aluminum coil must uperate within a very narrow temperature range $\Delta \mathbf{T}=5$ to $8 \mathrm{~K}$.

We can express the thermal design implications for a cryogenic-aluminum Yin-Yang coil in terms of a local and a global design requirement. Local'y at each point along the conductor, the total temperature rise required to transfer the Joule dissipation from the interior of the conductor to the helium coolant itself must not rause the conductor temperature to substantially exceed $20 \mathrm{~K}$. Because of the high conductivity of the aluminum conductor and its smal1 physical size, the temperature difference required for the conductive transfer of the Joule dissipation energy to the surface of the heliumcoolant passage appears to be insignificant relative to the convective film drop. Thus, for this preliminary anal; sis it appears that the conductive temperature difference can be neglected and only the film drop $\Delta \mathrm{T}_{\mathrm{f}}$ need be considered in formulating the local criterion.

In addition to the local design requirement discussed above, the cooling system for a nunsuperconducting, steady-state coil winding must be designed so that the global temperature rise $\mathrm{AT}$ of the coolant over the entire length $\ell$ of each coolant passage is not excussive. Since the global temperature rise is seu rely constrained in a eryogenic-aiuminum coil system $A T=5$ to $8 \mathrm{~K}$, there is a severe limitation on the length : of the coojunt passages between inlet and outlet manifolds. N1thougin the impact of the coolant passage length on the eoil. design is difficult to quantify without performing a much more detailed design study, the design of the inlet and outlet manifolding will probably become much more difficult as the coolant passage length becomes shorter.

'l'o analytically evaluate the design requirements discussed above, we must choose a conductor contiguration. For this study, we developed the conductor design shown in Fig. 5- $1 t$ where we assume that the square, highpurity aluminum conductor has been extruded around a thin, high-strength, aluminum-alloy cooling tube in the center of the conductor. The geometry 


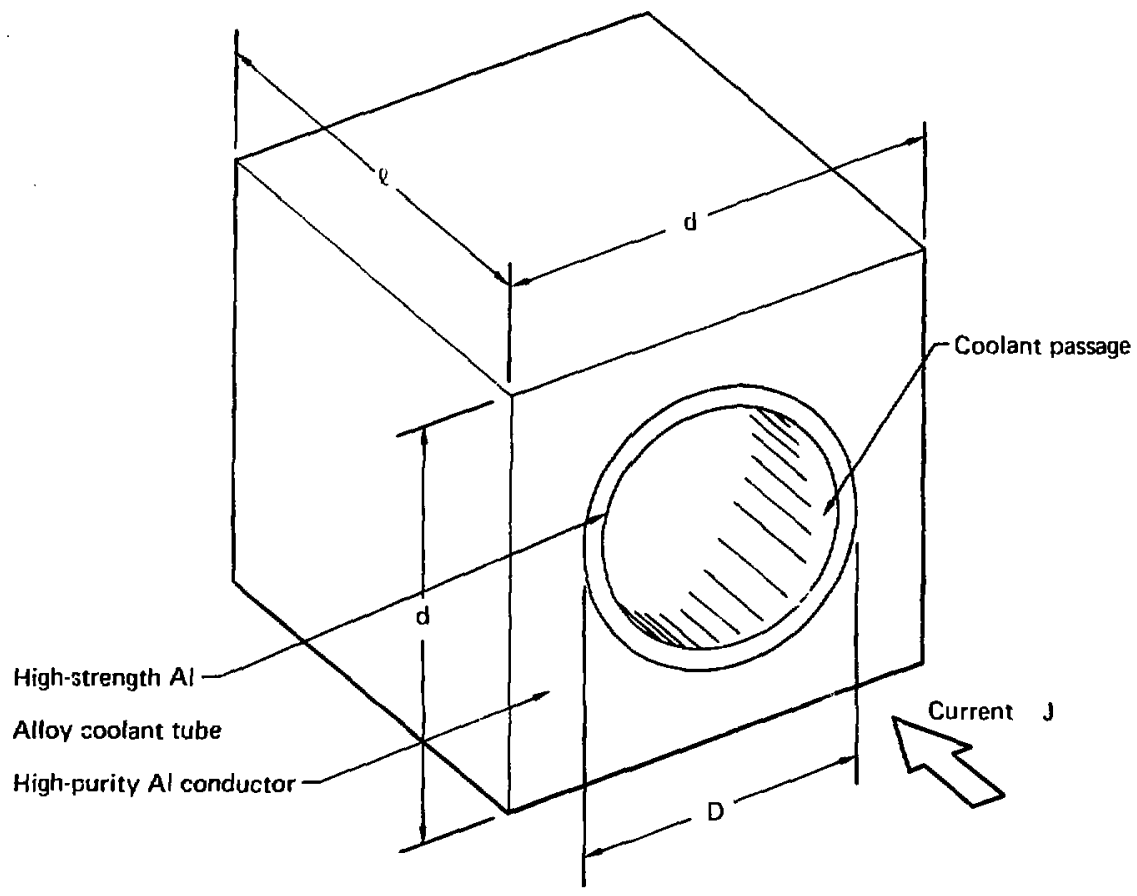

Fig. 5-16. Cryogenic aluminum conductor the Yin-Yang coil, where $f \equiv \frac{\text { cross-sectional area of the coolant duct }}{\text { total cross-sectional area of the conductor }}$.

of the conductor assembly (cooling tube and surrounding conductor) is determined by the ratio of the coolant duct to the conductor cross-sectional areas $f$, the dimension of the conductor side $d$, and the length $\&$ of the coolant passage between inlet and exit manifolds.

To analytically evaluate the thermal tmplications of the local design criterion, we develop a relation- heat transfer to the helium coolant.

ship between the current density and the film drop,

$$
\Delta T_{f}=\left[\frac{(1-f) d}{(\vec{u} f)^{1 / 2}}\right]\left(\frac{P_{A l}}{2 h}\right) j^{2},
$$

where the Joule dissipation power in a differential length of conductor is equated to the rate of convective 
Since the conductor ross section is assumed constant alon; each conductor, the terms enclosed $L_{;}$the brackets on the right-hand side of Eq. (5-23) are constant along a given coolant passage. The convective heat transfer coefficient $h$ is determined from the coolant parameter values with the following version of the Reynold's analogy :

$$
\left(\frac{h D}{K}\right)=0.023\left(\frac{\overrightarrow{D Q u}}{i}\right)^{0.8} \text {. }
$$

where

$k=$ thermal conductivity of helium coolant,

$C_{p} \because$ specific heat of helium coolant,

$\mu \equiv v i s c o s i t y$ of helium coolant, and

$\overline{\mathrm{pu}} \equiv$ mass velocity of helium coolant.

The electrical resistivity of the aluminum conductor $\rho_{A 1}$ is a function of its purity, temperature, and flux density. Thus, for a particular current density, coolant parameter values, and conductor design, the film drop is fixed for a given conductor temperature $T_{c}{ }$. Since the outlet temperature of the coolant is approximately determined by subtracting the film drop from the maximum conductor temperature $\left(\mathrm{T}_{0} \approx \mathrm{T}_{\mathrm{c}}-\Delta \mathrm{T}_{\mathrm{f}}\right)$, the $f$ ilm drop must be kept quite low $\left(\therefore \mathrm{T}_{\mathrm{f}} \lesssim 1 \mathrm{k}\right)$ Lo prevent a significant reduction of the alrcidy small global tomperature rise. $A$ decrease in the global temperature rise reduces the length of the coolant passages. The local therhal design requirement expressed by Eq. (5-23) is conceptually similiar to the cryostatic stability critcrion developed for the superconducting solenoid windings [Eq. $(5-3)]$.

To analytically evaluate the implications of a particular current density value with respect to the global design requirement, we develop the following relationship between the coolant passage length and the global coolant temperature rise fror the irst law of thermodynamics:

$$
\Delta T=\left(\frac{2 h \Delta T_{f}}{\overline{\rho u} C_{p}}\right)\left(\frac{1}{d} \sqrt{\frac{\pi}{f}}\right) \ell .
$$

In developing this relationship, we neglect frictional dissipation and evaluate the bulk properties of the coolant at the mean coolant temperature.

To evaluate the film-temperature drop and coolant-passage length for a given current density, we must deternine the value of several coolant parameters. Since the coolant entrance and exit temperatures are largely determined by the use of cryogenic-aluminum conductor material, only the coolant pressure must be 
speciffed to determine the thermodynamic properties of the helium coolant. In this Eirst-cut analysis, we somewhat arbitrarlly $11 \mathrm{mit}$ the coolant pressure to about $4 \mathrm{~atm}$.

In addition to the thermodynamic properties of the helium coolant, to evaluate the film temperature and the length of the coolant passage the mass velocity $(\overline{\rho u})$ of the helium coolant must also be specified. The mass velocity of the coolant is 1 imited by the large refrigerator power required to remove the friction dissipation power from the coolant at those very low temperatures. To evaluate this limitation, we develop an analytical expression from the first law of thermodynamies for the ratio $P$ of the pumping poner to the Joule dissipation power for an entire coolant passage. This relationship assumes an isentropic reversible pumping process:

$$
\begin{aligned}
P & =\left(\frac{\overline{\rho u} c_{p_{1}}}{j^{2} \rho_{A 1}}\right)\left(\frac{F}{1-f}\right) \\
& \cdot\left[\frac{1-\left(P_{0} / P_{1}\right)}{\ell} \frac{Y-1}{Y}\right],
\end{aligned}
$$

where

$P_{i} \equiv$ entrance coolant pressure,

$\mathbf{P}_{0} \equiv$ exit coolant pressure, and

$\gamma \equiv c_{p} / C_{v}$ for helium coolant.
We determine the ratio of outlet to inlet coolant pressures, neglecting compressfbility effects, from the folluwing relationshtps:

$$
\begin{aligned}
& \mathrm{P}_{i}^{2}-\mathrm{p}_{0}^{2}=2 \mathrm{RT}(\overrightarrow{\mathrm{ru}})\left(\frac{\mathrm{f}_{\mathrm{m}}}{2 r_{\mathrm{n}}}\right), \\
& \mathrm{f}_{\mathrm{m}}=0.00140+0.125 / \mathrm{Re}^{0.32},
\end{aligned}
$$

where

$\bar{T}=$ mean coolant temperature,

$\mathbf{R}:$ perfect gas constant,

$\mathbf{r}_{\mathrm{h}} \equiv$ hydraulic radius, and

$\operatorname{Re} \equiv$ Reynold's n'smber $=\frac{D \overline{Q u}}{\mathrm{~b}}$.

Since the pumping power rat lo calculated with Eqs. (5-26) through (5-28) does not include either the nonisentropic behavior of a real pump or the pressure losses in the coolant passage manifolding, the calculated pumping 2ower ratio must be yery small ( $P \leq 0.1$ ) to avoid significantly increasing the refrigeration costs. We determine the resistivity of the high-purity cryogenic aluminum conductor as a function of flux density for a representative conductor temperature $(20 \mathrm{~K})$ from a previous analysis in Ref. 5-6 (see $\mathrm{F} 1 \mathrm{~g}$, 5-17).

To determine the thermal design implicatjons of operating the cryogenicaluminum Yin-Yang coll at the desired current density level $\overline{\mathrm{J}}=3949 \mathrm{~A} / \mathrm{cm}^{2}$, 
Table 5-3), we calculate the global temperature rise $\therefore T$, film temperature $\therefore T_{F}$, pumping power fraction $P$, pressure ratio $\mathrm{P}_{0} / \mathrm{P}_{i}$, exit coolant $T_{0}$, and conductor temperatures $T_{c}$ from the previously developed relationships for typical coolant parameters (Table 5-4). All these calculations are based on the current lensity required for the high-fleld case

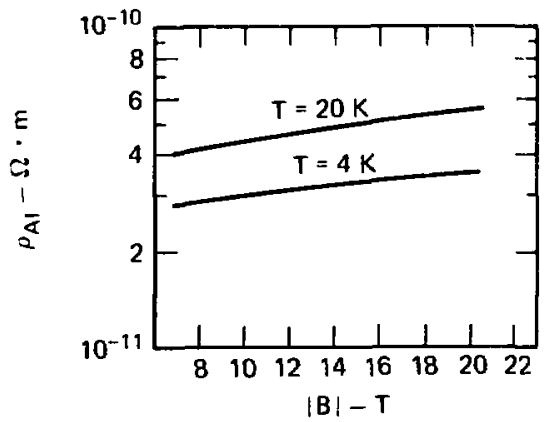

Fig. 5-17. Resistivity of high-purity aluminum (using magnetoresistance data from Ref. 5-6, where

$$
\begin{aligned}
& R \equiv \frac{\rho(0,273)}{\rho(0,4)}=2100, \text { and } \\
& \rho(0,273)=2.5 \times 10^{-8} \Omega \cdot M .
\end{aligned}
$$

$\left(B_{0} \approx 18 \mathrm{~T}\right.$ illustrated in $\mathrm{Fig}, 5-1$. From Table 5-4, it is seen that for the high-field current density the length of the coolant passage is less than the circumferential distance around the coil winding $(\vec{B} \approx 13.8 \mathrm{~m})$. Thls in combination with the relatively small size of the conductors - 576 conductors are required to $[111$ the Yin-Yang cross section - implies a large number of parallel coolant paths. If the $13.8-\mathrm{m}$ circumference of the Yin or Yang coll is divided into two 6.9-m coolant paths, then about 1150 parallel coolant paths are required for each coil winding ( $Y$ in or Yang).

In addition to the large number of coolant passages, the inaccessible location of the passages, which are deep within the winding, will further complicate the coil design. Although we have not considered it in this preliminary study, the development of a manifolding system capable of servicing a large number of of ten inaccessible flow passages while

Table 5-4. Coolant passage length in cryogenic-aluminum coil [where $\mathrm{d}=0.025 \mathrm{~m}, \mathrm{f}=0.15, \mathrm{p}_{\mathrm{i}}=4.04 \times 10^{5} \mathrm{~N} / \mathrm{m}^{2}(4 \mathrm{~atm})$, $\overline{\mathrm{ou}}=220.3 \mathrm{~kg} / \mathrm{m}^{3}, \mathrm{~T}_{i}=15 \mathrm{k}, \overline{\mathrm{j}}=3949 \mathrm{~A} / \mathrm{cm}^{2}$, and $j=4700 \mathrm{~A} / \mathrm{cm}^{2} \mathrm{j}$.

\begin{tabular}{llllll}
\hline$\ell(\mathrm{m})$ & $\Delta \mathrm{T}(\mathrm{K})$ & $\mathrm{T}_{0}(\mathrm{~K})$ & $\mathrm{P}_{0} / \mathrm{P}_{i}$ & $\mathrm{p}$ & $\mathrm{T}_{\mathrm{c}}(\mathrm{K})$ \\
\hline 7.5 & 4.30 & 19.30 & 0.945 & 0.082 & 20.11 \\
10.0 & 5.73 & 20.73 & 0.926 & 0.083 & 21.54 \\
12.5 & 7.16 & 22.16 & 0.907 & 0.084 & 22.97 \\
\hline
\end{tabular}


satisfying the additional requirements Imposed by structural, electrical, and constructional considerations appears very difficult. Thus, although a cryogenic-aluminum Yin-Yang coil design with the required current density appears thermally feasible, the relatively short allowable coolant passage length "..p probably less than one clrcumferential length around the coil - rendars the development of a complete design for a cryogenicaluminum coil a formidable and as yet unsolved design challenge.

\section{REFERENCES}

5-1. F. H. Coensgen, H\% Hajor Froject Iroposal, Lawrence I Livermore Laboratory, Rept.

LLL-Prop-142 (1976).

5-2. G. A. Carlson, Parometric Design Study of Tondem Mirror Fusion Reactors, Lawrence Livermore Laboratory, Rept. UCRL-79092 (1977); see also Chapter 10 of this report.

5-3. H. Hillmann, H. Kuckuck, H. Pfister, G. Rupp, E. Springer, M. Wilhelm, K. Wohleben, and and r. Ziegler, "Properties of :ultifllamentary $\mathrm{Nb}_{3} \mathrm{Sn}$ Conductors," in Fron. Sererom-

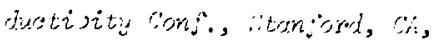
1976 (in preparation).

5-4. C. E. Taylor, Lawrence Livermore Laboratory, private communication (1977).

5-5. Z. J. J. Stekly, "State of the Art of Superconducting Magnets,"

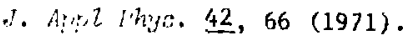

5-6. F. R. Flckett, "Nagnetores isttivity of Copper and MIuminum at Cryogenic Temperatures," in Prore. Fourtin Intomational cons. Axg. Tesh. $197 \%$ (p. 540-1).

5-7. D. N. Cornish, Lawrence Livermore Laboracory, private communication (1977).

5-8. Azroa structural Handbook, Aluminum Company of America, Pittsburg PA (1958).

5-9. Handbook on Materiats for Surerconducting "lachineny, (1974)

p. 4.2 1-10.

5-10. S. J. We1ls, Chemical Composition and Electrical Resistivity of Aluminum AlZoys, Hughes Aircrat: Company, Rept. AFML-D5161. 


\section{IAPTER 6. TMR NICIAONICS}

\section{$\therefore \therefore$}

Summary . . . . . . . . . . . . . . . . . . . . . 129-130

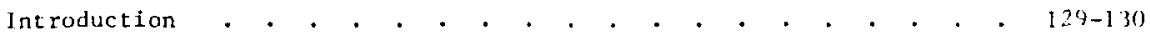
Shielding the Yin-Yang Cails . . . . . . . . . . . . . . 131 Central-Cell Blanket and Shielding . . . . . . . . . . . . 140

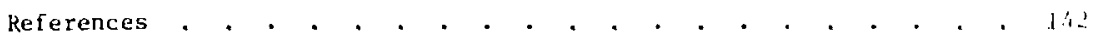


SUMMAKY

He have con seled prelimliniary nucleonles appraflath of the shicldeng requidred for tha YIn-Yany maspels in the TMR plugs and of the central-ced blanket composition that would provide a Lrithumbreeding ratio of 1.10). It. wats spectifled that shleldlng for the plus, coll tmust :

- bimit Lutal nuclearjy induced heilt ing lo the coll ind cold st ruselure (1) $10 \%$ of the $1^{2} \mathrm{~K}$ lecite ling in the infrratliatiol coll,

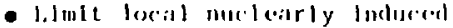
heat Jus: Lo three t Imesi the and tradlated values: innd

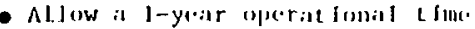
between room-temperature annealat of Hhe cryopenla islumfnum in Lhe Yis-Yang maggnols. Calculat [ons showed that an

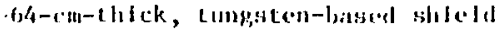
wenld meet these reejulrements,

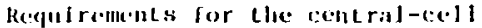
blanket and shfelding would be mel by

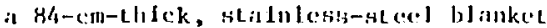
that comtalns lifuld llthlum. Such a blanket would have a trittum-breedfing rat lo of 1.10 and would provile an energy multelicat for of 1.20 .

\section{IN'RODUC'IION}

Irit lum breeding, conversion of thermonuclear neutrons to heat, radlitton damage, actlivation, and component and blolospical shfelding, are ald important nucleonlets stbjects that must be combledered In the destgin of a fosion reactor. for llifs initial appralsal of the tandem mlrror reactor (IMR), the I imjterl rucleonits effort expended was concentrated in Lwo areas:

- Sililedalng requlred for the endplay Yan-Yang: coils.

- Cuntral-cedl blankel.

l'rotorelins, Lhe Yan-Yank plup colls, which are made of alumbum and destaned (6) be llsart al cryogende temperatures,

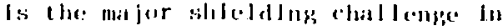

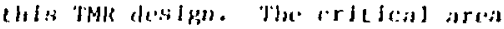
appear:i Lu be al the Juner mirror of

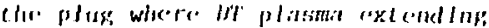

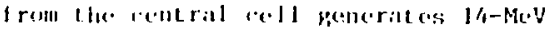
ment roms: all at silgnilleatre race.

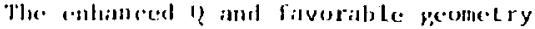
of the rentral coll allow us to conLomplate a blanket of modest perform-

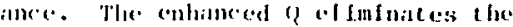

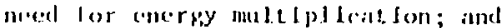
the very low areal for noulron st reaning (f rom the liarge length-to-dfameter rate of the cylindrical central cell) coupled with no requirement for energy mulefplicall fon leads; Lo onl.y a mlnlmal

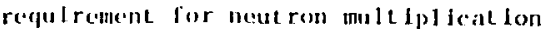
In the blinket. Sur overall objective is to keep the blanket as stmple and Incopenstve as poss lble. Shleldinf for the super conduct ing colts of the centril cell. Is In the 90 cms between the blanket and the colls, NInety $\mathrm{cm}$ of steel- and loakl-based shielding 
plus che blanket stomid provide more than emough procert ion tor thesic eojls.

SHIFIJING; THE: YIN-YNNC; (i) 113

Tlue plasmat plugst at cither emel ol the JNIR are conf loced by mintmum-ls

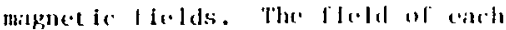
plust fa generaled by a pait at cryop:enle-allaninum, Yin-Yallp collts

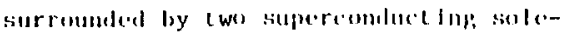

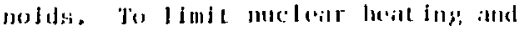

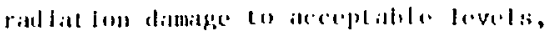
both :

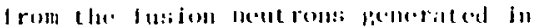
lesth the platima plugti ame th Ihe

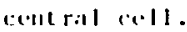

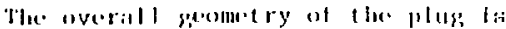

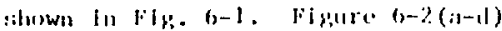

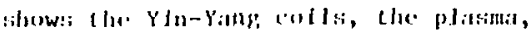

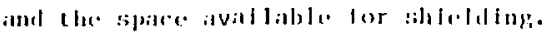

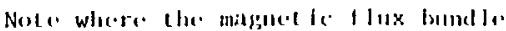
entafolug the plasmat patsises botwenth

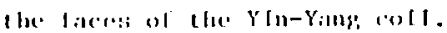

slifeldlup Llere is; a ma jor elial lempe beraluse splece lis at a premfutll. Alsu,

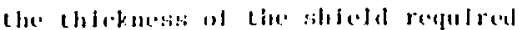

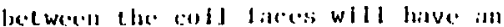
Important eifect on the overall size: af tha plus; and thus on its cost. Plgure 6-2 shows a 90-cm sepnracton between the faces of the Yh-Yans coll, a plastnil thickncess of $50 \mathrm{~cm}$, ind a plasma width of 90 to 100 est. A 5-cm-ehlek vacutum boundary itrumal the. plasmia provefales roum for the $3.5 \mathrm{MeV}$ alpha particjos with thefr l.5-cm

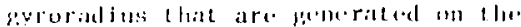
outer l fold liness. flac remalnings

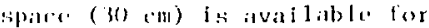

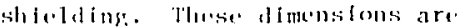
approximalely consistall with the plibs

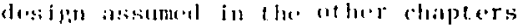
of lhi:a reporl and are a startios:

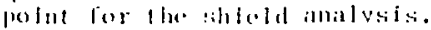

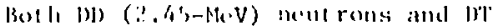
$\left(1 / .1-M_{1} \cdot v\right)$ neal rons ar. produed in

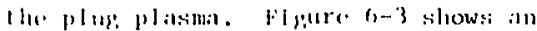

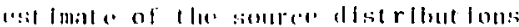
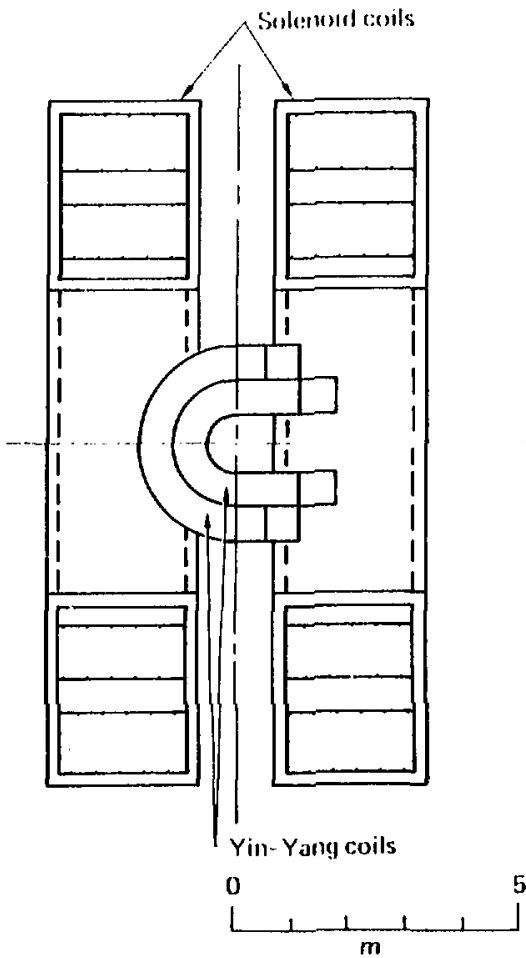

Fip. 6-1 . ciometry ol the 'JMk pluk. 


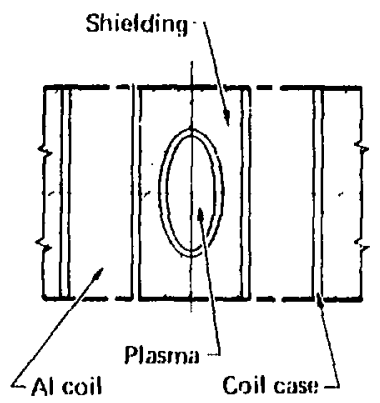

(a) Siect. A-A

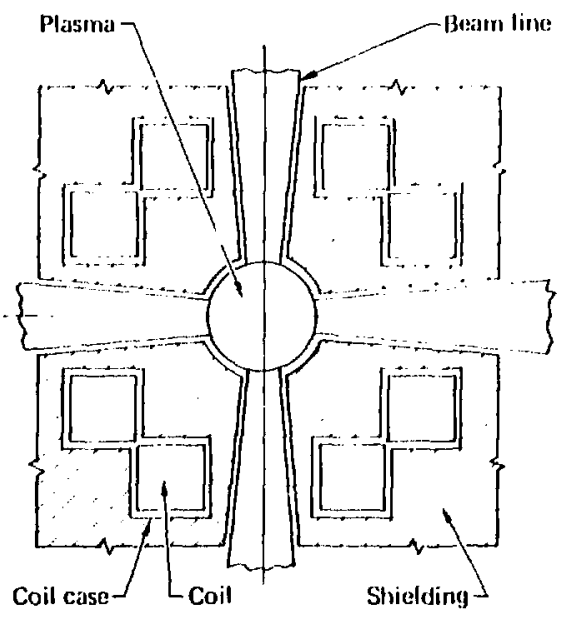

(b) Sect. B-B

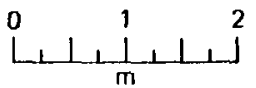

Fig. 6-2, Cross sections through the tMR plug, showing space avallable for shlelding. 


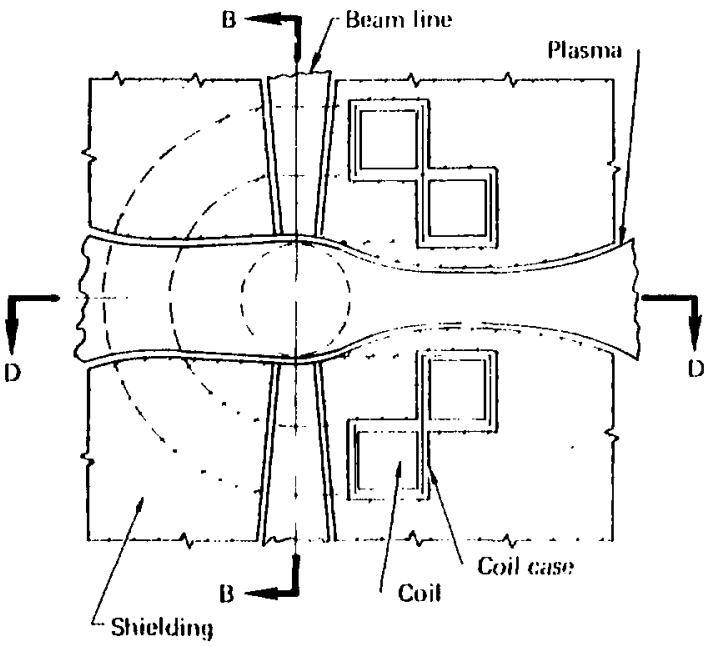

(c) Sece. C-C

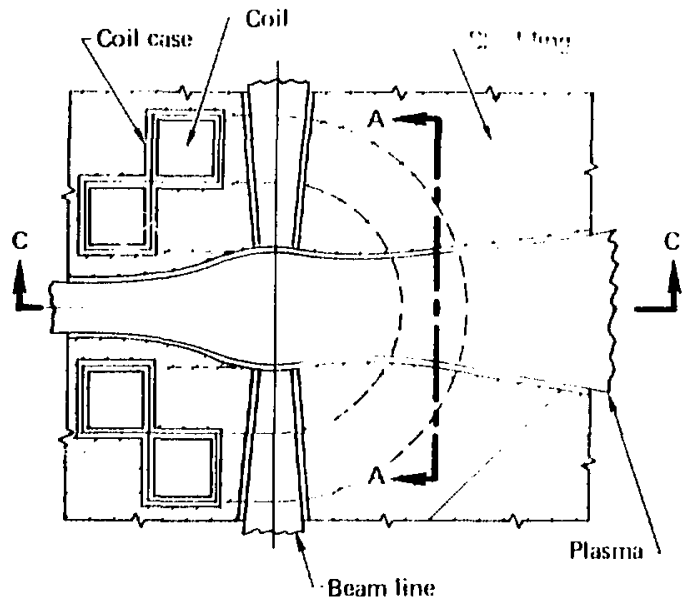

(d) Secı. D-D

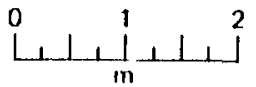

Fig. b.2 (cont Inued) 


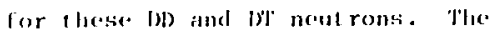
zera polnt on the \%-(hortzontal.) axlis Is: the plug, rontar; the 140-rm polnt Is a point ln the crincer of Lhe Yin-

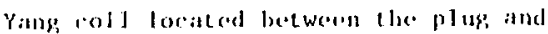
the central cell. The monsymongeto distrfbut lon of the [l']' react fou rala. rosillta rrom IJ'] platima a xlindlas, from tion enaleral coll lato tha plas,.

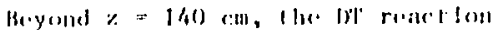
ratle remainti cometant at $1.9 \cdot 0^{1 \%}$

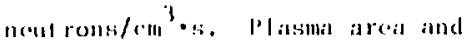
ment roll source st rellgllis varsilli ' $\%$ '

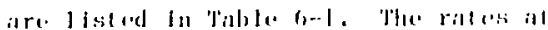

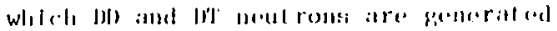
fa Ila Inmer hall of the plas: and

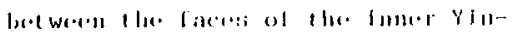

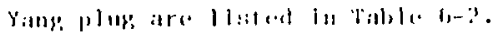

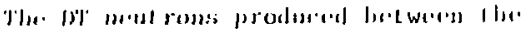

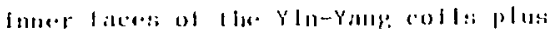

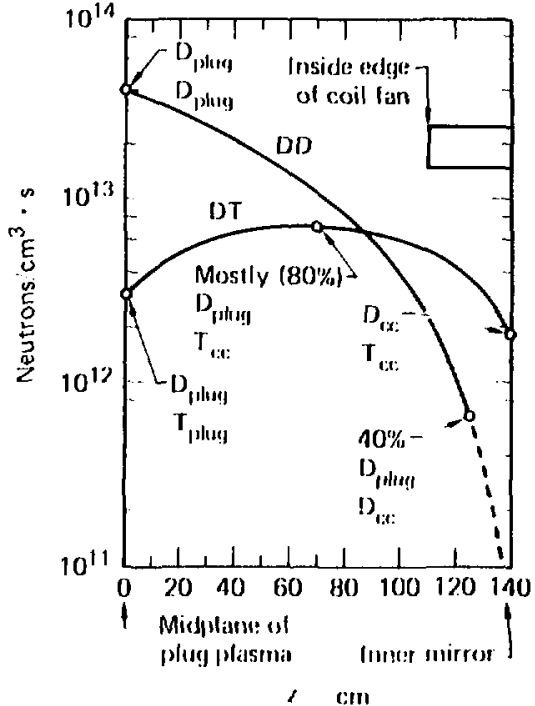

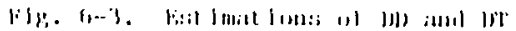

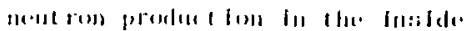

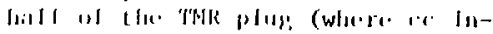

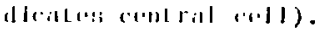

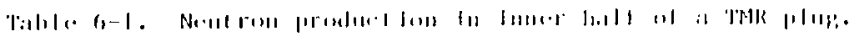

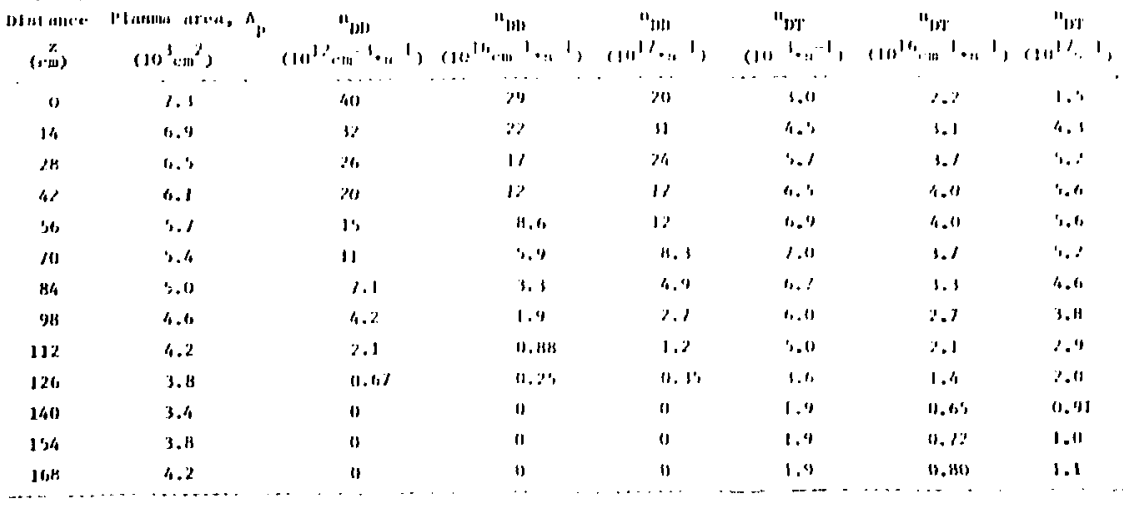




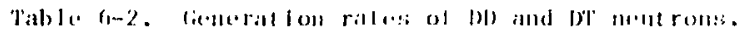

\section{Generallon ralle \\ (acelt rons/:i)}

$$
\begin{aligned}
& \text { Imer half of plas: } \\
& x=0101 \% \text { (1) }
\end{aligned}
$$

Batweren lincess on inmer

Y In-Yatlp $10 \mathrm{ill} ; z=110101 / 0 \mathrm{~cm}$
(D) ne:ut rons

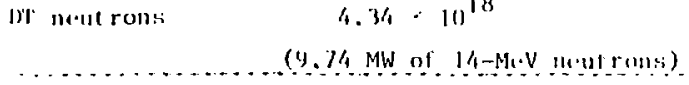

$1.14 \cdot 10^{11}$

$$
\text { (1.0)' MW) }
$$$$
6.1910^{11}
$$

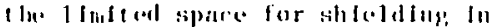
this roplan comblate fo form the

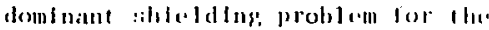
'I'MR .

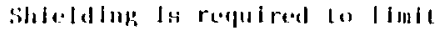

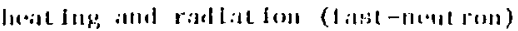

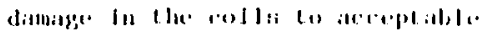
luvelis.

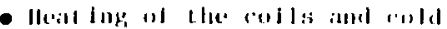

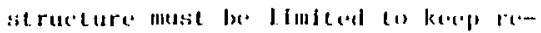

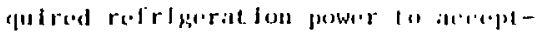
able. levelti.

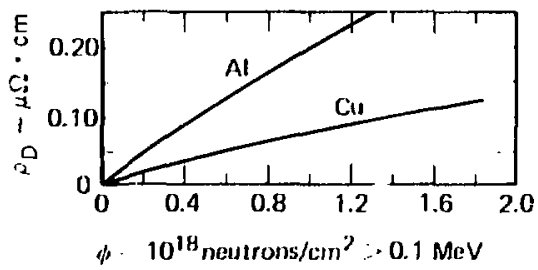

Fls. 6-4, Radlation-induced restatfvity lof lacease for copper and alumbun vi fast meutron fluence (li > $0.1 \mathrm{MeV})=7$ Lnitlal resistluities were $7.7,10^{-7}$ $\alpha \cdot \mathrm{cm}$, respectively. The irradiation temperature was $4.9 \mathrm{~K}$. (From Rer. 6-1.)

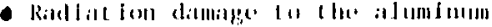

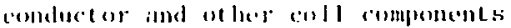

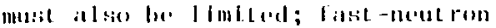

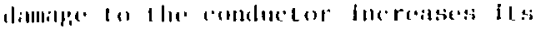
(.)

Fisture 6-4 :ilans: (1975) dilt: fo.

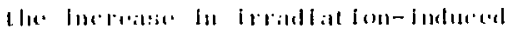

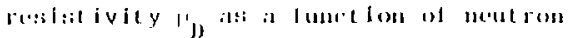

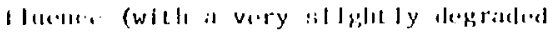

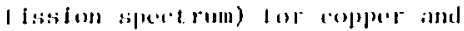
alumfaum al 4.9 K. Anesilling al roum

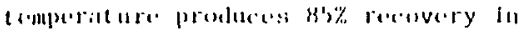
ropper and amplete recovery in

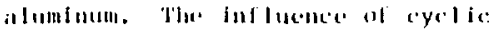

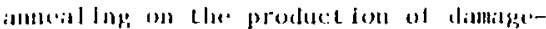

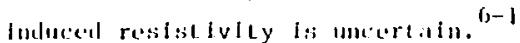
'The temperitlure alud resilstivity assimed lor lla alumitum conductor in the YinYallg rolls: are 20 k and $5.4 \cdot 10^{-9}$

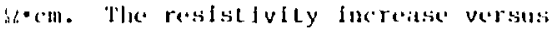

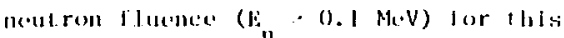
ronductor lis assumed bo be the same as shown in plg. 6-4. Since comductor current must remaln comstant, an fncreatse In conductor resistance mantfests itsell ats an increase in Joule $\left(1^{2} k\right)$ letat ing. 


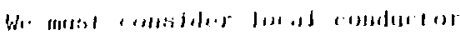

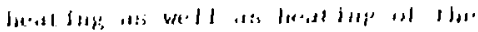

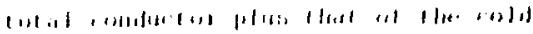

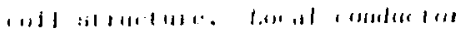

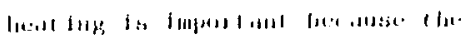

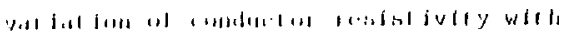

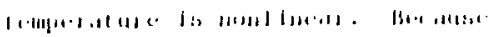

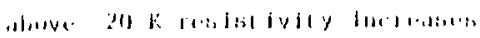

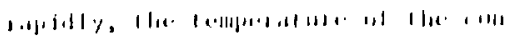

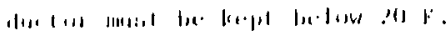

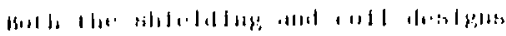

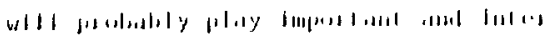

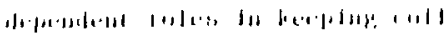

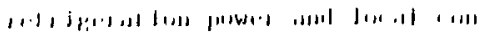

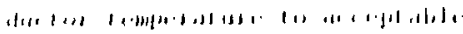

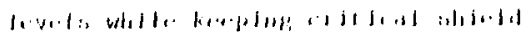

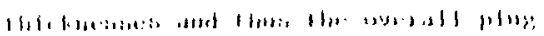

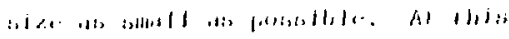

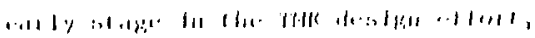

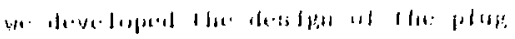

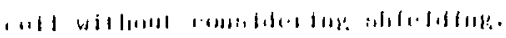

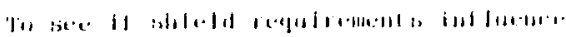

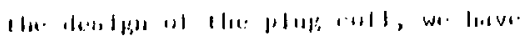

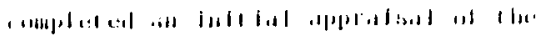

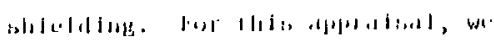

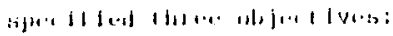

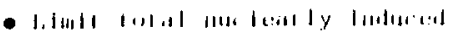

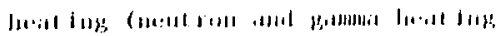

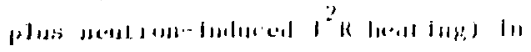

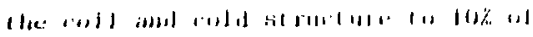

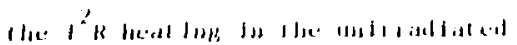

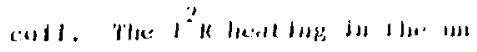

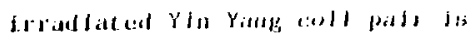
4) $\mathrm{kW}$;

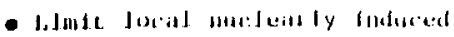

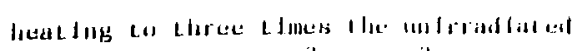

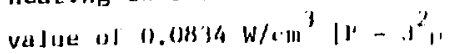

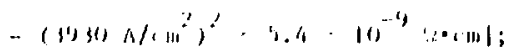
a)

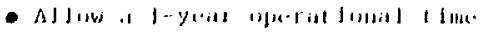

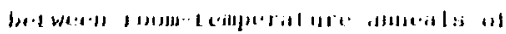

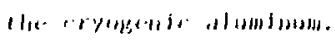

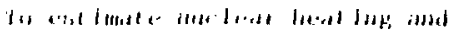

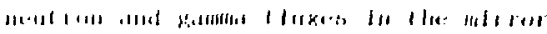

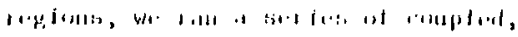

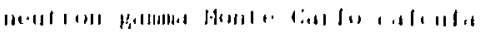

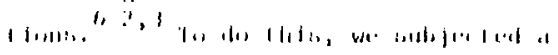

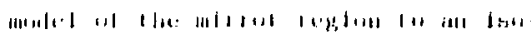

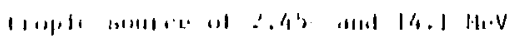

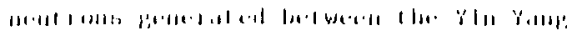

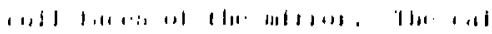

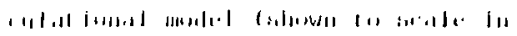

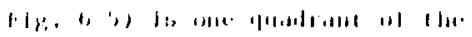

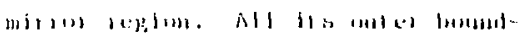

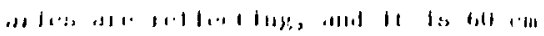

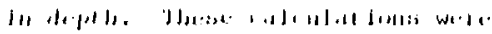

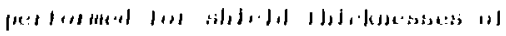

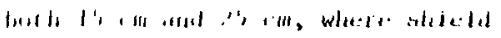

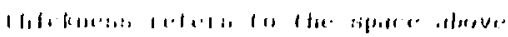

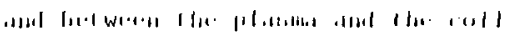

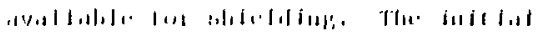

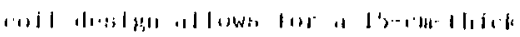

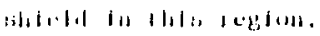

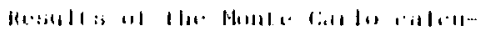

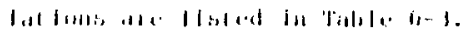

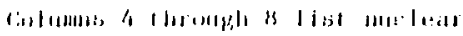

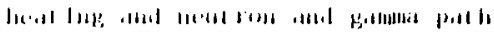

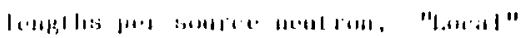

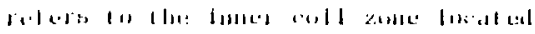

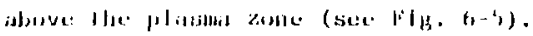

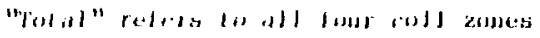

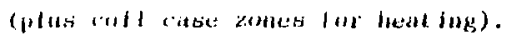

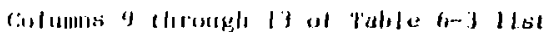

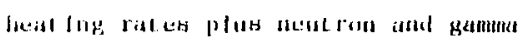




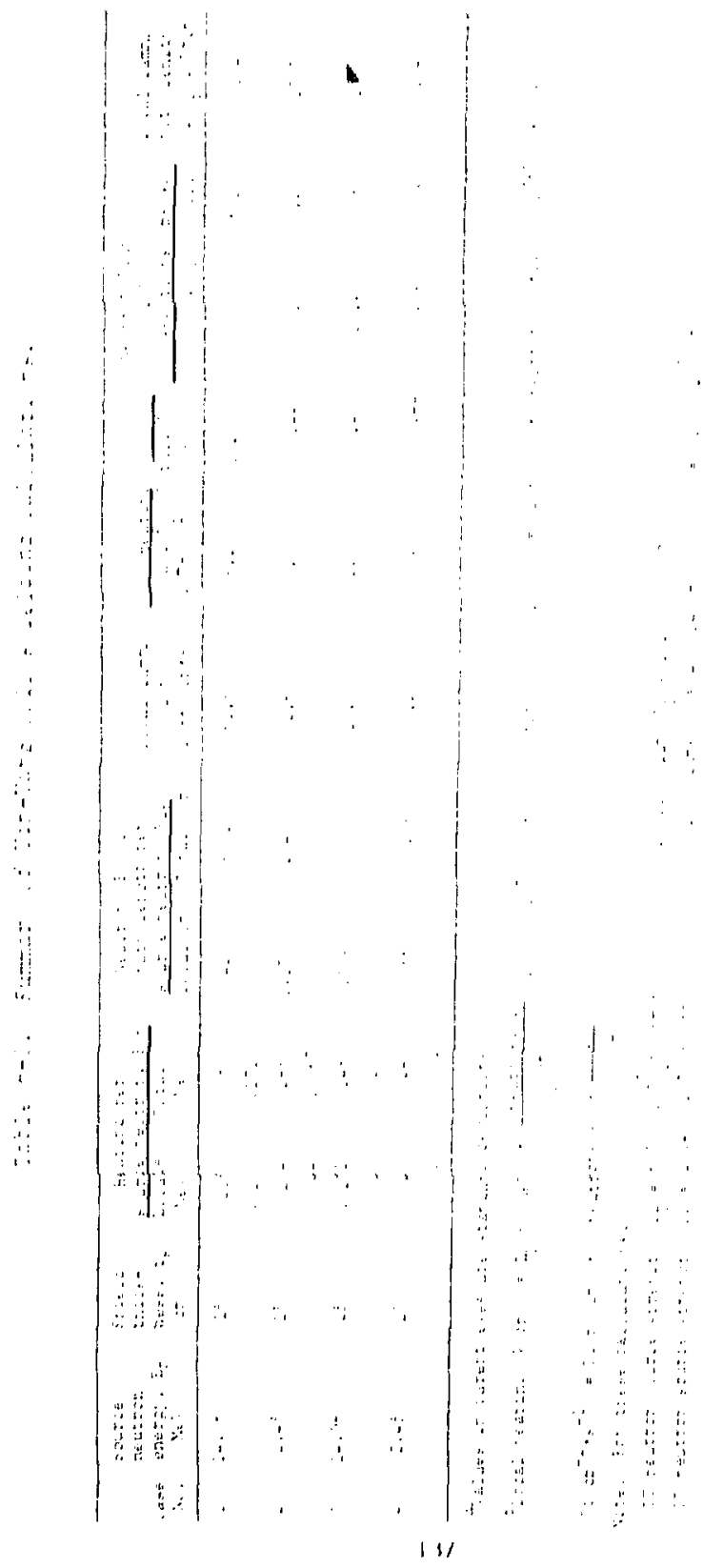




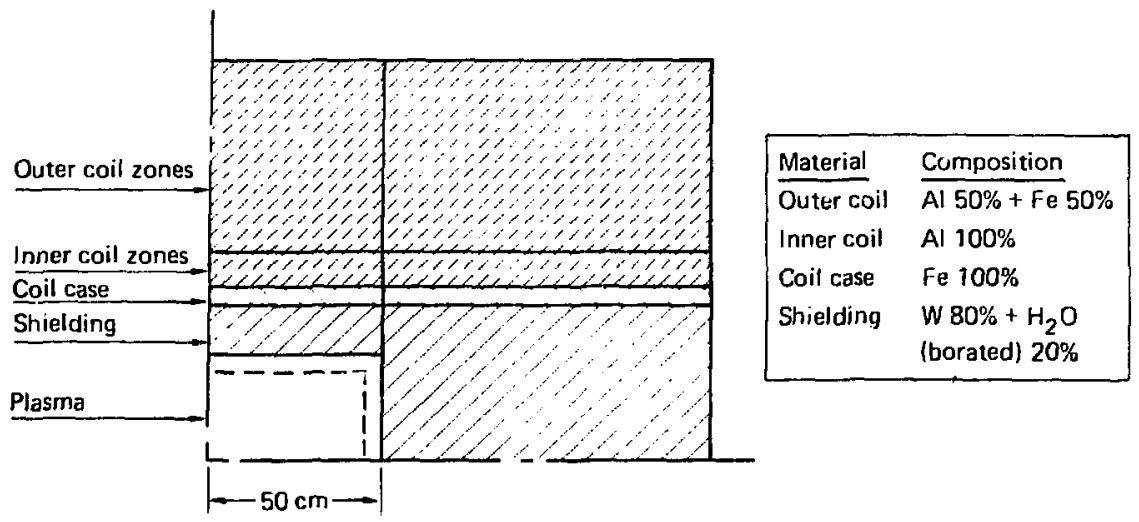

Fig. 6-5. Model used Eor Monte Carlo calculation of nuclear heat ing and neutron and gamma fluxes in the mirror regions of the TMR plug.

fluxes at the specifled DD and DT neutron-source strengths. Calculated local integral flux spectra for neutrons and gammas are given in Fig, 6-6 and 6-7, respectively.

With only $15 \mathrm{~cm}$ of shielding, these calculations predict that direct nuclear heating is $107 \mathrm{~kW}$. Also, at the calculated local neutron flux $\left[\phi_{\mathrm{DT}+\mathrm{DD}}(E>0.1 \mathrm{MeV})=1.96 \times 10^{13}\right.$ neutrons $\left./ \mathrm{cm}^{2} \cdot \mathrm{s}\right]$, the allowable local radiation-induced resistivity increases in aluminum of $3 \times p$ $=0.0162 \mu \Omega \cdot \mathrm{cm}$ is reached after only $3,780 \mathrm{~s}(1 \mathrm{~h})$ of operation $[\mathrm{t}=\Delta \rho /$ $\frac{\Delta \rho}{\Delta \phi} / \phi=0.0162 / 2.21 \times 10^{-19} / 1.94$ $\left.\times 10^{13} \mathrm{~s}\right]$.

It is clear that shield thickness must be increased and that the local allowable fast-neutron flux from DT neutrons will dictate what that shield thickness must be to allow 1 year of operation between anneals. The allowable local flux ( $\mathrm{E}>0.1 \mathrm{MeV})$ is:

$$
\begin{aligned}
& \phi_{\text {allowable }}=\Delta \rho \times \frac{\frac{1}{\Delta \rho}}{\Delta \phi} \times \frac{1}{\mathrm{t}} \\
& =0.0162(\mu \Omega \cdot \mathrm{cm}) \times \frac{1}{2.21 \times 10^{-19}} \\
& \underbrace{\mu \Omega \cdot \mathrm{cm}}_{\text {neutrons } / \mathrm{cm}^{2}} \times \frac{1}{3.15 \times 10^{7} \mathrm{~s}} \\
& =2 . j j \times 10^{9} \text { neutrons } / \mathrm{s} \cdot \mathrm{cm}^{2}
\end{aligned}
$$

Thus, our calculations show that the local neutron flux must be reduced four orders of magnttude below that achieved with the $15-\mathrm{cm}$-thick shield.

To estimate how thick the shield must be, we must know the attenuation properties of the shield. These 


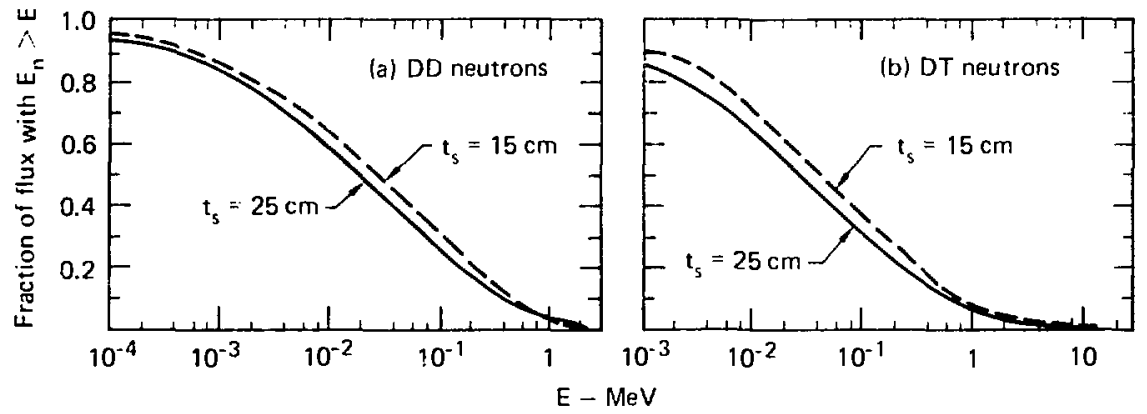

Fig. 6-6. Local neutron flux spectra from DD and DT neutrons.

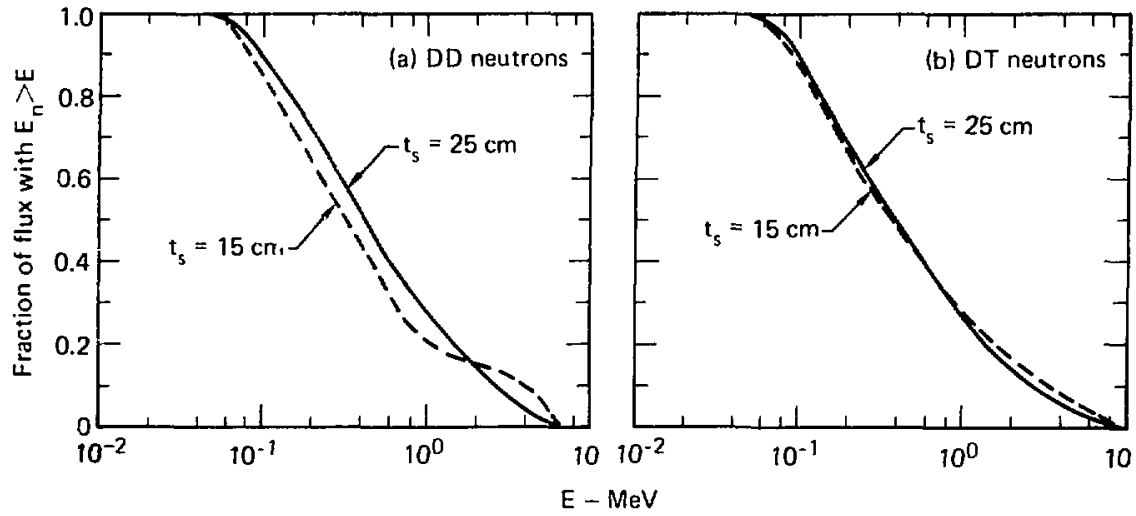

Fig. 6-7. Local gamma flux spectra from DD and DT neutrons.

properties are estimated by repeating the Monte Carlo calculations with a 25-cm-thick shield. Results of these calculations are listed in Table 6-3. Comparing the 15- and 25-cm cases gives scaling relationships by which we can estimate the required shield thickness. These relationships are 1isted in Table 6-4 as decade attenuation lengths (thickness of shield needed for a factor of 10 reduction in nuclear heating and neutron fluxes), With a $12.5-\mathrm{cm}$ decade attenuation length for the local fast fluence from DT neutrons, the estimated shield thickness needed to protect the in-Yang coil from DT neutrons is 


$$
\begin{aligned}
t_{S} & =15 \mathrm{~cm}+\log \left(\frac{t_{t S=15}}{t_{\text {allowed }}}\right) t_{/} \text {local } \\
& =15+\log \left(\frac{1.85 \times 10^{13}}{2.33 \times 10^{9}}\right) 12.5 \\
& =63.7 \mathrm{~cm} .
\end{aligned}
$$

Our assumption that DT fusion in the inner mirror dominates the shielding requirement for the plug coll appears to be correct, providing the coils with $\sim 64-\mathrm{cm}-t h i c k$ shields in the inner mirrors will require a significant increase in plug size, because the initial plug design allows for only $15 \mathrm{~cm}$ of shielding.

Another potential problem area is where beam lines pass close to coils. We have not examined beam-line shielding; however, we assume that a plug sized to provide the $\sim 64-\mathrm{cm}-$ thick shielding for the inner coil will have more than enough room to allow shielding the beam lines also. This assumption must be checked when a more exact and complete TMR shielding study is undertaken.

We used a tungsten-based shield for this shield analysis. Since tungsten is quite expensive, a cheaper iron plus lead shield should be used for most of the plug, where $\sim 1 \mathrm{~m}$ of shielding can be accomm dated. (If the latter were used in the inner region, $.90-\mathrm{cm}-t h i c k$ shielding would be needed.)

CENTRAL-CELL BLANKET AND SHIELDING

The fusion neutrons (effectively a 11 14-MeV DT neutrons) produced in the central plasma cell are converted to useful heat and used to breed tritium in the blanket. This blanket plus shielding must limit the nuclear heating and radiation damage in the superconducting colls of the central cell to acceptable levels.

The principle nucleonics objective for the blanket is the provision of adequate tritium breeding at low cost: energy amplification in the blanket is not a primary objective. Although

Table 6-4. Shield attenuation lengths.

\begin{tabular}{lcccc}
\hline $\begin{array}{l}\text { Source } \\
\text { neutron } \\
\begin{array}{l}\text { energy } \\
\text { MeV) }\end{array}\end{array}$ & $\begin{array}{c}\text { For energy } \\
\text { Local }\end{array}$ & $\frac{\text { Shield attenuation length (cm/decade) }}{\text { depition }}$ & $\frac{\text { For neutron flux }}{\text { Total }}$ & 0.1 MeV) \\
\hline 14.1 & 12.7 & 12.2 & 12.5 & Total \\
2.45 & 9.42 & 9.21 & 8.84 & 12.2 \\
\hline
\end{tabular}


there are many conceptual blankets that might meet this objective, we have chosen to look first at one consisting of a stainless-steel structure, a liquid-1ithium (natural) tritium-breeding medium, and helium coolant. This choice does not imply that this blanket is best, only that it is a reasonable starting point. A breeding ratio $\mathrm{T} / \mathrm{n}$ of 1.10 tritons per DT fusion in the central cell is considered adequate. An excess of 0.10 tritons per DT fuston would cover losses and allow for uncertainties in the calculations and nuclear data.

To determine the performance envelope of a cylindrical, stalnlesssteel blanket containing lithium, we performed a series of neutronics calculations in which the blanket was modeled as a cylindrical annulus $119 \mathrm{~m}$ long with an inner radius of $154 \mathrm{~cm}$. Calculations were made for various combinations of first-wall thicknesses $(0$ or $2 \mathrm{~cm})$ and ratios $(0$ to 0.3$)$ of stainless-steel volume fraction to lithium volume fraction.

Results of these calculations are plotted in Fig. 6-7 for three effective lithium thicknesses. (Effective thickness is geometric thickness times volume fraction.) For these calculations, the lithium volume fraction is held constant at 0.649 while the stainless-steel volume fraction is varied. For thcse calculations, we used 316 stainless steel (SS-316) having a density of $7.97 \mathrm{~g} / \mathrm{cm}^{3}$ composed of $68.5 \mathrm{wt} \% \mathrm{Fe}+12 \mathrm{wt} \% \mathrm{Ni}$ $+17 \mathrm{wt} \% \mathrm{Cr}+2.5 \mathrm{wt} \% \mathrm{Mo}$. A cylindrical volume source of isotropic, $14-\mathrm{HeV}$ neutrons, $2.3 \mathrm{~m}$ in diameter and $119 \mathrm{~m}$ long, approximates the plasma.

The curves in Fig. 6-7 are used to examine the traieofis in blanket mrchanical:design (e.g., flrst-wall thickness, ratio of structure to lithium, and blanket thickness) needed to achieve the desired $\mathrm{T} / \mathrm{n}=1.10$. To use the curves, specify two of the three variables and find the third variable by a linear interpolation between the appropriate curves.

After a number of iterations, we evolved an acceptable mechanical design for the blanket that meets the tritium-breeding requirement. This design bas a $0.5-\mathrm{cm}-$ thick wall, a lithium volume fraction of 0.691 , and a SS-316 volume fraction of 0.179 . From Fig. 6-8, the thickness required for $\mathrm{T} / \mathrm{n}=1.10$ is $34.1 \mathrm{~cm}$. Energy multiplication in this blanket is 1.20.

The conceptual design of the central cell allows for $90 \mathrm{~cm}$ of shielding between the blanket and blanket coolant plena and the superconducting coils of the central cell. Based on an early shielding study, 6-4 the blanket plus $90 \mathrm{~cm}$ of iron- and lead-based shielding should provide sufficient protection for the centralce11 coils. 


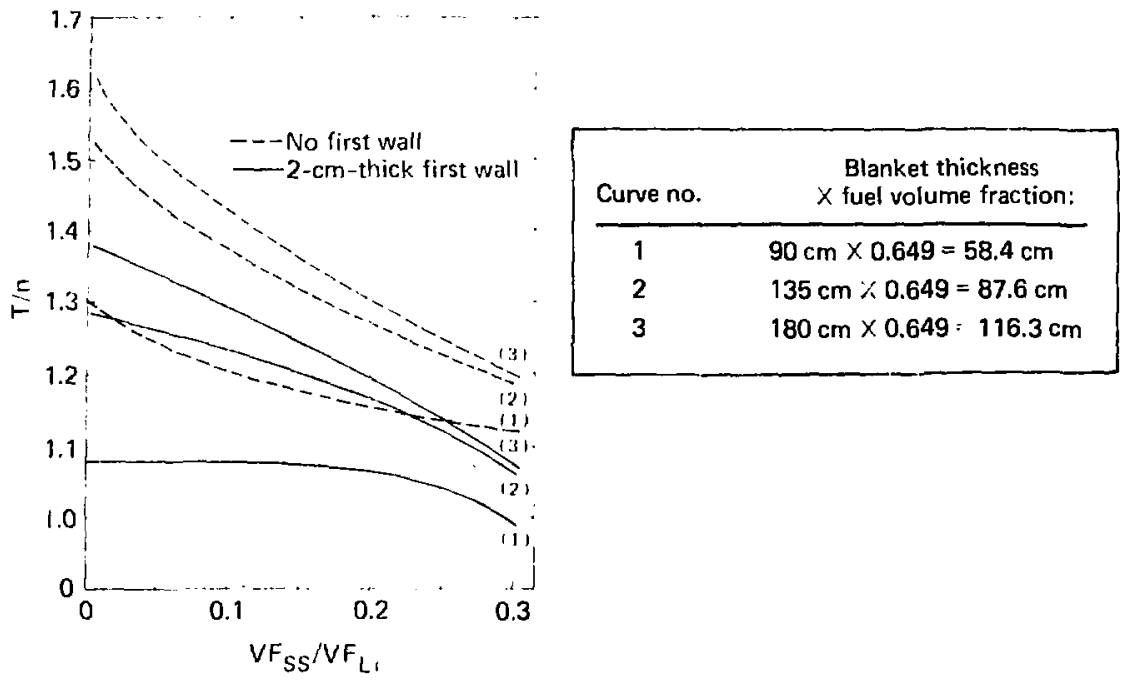

Fig. 6-8. Tritium breeding ratio $\mathrm{T} / \mathrm{n}$ in a lithium and stainless-steel blanket vs the ratio of the volume fraction of stainless steel to that of lithium $\mathrm{VF}_{\mathrm{SS}} / \mathrm{VF}_{\mathrm{Li}}$ * Blanket geometry: cylindrical; inner radius $=156 \mathrm{~cm}$; Length $=119 \mathrm{~cm}$.

REFERENCES

6-1. J. F. Guess, R. W. Boom, R. R. Coltman, Jr., and S. T. Sekula A Survey of Radiation Damage Effects in Superconducting Magnet Components and Systems, Oak Ridge National Laboratory, Rept. ORNL-TM-5187 (1975).

6-2. E. F. Plechaty and J. R. Kimlinger, TARTNP: A Coupled Neutron-Photon Monte Carlo Transport Code, Lawrence
Livermore Laboratory, Rept. UCRL-50400, Vol. $14: 29 / 6)$.

6-3. R. J, Howerton et al. An Integrated system for Production of Neutronies and Photonics Caleulational constants, Lawrence Livermore Laboratory, Rept. UCRL-50400, Vol. 6, (1975) and Vol. 16 (1976). 6-4. R. W. Moir, Scientific Editor, Stondard Mirmor Fusion Reactor Design Study, Lawrence Livermore Laboratory, Rept. UCID-17644 (in preparation). 


\section{CHAPTER 7. A NEUTRAL-BEAM INJECTOR FOR THE TANDEM-MIRROR FUSION REACTOR DELIVERING $147 \mathrm{MW}$ OF $1.2-\mathrm{MeV}^{\circ}$}

\section{土. H. menk and \%. H. Homizton}

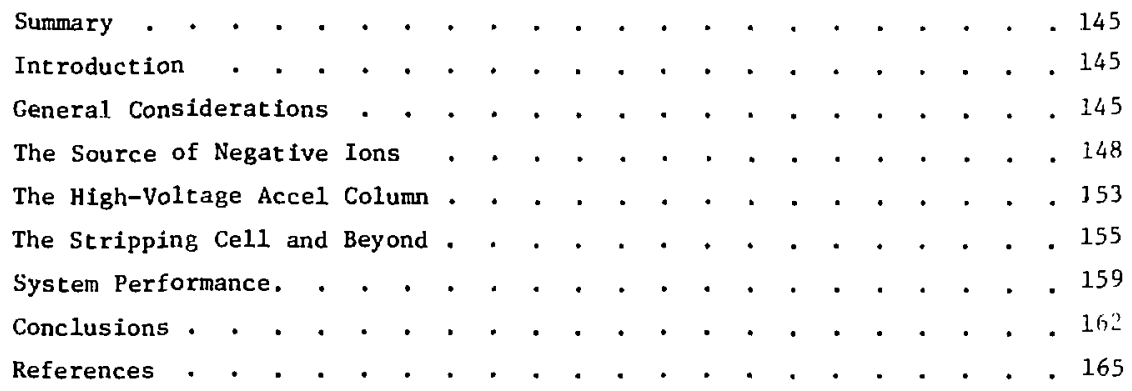

*on loan from Westinghouse Electric Corp. 
SUMMARY

We present a conceptual design of a high-current, $1.2-\mathrm{MeV} \mathrm{D}^{\mathrm{O}}$ injector with an anticipated operating efficlency of $73 \%$. Major advances in beam technology are needed to meet these requirements, including a continuous source of negative lons, an efficient electron-stripping cell, and the development of associated power conditioning and control equipment. $\quad 411$ components in our proposed beam line are elaborations of physics experiments already reported in the literature; therefore, we believe the neutral-beam requirements of the tandem mirror reactor (TMR) can be realistically satisfied in the not too distant future.

\section{INTRODLCTION}

The TMR ${ }^{7-1}$ requires four neutralbeam injectors, each capable of delivering a continuous $122.5 \mathrm{~A}$ of $1.2-$ MeV deuterium. Considerable development must be expended to make these injectors reliable, efflcient, and at reasonable cost. No revolutionary inventions are needed to meet these goals because sultable beam-1ine components can be made from extrapolations of current experimental apparatus. In this study of neutral-bean Infectors, we shall therefore consider the general characteristics of the beam IIne and the nature of the components best suited to it, analyze each component in detail, and evaluate the performance of the ensemble.

\section{GENERAL CONSIDERATIONS}

High-energy neutral beams are formed by neutralizing ions, previously extracted from a plasma source, which are accelerated to the desired energy and afmed at an appropriate focus. As a consequence, the power efficiency of a neutral-beam line is highly dependent upon the fon neutralfzation efficlency.

Neutral beams of $100 \mathrm{keV}$ or less can be efficlently made from positive ions that have been neutralized by charge exchange in a gas or vapor cell however, this process is so theffective at higher energies that efficiency enhancement techniques become attractive. For good performance, we must have either continuous recirculation of unneutralized lons through the neutralizer cell ${ }^{7-2}$ or energy recovery from the remaining unneutralized ions. $^{7-3}$

At $1.2 \mathrm{MeV}$, less than $0.04 \%$ of an atomic deuterlum ion beam is neutralized in a gas or vapor cell. $.^{7-4} \mathrm{Be}-$ cause enhancement techniques are not much help, we must turn to other, more effective sources of neutrals. Beams of molecular Ions could be considered for this purpose. 
About $10 \%$ of a beam of $2.4-\mathrm{MeV}$ of $\mathrm{D}_{2}^{+}$ions can be neutralized in a gas cell to split into two $1.2-\mathrm{MeV}$ atomic components. Similarly, $23 \%$ of a 3.6-MeV beam of $\mathrm{D}_{3}^{+}$ions can be neutralized to dissociate into three $1.2-\mathrm{MeV}$ atomic components; however these high voltages introduce insulation problems. only $1.2 \mathrm{MV}$ is required when negative ions are used as a source of very high-energy neutral beams.

The extra electrons can be detached from negative deuterium ions. ${ }^{7-5}$ This detachment could be done for a beam of 1.2-MeV ions with elther an electric field of about $4 \mathrm{MV} / \mathrm{cm}$ or a magnetic field of approxlmately $36 \mathrm{~T}$; however, these fields are excessive. Although photodetachment could achieve 95\% str1pping, the required optical cavity is too large to be practical.

The optimum stripping efficiencies of gas, vapor, and plasma cells are insensitive to the target composition and are relatively independent of the beam energy above $100 \mathrm{keV}$. A well designed plasma cell of proper thickness could stzip $85 \%$ of an incident negative-ion beam; a gas or vapor cell of suitable thickness could strip 65\% of a corresponding beam.

If the size of the optical cavities required for photodetachment cannot be significantly reduced, plasma stripping of negative ions will be the most favorable method for forming $1.2-\mathrm{MeV}$ neutrals. Plasma strlpping offers the highest neutralization efficiency in a practical stripping-cell design.

The stripping-cell plasma considered here is generated by ionizing cesium vapor on two hot, tungsten plates one on each side of the ion-beam line - in a process similar to that employed in a $Q$ machine. ${ }^{7-6}$ The tungsten temperature must be high enough to support electron emission for spacecharge neutralization of the cesium lons.

Although negative ions are easy to strip, their large stripping cross section creates problems in the accel region of the beam. The ions and electrons generated from charge exchange and ionization of the background gas in the wake of the highenergy beam will bombard the grid, causing it to sputter and overheat. To obtain an acceptable grid loading which can be sustained continuously, the background gas density must be low and the beam current density held down, thereby reducing the rate of background ion and electron production.

The current density of the beam in a Pierce extraction geometry ${ }^{7-7}$ is already limited by the maximum tolerable voltage stress between adjacent grids. In addition, a low-pressure environment must be maintalned above the accel column.

Suitable pressure can be obtained if the injector walls at ground potential are covered with cryopump panels. 
The cryopumps should be rotated occasionally so that they can be outgassing on the outer side while still pumping on the inside.

Forming negative ions via doublecharge exchange in a cesium-vapor cell helps to reduce the gas load. This ce11 converts about $20 \%$ of an incident $2-\mathrm{keV}$ positive ion beam into negative $^{7-8}$ ions and acts as a gas curtain to block the flow of low-temperature neutral gas streaming out of the positive-ion sources. ${ }^{7-9}$ As a result, the gas flowing out of the positiveion source can be pumped independently from that in the negative-ion accel region.

In this study, we use a Lawrence Berkeley Laboratory/Lawrence Livermore Laboratory ion source with hollowtungsten, barium impregnated cathodes to provide a long, continuous operating life. We extract a beam $8 \mathrm{~cm}$ wide and 5 m long. This cross section facilitates gas removal and simplifies the design of the cesium double charge-exchange cell and the plasmastripping cell. The narrow beam also makes it possible to use short grid laterals, which are easier to malntain at a uniform temperature.

The extraction grids are $40 \%$ transparent and have hollow molybdenum laterals that are cooled to $500^{\circ} \mathrm{C}$ by a flow of 11quid metal. The source, mounted inside a large vacuum duct, is supported by high-voltage insulators above and below the beam line. Gas is removed from this region by two large mercury ejector pumps mounted at the upper and lower ends of the pump duct.

Maintaining reliable high-voltage vacuum insulation is a critical prob$\therefore \mathrm{m}$ in the design of an MeV injector. Lxperience shows there is less likelihood of breakdown across a sertes of low-voltage gaps than there is across a single hlgh-voltage gap. Therefore, electrcstatic shields are introduced at various intermediate potentials between the high-voltage components and ground. These shields are at the same potential as the various grids in the accel column. The source is at $-600 \mathrm{kV}$ with respect to ground; the stripping cell is at $+600 \mathrm{kV}$. Background pressure in this region is reduced by pumping through $80 \%$ transpartnt electrostatic shields.

The capacitance between adjacent: shields stores many joules of energy. Thus any incidental discharge can easily turn into a catastrophic arc. Thts arc can be inhibited by forning the shields out of many small sections. These sections can be isolated by using resistors which impede the transfer of energy from section to section.

\section{Auxiliary components are housed} above and below the beam line in large, high-pressure $\mathrm{SF}_{6}$ vessels that are shielded from the neutron and gamma fluxes emitted by the reactor. These 
vessels hold electrical power supplies, isol.2tion transformers, high-voltage insulators, liquid-metal heat exchangers, and gas and water services for the fon source. Although the design of power supplies is not a trivial task, we shall not address that problem in this study.

THE SOURCE OF NEGATIVE IONS

As part of an operating reactor, the source must deliver a continuous beam of negative ions for thousands of hours whlle permitting very little low-temperature gas to flow into the accel regton. This can be accomplished with a suitably designed double charge-exchange cell. If the cell has the proper thickness (i.e., vapor density-length product), the cesium vapor converts $20 \%$ of a $2-\mathrm{keV}$ beam of positive ions into negatives; the remainder of the beam exits as 2-keV neutrals. The cestum vapor also acts as a curtain that blocks the flow of low-temperature gas along the beam line.

To facilitate pumping low-temperature gas from the source, the lons are formed into a large beam of narrow width. The source (Fig. 7-1) delivers $800 \mathrm{~A}$ of positive fons. (at a current density of $0.5 \mathrm{~A} \cdot \mathrm{cm}^{-2}$ ) through a sequence of four $40 \%$ transparent grids that are $8 \mathrm{~cm}$ wide and $5 \mathrm{~m}$ long.
Average current density in the extracted beam is $0.2 \mathrm{~A} \cdot \mathrm{cm}^{-2}$.

A version of the LBL/LLL source (described elsewhere ${ }^{7-5}$ ) can be modifled to use indirectly heated, hollow cathodes made of two tungsten, barium-1mpregnated emicters mounted Eace to face. The source plasma orfiginates from a series of $45-V$ discharges, requiring $1.93 \mathrm{~kW}$ of arc power per extracted ampere, and the heaters operate at $5 \mathrm{~V}$ with $0.19 \mathrm{~W} / \mathrm{A}$.

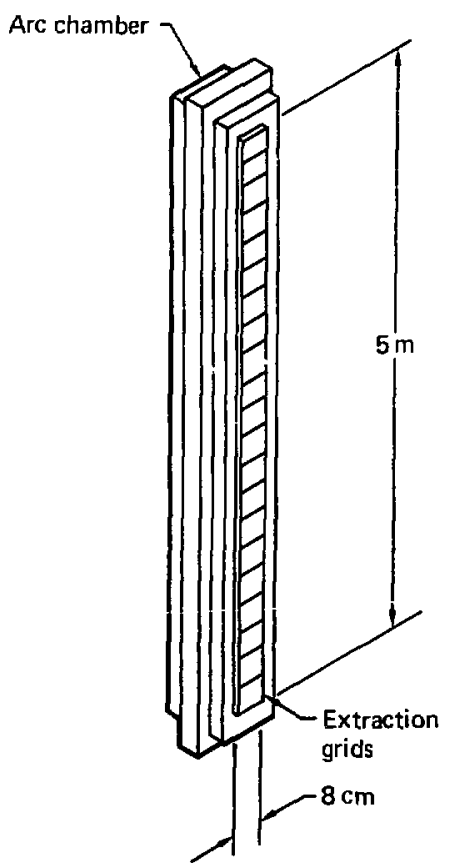

Fig. 7-1. Detalls of a 800-A ion source where $\eta_{1}=40 \%, \dot{\eta}_{2}=50 \%, n_{3}$ $=10 \% ; P_{h t r}=0.15 \mathrm{MW}(5 \mathrm{~V})$, and $P_{\text {arc }}$ $=1.54 \mathrm{MW}(45 \mathrm{~V})$. 
Thus, the total arc power its $1.54 \mathrm{M}$ and the filament power is $0.15 \mathrm{MN}$.

Gas seeping out of the ion source plasma flows through the aperture in the grids and is pumped away via a large vacuum duct behind the source (see Fig. 7-2). Although the LBL/LLL source delivers an ion beam with a composition of $r_{1}=75 \% \mathrm{D}^{+}, r_{2}=15 \%$ $\mathrm{D}_{2}^{+}$, and $r_{3}=10 \% \mathrm{D}_{3}^{+}$, we can assume that the beam composition, in the absence of hot-tungsten filaments, will be $\eta_{1}=40 \% \mathrm{D}^{+}, \mathrm{r}_{2}=50 \% \mathrm{D}_{2}^{+}$, and $r_{3}=10 \% \mathrm{D}_{3}^{+}$, with a gis efficiency ${ }^{\circ} \mathrm{C}$, $=30 \%$, the extracted ton current $\left(D^{+}\right)$ is accompanied by a gas flow of

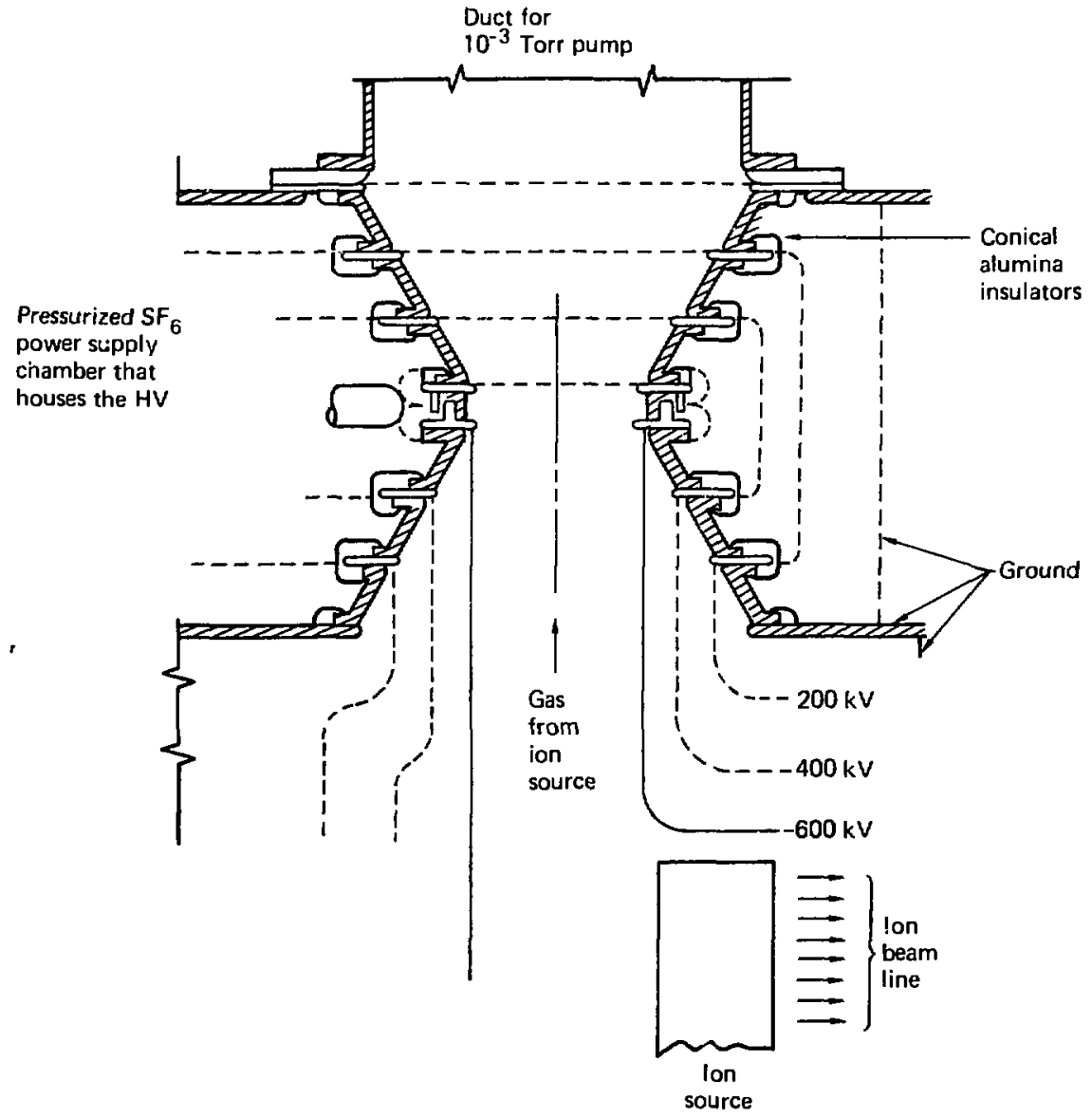

Fig. 7-2. Pumping through the high-voltage insulators. 


$$
\begin{array}{ll}
Q_{p}=(0.19)\left(\frac{1}{\xi_{\mathrm{C}}}-1\right)\left(\frac{1}{2} r_{\mathrm{I}}+r_{2}\right. & \text { must be at least } \\
& \left.+\frac{3}{2} n_{3}\right) \mathrm{I}^{+}=302 \operatorname{Torr} \cdot 1 \cdot \mathrm{s}^{-1} \cdot \quad \mathrm{R}=\left[\frac{\mathrm{Q}_{\mathrm{p}}}{7.28 \pi L 0}\right]^{1 / 2}\left(\frac{\mathrm{M}}{\mathrm{T}}\right)^{1 / 4}=30 \mathrm{~cm} .
\end{array}
$$

This gas is removed by two large mercury ejector pumps located at the

Grid 1 floats (see Fig, 7-3), drawupper and lower ends of the pump duct. ing a net zero current of ions and The throat pressure of the pump is assumed to be $10^{-3}$ Torr; the pressure in the vicinity of grid 4 is maintained at $2 \times 10^{-3}$ Torr. To accommodate the gas at $500 \mathrm{~K}$, the pump duct radius electrons from the plasma; grid 2, at $-11.75 \mathrm{kV}$ with respect to the source,

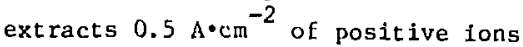
from the plasma. These ions are subsequently decelerated to $-1.75 \mathrm{keV}$ at

$\begin{array}{ccc}\begin{array}{c}\text { Ion } \\ \text { source }\end{array} & \begin{array}{c}\text { Double } \\ \text { charge } \\ \text { exchange }\end{array} & \begin{array}{c}\text { Accel } \\ \text { column }\end{array} \\ & & \end{array}$

\section{Stripping Electrostatic cell shields}

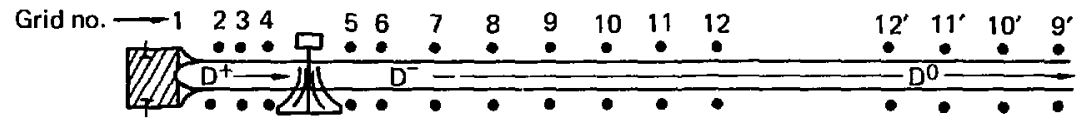

Component profile
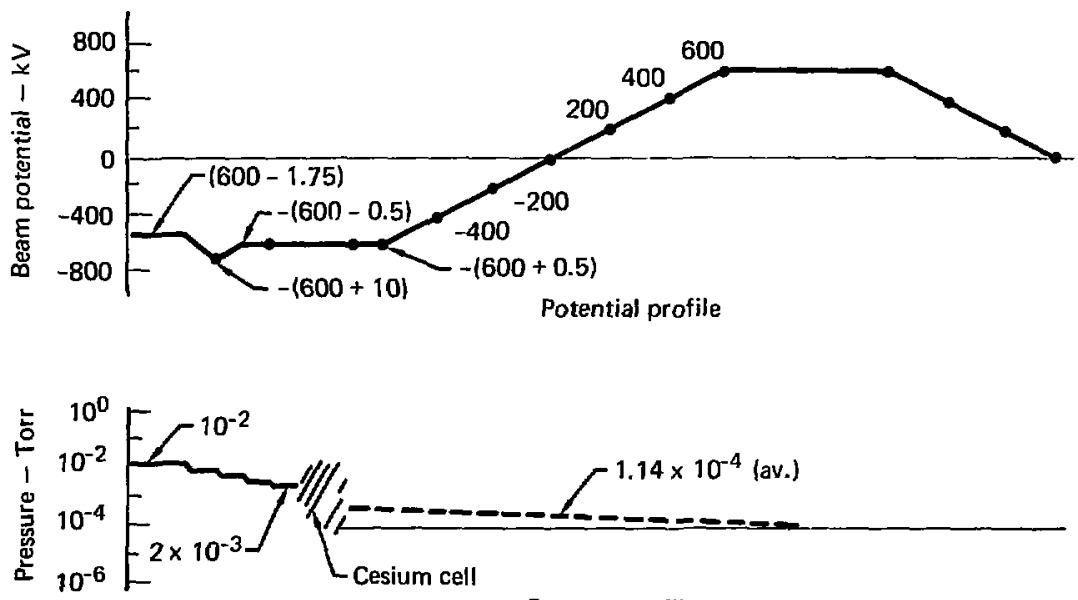

Pressure profile

Fig. 7-3. Beam-1ine profiles (component, potential, and pressure). 
grid 4 for injection into the cesiumvapor cell. To prevent ions from being drawn into the grid 2-3 region, grid 3 is biased at $+500 \mathrm{~V}$ with respect to grid 4. Extraction grids 1 through 4 are curved to aim the positive ions at a line focus in the plane of grid 6 . The maximum theoretical peak current density that can be obtained at the focus of a two-dimensional beam is

$\hat{J}_{\max }=J_{K}\left(\frac{4 \mathrm{eV}}{\pi \mathrm{KT}}\right)^{1 / 2} \alpha$,

where $J_{K}$ is the emitted current density, $V$ is the beam energy in the region of the focus, $\mathrm{KT}$ is the ion energy, and $\alpha$ is the half angle that encompasses all ion trajectories passing through the focus. If $20 \%$ of the positive ion current is converted into negative ions in the cesium cell and the grid is $40 \%$ transparent, the virtual source of negative ions has a current density of $0.04 \mathrm{~A} \cdot \mathrm{cm}^{-2}$. The potential at grid 6 is $2.25 \mathrm{keV}$ relative to the Ion source; the angle a equals the ratio of half the beam width ( $4 \mathrm{~cm}$ ) to the distance from the ion source to the focus (50 cm).

We can assume from Eq. (7-1) that the ions have a distribution of velocities normal to the beam axis that is a function of their temperature in the source. However, allowance should be made for the transverse energy imparted to the ions by the curvature of the electric fields, by scattering, and by the dissociation of the $\mathrm{D}_{2}^{+}$and $\mathrm{D}_{3}^{+}$ molecules in the beam. The effective transverse energy of ions emitced from an IBL/LLL source operating at $15 \mathrm{kV}$ is observed to be $4.6 \mathrm{eV}$, and the corresponding energy of the ions emitted from this source will be at last twice that value. Therefore, the peak current denstty of negative ions in the plane of grid 6 must be about $0.056 \mathrm{~A} \cdot \mathrm{cm}^{-2}$, with an average value of somewhat less than that.

Exilucted positive ions in transit from the ion source to the cesiumvapor cell are subject to charge exchange with the background gas. The fraction of the beam lost in this way can be estimated by

$$
F_{10}=n_{b} \sigma_{10} x
$$

where $n_{b}$ is the density of the background gas, $\sigma_{10}$ is the average cross section of neutralization, and $X$ is the path length. If one assumes an equal pressure drop across each grid, then a source pressure of $10^{-2}$ Torr and a pressure beyond grid 4 of $2 \times 10^{-3}$ Torr will result in a pressure of $8 \times 10^{-3}$ Torr in the grid 1-2 region. With the gas at $1000 \mathrm{k}$, the background density between grids $1-2$ will be $8 \times 10^{13} \mathrm{~cm}^{-3}$. Ions can be extracted from the plasma at $0.5 \mathrm{~A} \cdot \mathrm{cm}^{-2}$ with a bias of $-11.75 \mathrm{kV}$ if the grid $1-2$ spacing is $0.28 \mathrm{~cm}$ 
(according to Child's Law). The neutralization cross section corresponding to the mean ion energy across the gap is estimated to be $6 \times 10^{-16} \mathrm{~cm}^{2} / \mathrm{D}_{2}$, so that $\mathrm{F}_{10}$ equals

$1.5 \%$. Conditions between grids $2-3$ are similar; hence, another $1.5 \%$ of the beam is lost chere.
The above values are recorded in the second and third Iines of Table 7-1, along with an estimatei background Ionization rate that is equivalent to $0.1 \%$ of the positive-ion beam. Only $776 \mathrm{~A}$ of the $800 \mathrm{~A}$ of lons emitted from the source enter the double charge-exchange cell.

Table 7-1. Distribution of currents along the beam 11ne.

\begin{tabular}{|c|c|c|c|c|c|c|c|c|}
\hline \multirow[b]{2}{*}{ Line } & \multirow[b]{2}{*}{$\begin{array}{l}\text { Region along } \\
\text { beam line }\end{array}$} & \multirow[b]{2}{*}{$\begin{array}{l}\text { beam } \\
\text { eutralization } \\
(\%)\end{array}$} & \multicolumn{3}{|c|}{ Beam current ${ }^{a}$} & \multirow[b]{2}{*}{$\begin{array}{c}\text { 8adikgrouni } \\
\text { tondzation } \\
(\%)\end{array}$} & \multicolumn{2}{|c|}{ Background current ${ }^{b}$} \\
\hline & & & $(A)$ & $\begin{array}{l}D \\
(A)\end{array}$ & $\begin{array}{c}D^{0} \\
(A)\end{array}$ & & Ion & $\begin{array}{l}\text { Electron } \\
\text { (A) }\end{array}$ \\
\hline \multirow[t]{2}{*}{1} & Ion source & - & 799.7 & - & - & - & - & - \\
\hline & $\begin{array}{l}\text { Extractor: } \\
\text { between grids }\end{array}$ & & & & & & & \\
\hline 2 & $1-2$ & 1.5 & 787.7 & & $(12,0)$ & 0.1 & 0.8 & -0.9 \\
\hline 3 & $2-3$ & 1.5 & 775.9 & & $(11.8)$ & 0.1 & 9.8 & -0.8 \\
\hline \multirow[t]{2}{*}{4} & $\begin{array}{l}\text { Double charge- } \\
\text { exchunge c=ll }\end{array}$ & 80.0 & - & \pm 55.2 & $(620.7)$ & 10.0 & -15.5 & 1.5 \\
\hline & Betweell grtds & & & & & & & \\
\hline 5 & $3-6$ & - & - & - & - & 0.2 & -0.3 & 0.3 \\
\hline 6 & $6-7$ & 1.3 & - & 153.2 & $(2.0)$ & 0.24 & 0.4 & 0.4 \\
\hline 7 & $7-8$ & 0.5 & - & 152.4 & $(0.8)$ & 0.24 & -0.4 & 0.4 \\
\hline 8 & $8-9$ & 0.3 & - & 152.0 & $(0.4)$ & 0.16 & -0.2 & 0.2 \\
\hline 9 & $9-10$ & 0.2 & - & 151.7 & $(0.3)$ & 0.11 & -0.2 & 0.2 \\
\hline 10 & $10-11$ & 0.2 & - & 151.4 & $(0.3)$ & 0.09 & -0.1 & 0.1 \\
\hline 11 & $11-12$ & 0.1 & - & 151.2 & $(0.2)$ & 0.07 & -0.1 & 0.1 \\
\hline 12 & $\begin{array}{l}\text { Stripping cell: } \\
\text { between } \\
\text { grids 12-12' }\end{array}$ & 81.5 & $(27.2)$ & $(0.8)$ & 123.2 & 0.2 & 0.2 & -0.2 \\
\hline 13 & $\begin{array}{l}\text { Drift region } \\
\text { through electro- } \\
\text { static shield } \\
\text { and beyond) }\end{array}$ & 0.6 & $(0.7)$ & - & 222.5 & 0.6 & 0.7 & 0.7 \\
\hline
\end{tabular}

${ }^{a}$ The main beam current is 1talicized; numbers in parenthases represent beam loss.

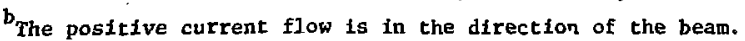


The combined reaction of cesium and background gas between grids 3-6 constitutes the double charge-exchange cell. Thus, $20 \%$ of the positive ion beam is converted to negatives and the remaining $80 \%$ exits as neutrals. This is shown in the fourth and $f$ if th lines of Table 7-1, along with an istimated electron drain (equal to $10 \%$ of the beam current) out of the cesium to grid 3 and a corrcsponding drain of positive ions (equal to $0.2 \%$ of the beam current) to grid 6 . Consequently, $155 \mathrm{~A}$ of $\mathrm{D}^{-}$and $621 \mathrm{~A}$ of neutrals enter the accel region at $\sim 2 \mathrm{keV}$.

THE HIGH-VOLTAGE ACCEL COLUMN

A Pierce-type accel system accelerates the negative ions as though they were part of a beam of infinite cross section. This is done by varying the potential along the beam line in accordance with Child's Law for planar geometry; i.e.,

$$
J=q \frac{v^{3 / 2}}{x^{2}},
$$

where $J$ is the beam-current density, $q$ is a constant, and $V$ is the potential at any distance $X$ from the ion source.

The potential along a beam of finite size is zontrolled, in practice, by a sequence of grids placed around the beam at suitable voltages. If this potential is to be effective, the spacing between adjacent grids $(\Delta x)$ must be about the same as the beam width. Therefore, if $\Delta V$ is the potential between adjacent $g r i d s$, the average stress between them is

$$
\left(\frac{\Delta V}{\Delta x}\right)=4 / 3\left(\frac{J}{q}\right)^{1 / 2} v^{1 / 4} \cdot(7-2)
$$

The greatest stress occurs between grius at the highest potential. If we specify a mazimum tolerable stress $\left(E_{M 1}\right)$ to be permitted between grids, we can establish a maximum current density that can be used in the accelerator. By rearranging Eq. $(7-2)$, we find

$$
J_{M}=(9 / 16) q E_{M}^{2} v_{O}^{-1 / 2}
$$

Equation (7-3) shows that the maximum allowable current density in a Pierce column varies inversely with the square root of the desired energy beam. If we apply Eq. $(7-3)$ to a deuterium negative-ion beam with no molecular components, we have

$$
\begin{aligned}
q=(4 / 9) \varepsilon_{0}\left(\frac{2 e}{M}\right)^{1 / 2} & \\
& =3.88 \times 10^{-8} \mathrm{AV}^{-3 / 2} .
\end{aligned}
$$

Thus, if $E_{M}$ is assumed to be equal to or less than $50 \mathrm{kV} / \mathrm{cm}$, the current density in a 1.2-MeV accelerator should not exceed $0.05 \mathrm{~A} \cdot \mathrm{cm}^{-2}$.

If we rewrite Child's Law, we can find the appropriate grid location at any potel -1al from 


$$
x=(q / .1)^{1 / 2} v^{3 / 4}
$$

$$
=8.81 \times 10^{-4} \mathrm{v}^{3 / 4} \mathrm{~cm},
$$

where if equals $0.05 \mathrm{~A} \cdot \mathrm{cm}^{-2}$. We have used Eq. (7-4) to estimate the location of grids 6-12, arbitrarlly setting the grid potentials at multiples of $200 \mathrm{kV}$. lad we chosen to conduct a more detalled study, we would have used computer analysis to verify the grid potentials, location, and shape.

The positive-ion beam extracted from the source is driven through the cesium double charge-exchange cell, where $20 \%$ of it becomes negative and thi remainder becomes neutral. As a result, all ions extracted from the source enter the accel region, but only those atoms in the high-energy neutral beam leave the injector. A gas load equivalent to their difference must be pumped away by the cryopump panels surrounding the beam line.

The low-temperature gas flow equivalent to the extracted ion beam $\left(\mathrm{I}^{+}\right)$ can be expressed as

$$
\begin{aligned}
u_{B} & =(0.19)\left(\frac{1}{2} n_{1}+n_{2}+\frac{3}{2} n_{3}\right) I^{+} \\
& =129.2 \operatorname{Torr} \cdot 1 \cdot \mathrm{s}^{-1} .
\end{aligned}
$$

The gas flow equivalent to $122.5 \mathrm{~A}$ of neutral beam $\mathrm{D}^{0}$ is

$Q_{N}=(0,19) D^{0}=23.3 \operatorname{Torr} \cdot 1 \cdot \mathrm{s}^{-1}$.

The cryopumps must therefore handle the difference:

$Q_{c p}=\left(Q_{E}-q_{n}\right)=105.9 \operatorname{tarr} \cdot 1 \cdot \mathrm{s}^{-1}$.

$A$ baffled cryopanel has a pumping speed of $91 \cdot \mathrm{s}^{-1} / \mathrm{cm}^{2}$. This will be reduced in practice to about 2 $1 \cdot \mathrm{s}^{-1} / \mathrm{cm}^{2}$ to allow for the pumping restriction created by the ele:trostatis shields between the beam line and the pumping walls. Thus, two 5-m by $5-m$ walls of cryopanels - one on each side of the beam line - will establish a pumping speed of $10^{6}$ $1 \cdot \mathrm{s}^{-1}$, and the average pressure in the injector will be less than

$$
p=\frac{Q C P}{S}=10^{-4} \text { Torr. }
$$

The fraction of negative ions that becomes neutral as a result of electron stripping between the various grids of the accel system can be estimated by

$$
F_{-10}=n_{b} \int_{\Delta x}{ }_{-10} d x .
$$

The ionization rate of the background gas can be similarly evaluated in terms of a fraction of the incident beam; i.e.,

$$
F_{i}=n_{b} \int_{\Delta X} \sigma_{i} d x .
$$

The stripping cross section for negative ions $\left(\sigma_{-10}\right)$ and the ionization cross section $\left(\sigma_{1}\right)$ are both known 
ro be functions ut lie cuscrit of the incident ion bein (sed Fin. 7-4): the variation of the bean potential ilong the baan path has been previously evaluated. This enables , s to datermine that the cross sections are a function of the beam path (sce Fig. 7-5). be have calculated the arca under each section of curves, corresponding to particular grid gaps. The fractions $F_{-10}$ and $F_{i}$ are computed from an assumed background has density of $\mathrm{n}=2.3 \cdot 10^{12} \mathrm{~cm}^{-3}$. These values are tabulated is the beam neutralization and the background ionization in lines 6 through 11 of Table 7-1. From these values, we determine that only $151 \mathrm{~A}$ of $\mathrm{D}^{-}$enters the stripping cell.

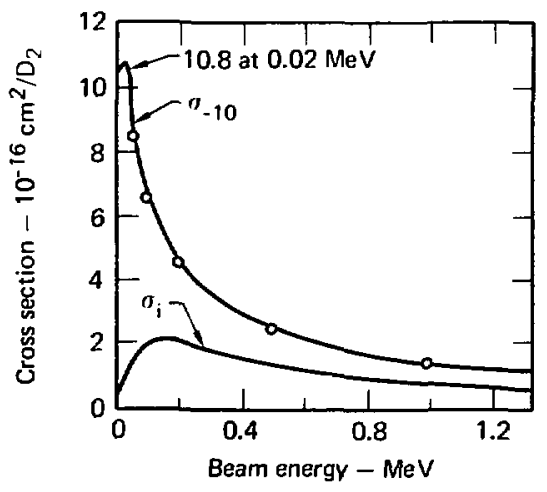

Fig. 7-4. Ionization and chargeexchange cross sections as a function of beam energy.

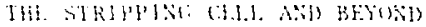

The fractions of the incident negative-ion beam that remain negative, become neutral, or become positive can be represented by the same equations for both a vapor coll and a plasma cel1; $1 . .$. ,

$$
\begin{gathered}
F_{0}=\left(\begin{array}{c}
-10 \\
-10-j 01
\end{array}\right)[\exp (-01 "), \\
\left.-\exp \left(-j-10^{\circ}\right)\right], \\
F^{-}=\exp \left(-;-10^{i}\right) \\
F^{+}=\left(1-F_{0}-F^{-}\right),
\end{gathered}
$$

where $j_{-10}$ is the stripping cross section of the negative ion, and $0_{01}$

Grid no.

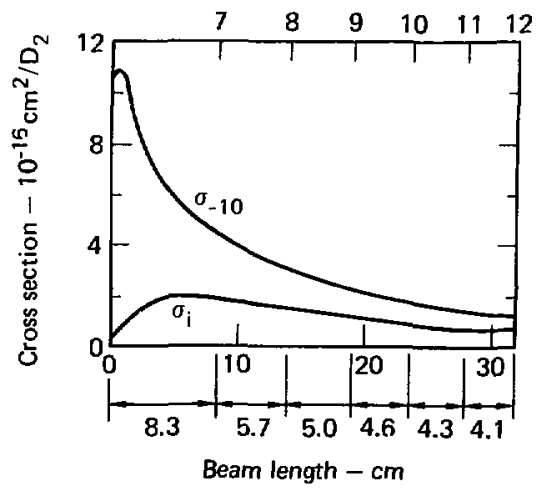

Fig. 7-5. Ionization and chazgeexchange cross sections along the beam path. 
is the corresponding ionization cross section of the neutral. At high energy, we neglect the cross sections $\sigma_{1-1}$, $\sigma_{-1,1}$, and $\sigma_{0-1}$.

The approprlate cross sections for a 1.2-MeV negative ion beam are listed below for l,oth vapor and plasma.

$\begin{array}{lll}\begin{array}{c}\text { Cross section } \\ \left(10^{\left.-16 \mathrm{~cm}^{2} \text { /atom }\right)}\right.\end{array} & \text { Vapor } & \text { plasma } \\ \sigma_{-10} & 1.2 & 14.0 \\ \sigma_{01} & 0.26 & 0.66\end{array}$

The solutions to Eqs. (7-5) through (7-7) are plotted as a function of target thickness in Figs, 7-6 and 7-7. An optimum stripping of $65 \%$ is obtainable with a vapor target that is $1.6 \times$ $10^{16} \mathrm{~cm}^{-2}$ thick; an optimum $85 \%$ stripping can be obtained with a plasma target $2 \times 10^{15} \mathrm{~cm}^{-2}$ thick. The high efficiency of plasma stripping has been experimentally verified. ${ }^{7-10}$

The unneutralized portion of the beam at the optimum vapor- and plasmacell thickness is composed of almost equal densities of positive and negative ions. This composition introduces problems when one attempts to recover the energy from the ions. To circumvent this difficulty, we propose to use an over-fense plasma cell. The stripping efficiency of this overdense cell would be reduced to $81.6 \%$, $18.0 \%$ of the beam would change to positive ions, and the remaining $0.5 \%$ would remain negative. This is shown in the twelfth line of Table 7-1.

The positive 1ons, generated from negatives by the loss of two electrons, have a $2.4-\mathrm{MeV}$ energy relative to the ion source, or a $1.8-\mathrm{MeV}$ energy relative to ground. The beam crosssectional area is somewhat larger than $8 \times 500 \mathrm{~cm}$ and has a positive-ion current of $27.2 \mathrm{~A}$. This corresponds to a positive-ion current density of less than $6.8 \times 10^{-3} \mathrm{~A} \cdot \mathrm{cm}^{-2}$ and a power density of less than $12.2 \mathrm{~kW} \cdot \mathrm{cm}^{-2}$ at the ground-potential beam dump. If the beam were allowed to expand to about four times its original size, it could be readily collected in a grounded beam dump at an intensity of $-3 \mathrm{~kW} \cdot \mathrm{cm}^{-2}$ (see Fig. 7-8). A power savings of 17.1 MW could be realized, assuming a $35 \%$ efficient thermal recove $\%$.

A plasma thickness of roughly 2 $\times 10^{15}$ ions $/ \mathrm{cm}^{2}$ is required in the stripping cell to obtain the desired efficiency. This creates a need for a cell, 20 to $200 \mathrm{~cm}$ long, with a plasma density of $10^{14}$ to $10^{13} \mathrm{~cm}^{-3}$. The plasma ion density in the stripping cell must be sufficiently high $80 \%$ or better - to prevent a significant fraction of the high-energy neutralized beam from being re-ionized by collisions with background neutrals.

These requirements can be satisfled in a metal-vapor plasma produced by surface ionization if the ionization potentlal of the vapor is low and the 


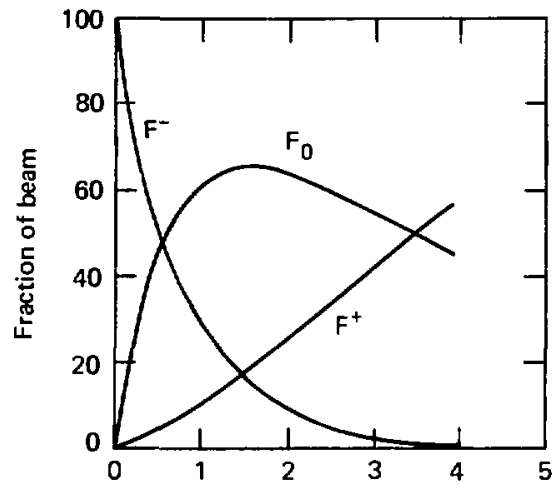

\begin{tabular}{|l|c|c|}
\hline \multicolumn{1}{|c|}{ Item } & Optimum & Preferred \\
\hline $\mathrm{F}_{0}(\%)$ & 65.5 & 60.3 \\
$\mathrm{~F}^{+}(\%)$ & 19.8 & 34.7 \\
$\mathrm{~F}^{-}(\%)$ & 14.7 & 5.0 \\
Target & & \\
thickness & & \\
$\left(10^{16} \mathrm{~cm}^{-2}\right)$ & 1.6 & 2.5 \\
\hline
\end{tabular}

Target thickness $-10^{16}$ atoms $/ \mathrm{cm}^{2}$

Fig. 7-6. Beam composition in a cesium-vapor stripping target.

surface has a high work function. Surface ionization for the impingement of metal vapor on most refractory metals has been studied, and the theory for cesium vapor in contact with hot tungsten is well known. ${ }^{7-11}$ Numerous experiments ${ }^{7-6}$ on "Q machines" and the like have shown that atom, ion, and electron fluxes are a function of surface ionization and thermionic electron emission, not volume effects. The stripping cell must therefore have

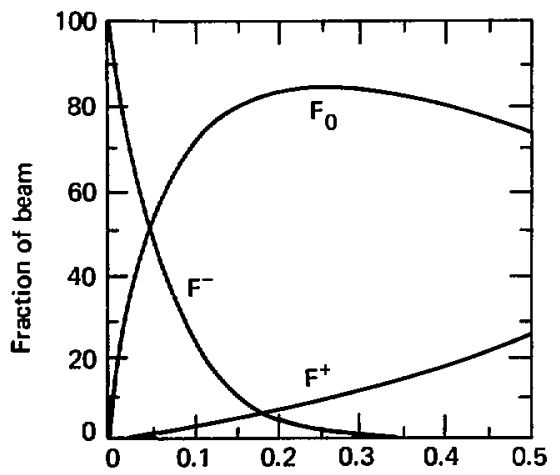

\begin{tabular}{|l|c|c|}
\hline \multicolumn{1}{|c|}{ Item } & Optimum & Preferred \\
\hline $\mathrm{F}_{0}(\%)$ & 85.7 & 81.5 \\
$\mathrm{~F}^{+}(\%)$ & 8.4 & 18.0 \\
$\mathrm{~F}^{-}(\%)$ & 5.9 & 0.5 \\
$\begin{array}{l}\text { Target } \\
\text { thickness } \\
\left(10^{16} \mathrm{~cm}^{-2}\right)\end{array}$ & 0.2 & 0.38 \\
\hline
\end{tabular}

Target thickness $-10^{16}$ (electrons + ions) $/ \mathrm{cm}^{2}$

Fig. 7-7. Beam composition in a cesium-plasma st ripping cell. 
a cesium ion density equal to the electron density. This requires an emitted electron current density of 10 to $100 \mathrm{~A} \cdot \mathrm{cm}^{-2}$ and a corresponding tungsten temperature of 1400 to $3300 \mathrm{~K}$, depending on what fraction of the surface $(\Theta)$ is coated with cesium. Since the evaporation rate of cestum atoms and ions from the tungsten surface depends upon the temperature and $\checkmark$, an $80 \%$ lonlzed plasma implies a value of $\theta$ that is no greater than 0.1 . Experiments ${ }^{7-6}$ have shown that these requirements can be met for plasma densities of $10^{13}$ to $10^{14} \mathrm{~cm}^{-3}$ when the temperature of the tungsten is at 2300 to $2800 \mathrm{~K}$.

For several reasons, stripping cells should be designed at relatively low density $\left(10^{13} \mathrm{~cm}^{-3}\right)$ and greater length $(200 \mathrm{~cm})$ :

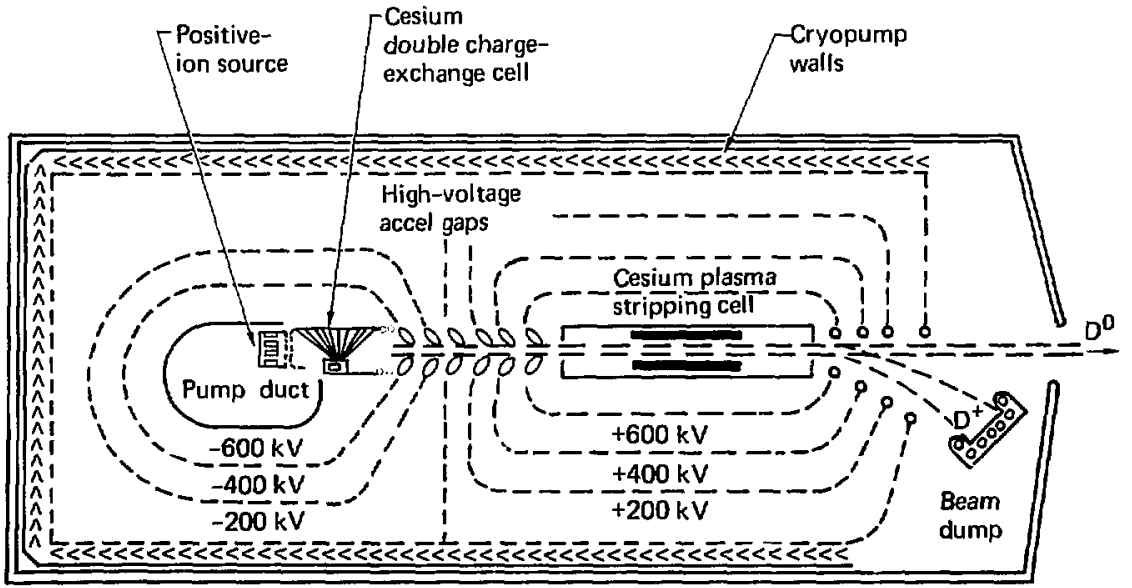

Fig. 7-8, A 1,2-MeV neutral-beam injector. 
along the beam line into the ion source or the reactor. Cesium losses in a $Q$ mechine are prevented by a transverse magnetic field of about $0.1 \mathrm{~T}$. If such fields were introduced at the entrance and exit to the stripping cell, no serious deflection of the ion beam would result at $1.2 \mathrm{MeV}$. Hot-tungsten sheets can be hung vertically in the infectors, thus limiting the severity of the structural problem.

If the background pressure beyond the stripping cell is $10^{-5}$ Torr or less and the gas temperature is $500 \mathrm{~K}$, the density will be about $2 \times 10 \mathrm{~cm}^{-3}$. The ionization cross section of the neutral beam at $1.2 \mathrm{MeV}$ will be $\sim 0.32 \times 10^{-16} \mathrm{~cm}^{2} / \mathrm{D}_{2}$, and the background ionization cross section will be about the same. The fraction of the neutral beam lost in a 10-m drift region will correspond to $\mathrm{F}_{01}=\mathrm{n} \sigma_{01} \mathrm{X}=0.6 \%$, while the background ionization corresponds to $0.7 \mathrm{c} / \mathrm{s}$. These values are shown in the last line of Table 7-1.

\section{SYSTEM PERFORMANCE}

Throughout this study, we have estimated the background chargeexchange and ionization currents along the beam line (see Table 7-1). Table 7-2 shows the corresponding grid currents that result when every background ion goes to its closest positive electrode and every electron goes to its closest negative electrode. The power supplies needed to sustain these currents are shown in Fig. 7-9. Table 7-3 shows the power dissipation derived from Table 7-2 at each of the grids.

All electrodes (including the ion source) are maintained at about $500^{\circ} \mathrm{C}$ by removing the dissipated heat via circulating liquid metals. This allows recovery of some waste heat by means of high-voltage, insulated, heat exchangers located in the pressurized $\mathrm{SF}_{6}$ chambers. Some of this thermal energy can be used to heat the mercury ejector pumps and to evaporate the cestum in the double charge-exchange cell. The remainder, converted to electricity at $35 \%$ efficiency, results in a savings of $15.5 \mathrm{MW}$, as shown in Table 7-4. From the net result shown in Table 7-5, we determine that the neutral-beam injector has an overall power efficiency of $73 \%$.

It is impossible to establish accurately the cost of each injector from the data we have presented. However, we can estimate the cost on the basis of $\$ 320 / \mathrm{kW}$ divided by the beam efficiency. This gives an estimated total of $\$ 65$ million for the entire injector system for the TMR. 
Table 7-2. Estimates of grid currents. The odd-numbered lines represent the beam loss due to charge exchange; the even numbered lines show the background current caused by ionization.

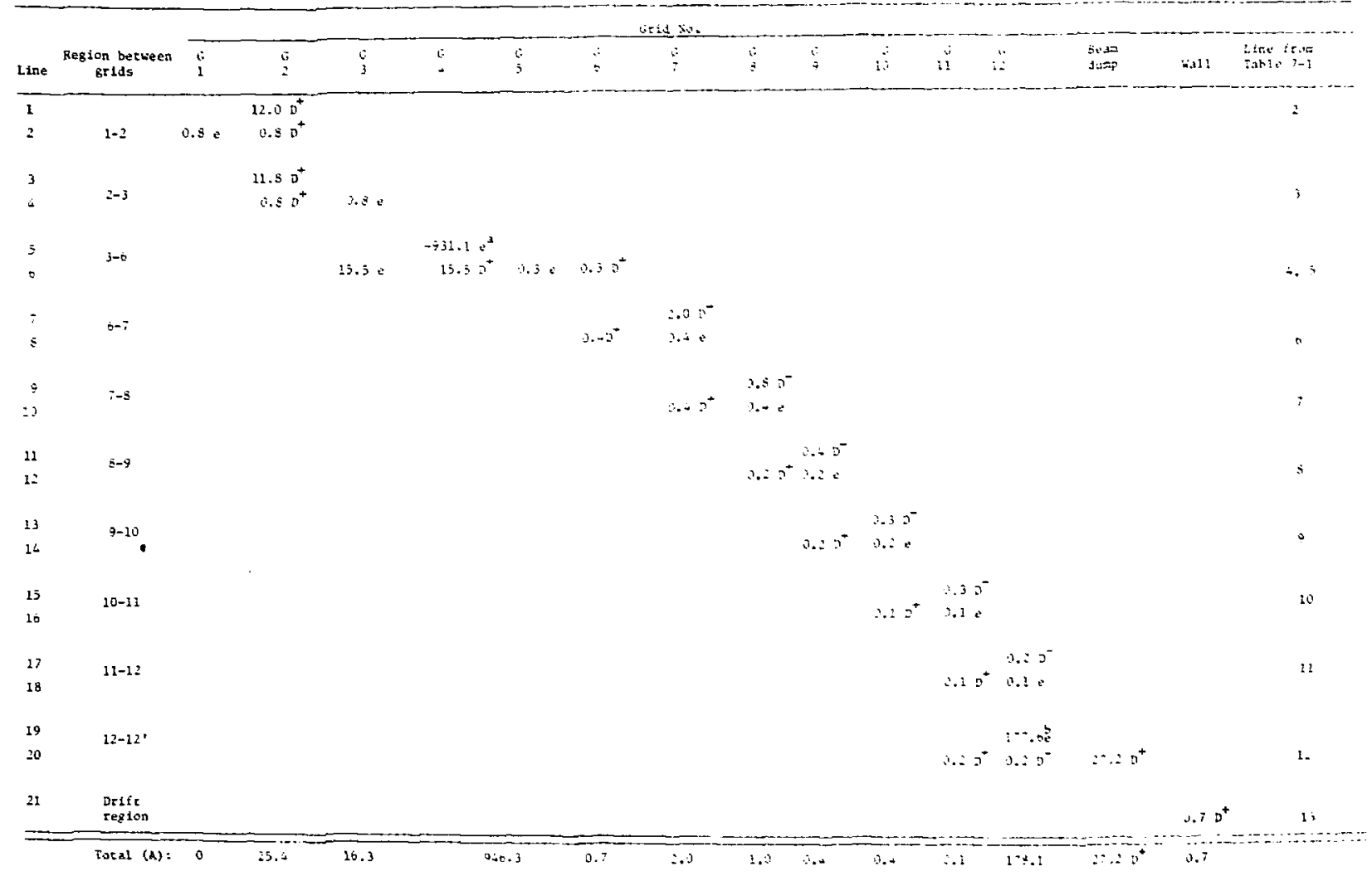

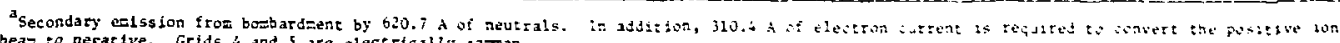
beaz :o nagative. Grids 2 and 5 age electrically soxs.

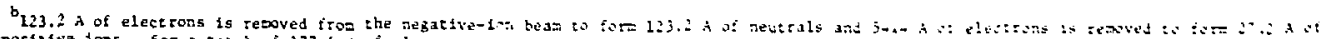
positive tons - for a total of 177.6 A of electrons. 


\section{Table 7-3. Crid dissipation data taken from Table 7-2.}

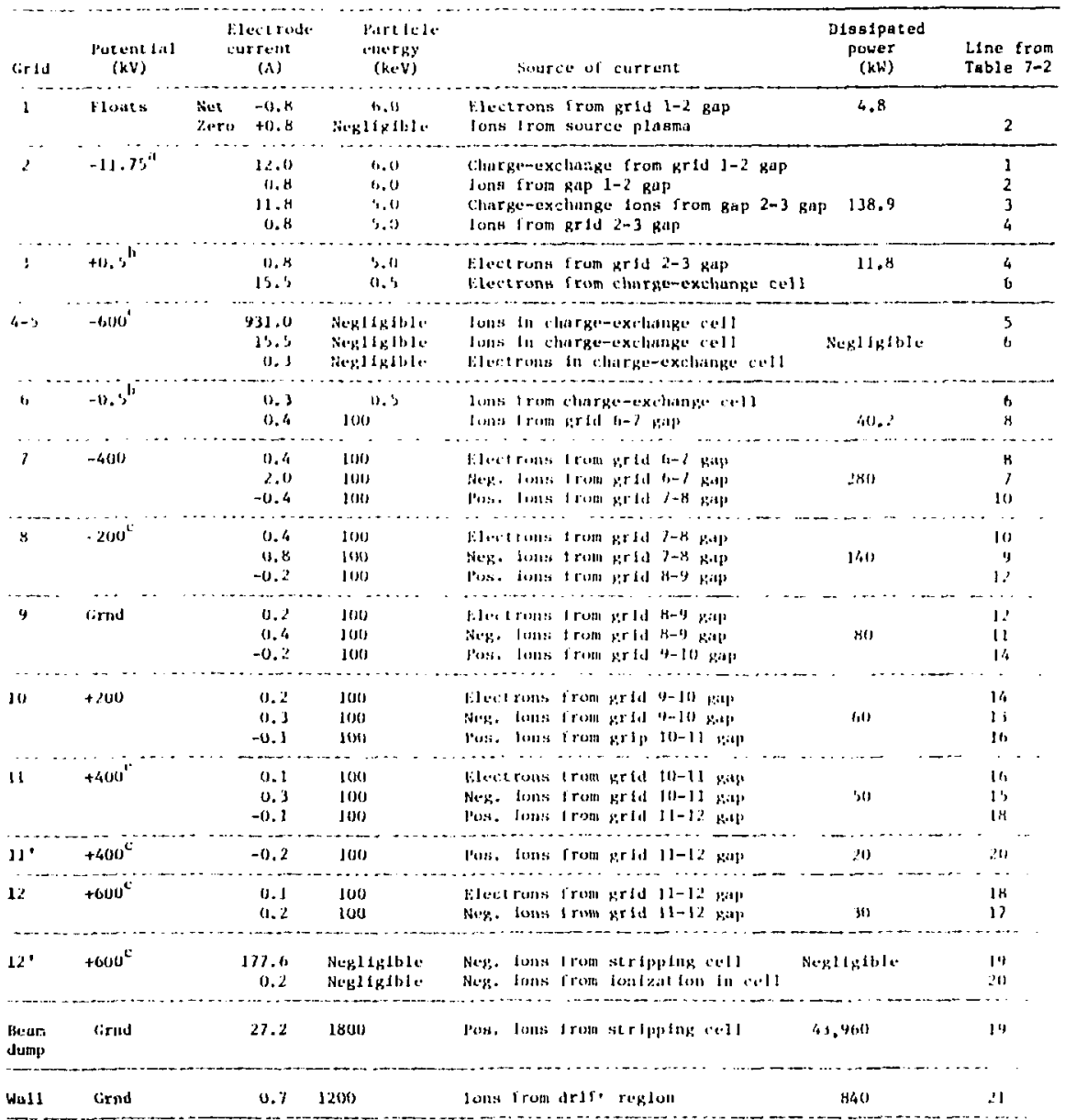

Relaclec to sourcu.

${ }^{b}$ Relat lue ta charge-exchange eell.

Relat ive to proulit. 
We have described a neutral-beam injector that consists of flve components, each entalling a significant development effor $\mathrm{L}$. These components are

- A continuously operating source of negative Ions. This source uses a gas-tight, ceslum-vapor cell equipped with a flowing, liquid-metal cooling system.

- A high-voltage, negative-ion accel system design with conservative gi id loadings and an acceptable level of high-voltage stress.

A plasma-stripping cell modeled after a " $Q$ machine" and a beam dump to collect the unstripped ions.

- A large injector assembly whose walls are covered with continuously regenerating cryopanels and a complex set of high-voltage electrostatic shields that inhibit voltage breakdown.

- Reliable power supplies with associated protective equipment and diagnostic display and control components.

The prospect of a 122-A injector of 1.2-MeV neutral deuterfum atoms

\begin{tabular}{llc} 
Electrode & $\begin{array}{l}\text { Electrode } \\
\text { area }\left(\mathrm{cm}^{2}\right)\end{array}$ & $\begin{array}{l}\text { Dissipated } \\
\text { power }(\mathrm{kW})\end{array}$ \\
\hline$P_{\mathrm{fii}}$ & 10,000 & $\left\{\begin{array}{c}150 \\
1,540\end{array}\right.$
\end{tabular}

Grid

\begin{tabular}{|c|c|c|}
\hline 1 & 2,000 & 5 \\
\hline 2 & 2,000 & 140 \\
\hline 3 & 2,000 & 12 \\
\hline 4,5 & 2,000 & - \\
\hline 6 & 2,500 & 40 \\
\hline 7 & 2,500 & 280 \\
\hline 8 & 2,500 & 140 \\
\hline 9 & 2,500 & 80 \\
\hline 10 & 2,500 & 60 \\
\hline 11 & 2,500 & 50 \\
\hline 12 & 2,500 & 30 \\
\hline $12^{\prime}$ & 2,500 & \\
\hline $11^{\prime}$ & 2,500 & 20 \\
\hline Beam dump & 18,000 & 48,960 \\
\hline & Total: & 52,347 \\
\hline
\end{tabular}

Total waste heat (from table above)

Direct use of waste heat:

Mercury ejector pump 6,000

Cesium double chargeexchange cell 2,000

Total: less direct use of waste heat $\frac{8,000}{44,347}$

Waste heat

Electric power obtained from waste heat (at $35 \%$. converston efficiency) $15,521 \mathrm{~kW}$ 
may be awesome, but we have identified no basic constraints that would prevent its construction. The model we present is, in fact, based upon suc- cessful physics experiments. rranslating these ideas into a reliable operating machine will, nevert reless, be an impressive undertaking.

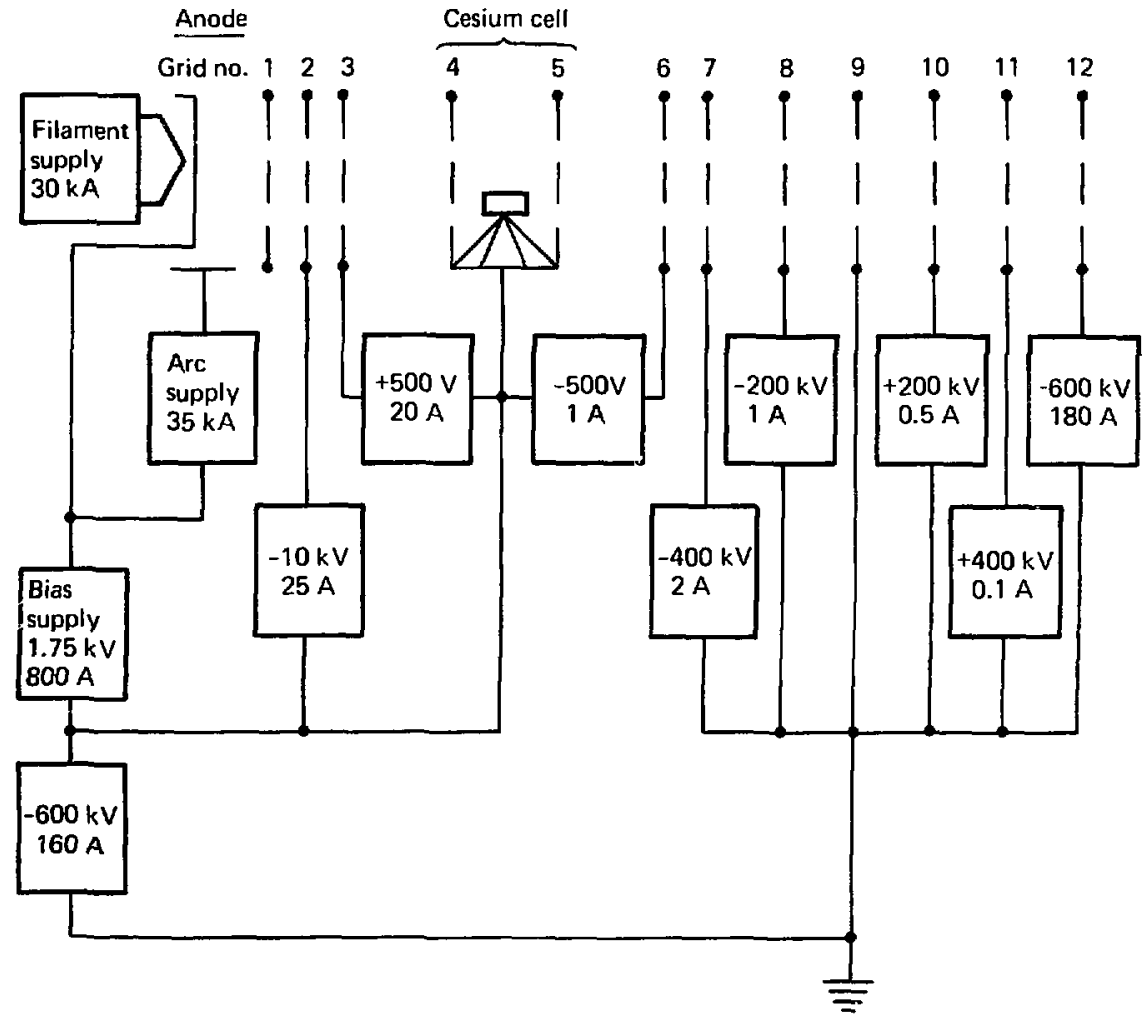

Fig. 7-9. Power supplies needed to sustain the currents in a $1.2-\mathrm{MeV}$ neutralbeam injector. 
Table 7-5. Power distribution.

\begin{tabular}{|c|c|c|c|c|c|}
\hline $\begin{array}{l}\text { Power } \\
\text { supply }\end{array}$ & $\begin{array}{l}\text { Vol tage } \\
(\mathrm{kV})\end{array}$ & $\begin{array}{l}\text { Current } \\
\text { (A) }\end{array}$ & $\begin{array}{l}\text { Power output } \\
\text { (MW) }\end{array}$ & $\begin{array}{c}\text { Efficiency } \\
(\%)\end{array}$ & $\begin{array}{l}\text { Power input } \\
\text { (MW) }\end{array}$ \\
\hline Filament & $5^{a}$ & $30^{b}$ & 0.15 & 90 & 0.17 \\
\hline Arc & $45^{a}$ & $35^{b}$ & 1.58 & 90 & 1.76 \\
\hline Bias & 1.75 & 800 & 1.40 & 90 & 1.56 \\
\hline \multicolumn{6}{|l|}{ Grid } \\
\hline 2 & 10.0 & 25 & 0.25 & 90 & 0.28 \\
\hline 3 & 500 & 20 & 0.01 & 90 & 0.01 \\
\hline 6 & -500 & 1 & - & 90 & - \\
\hline Cathode & -600 & 160 & 96.00 & 97 & 98.97 \\
\hline \multicolumn{6}{|l|}{ Grid } \\
\hline 7 & -400 & 2 & 0.80 & 90 & 0.89 \\
\hline 8 & -200 & 1 & 0.20 & 90 & 0.22 \\
\hline 10 & 200 & 0.5 & 0.10 & 90 & 0.11 \\
\hline 11 & 400 & 0.1 & 0.04 & 90 & 0.04 \\
\hline 12 & 600 & 180 & 108.00 & 97 & 111.34 \\
\hline Total pov & I supply & t : : & & & 215.35 \\
\hline \multicolumn{6}{|c|}{ Auxiliary equipment: } \\
\hline \multicolumn{4}{|c|}{ Mercury ejector pumps (operate from waste heat) } & & 0.00 \\
\hline \multicolumn{4}{|c|}{ Roughing pump (negligible) } & & 0.00 \\
\hline \multicolumn{4}{|c|}{ Cryopumps (at $0.7 \mathrm{~h} / 1 . \mathrm{s}^{-1}$ ) } & & 0.70 \\
\hline \multicolumn{5}{|c|}{ Double charge-exchange cell (operates from waste heat) } & 0.00 \\
\hline \multicolumn{5}{|c|}{ Plasma-stripping cell } & 1.00 \\
\hline \multicolumn{5}{|c|}{ Total power: } & 217.00 \\
\hline \multicolumn{5}{|c|}{ Energy recovery (from Table 7-4): } & 15.50 \\
\hline \multirow{2}{*}{\multicolumn{5}{|c|}{$\begin{array}{l}\text { Beam power output }(122.5 \mathrm{~A} \text { at } 1.2 \mathrm{MeV}): \\
\text { Injector efficiency } \frac{\text { beam power output }}{\text { total power }- \text { energy recovery }}\end{array}$}} & 147.00 \\
\hline & & & & & \\
\hline
\end{tabular}

axpressed as volts.

${ }^{b}$ Expressed as kiloamps. 


\section{REFERENCES}

7-1; T. K. Fowler and B. G. logan, "The Tandem Mirror Reactor,"

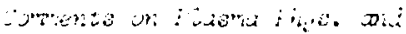

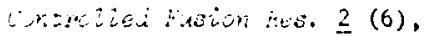
167 (1977).

7-2, J. W. Beal and V. K. Neil, A Hethod for dehiesing lun ite

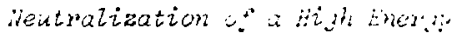
Chargel Pirticte Exw, Lawrence Livermore Laboratory, Rept. UCRI-76505 (1974).

7-3. W. L. Barr and R. W. Molr, "A Review of Direct Energy Conversion for Fusion Reactors," in Proc. Second Topical leeting reehnology of Controzled Nuclear jusion, Kichland WA, 1976 (ERDA, CONF760935, 1976), p. 1181.

7-4. K. H. Berkner, R. V. Pyle, and $J$. W. Stearns, "Intense, Mixed-Energy, Hydrogen Beams for CTR injection," Wuez. Fusion 15, 249 (1975).

7-5. J. H. Fink, W. L. Barr and G. W. Hamilton, A Study of Efficient High-Power, HighEnergy Neutral Beoms for the Reference Mirror Reactor, Lawrence Laboratory, Rept. UCRL-52173 (1976).
7-0. $\therefore$. kynn, rinceton University, private contumication (1977)

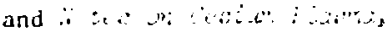

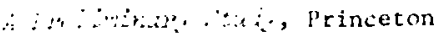
Universicy, Princeton, A, J., Tuchnical Memorandum No. 81 (1959).

7-7. I. J. M. Sluyters, R. A. Mari, v. Kovarik, R. Lockey, and S. Senacor, "A.Bright HighGradient 750-keV lon Gun,"

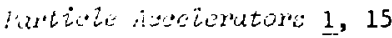
(1970) .

7-8. A. S. Schlachter and J.W. Stearns, "Equilibrium Yield of $\mathrm{D}^{-}$by Charge Exchange of $0.5-3 \mathrm{keV} \mathrm{D}^{+}$in Cesium Vapor," Bult. An. Phys. Soc. 21, 1135 (1976).

7-9. 0. A. Anderson, A Compact High-Energy Neutral Beam System, Lawrence Livermore Laboratory, Rept. UCID-16914 (1975).

7-10. G. I. Dimov and G. V. Roslyakov, "Conversion of a Beam of Negarive Hydrogen Ions to Atomic Hydrogen in a Plasma Target at Energies Between 0.5 and $1.0 \mathrm{MeV}, "$ Nucl. Fusion 15, 551 (1975).

7-11. J. B. Taylor and I. Langmuir, "The Evaporation of Atoms, Ions and Electrons from Cesium Films on Tungsten," Phys. Rev. 44, 423 (1933). 


\title{
CHAPTER 8. DIRECT ENERGY CONVERTER FOR THE TANDEM MIRROR REACTOR
}

\author{
W. L. BarP
}

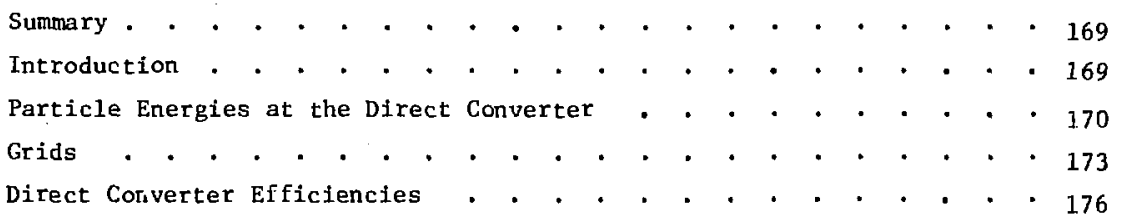


SUMMARY

Direct converters to recover power from the plasma lost from the ends of the Tandem Mirror Reactor (TMR) can be very effective. The high ambipolar potential and the low ion temperature result in good efficiency even with a single collector stage. About $60 \%$ of the total efflux power (carried by escaping fuel ions, alpha particles, and electrons) can be directly recovered after allowing for losses due to plasma electrons, grid interception, secondary and thermionic electrons. The two types of region in the TMR - the central cell and the end plugs - result in two distinct energy groups of ions and suggest a two-stage direct converter. The addition of a second collector stage in the direct converter raises its efficiency to about 70\%. The direct converter would also serve to control the recycling of cold electrons from the end walls. Problems associated with space charge, voltage holding, and capacitively stored energy appear to be solvable.

INTRODUCTION

A TMR produces a set of conditions at the ends that is quite different from that of other mirror reactors. In particular, the high ambipolar potential in the end plugs results in a high minimum energy for the efflux ions when they reach the direct converter (DC). Also, the high potential in the end plugs enhances the confinement of the alpha particles. Methods for preventing the buildup of alphas are discussed in the chapter on plasma physics (Chapt. 3). Here, we assume for simplicity that the alphas thermalize and finally escape to the DC in a manner stmilar to the escape of fuel ions from the central cell. If in fact the efflux alphas are concentrated in a particular flux tube, this should not require any major change in the DC. The large potential difference between the plasma in a plug and the grounded grid at the $D C$ is not expected to be a problem. The plasma density at the magnetic mirror is low compared to the density at the center of the plug $\left(10^{9} \mathrm{~cm}^{-3}\right.$ vs $\left.10^{15} \mathrm{~cm}^{-3}\right)$. For electron density to be equal to the ion density at both places, the potential at the mirror must be down about $1 / 13$ from the value at the center. Therefore, because the potential at a mirror is less than $\mathrm{kT}_{\mathrm{e}}=42 \mathrm{keV}$, only a modest potential difference exists between the mirror and the end wall.

Even so, there remains a small gradient in potential outside of the mirrors that tends to pull cold 
electrons from the end walls into the plasma. These electrons are produced on the end walls almost entirely by ion rather than electron impact, because the energy of the primary electrons is so high $(\sim 42 \mathrm{keV})$ that their coefficient for the production of secondary electrons is extremely small. Therefore, by collecting the ions on positive collectors in a direct converter, the only electrons produced at the end walls will be those from the grids in front of the DC. The direct converter thus can play the dual role of recovering power from the ions and of controlling the release of electrons from the ends.

The magnetic field at the $D C$ is low, only about $100 \mathrm{G}$, because of the large expansion ratio that is required to reduce the power density from the $1400 \mathrm{MW} / \mathrm{m}^{2}$ in each mirror throat to the allowed $1 \mathrm{MW} / \mathrm{m}^{2}$ at the DC.

Other novel features of the TMR that affect the $D C$ are the high value of $Q$ and the two distinct groups of Ion energies, as discussed next.

PARTICLE ENERGIES AT THE DIRECT CONVERTER

The performance of the DC depends on thi energies of the various charged particles at the entrance to the DC. The energies there are determined by the energies and the ambipoiar potentials inside the plug and central-cell regions. Although the DC actually consists of two units (one at each end), the currents and powers to the DC are calculated here for the combined DC system. Quantitics evaluated at the $D C$ will be indicated by a prime to distinguish them from the corresponding values inside the reactor. Otherwise, the notation used here is the same as that used in the sectlon on plasma physics.

The total charge particle power $P_{d c}$ at the $D C$ is given by the sum

$$
P_{d c}=1 \bar{E}_{p}^{\prime}+1 \bar{E}_{c}^{\prime}+\frac{1}{2} 1_{\mu}^{\prime} E_{\mu}^{\prime}+I_{e} \bar{E}_{e}^{\prime},
$$

where $\mathrm{I}_{\mathrm{p}}^{\prime}=438.5 \mathrm{~A}$ is the ion current from the plugs, which is just equal to the trapped fraction (89.6\%) of the neutral-beam equivalent current injected into the plugs. The average energy $\overline{\mathrm{E}}_{\mathrm{P}}^{*}$ of these ions at the $\mathrm{DC}$ is equal to the injection energy, 1200 $\mathrm{keV}$, first reduced by the loss due to electron drag during the containment time of an average plug ion, and then increased by the difference in potential between plug and DC. The amount $\Delta E_{p}$ by which electron drag reduces the energy of a plug ion during its lifetime is estimated here by multiplying the average rate of energy transfer by the average Iffetime of a plug ion. That is, 


$$
\begin{aligned}
L E_{p} & =\left(\bar{E}_{p}-1.5 T_{e}\right)(n \tau)_{p} /(n:)_{i e} \\
& =743 \mathrm{kev},
\end{aligned}
$$

because $\overline{\mathrm{F}}_{\mathrm{p}}=878 \mathrm{keV}$ in the plugs and the equipartition tine $(n){ }_{i e} \approx 10^{12}$ $\mathrm{T}_{\mathrm{e}}^{3 / 2}$ in tisese units. The potential drop from plug to $\mathrm{x}$ is $:_{e}+:_{1}=351$ kv. Therefore, $\overrightarrow{\mathrm{F}}_{\mathrm{p}}^{*}=807 \mathrm{keV}$. The current 1; from the central cell to the $D C$ can be determined from the power balance (below) to be $1_{c}^{\circ}=$ $1284 \mathrm{~A}$. The mean energy of these ions as they clear the potential barrier in the end plugs has been shown to be equal to 'T there, and $\mathrm{I}_{\mathrm{c}}=30 \mathrm{keV}$. They are then accelerated by the $350-\mathrm{kV}$ potential difference, giving $\overrightarrow{\mathrm{E}}_{\mathrm{c}}^{*}=380 \mathrm{keV}$.

The electrical current due to alpha particles, $\mathrm{I}^{\prime}=288 \mathrm{~A}$, is obtained directly from the rate of fusion reactions: $\mathrm{I}_{\mathrm{A}}=2 \mathrm{eP}_{\mathrm{F}} / \mathrm{E}_{\mathrm{F}}$, with $P_{F}=2532 \mathrm{sW}$ and $E_{F}=17.58 \mathrm{MeV} . \Lambda 11$ of the alphas are assumed to thermalize $\left(f_{s}=1.0\right.$, see Chapt. 3), so that the mean energy of the alphas at the DC is $\vec{E}_{\alpha}^{\prime}=30+2 \% 350=73 n \mathrm{keV}$ by the same reasoning as for $\overline{\mathrm{E}}_{\mathrm{c}}^{\prime}$. Since the electrons are also electrostatically confined, their mean energy at the DC is just $\bar{E}_{e}^{\prime}=T_{e}=$ $42 \mathrm{keV}$. The electron current $\mathrm{I}_{\mathrm{e}}^{\prime}$ must be equal to the sum of the ion currents:

$$
I_{e}^{\prime}=I_{p}^{\prime}+I_{c}^{\prime}+I_{\alpha}^{\prime}
$$

Whon Eqs. 8-1 and 8-2 are combined, 1: is determined in terms of $\mathrm{p}^{-}$, and

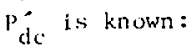

$\mathrm{P}_{\mathrm{dc}}=\mathrm{P}_{\mathrm{in}}+0.2 \mathrm{P}_{\mathrm{F}}-0.8 \mathrm{I} \mathrm{E}_{\mathrm{c}} \cdot(8-3)$ Here, $P_{i n}=526 \mathrm{sW}$ is the power that is injected and trapped, and $\mathrm{F}_{\mathrm{F}}=$ $2530 \mathrm{Mt}$ is the fusion power. The second term in the right-hand side of Eq. $8-3$ fives the power carried by the alphas, and the last term represents the $80 \%$ of the residual kinetic energy, $\vec{E}_{c}=\frac{3}{2} \mathrm{~T}_{c}$, of the reacting $\mathrm{D}^{+}$ and $\mathrm{r}^{+}$ions that is carried away by the resulting neutrons and is not available for direct conversion. This last term has only a $1 \%$ effect here and is therefore ignored in determining $\mathrm{P}_{\mathrm{dc}}^{*}$ and $\mathrm{I}_{\mathrm{c}} \cdot$. When these three equations are combined, the result is that $\mathrm{I}_{\mathrm{c}}^{\prime}=1284 \mathrm{~A}$ and $\mathrm{I}_{\mathrm{e}}^{\prime}=$ $2011 \mathrm{~A}$.

It is interesting to check the self-consistancy of the parameters. From Table 2-2 in Chapt. 2, the volume of plasma in the central cell is $v_{c}=452 \mathrm{~m}^{3}$, the density is $\mathrm{n}_{c}=$ $1.1 \times 10^{20} \mathrm{~m}^{-3}$, and $(\mathrm{nT})_{\mathrm{c}}=$ $7.7 \times 10^{20} \mathrm{~s} / \mathrm{m}^{3}$. Combining these values gives $I_{c}^{\prime}$, the loss current from the central cell, as

$$
I_{c}^{\prime}=V_{c} n_{c}^{2} e /(n \tau)_{c}=1140 \mathrm{~A} .
$$

This is on $1 y$ about $10 \%$ lower than the value obtained from $\mathrm{P}_{\mathrm{dc}}^{-}$and serves as 


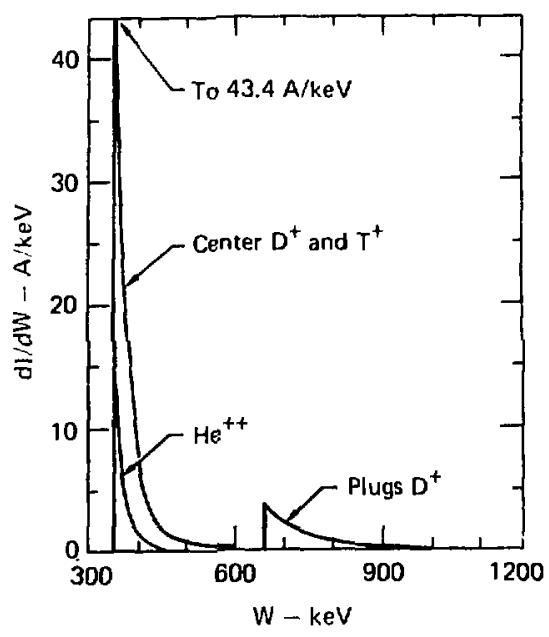

Fig. 8-1. The distribution In ion energy at the direct converter. For $\mathrm{He}^{++}$, the energy per unit charge is plotted.

a satisfactory check on the various quantities involved. In analyzing the $D C$, we use $I_{C}^{\prime}=1284 \mathrm{~A}$.

The approximate energy distributions for these three groups of ions at the $\mathrm{DC}$ are sketched in Fig. 8-1. For the fuel ions from the central cell, we take a two-dimensional Maxwe1lian

$$
\begin{aligned}
\frac{\mathrm{dI}_{\mathrm{c}}^{\prime}}{\mathrm{dE}_{\mathrm{c}}^{\prime}} & =\left(5.06 \times 10^{6} \mathrm{~A} / \mathrm{k}_{\mathrm{t}} \cdot \mathrm{V}\right) \\
& \cdot \exp \left(-\mathrm{E}_{\mathrm{c}}^{\prime} / 30.0\right), 350 \leq \mathrm{E}_{\mathrm{c}}^{\prime},
\end{aligned}
$$

where the low-energy cutoff is set by the minimum energy that an ion can have after passing over the potential barrier in the plugs. Similarly, for the alpha particles we take

$$
\begin{aligned}
\frac{\mathrm{dI}^{\prime}}{\mathrm{dE}^{\prime}} & =\left(1.35,10^{11} \mathrm{~A} / \mathrm{keV}\right) \\
& \cdot \exp \left(-\mathrm{E}_{, \prime}^{\prime} / 30.0\right), 730 \simeq \mathrm{E}_{\mathrm{\prime}}^{\prime} .
\end{aligned}
$$

The distribution function for the ions from the plugs is different. Neutral atoms injected with energy $E_{p, \text { in }}$ are ionized and trapped in the plugs. Once tonized, they begin to lose energy to the electrons, which have a lower mean energy. As the ion energy decreases due to the electrou drag, the frequency of elastle collisions with other ions increases, with the result that as its energy is lowered an ion has an increasing probability of finding the loss cone and escaping from the plug. The energy distribution of the ions escaping from the plug is therefore peaked at low energy. At the $\mathrm{DC}$, the entire distribution is shifted up in energy by the difference in potential.

An expression that fits this description and gives the known total current and power from the plugs is

$$
\begin{gathered}
\frac{\mathrm{dI}_{\mathrm{p}}^{\prime}}{d \mathrm{dE}_{\mathrm{P}}^{\prime}}=3.47 \times 10^{9} \times\left(\mathrm{E}_{\mathrm{p}}^{\prime}-350\right)^{-3.6}, \\
658 \leq \mathrm{E}_{\mathrm{p}}^{\prime} \leq 1550 .
\end{gathered}
$$

The lower limit on $E_{p}^{\prime}$ is determined by the ambipolar potential $\phi=350 \mathrm{kV}$ 
and the nirror ratio $\mathrm{R}=2.14$ in the plugs :

$$
E_{P, \text { min }}^{\prime}=\frac{R \phi}{R-1}=658 \mathrm{keV} .
$$

The upper limit is just the 1200-keV injection energy increased by the $350-k V$ difference in potential.

Figure 8-1 shows a plot of the combined energy distribution for the three groups of ions at the DC. The two distinct energy groups suggest that to recover both groups efficlently the DC should have two collector stages. The possible efficiencies of both a single-stage and a two-stage DC are evaluated here.

GRIDS

The direct converters that are evaluated here use immersed grids to control the electrons and prevent them from reaching the positive ion collectors (see Figs. 8-2 and 8-3). Two grids are used: the first is held at ground potential and the second is held negative to reflect the electrons. Therefore, the sink for the electrons is the grounded grid, which must be designed to handle all of the power from the electrons plus the power from those Ions that are intercepted. It can be seen from the inmediately preceding discussion of particle energies that the electrons carry about $8 \%$ of the power to the DC. To prcvide an adequate sink for the electrons and to handle the large thermal power, the grounded grid is about $5 \%$ opaque to the beam. It therefore receives about $13 \%$ of the total power to the DC.

The thermal load on the negative grid results only from the ions that it intercepts. It is therefore destrable to keep this grid as transparent as possible, Considerations of heat transfer and of voltage holdIng set the minimum practical opacity at 1 to $2 \%$ for this grid.

iveither grid can be allowed to reach a temperature where thermionic electron emisston is significant, because neither the DC nor the reactor can tolerate a large flux of cold electrons. It is this restriction that sets the limit on the power density that can be handled by the DC.

Convectively cooled grids can be used up to equivalent input power densities of about $500 \mathrm{~W} / \mathrm{cm}^{2}$ if the span is less than about $3 \mathrm{~m}$. Beyond these ranges, the grid becomes too opaque to be practical. Both water and high-pressure hellum have been studied as coolants. Smaller tubes can be used for water than for helium, but the heat is removed from water at a temperature that is too low to allow efficient recovery in a thermal cycle. However, because of 
1032-MW input:

438.5-A, 807-keV $D^{+}$

1284-A, 380-keV, $D^{+}+T^{+}$

288-A, 731-keV He ${ }^{++}$

2011-A, 42-keV e-
First

grid

$v=0$

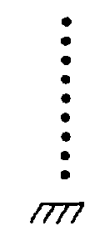

Ground connection
Second

grid

$-170 \mathrm{kV}$

152-A input at $-170 \mathrm{kV}$

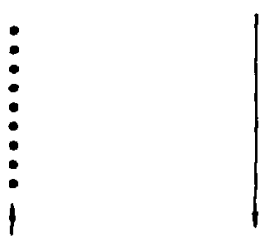

Ion collector

$+350 \mathrm{kV}$

1853-A output at $+350 \mathrm{kV}$

Fig. 8-2. Power and current flow in a single-stage direct converter on the $T M R$, where the efficiency is $\eta_{D C}=[(1853 \times 350)-(152 \times 170)] / 1.032 \times 10^{6}$ $=0.603$.

the danger of fallure among the many tubes operating close to their mechanical limits, convectively cooled grids of all kinds should probably be avoided.

Here, we postulate radiatively cooled grids. Grids made from a carbon/carbon composite material appear able to handle the highest power density of any of the possible materials for radiatively cooled grids. Besides having a high emissivity and a relatively high work function (for lower temperature and decreased thermionic electron emission), the carbon grids appear strong enough to span large distances, thus reducing interception

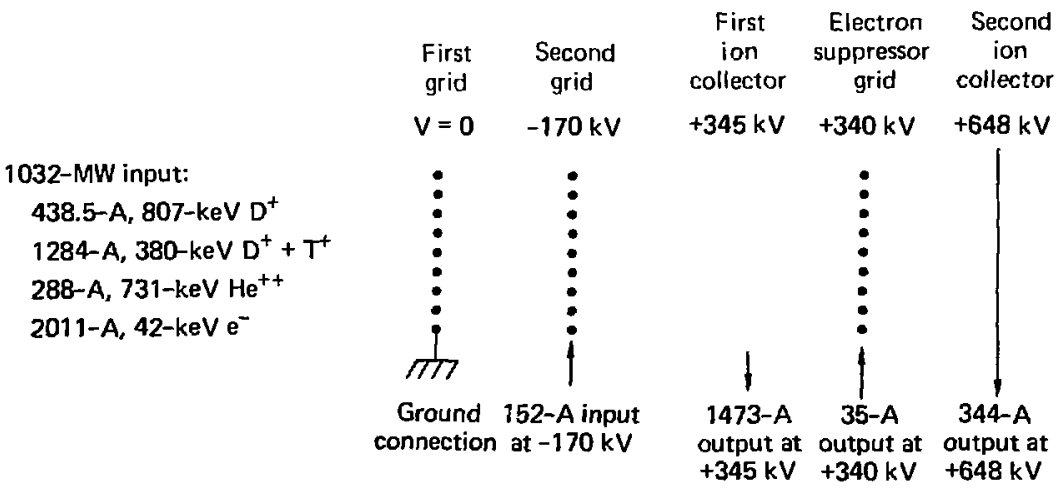

Fig. 8-3. Power and current flow in a two-stage direct converter on the TMR, where the efficiency is $n_{D C}=[(1473 \times 345)+(35 \times 340)+(344 \times 648)$

$-(152 \times 170)] / 1.032 \times 10^{6}=0.695$. 
of the beams by support structure.

Since the efflux plasma is guided by the magnetic field that exists outside the Yin-Yang coils at the ends, the beam is fan shaped with a cross section that is thin compared to the width. By orienting the coils so that the two efflux fans are both horizontal, the grids can be supported above and below across the smaller dimension. No support structure need be immersed in the beam.

The lengths of the fan-shaped expanders are determined by the amount of expansion required to reduce the power density to values that the grids can tolerate. Studies of radiative heat transfer in similar grid structures have shown that graphite grids whose elements have circular cross sections are useful up to about $200 \mathrm{~W} / \mathrm{cm}^{2}$ when the energy of the incident $\mathrm{D}^{+}$and $\mathrm{T}^{+}$ions is about $170 \mathrm{keV}$. Here, the mean energy is $\bar{W}_{i}=472 \mathrm{keV}$, with the result that the collector voltages are about three times higher and the loss of power due to thermionic emission at $200 \mathrm{~W} / \mathrm{cm}^{2}$ is also about three times higher than at $170 \mathrm{keV}$. However, thermtonic emission decreases rapidly as the beam power density is decreased. A power density of 100 $\mathrm{W} / \mathrm{cm}^{2}$ appears to be reasonable, and that is the value that was chosen for this preliminary study.
Because the grounded grid receives all of the primary electrons and most of the secondary and thermionic electrons in addition to the intercepted ions, it actually receives about three times as much power as it simply intercepts from the ions. Thus, the effective power density at the grounded grid is about $330 \mathrm{~W} / \mathrm{cm}^{2}$. To radiate this increased power without heating to thermionic emission temperatures, the elements in the grid can have a noncircular cross section. This can give an increased surface area for radiating away the heat without increasing the beam interception. Maintaining the alignment of such elements may be a serious problem.

The spacing between grids must be small enough to avoid space-charge limitation of the input beam current. Since the input power density is 100 $\mathrm{W} / \mathrm{cm}^{2}$ and the mean ion energy is 472 $\mathrm{keV}$, the current density is $2 \times 10^{-4} \mathrm{~A} / \mathrm{cm}^{2}$. In $\mathrm{Fig} \cdot 8-1$ note that there are two groups of ions; those with a mean energy of $380 \mathrm{keV}$ per unit of charge, and those with $807 \mathrm{keV}$. Also in Fig. 8-1, note that the first ion collector should be set at $350 \mathrm{kV}$. When retarded by $350 \mathrm{kV}$, these two groups of ions have the same density as a $1.6 \times 10^{-4} \mathrm{~A} / \mathrm{cm}^{2}$ beam of mono-energetic ions with 380 keV of initial energy. Such $\approx$ beam 
is space-charge limited at $350 \mathrm{kV}$ when the spacing $1 \mathrm{~s} 3.0 \mathrm{~m}$ from the $V=0$ equipotential. Therefore, the spacing between negative grid ( -170 $\mathrm{kV})$ and first collector $(+350 \mathrm{kV})$ need only be less than $4.5 \mathrm{~m}$.

Such a large spacing is easily compatible with voltage-holding requirements. According to the Paschen curve, gas breakdown in $\mathrm{H}_{2}$ is avoided if the pressure is kept below $2 \times 10^{-4}$ Torr. Data on surfaceinitiated breakdown indicates that the $520-\mathrm{kV}$ difference can be held across gaps in vacuum as small as 10 $\mathrm{cm}$.

Although the interelectrode spacing could be reduced to a few tens of $\mathrm{cm}$, the stored electrostatic energy that could be released in a spark is reduced if the spacing is large. Sparks that are driven by less than about $10 \mathrm{~J}$ of capacitively stored energy tend to heal the surface and help to prevent other breakdowns, whereas much more than $10 \mathrm{~J}$ damages the surface and makes other breakdowns more likely. The energy stored in the capacitor formed by the collector and the negative grid is 0.30 $\mathrm{J} / \mathrm{m}^{2}$ when the spacing is $4.0 \mathrm{~m}$ and the roltage difference is $520 \mathrm{kV}$, Therefore, $10 \mathrm{~J}$ is stored in $33 \mathrm{~m}^{2}$ of area, and since each DC has $516 \mathrm{~m}^{2}$ of frontal area, each must be divided Into about 16 sections to keep the energy stored in each section below
$10 \mathrm{~J}$. It was partly to facilitate this division into sections that both of the fan-shaped expander tanks were oriented horizontally. Separate supports for the different sections can be located about and below the beam without increasing the interception.

The actual design of the $\mathrm{DC}$ is left for future work. This preliminary analysis simply indicates that a design is possible and it predicts the performance of the DC. A much more detailed study is required to select the matertals and design the structure. Additional thought must be given to the design of the heattransfer system, of the high-voltage insulators, of the cryopanel vacuum pumps, and of the plasma scrape-off region. (The scrape-off region acts as a dump for high-2 impurities on the outer flux lines.)

\section{DIRECT CONVERTER EFFICIENCIES}

The effictency of the DC can be determined by tabulating the amount of power that is lost to each of the various loss mechanisms. Table 8-1 itemizes the amounts of power that are made unavailable for direct conversion by each mechanism in the approximate order that they are encountered by the incident beam. In the following text, a single-stage DC is considered first; a two-stage $D C$ 
is then analyzed by comparing it with the single-stage unit.

\section{Efficiency of a Single-Stage}

\section{Direct Converter}

The first loss from the $1032 \mathrm{MW}$ of incident power is that $o^{-}$the primary electrons. $\Lambda$ 2011- $\Lambda$ electron current arrives at the DC with a mean energy of $42 \mathrm{keV}$ per electron. This amounts to $85 \mathrm{MW}$ of incident power that is dissipated on the first grid. Since the first (grounded) grid is $5 \%$ opaque, it intercepts $47 \mathrm{MW}$ of the 947 MW of ions. Similarly, the negative grid intercepts $2 \%$, or 18 $M W$, of the remaining ions. This 18 MW of ions amounts to $38 \mathrm{~A}$, which also contributes to the drain on the negative power supply listed near the sottom of the table.

Loss of fons by charge exchange with gas in the expander is negligible at these relatively high energies if the pressure is held below $5 \times 10^{-5}$ Torr.

A single collector can recover al1 1872 A of ions that pass through the grids if the collector potentlal is not greater than the minimum ton energy per unit of charge. In Fig. $8-1$, note that the minimum energy is $350 \mathrm{keV}$. Since the recovered power is proportional to the collector potential, it is set at the maximum value, $350 \mathrm{kV}$. Then, the recovered power is $350 \mathrm{kV} \times 1.872 \mathrm{kA}=655 \mathrm{MW}$ from the $882 \mathrm{NW}$ of ion power that reaches the collector. The 227-MW difference is removed as heat from the collector.

We mentioned earlier that $38 \Lambda$ of ions are intercepted on the negative grid. Each fon releases about two secondary electrons from the grid. Also, a small emission current of thermionic electrons will result from the heating of the grid by the ions. Thus, the total drain on the negative power supply is about four times (allowing one unit of $38 \mathrm{~A}$ for emission) the Ion current, or $152 \mathrm{~A}$. At a grid potential of $-170 \mathrm{kV}$, this is a power loss of $26 \mathrm{MW}$. Grid potential is set at $-4 \mathrm{~T}$ to stop nearly all primary electrons.

The final loss mechanism in a single-stage DC is due to that part of the $38 \mathrm{~A}$ of thermionic electrons from the negative grid that is accelerated onto the collector. About half of the electrons will go each way because they are emitted uniformly over the surfare of a grid element. Secondary electrons are created only on one-half of the surface, and they all exit away from the collector and, together with half of the thermionic electrons, deposit another $16 \mathrm{NW}$ of heat on the grounded grid. Half of 38 A collected at 350 $k V$ results in a loss of 7 MW of power. Finally then, $622 \mathrm{MW}$ of net electric power is recovered from the 
incident $1032 \mathrm{MW}$. A single-stage DC can therefore be expected to recover $60.3 \%$ of the total incident power.

Table 8-1 summarizes the losses and Fig. 8-2 shows schematically the recovered and supplied power. The table shows that the largest loss is due to the rather poor match of a single collector potential to a spread in energy. However, all 227 MW of ion heating plus $10 \mathrm{MW}$ of electron heating at the collector is available for thermal conversion. (This includes $3 \mathrm{MW}$ listed as a drain on the negative supply.) The $173 \mathrm{MW}$ of heat radiated from the grids is difficult to recover because of the large area that receives it. In the chapter on parametric analysis (Chapt. 10), it is assumed that all $410 \mathrm{MW}$ of heat is used in a thermal cycle.

Efflciency of a Two-Stage Direct Converter

The presence of two distinct groups in the ion energy distribution (see Fig. 8-1) suggests that a DC

Table 8-1. Summary of losses from the one- and two-stage direct converters for a 1032-MW input poiser.

\begin{tabular}{|c|c|c|c|c|}
\hline \multirow[b]{2}{*}{ loss mechanism } & \multicolumn{2}{|c|}{ One-stage } & \multicolumn{2}{|c|}{ Two-stage } \\
\hline & $\begin{array}{l}\text { Loss } \\
(M W)\end{array}$ & $\begin{array}{l}\text { Remains } \\
(\mathrm{MW})\end{array}$ & $\begin{array}{l}\text { Loss } \\
\text { (MW) }\end{array}$ & $\begin{array}{l}\text { Remains } \\
\text { (MW) }\end{array}$ \\
\hline Unrecovered primary electrons & 85 & 947 & 85 & 947 \\
\hline Interception of ions by grounded grid & 47 & 900 & 47 & 900 \\
\hline Interception of ions by negative grid & 18 & 882 & 18 & 882 \\
\hline Charge exchange & 0 & 882 & 0 & 882 \\
\hline $\begin{array}{l}\text { Remaining kinetic energy of ions when } \\
\text { collected }\end{array}$ & 227 & 655 & 101 & 781 \\
\hline Loss due to the mean angle of incidence & 0 & 655 & 11 & 770 \\
\hline $\begin{array}{l}\text { Loss due to the spread in angle of } \\
\text { incidence }\end{array}$ & 0 & 655 & 13 & 757 \\
\hline Drain on negative grid power supply & 26 & 629 & 26 & 731 \\
\hline Collection of thermionic electrons & 7 & 622 & 7 & 724 \\
\hline Suppressor grids & 0 & 622 & 7 & 717 \\
\hline Recovered power: & & 622 & & 717 \\
\hline Lost power: & & 410 & & 315 \\
\hline Efficiency $(\%)$ : & & 60.3 & & 69.5 \\
\hline
\end{tabular}


with two collectors could be more efficient that a single-stage unit. A two-stage Venetian-blind (VS) DC is similar to the single-stage DC just examined, but has an added collector and suppressor grid (see Fig, 8-3). As shown in Table 8-1, losses to the first two grids and to charge exchange are the same for one- and two-stage direct converters. The main advantage of the VB comes from its two collectors, whose potentials can be adjusted to fit the energy distribution of the ions.

Figure 8-1 suggest that with ideal energy sorting it should be possible to collect all central-cell ijns and $\alpha$-particles at $350 \mathrm{kV}$ and all plug ions at $658 \mathrm{kv}$. The currents of these three groups of ions after allowing for grid inter ception are $1195 \mathrm{~A}, 268 \mathrm{~A}$, and 4C, A, respectively. The recovered power then could be $512 \mathrm{MW}$ on the first collector and 269 MW on the second, for a total of $781 \mathrm{MW}$ recovered and the remaining $10 \mathrm{i}$ MW appeari's as heat.

To sort the ions according to energy, the VB must be tilted at an angle whose optimum value is $6.9^{\circ}$ to give the ions a mean incident angle of $83.1^{\circ}$. This tilting requires the reduction of the collector potentials by a factor $\cos ^{2}\left(6.9^{\circ 3}\right)=0.986$ and reduces the recovered power by the same factor to $770 \mathrm{MW}$. Also, the energy sorting is not perfect because the spread in incident angle causes some high-energy ions to be intercepted by the low-energy collector. The larger expansion in the magnetic expander reduces this spread and the resulting interception on lateral surfaces to a small but significant value. This interception results in about $10 \%$ of the $408 \mathrm{~A}$ of plug ions being collected at $350 \mathrm{kV}$ instead of - $658 \mathrm{kV}$, tor a loss of about $13 \mathrm{kw}$. As in the single-stage $\mathrm{DC}$, the drain on the negative power supply amounts to $26 \mathrm{MN}$. Also, because we assume that all thermionic electrons that reach the collectors are caught on the first collector at $350 \mathrm{kV}$, the 7-MW loss is the same as for a single-stage collector.

One additional loss in the $V B$ results from the emission of secondary electrons from the suppressor grid (see Fig. 8-3). This grid is directly behind the first collector assembly and is held at a slightly lower potential than that collector to prevent secondary electrons produced on the first collector from flowing to the higher potential of the second collector. About $80 \%$ of the $1463 \mathrm{~A}$ of ions collected on the first stage is first transmitted by it and then passes through the suppressor grid from behind. If the grid is $1 \%$ opaque and if the secondary emission coefficient is 
about 2, then $23 \mathrm{~A}$ of electrons will be released from the rear surface of the grid and pulled into the second collector. Since the potentlal

difference is about $310 \mathrm{kV}$, the power loss is $7 \mathrm{MW}$.

Finally then, the net power recovered by the two-stage $V B$ out of the total incldent $1032 \mathrm{MW}$ is $717 \mathrm{MW}$, for a net efficlency of $69.5 \%$ (compared to $60.3 \%$ for the singlestage direct converter (see Table 8-1 and Fig. 8-3). The $142 \mathrm{MW}$ of heat generated on the two ion collectors is available for processing in a thermal cya:e because both collectors are convectively cooled. This $142 \mathrm{MW}$ is composed of $101 \mathrm{MW}$ from ion kinetic energy, $11 \mathrm{MW}$ plus $13 \mathrm{MW}$ from Interception due to angles of incidence, 3 of the $26 \mathrm{MW}$ from the negative grid, $7 \mathrm{MW}$ of thermionic electrons, and $7 \mathrm{MW}$ from the suppressor grid (see Table 8-1). In the singlestage DC, $237 \mathrm{MW}(227+3+7)$ of heat is generated on the single collector. 


\section{CHAPTER 9. POWER SLPPLIES FOR}

THE TANDEM MIRROR REACTOR

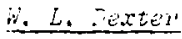

\section{Sumery}

Power Supplies for the Ion Sources and the Direct Converter . . . . 183

Power Supplies for the Magnets . . . . . . . . . . . . . 186

Power Supply Efficiencies . . . . . . . . . . . . . . . 187-188 
SUMMARY

In this chapter, we describe the power requirements and supplies for the Tandem Mirror Reactor (TMR) ion sources, direct converters, and magnets. The efficiencies of the power supplies are also estimated.

POWER SUPPLIES FOR THE ION SOURCES AND THE DIRECT CONVERTER

The TMR has four ion sources and a one-stage direct converter at each end. Figure 9-1 shows the direct converter and a single ion source with its asscciated power supplies.

In normal operation, a substantial amount of power for the ion sources comes from the direct converters; however, before plasina buildup, the direct cuiverters consume rather than supply power. Also, the heaters in the cesium cell require power during startup. During startup, the entire system requires 887 MVA; during running, 229 MVA.

The output of the direct converter is positive $350 \mathrm{kV}$ at $1853 \mathrm{~A}$. The positive accel grid of the ion source requires $700 \mathrm{kV}$; to utilize the output of the direct converter for this grid, a 268-kV topping power supply is provided. A series tube modulator provides isolation between the four sources. A total of $712 \mathrm{~A}$ is required for the four ion sources; the remain- ing $1141 \mathrm{~A}$ from the direct converter is converted to $60 \mathrm{~Hz}$ and returned to the $230-k V$ ac power bus.

\section{Ion Source Power Supplies}

The power supplies and associated equipment for the ion sources can be broken down into the following major categories:

- Filament and arc power supplies powered from an $800-\mathrm{Hz}$ power source. - Low-capacity insulating transformers.

- 60-Hz to 800-Hz converters.

- Negative 600-kV power supply.

- Positive topping power supply.

- Modulator regulator.

- Intermediate power supplies for the positive and negative grid of the ion source.

- Q-machine power supply.

The filament and arc power supplies are mounted on the high-voltage structure of the ion source. To reduce the physical size and weight, they are powered from a $300-\mathrm{Hz}$ power source. The size of both transformers and filters can be substantially reduced by using high-frequency power. Because laminated transformer cores can be used, $800 \mathrm{~Hz}$ was chosen as a logical frequency. Smaller power supplies offer an additional advantage: because they have a reduced capacity to ground and therefore less stored energy, damage to the ion source grid during 


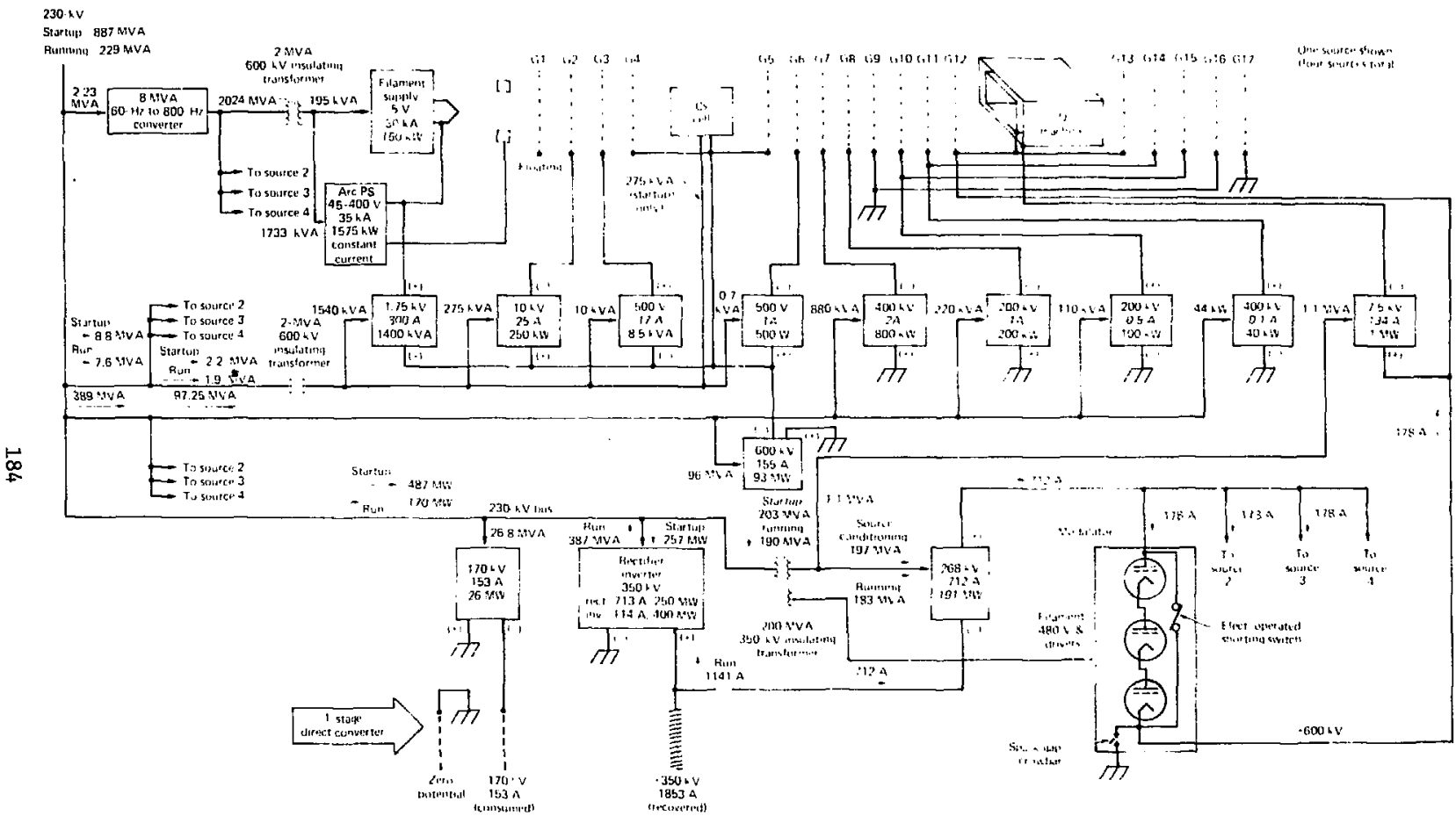

Fig. 9-1. Direct converter and a single ion source plus associated power supplies. 
sparking is reduced. The filament supply is a low-voltage, high-current transformer having built-in reactance to limit the turn-on current when the filaments are cold. The arc supply Is a transformer-thyristor arrangement in which the th;ristor control provides constant-current characteristics.

The arc supply has a turn-down feature that reduces the arc current whenever a spark discharge is detected in the accel power supplies.

The high-voltage insulating transformers are designed for low interwinding capacity. This is achieved by making small coils with high current density and by providing large windows in the core. The insulation is pressurized sulfur-hexafloride gas.

The $60-\mathrm{Hz}$ to $800-\mathrm{Hz}$ converters are a conventional rectifier-thyristor, inverter-transformer arrangement that is optimized for low losses by running low current densities in the transformer windings.

The negative $600-\mathrm{kV}$ accel power supply is a transformer-rectifierfilter arrangement having a series tube modulator in the out put and thyristors in the primary line to adjust the output voltage. A sensitive current detector in the output detects sparkfing in the source electrodes and signals the arc supply to reduce the arc current.

The positive topping power supply is similar in design to the negative power supply except that it does not have a modulator and it is large enough to power four sources.

The posftive $600-\mathrm{kV}$ modulators are a series high-vacuum tube arrangement and provide precise voltage control of the accel voltage during source conditioning. After the sources are baked in, a remotely operated switch bypasses the series tubes, thereby reducing the power loss caused by the tube drop. A spark-gap crowbar diverts the output of the accel power supply in the event of a spark breakdown in the ion source grids.

The power supplies for the negative grid of the ion source are relatively low-voltage power supplies electrically stacked on the main accel voltage to achieve the required grid potentials. These power supply cabinets are at 600-kV accel potential; therefore, power is supplied to them iy an insulating transformer.

The power supply for the Q-machine is at $600 \mathrm{kV}$ above ground; therefore, power is provided to it from an insulating transformer that also provides power to the $268-\mathrm{kV}$ topping power supply.

\section{Direct Converter Power Supplies}

The direct converters require two different power supplies: a conventional transformer-rectifler that supplies power at all times to the first grid and an inverter-rectifier 
connected to the collector assembly that can supply power during start-up and also recover power and deliver it to the power lines during normal operation. The inverter-rectifier consists of a thyristor-rectifier bridge that converts ac to dc and a thyristorinverter bridge that converts de to ac. The inverter bridge is an electronjc switching device that sequentially connects a dc bus to the appropriate lines of an ac system. The rectifier bridge and the Inverter bridge each has its own firfing circuits. The input slgnals of the two firing circuits are driven from an inverter-rectifler logic chassis that provides a continuous transition from rectifier to inverter operation by means of a single input signal.

The direct converter power supplies are mounted outdoors on a transformer pad, and the high-voltage units are insulated by high-pr.ssure sulphurhexafloride gas.

POWER SUPPLIES FOR THE MAGNETS

The reactor has the following cryogenic magnets:

- Two plug coil sets, each consisting of a Yin-Yang coil pair and a solenoldal pair.

- Thirty-four central-cell solenoids.

The same power-supply design is used for all coils. The inventory of power supplies for the entire reactor is as follows:

$\begin{array}{ll}\text { - Yln-Yang coils: } & \begin{array}{l}2 \text { power } \\ \text { supplies }\end{array} \\ \text { - Ylug solenoidal coils: } & 4 \begin{array}{l}\text { power } \\ \text { supplies }\end{array} \\ \text { - Central-cell solenolds: } 17 & \begin{array}{l}\text { power } \\ \text { supplies }\end{array}\end{array}$

Tota1 : 23

Fach power supply has the following ratings :

- Dutput voltage: $60 \mathrm{~V}$

- Output ripple: $<250 \mathrm{mV}$

- Output current: $10 \mathrm{kA}$

- Power : $600 \mathrm{~kW}$

The charging time of the magnet coils is $24 \mathrm{~h}$. The power supplies have the following unique features:

- The output dc circuit breaker is capable of interrupting $10 \mathrm{kA}$ with $10 \mathrm{kV}$ across the contacts. A discharge resistor absorbs the energy stored by the magnet.

- The rate of charge into the magnet coll is precisely controlled in accordance with a prescribed plan.

- In the event of a magnetic quench or fault, the power supply would be automatically de-energized.

- The power supply contains an inverter that returns the energy stored in the magnet to the power lines when the magnet is discharged.

- The power supply has a two-loop regulator that provides a current stability of $1 \%$ and controls and limits the maximum rate of change of voltage. 
- The power supply has a control system that detects the onset of a magnetic quench and continuously monitors the following parameters:

- Coil current

- Charging and discharging voltage

- Coil intertum voltage

- Lead voltage drop

- Level in liquid-helium reservoir

- Helium-gas pressure and evaporation rate

- Change in magnet coil flux.

The power supplies for the magnets, in common with all other major electrical components, hav. jrovisions for either manual or computer control. Also, computer storage is provided for taking and storing the values of various coil parameters.

POWER SUPPLY EFFICIENCIES

A11 power supplies in the TMR system are optimized for high effi-
Table 9-1, Estimated efficiencies of TMR rower supplies.

\begin{tabular}{cc}
$\begin{array}{c}\text { Power supply } \\
\text { (MVA) }\end{array}$ & $\begin{array}{c}\text { Ffficiency } \\
(\%)\end{array}$ \\
\hline 10 & $>97$ \\
4 to 10 & $>95$ \\
4 & $>90$ \\
\hline
\end{tabular}

ciency by running the current densities of the transformer windings at a conservative level. The power loss in the rectifier thyristors is negligible (about 0.5\%). We expect large systems of this type to have an efficiency in excess of $95 \%$. Utility companies that operate large dc transmission systems attain an overall efficiency better than $97 \%$. The efficiencies that we have estimated for the TMR power supplies are iisted in Table 9-1. 


\section{CHAPTER 10. PARAMETRIC ANALYSIS}

G. A. Carlson

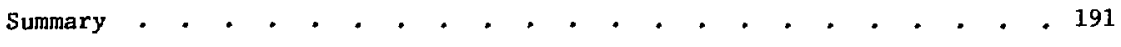

The Analytic Model . . . . . . . . . . . . . . . . . . 191

Cost Optimization . . . . . . . . . . . . . . . . . . . 196

Other Design Considerations . . . . . . . . . . . . . . . 200

References . . . . . . . . . . . . . . . . . 208 
SUMMARY

The results of this parametric design study illustrate the variation in Tandem Mirror Reactor (TMR) characteristics with changes in the independent design parameters, reveal the set of design parameters that minimize the cost of the reactor, and show the sensitivity of the optimized design to physics and technological uncertainties.

THE ANALYTIC MODEL

\section{Physics}

The heart of the analytic mode1 for the TMR is the simple, selfconsistent description of TMR physics given in Chapt. 3 . (An almost identical physics model was presented in App. B of Ref. 10-1.) This model relates the densities, energies, and containment times of the ions and electrons in the plugs and central cell. The plugs are assumed to be mirror machines having classical end losses and sustained by the injection of high-energy neutcal beams. (Siace the purpose of the end plugs is to stopper the central cell and not to produce fusion power, single-species injection is proposed, e.g., either deuterium or tritium.) The central cell is fueled by low-energy neutral beams of $d$ :uterium and tritium.
Electrons heated by the energetic ions in the plugs in curn heat the cold ions in the central cell.

The equations of the physics model can be self-consistently solved in a number of ways. In this first analytic model, we find it most convenient to specify the plug injection energy, the plug mirror ratio, the mirror ratio between the plugs and the central cell, the plasma $\beta$ in the plugs and in the central cell, and the temperature of the centralcell ions. The physics output then consists of the various energies, containment parameters ( $\left.n T^{\prime} s\right)$, density ratios, the plasma volume ratio between the central cell and plugs, and $Q$ (thermonuclear power divided by trapped injected power).

\section{Reactor Design}

Next, we specify the particular reactor design. First, specification of a single magnetic field strength (usually the central field of the plug) allows calculation of all the plasma densities and the fusion power density in the central cell. Then, specification of the blanket energy multiplication factor $M$ and various efficiencies (of thermal conversion, direct conversion, and neutral-beam injection) allows calculation of power flows. At this point, the power quantities are only relative 
because an absolute power level has not been selected.

Finally, specification of a single dimension or power quantity (we usually choose to specify the net electric power) allows complete design of the reactor. The dimenstons of the cylindrical central-cell plasma and the approximately spherical plug plasmas are completely determined by the central cell-to-plug volume ratto, the fusion power density of the central cell, the desired total fuston power, and the requtrement for magnetic flux conservation throughout the machine.

The plug magnets are designed to provide the specified magnetic field and to be large enough to contain the plug plasma. The scaling laws for the plug magnets were derived from the point designs described in Chapt. 5 .

The design of the central cell begins at the cylindrical first wall (three alpha gyroradii away from the plasma) and proceeds outward through the blanket, shield, magnet, support structure, handling and maintenance equipment, and finally the reactor building. The scalliug le:s for the central cell were derived from the point design described in Chapt. 4. In all cases, the blanket and shield thicknesses are held constant at 94 and $86 \mathrm{~cm}$, rispectively. Thus, the primary variables in the central-cell design are the length, first-wa11 radius, and magnetic field strength. The plant design is completed by sizIng the injectors, the direct converters, and the thermal conversion system.

\section{Cost Est Imate}

Estimates of direct capttal costs for all elements of the power plant permtt a final estimate of the cost of power.

The cost of the central cell tends to be dominant and ts therefore the most carefully evaluated. It is broken down into separate cost estimates (see Table 10-1) for the blanket, shield, vacuum vessel, solenoidal coil, coil restraining structure, coil case, main support structure, the crawler-transporter under each central-cell module, and the central-cell portion of the reactor building. The scaling laws for these costs were derived from the point design described in Chapt. 4.

The cost of the $p^{7} 1 \mathrm{~g}$ is broken down into separate cost estimates (see Table 10-2) for the plug coils, coil restrainfing structures, coll refrigerators, and the plug portion of the reactor building. The scaling laws for the coil-related costs are derived from the point designs in Chapt. 5.

Cost estimates for the thermal conversion, direct conversion, and 
Table 10-1. Sumary of cost estimates for central cel1.

I tem

Blanket (estimated on a per unit mass basis):

Stainless steel structure

$\$ 22 / \mathrm{kg}$

Neutron moderator and tritium-breeding

material ${ }^{a}$

Shield (estimated on a p.er unit mass basis):

Stainless steel

lead cement

Borated carbon

Vacuum vessel (estimated on a per unit mass basis):

Stainless steel

Solenoidal coil (always at a low magnetic field

strength (2.4 T in the point design) and

conservatively sized for an overal.] current

density of $1200 \mathrm{~A} / \mathrm{cm}^{2}$.)

Conductor (density assumed to be that of

copper)

Cost of winding the coil

Coil restraining structure and coil case

(stainless steel)

Main support structure (stee1)

Crawler-transporter under each central-cell module (cost assumed to scale linearly with

the mass of the central-cell module)

Central-cell portion of the reactor building

(cost assumed to scale linearly with the

length of the central cell $\mathrm{L}_{c}$ and with the

square of the outer radius of the central

ceil $r_{\text {outer }}$ )
$\$ 11 / \mathrm{kg}$

$\$ 1 / \mathrm{kg}$

$\$ 5.50 / \mathrm{kg}$

$\$ 14 / \mathrm{kg}$
Cost estimate
$\$ 6.60 / \mathrm{kg}$

$\$ 0.0023 / \mathrm{A} \cdot \mathrm{m}$

$\$ 14 / \mathrm{kg}$

$\$ 11 / \mathrm{kg}$

Normalized to $\$ 600$ thousand for a 3-m-long module weighing $7.2 \times 10^{5} \mathrm{~kg}$.

Normalized to $\$ 24$ million for $L_{c}=100 \mathrm{~m}$ and $r_{\text {outer }}=$ $4.5 \mathrm{~m}$

\footnotetext{
${ }^{a}$ The $\$ 25 / \mathrm{kg}$ estimate was made for 1 ithlum aluminate, one of che proposed breeding matertals (see Chapt. 4). The final design choice was for an approximately equal volume of encapsulated liquid lithium. We believe that our blanket cost estimate is somewhat high for this case.
} 
Table 10-2, Summary of cost estimates for plugs.

Plug coils (a cryogenic-A.l Yin-Yang coil pair inside

a superconducting solenoidal pair)

Solenoidal pair (designed for an overall current

density of $3000 \mathrm{~A} / \mathrm{cm}^{2}$ )

$\$ 0.0013 / \mathrm{A} \cdot \mathrm{m}$

- plus winding

$\$ 0.0023 / A \cdot m$

Stainless-steel restraining structure for the

solenoidal pair

$\$ 22 / \mathrm{kg}$

Yin-Yang coil pair (pure-A1 conductor and A1-a1loy

internal structure)

- plus winding

$\$ 0.0023 \mathrm{~A} \cdot \mathrm{m}$

Coil restraining structures (a stainless-steel.

external restraining clamp whose mass is

estimated from the Yin-Yang study in Ref. 10-2)

$\$ 22 / \mathrm{kg}$

Coil refrigerators (cost of refrigeration scales with

$\$ 40$ million

the $7 / 10$ power of the refrigerator input power, which

is estimated to be $50 \mathrm{~W}$ of heat per $\mathrm{W}$ removed from the

coil. This input power - $23 \mathrm{MW}$ in the point design -

is also subtracted from the gross electric power of

the plant when we calculate the net electric power)

Plug portion of the reactor building (assumed to scale

Normalized to $\$ 19$

with the square of the outer radius $r_{\text {outer }}$ of the central

million of $r_{\text {outer }}$ ce11)

$=4.5 \mathrm{~m}$

injection systems are summarized in Table 10-3.

The reactor systems just discussed do not include all of the systems considered in the cost estimate for our Standard Mirror Fusion Reactor as reported in Ref. 10-2. Systems not explicltiy included are the cryopanel vacuum system for the injectors and direct converters, the refrigera- tion system for the cryopanels and the superconducting colls, the plant electrical equipment, instrumentation and controls, the tritium handling system, miscellaneous buildings, and site improvements. Our preliminary estimate for the cost of these systems for a $1000-M W(e)$ TMR is $\$ 270$ million. As an economic figure of merit, we add all the above direct capital 
Table 10-3. Summary of cost estimates for thermal conversion, conversion, and injection systems.

Item

Cost estimate

Thermal conversion system (includes blanket coolant $\$ 70 / \mathrm{kW}$ of thermal loop, direct converter coolant loop, steam genetators, power handled by the turbine generators, steam condensers, all steam and thermal converter. water piping, cooling towers, and the turbine hall).

Direct conversion system (includes direct converter vacuum tank, collector elements, electrical conditioning equipment, and thermal panels for the radiative cooling of collector elements)

Injection system (includes injector plus their power supplies) ${ }^{\mathrm{a}}$
$\$ 130 / \mathrm{kW}$ of chargedparticle power entering the direct converter.

$\$ 200 / \mathrm{kW}$ of electrical power input to the injectors.

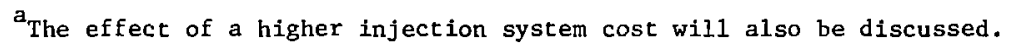

$\operatorname{costs}^{*}$ and divide by the net electric power to obtain the direct capital cost per unit of installed capacity $[\$ / k W(e)]$. We have used the minimization of this figure of merit to optimize the design of the TMR. (In our Standard Mirror Fusion Reactor study, ${ }^{10-2}$ we pointed out a deficiency

* We emphasize that the estimated costs are direct capital costs only and that no indirect costs have been added. In our Standard Mirror Fusion Reactor study, $10-2$ we estimated that indirect costs (indiract field costs, engineering services, contingency, interest during construction, and general office costs) are 1.48 times the direct capital costs. of the $\$ / k W(e)$ figure of merit; namely, designs with higher neutron loadings on the first wall are not properly penalized for their more frequent outages for blanket maintenance. For that reason, we used the cost of net electrical energy (mills/kWh) as the economic figure of merit in Ref. 10-2. We shall adopt this method for future analytic models of the TMR. We suspect that our results will be about the same since the first-wall loading of the optimized TMR point design is only $2.1 \mathrm{MW} / \mathrm{m}^{2}$ (vs 3.3 for our standard mirror reactor). 


\section{COST OPTIMIZATION}

Input for the Point Design

We chose to specify a net electric power of $1000 \mathrm{MW}(e)$ for the TMR point design. (lower and higher power levels will te discussed later in this chapter.) Other input parameters held constant in our search for an optimized point design were as listed in Table 10-4.

Table 10-4. Paraneters held constant in determining an optimized TMR design, for net electric power of $1000 \mathrm{MW}(\mathrm{e})$ and deuterium plug injection.

\begin{tabular}{lc}
\hline Parameter & Value \\
\hline Vacuum mirror ratio in plug & 1.07 \\
Beta of plug plasmas & 1.0 \\
Beta of central-cell plasma & 0.7 \\
Jraction of u-particles & \\
adiabatically confined & 1.0 \\
Vacuum central field of plug & $16.5 \mathrm{~T}$ \\
Blanket energy multiplication & 1.2 \\
Thermal conversion effteiency & 0.4 \\
Direct conversion efficiency & 0.6 \\
lnjection efficiency & 0.8 \\
\hline
\end{tabular}

Optimization of the Point Design

The remaining input parameters that must be specified in order to calculate a TMR design are the injection energy, the temperature of the central-cell ions, and the vacuum mIrror ratio between the center of the plug and the central cell. We varied these three parameters in our search for an optimized point design. The results are shown in Figs. I0-1, where we plot $\$ / k W(e)$ versus the three parameters. The minimum cost of $\$ 1250 / \mathrm{kW}(\mathrm{e})$ occurs for Injection energy $=1.2 \mathrm{MeV}$ Central-cel1 ion temperature $=30 \mathrm{keV}$ Plug-to-central cell $\mathrm{R}_{\text {vac }}=7.0$ We choose this minimum cost design as the TMR point design.

In ligs. 10-2 and 10-3 we show the variations of two reactor figures of merit: the recirculating power fraction (defined as the gross electrical power minus the net electrical powec, divided by the gross electrical power) and the neutron loading of the first wall. TMR optimization is always a tradeoff between a good power balance (low recirculating power fraction) and a high central-celI power density (high neutron loading of the first wal1). Note that moving off-optimum results in a "good" change in one figure of merit and a "bad" change in the other.

The energy-dependent curves, (a) in Figs. 10-1,2, and 3 indicate a rather shallow cost minimum over the range of injection energy considered. This is somewhat misleading because the performance of the TMR becomes very sensitive to injection energy at lower energies. Figure 10-4(a) shows the cost of the $1000 \mathrm{MW}(\mathrm{e})$ TMR ovcr a wider range of injection energy. 

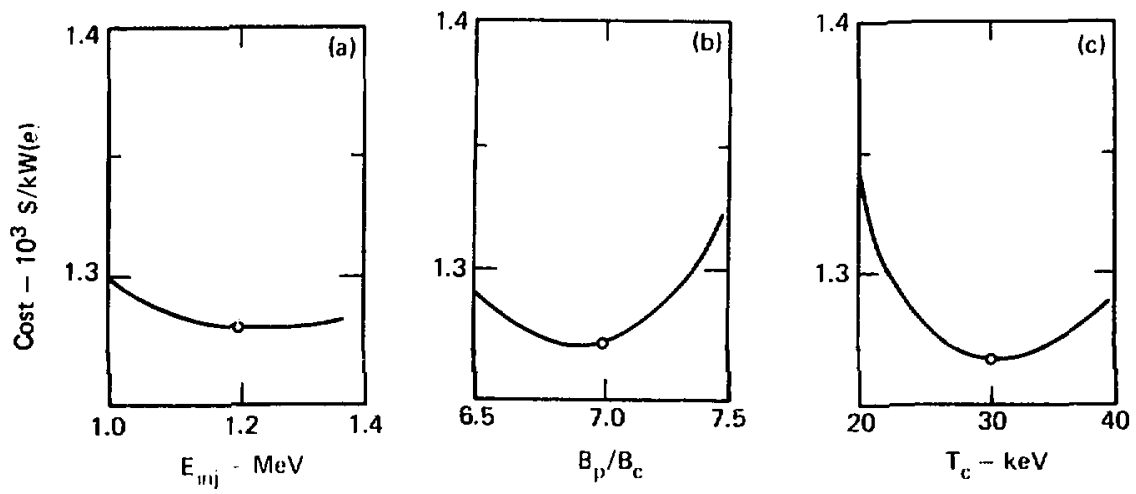

Fig. 10-1. Effect on cost of 1000-MW(e) TMk's of varialtion in (al) inilecton chergy Einj, (b) vacuum mirror ratio becwese the center of the plug and the central cel $1 \mathrm{~B} / \mathrm{B}_{\mathrm{C}}$, and (c) temperature of the ions in the ecent ral $\ldots 11 \mathrm{r}$.

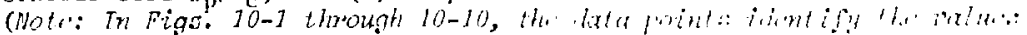
weterted for the point designis)
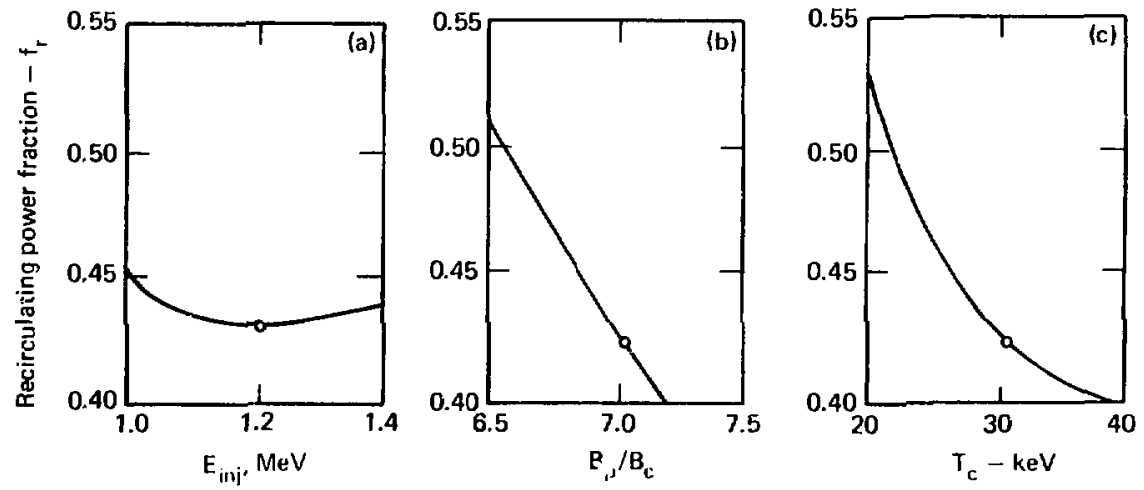

Fig. 10.-2. Effect on recirculating power fraction fr of $1000-M W(c)$ TMR's of variation in the parameters defined in $\mathrm{Fig}$. 10-1. 


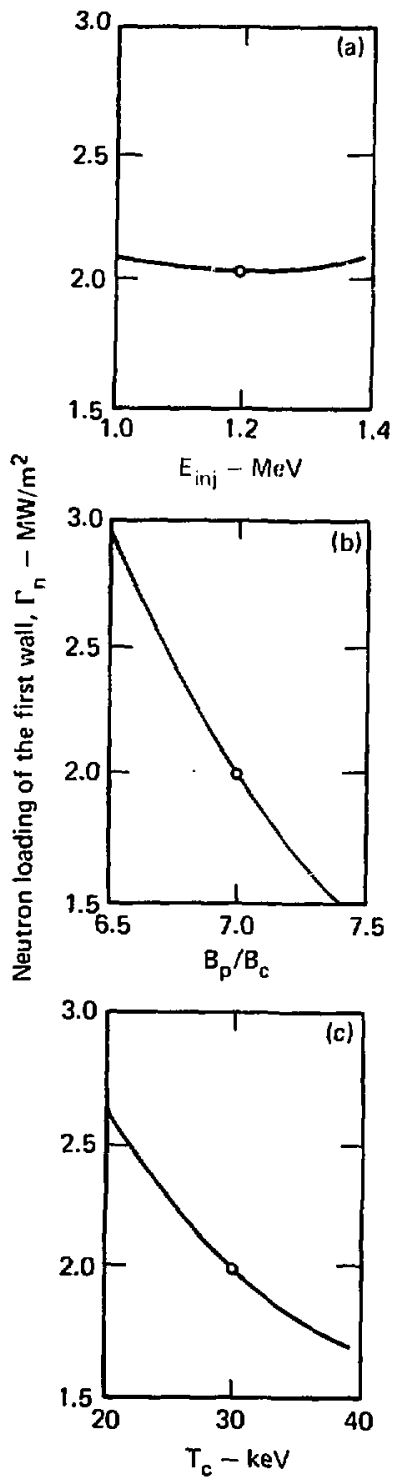

Fig. 10-3, Effect on the neutron loading of the first wall of 1000ME(e) TMR's of variation in the parameters defined in Fig. 10-1.
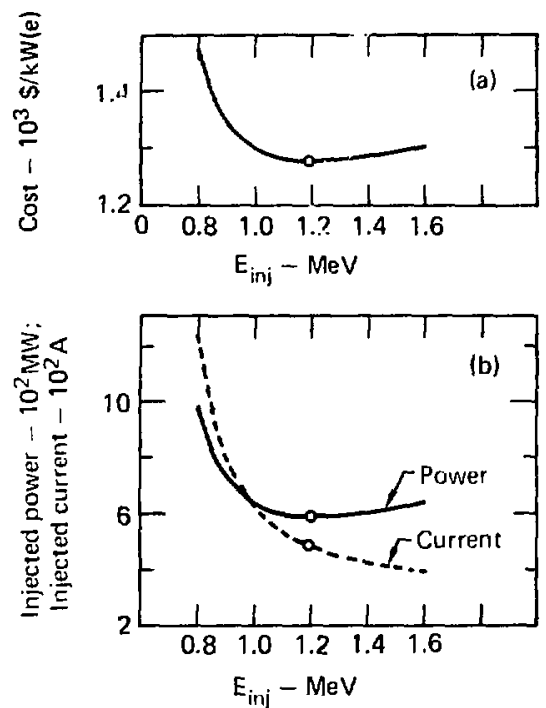

Fig. 10-4. Performance of 1000-Mto(e) TMR: (a) variation in cost over a range of injection energies, and (b) variation of the total neutralbean power and current injected into the plugs.

Shown in Fig. 10-4(b) is the variation of the total neutral-beam power and current injected into the TMR plugs. Note the sharp increase in cost with decrease in injection energy. At 800-keV injection energy, $Q$ has dropped to 2.9 and the recirculating power fraction has increased to 0.56 . At still lower injection energies, $Q$ drops precipitously, primarily because the plugs can no longer support a large central-ce11 plasma at fusion temperatures. At $650-\mathrm{keV}$ injection energy, $Q$ is only 0.5 and the reactor no longer produces net power. 
Table 10-5. Plasma parameters for the TMR point deisgn.

\begin{tabular}{|c|c|}
\hline Parámeter & Value \\
\hline Injection energy & $1.2 \mathrm{MeV}$ \\
\hline Average plug ion energy, $E_{p}$ & $878 \mathrm{keV}$ \\
\hline Electron temperature, $T_{e}$ & $42 \mathrm{keV}$ \\
\hline Central-cell ion temperature, $\mathrm{T}_{\mathrm{c}}$ & $30 \mathrm{keV}$ \\
\hline Electron potential, $c$ & $263 \mathrm{keV}$ \\
\hline Central-cell ion potential, $c$ & $38 \mathrm{keV}$ \\
\hline Plug 6 & 1.0 \\
\hline Central-cell & 0.7 \\
\hline Plug particle nt & $2.5 \times 10^{14} \mathrm{~s} / \mathrm{cm}^{3}$ \\
\hline Central-cell particle nt & $7.7 \times 10^{14}$ \\
\hline Central-cell to plugs plasma volume ratio & 500 \\
\hline Plug-to-central cell ion density ratio & 7.96 \\
\hline$\langle\sigma v\rangle_{D T}$ & $6.64 \times 10^{-16} \mathrm{~cm}^{3} / \mathrm{s}$ \\
\hline Plug ion density, $n_{p}$ & $8.57 \times 10^{14} \mathrm{~cm}^{-3}$ \\
\hline Central-ceil ion density, $n_{c}$ & $1.08 \times 10^{14}$ \\
\hline Plug plasma radius, $r_{p}$ & $0.48 \mathrm{~m}$ \\
\hline Central-cell plasma radius, $r_{c}$ & $1.22 \mathrm{~m}$ \\
\hline Fusion power density & $5.41 \mathrm{~W} / \mathrm{cm}^{3}$ \\
\hline First-wall neutron loading, $\Gamma_{n}$ & $2.06 \mathrm{MW} / \mathrm{m}^{2}$ \\
\hline Q & 4.81 \\
\hline
\end{tabular}


Table 10-6. Physical characteristics of the TMR point design.

\begin{tabular}{lc}
\hline \multicolumn{1}{c}{ Item } & Value \\
\hline Plug vacuum mirror ratio, $R_{\text {vac, plug }}$ & 1.07 \\
Plug vacuum central field, $B_{0, \text { plug }}$ & $16.5 \mathrm{~T}$ \\
Plug center-to-central cell mirror ratio & 7.0 \\
Central-cell vacuum fleld & $2.4 \mathrm{~T}$ \\
Central-cell dimensions: & $101 \mathrm{~m}$ \\
Length, $\mathrm{L}_{\mathrm{c}}$ & $1.56 \mathrm{~m}$ \\
First-wall radius, $\mathrm{r}_{\mathrm{fW}}$ & $4.52 \mathrm{~m}$ \\
\hline
\end{tabular}

Description of the Point Design

The plasma characteristics of the $0 .+$,ized point design are given in Table 10-5. The physical characteristics of the reactor are given in Table 10-6. The power-flow quantities are given in Table 10-7. Finally, Table 10-8 gives the breakdown for the direct capital costs of the point design.

OTHER DESIGN CONSIDERATIONS

We investigated the effect on reactor design of values other than those used in the point design.

\section{Other Power Levels}

Figure 10-5(a) shows the $\$ / \mathrm{kW}(\mathrm{e})$ cost of TMR's designed for net power outputs ranging from 250 to $2000 \mathrm{MW}(\mathrm{e})$. The results plotted represent designs that have not been reoptimized; $i$.e.,
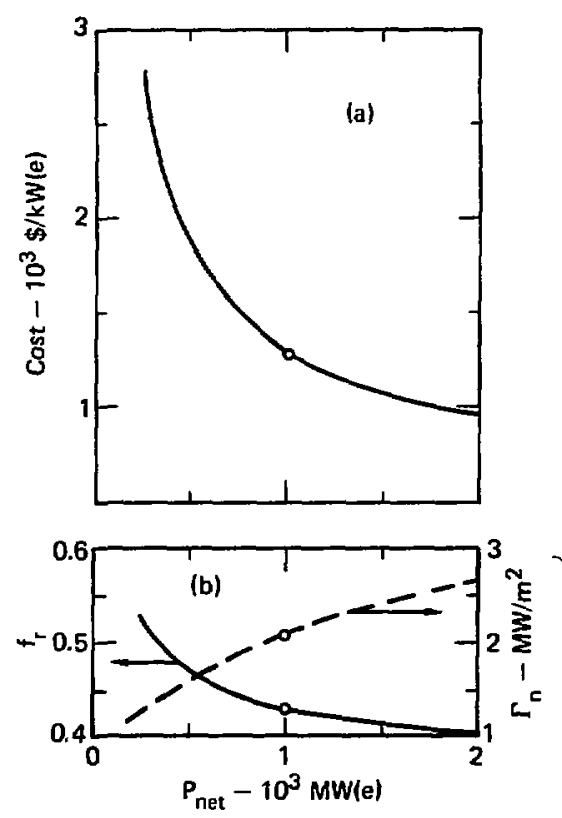

Fig. 10-5. Effect upon (a) cost and (b) recirculating power fraction $f_{r}$ and neutron loading of the first wall $\Gamma_{n}$ of variation in the net power output $P_{n e t}$ of the TMR. 
Table 10-7. Power-flow quantitles in the TMR point design.

\begin{tabular}{|c|c|}
\hline Item & $\begin{array}{l}\text { Value } \\
\text { (MW) }\end{array}$ \\
\hline Electric input power to injectors & 734 \\
\hline Injected neutral-beam power & 587 \\
\hline Trapped neutral-beam power & 526 \\
\hline Fusion power & 2532 \\
\hline Thermal power Into blanket & 2026 \\
\hline Thermal power out of blanket & 2431 \\
\hline Charged-particle power into direct converter & 1033 \\
\hline Electric power out of direct converter & 620 \\
\hline Thermal power into thermal converter & 2844 \\
\hline Electric power out of thermal converter & 1138 \\
\hline Gross electric power & 1757 \\
\hline Auxiliary power & 23 \\
\hline Net electric power & 1000 \\
\hline Recirculating power fracticn: & 0.43 \\
\hline System efficiency: & 0.34 \\
\hline
\end{tabular}

they have the same injection energy, central-cell ion temperature, and plug-to-central cell mirror ratio as the point design. We found that reoptimization of the central-cell ion temperature, the plug-to-central cell mirror ratio, and the ignition energy for the $250 \mathrm{MW}(e)$ and $2000 \mathrm{MW}(\mathrm{e})$ cases had almost no effect on the costs shown in the figure. Figure 10-5(b) shows that the cost decreases with increasing power for two reasons: a decrease in the recirculating power faction and an increase in first-wall loading. The optinized 2000-MW(e) TMR has a 150$\mathrm{m}-1$ long centra1 cell and costs $\$ 980 / \mathrm{kW}(\mathrm{e})$. 
Table 10-8. Cost breakdown - TMR point design.

\begin{tabular}{|c|c|c|}
\hline Item & $\begin{array}{c}\text { Cost } \\
(\text { millions of } \$)\end{array}$ & $\%$ of total \\
\hline \multicolumn{3}{|l|}{ Central cell } \\
\hline Blanket & 114 & 8.9 \\
\hline Shield & 62 & 4.9 \\
\hline Vacuum vessel & 11 & 0.9 \\
\hline $\operatorname{cot1}$ & 35 & 2.7 \\
\hline Coil structure & 21 & 1.6 \\
\hline Main structure & 51 & 4.0 \\
\hline Crawler-transporter & Subtotal: & $\frac{1.7}{24.7}$ \\
\hline Plug coils & 171 & 13.3 \\
\hline Reactor building & 44 & 3.4 \\
\hline Injector system & 147 & 11.5 \\
\hline Direct conversion system & 234 & 10.5 \\
\hline Thermal conversion system & 199 & 15.5 \\
\hline Other & Total: $\quad \frac{270}{1,281}$ & $\frac{21.1}{100}$ \\
\hline
\end{tabular}

\section{Tritium Plug Injection}

For the point design, we assume that deuterium is injected into the plug. However, we also investigated tritium injection because of the potential advantage it offers: at the same energy, beam penetration through the plasma is less and velocity space scattering is slower (i.e., the plug nT is greater). A third phystcs effect, this one detrimental, Is an increase in the equilibration time between the ions and electrons in the plugs. This effect tends to reduce the attainable volume ratio between the central cell and the plugs, and hence to reduce $Q$.

We recalculated the point design with tritium injection (without reoptimization) and found only a slight cost reduction [from $\$ 1280 / \mathrm{kW}(\mathrm{e})$ to $\$ 1240 / \mathrm{kW}(\mathrm{e})\}$. As expected, $\mathrm{n} \tau$ plug increased (to $3.4 \times 10^{14} \mathrm{~s}$ ), but the reduction in volume ratio (to 300) resulted in a net decrease in $Q$ (to 3.9). However, the recirculating power fraction increased only a small amount (to 0.46 ) because the neutralbeam trapping fraction Increased to 0.98. Finally, the neutron loading 
of the first wall increased to $2.5 \mathrm{MW} / \mathrm{m}^{2}$ because the smaller volume ratio resulted in a shorter, fatter reactor.

Reoptimization of the tritium injection case would result in the tradeoff of some of the increased wall loading for a liswer recirculating power fraction. However, the potential for improvement is not great. For this reason and also because of the added complications of handling tritlum in the highenergy injectors (for which we assessed no additional costs), we discarded the tritium option.

\section{Variation of Central-Cel1 $B$}

The point design value of the central-cell beta $\beta_{c}$ was 0.7 , and the central-cell plasma was assumed to obey the "long, thin" approximation; i.e.,

$$
B_{\text {plasma }}=B_{\text {vacuum }}\left(1-\beta_{c}\right)^{1 / 2} \text {. }
$$

Recent physics analyses indicate that the central-cell plasma may be stable for $B_{c}$ as high as 0.95 . Figure 10-6 shows the cost of optimized (centralcell ion temperature and plug-tocentral cell mirror ratio) 1000-MW(e) TMR's as a function of $\beta_{c}$. For $\beta_{c}=0.95$, the cost of an optimized 1000-MW(e) TMR is reduced to $\$ 1080 / \mathrm{kW}(e)$. This reactor ts consider-

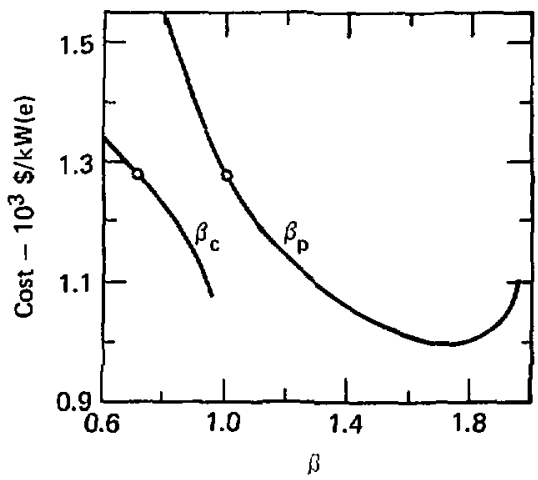

Fig. 10-6. Cost of optimized 1000MN(e) TMR's as a function of centralcell beta $\beta_{c}$ and plug beta $\beta_{p}$.

ably shorter and fatter than the point design: the central-cell length $L_{c}$ is $55 \mathrm{~m}$ (versus $100 \mathrm{~m}$ ) and the first-wall radius is $2.2 \mathrm{~m}$ (versus $1.6 \mathrm{~m}$ ). The recirculating power fraction is reduced to 0.34 , and tine first-wall loading is increased slightly to $2.2 \mathrm{MW} / \mathrm{m}^{2}$.

\section{Variation of Plug B}

The point design value of plug beta $\beta_{p}$ was 1.0 , and the plug plasma was assumed to obey a "short", fat" approximation for $2 X I I B-l i k e$ plasmas; i.e.,

$B_{\text {plasma }}=B_{\text {vacuum }}\left(1-\frac{B_{P}}{2}\right)$

Note that complete exclusion of the magnetic field by the plasma (just prior to field reversal) would require 
$\beta_{p}=2$. Experiments on 2XIIB indicate that $\beta_{p}$ in the range of 1 to 2 may be possible.

Figure 10-6 shows the cost of optimiaed (central-cell ion temperature and plug-to-central cell mirror ratio) $1000 \mathrm{MW}(\mathrm{e}) \mathrm{TMR}$ 's as a function of $B_{p}$. It can be seen that there is an optimum value of $\beta_{p}=1.7$, for which the reactor cost is reduced to $\$ 1000 / \mathrm{kW}(\mathrm{e})$. This reactor is much more compact than the point design: $\mathrm{L}_{c}$ is $57 \mathrm{~m}$ and the first-wall radius is only $0.7 \mathrm{~m}$. The recirculating power fraction is reduced to 0.33 , and the neutron loading of the first wall is a high (probably too high) $7.2 \mathrm{MW} / \mathrm{m}^{2}$. The latter effect results because the optimum plug-to-central cell mirror ratio is only 3.5 (versus 7.0 for the point design), which results in a high ion density in the central cell $\left(5.7 \times 10^{14} \mathrm{~cm}^{-3}\right)$. This optimum design for high plug $\beta$ would probably change if we adopted the mill/kWh minimization method, including the costs of blanket maintenance.

Variation of $f_{\alpha}$

For the point design, we assume that $f_{\alpha}$, the fraction of alpha particles adiabatically confined, was unity. Although this appears possible, it also appears that the confinement of these particles could be intentionally spoiled by a redesign of the transition region between the plug and the central cell. Alpha heating would then be reduced, but at the same time the reduced alpha pressure in the central cell would permit a higher fuel density in the central cell.

We investigated the design of a 1000-MW(e) TMR with $\mathrm{F}_{\alpha}=0.5$ and found that reoptimization (Injection energy, central-cel1 Ion temperature, and plug-to-central cell mirror ratio) yielded a cost of $\$ 1350 / \mathrm{kW}(\mathrm{e}), 5 \%$ higher than the point design. The loss of alpha heating caused this reactor to optimize at a plug injection energy of $1.5 \mathrm{MeV}$.

Variation of $\mathrm{B}_{0}$, plug

The vacuum magnetic field strength at the center of the plug, $B_{O}$, plug, was chosen to be $16.5 \mathrm{~T}$ for the point design. Figure 10-7(a) shows the predicted reactor cost (without reoptimization) as $\mathrm{B}_{0}$, plug is varied from 15 to $18 \mathrm{~T}$. Figure $10-7(\mathrm{~b})$ shows that as $\mathrm{B}_{0}$, plug is increased, both reactor figures of merit - the recirculating power fraction and neutron loading of the first wall improve, and thus the cost decreases. The decreasing rate of cost reduction with increasing $B_{O}$, plug is due to the rapidly increasing cost of the plus magnets. Increasing the plug field from its point design value to $18 \mathrm{~T}$ reduces the reactor cost by only 
$1.8 \%$. Also, we note that there is only a $3.4 \%$ increase in reactor cost if we reduce the plug field from its point design value to $15 \mathrm{~T}$.

\section{Variation of the Vacuum Mirror}

Ratio of the Plug

The vacuum mirror ratio of the plug coll, Rvac,plug, was chosen to be 1.07 for the point design. A plug mirror ratio this low, coupled with a maximum allowable magnetic field strength, permits efther a high confining field in the central cell (high fusion power density) or a high ratio of field (and thus density) betwean the plugs and the central cell (goad
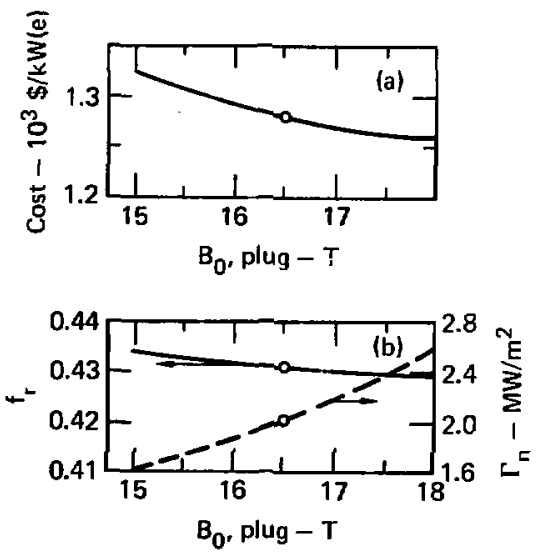

Fig. 10-7. Effect on (a) predicted reactor cost and (b) recirculating power fraction $f_{r}$ and neutron loading of the first wall $\Gamma_{n}$ of varia$t$ ion in $\mathrm{B}_{0}$, plug, the vacuum magnetic field strength at the center of the plug, for 1000-MW(e) TMR's with vacuum mirror ratio of the plug $R_{\text {vac, }}$ plug $=1.07$. central-cell confinement). The low plug mirror ratio was chosen in the expectation that these gains were more important than better plug confinement .

Figure 10-8 shows the predicted cost of optimised (central-cell ion temperature and plug-to-central cel.I mirror ratio) 1000-MW(e) TMR's as a function of $R_{\text {vac,plug }}$ for a constant value of the plug mirror field $(17.7 \mathrm{~T})$. This means that as $R_{\text {vac,plug }}$ is increased from its point design value of 1.07 , the vacuum magnetic field strength at the center of the plug decreases from its point design value of $16.5 \mathrm{~T}$. Figure 10-8

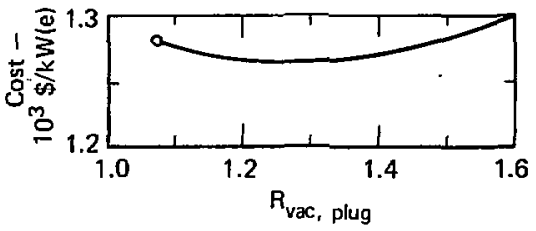

Fig. 10-8. Predicted cost of optimized 1000-MN(e) TMR's as a function of the vacuum mirror ratio of the plug $\mathrm{R}_{\text {vac, }}$ plug for plug mirror field $B_{\text {mirror }}=17.7 \mathrm{~T}$.

shows that an optimum mirror ratio extsts at about $\mathrm{R}_{\text {vac,plug }}=1.25$, somewhat higher than the point design value. However, the optimum is quite shallow, and the minimum cost is only $1.5 \%$ less than that for the point design. 
Variation of Blanket Energy

Multiplication

The blanket energy multiplication factor, $M$, is 1.2 for the point destgn. Figure 10-9 shows the predicted - t. for 1000-MW(e) 'TMR's (without $r$ optimization) as a function of $M$. The cost is insensitive to smail changes in $M$.

The Effect of a Beryllium Blanket

On the basis of our conceptual design of a Standard Mirror Fusion Reactor, ${ }^{10-2}$ we predict that an $M$ of 1.7 to 1.9 could be achieved in IMR with a beryllium-bearing blanket, which would cost about 2.4 times as much as the non-beryllium blanket.

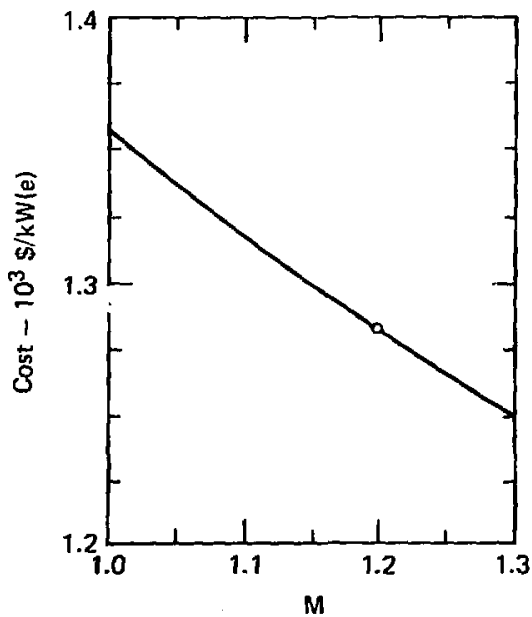

Fig. 10-9. Predicted cost for 1000MW(e) TMR's (without optimization) as a function of the blanket energy multiplication factor $M$.
We investigated the use of a beryllium blanket in the 1000-MW(e) TMR, and found that with reoptimization (central-cell ion temperature and plug-to-central cell mirror ratio), a beryllium-bearing TMR would be $3 \%$ less expenstve at $M=1.7$ and $6 \%$ less expensive at $M=1.9$. Either of these reactors would be considerably shorter than the point design $\left(L_{c}=62 \mathrm{~m}\right.$ for $M=1.7 ; L_{c}=59 \mathrm{~m}$ for $M=1.9$ ),

\section{Variation of Conversion Ef fictencies}

The point design values for conversion efficiencies are 0.4 for the thermal converter (Including the bottoming cycle of the direct converter, 0.6 for the direct converter, and 0.8 for the injector system. (Recent work on the injector system, discussed in chapt. 7, indicates that 0.7 may be a more accurate prediction of the injector system effictency.)

Pigure 10-10 shows the percentage change in the predicted cost of 1000-MV(e) TMR's without reoptimization) as a Eunction of the three efficiencles. For a given percentage point change in efficiency, the change in reactor cost is the greatest for changes in the thermal efficiency and the least for changes in the direct converter efficiency.

We also investigated the effect of a simultaneous 5 percentage point change in all three efficiencies from their point design values. For a 5 

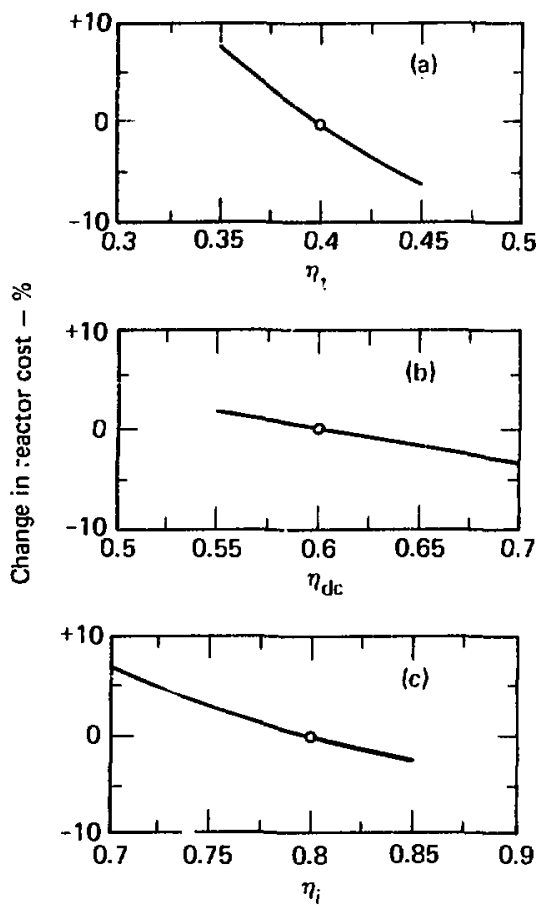

Fig. 10-10. Percentage change in the predicted crst of 1000-MW(e) TMR's (without reoptinization) as a function of the efficiencies (a) of the thermal converter $n_{t}$, (b) of the direct converter $n_{d c}$, and (c) of the injector system $n_{i}$.

percentage potnt decrease in the efficiencies, the predicted cost of. the 1000-MW(e) TMR (without reoptimization) increased by $14 \%$; for a 5 potnt increase, the reactor cost decreased by $9 \%$.

\section{Variation of Injector Cost}

For the point design (and all the parametric variations discussed above) the injector system for the plug estimated to cost $\$ 200 / \mathrm{kW}$ of electrical power input to the injectors. (since the point design value for injector efficiency was estimated to be 0.8 , this cost is equivalent to $\$ 250 / \mathrm{kW}$ of neutral-beam power.) Because recent work suggests that this value nlay be low, we investigated the effect of a doubled cost for the injector system: $\$ 400 / \mathrm{kW}$ of electrical power input, or $\$ 500 / \mathrm{kW}$ of neutral-beam power. The result for a woptimisud (central-cell ion temperaturc and plug-to-central cel1 mirror ratio) $1000-M W(e)$ IMR is an $11 \%$ increase in the pre ted reactor cost. Thus, it is quite important to resolve the question of injector cost. In Chapt. 7, the cost estimate of $\$ 320 / \mathrm{kW}$ is intermediate between the $\$ 250$ and $\$ 500$ values; our best curreni estimate therefore represents a $5 \%$ increase in reactor cost.

\section{Electron Heating}

Direct heating of electrons in the TMR is an attractive idea because it would reduce the required neutralbeam injection energy in the end plugs. In our investigation of the ef fect of electron heating, we assume that the electrical efficiency of such heating as well as its cost per unit power ts the same as for the neutra1beam injectors. Figure 10-11 shows the optimum neutral-beam energy and 


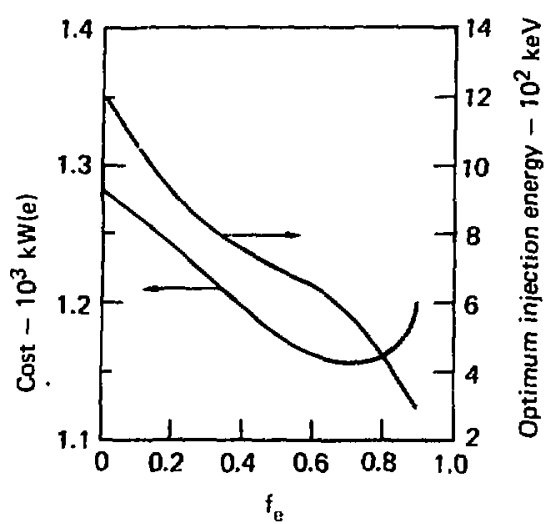

Fig. 10-11. Opt Imum neutral-beam injection energy and predicted cost of opt Imized 1000-MW(e) 'I'MR's as functions of $f_{e}$, the rraction of the total. heating that goes to the electrons.

the predicted cost of optimized $1000-M W(e)$ reactors as functions of $f_{e}$, the fraction of the total heating that goes directly to the electrons.
For our point design with neutralbeam injection only, $f_{e}=0$. There is an optimum value of $f$ near 0.75 for which the cost of the reactor is reduced to $\$ 1160 / \mathrm{kW}(\mathrm{e})$. The neutra1beam injection en:rgy for this optimized reactor ts $500 \mathrm{keV}$.

\section{REFERENCES}

10-1. F. M. Coensgen, IMK Major l'roject proposal (Appendix B: "landem Mirror Reactor Scaling" by B. G. Logan), Lawrence Livermore Laboratory, kept. LLL-Prop 148 (1977).

10-2. R. W. Moir, Sctentific Editor, itanlard Mirrö Fusion Reactor besign Study, Lawrence LIvermore Laboratory, Rept . UCII-17644 (in preparation). 


\section{CHAPTER 11. STARTIP SCENARIO}

\section{H. G. Lown and h. W. Hoir}

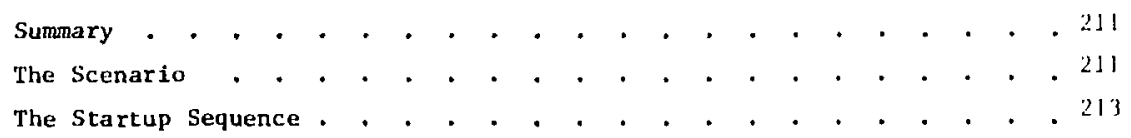


SUMMARY

In this chapter, we present some preliminary thinking about how to start up the Tandem Mirror Reactor (TMiR). Considerations incluje startup time, total invested 1.2-MeV neutralbeam power, and the sequence followed to achieve a steady-state power output of $1000 \mathrm{MW}(\mathrm{e})$.

THE SCENARLO

In our preliminary thinking about the startup scenario for the TMR, we consider a startup procedure in which beams from the 1.2-MeV neutral-beam modules ${ }^{*}$ impinge on a low-energy, initial plasma target of density $\left.\mathrm{n}_{\mathrm{p}}\right|_{\mathrm{t}=0} \equiv \mathrm{n}_{\mathrm{pO}}=0.01 \mathrm{n}_{\mathrm{pf}}$, where $\mathrm{n}_{\mathrm{pf}}$ is cice final (asymptotic) plug density. We neglect the initial power and energy required to provide the target plasma. The initial target density in $2 X I I B$ is about $1 \%$ of the maximum value (plusma stream density $n_{s}=10^{1.2}$; final $2 \mathrm{X}$ density $\hat{\mathrm{n}}=10^{14}$ ). We wish to calculate the startup time $t_{s}$ and the total neutral-beam energy $W_{b}$ invested during startup of the TMR:

$W_{b} \equiv \int_{0}^{t} s P_{b}(t) d c$.

The startup time $t_{s}$ can be defined

"When any module is "on", it is on at full voltage, current density, and power. as the time required for the density in the plug (and the corresponding density in the solenoid

$$
\frac{n_{c}(t)}{n_{c f}}=\frac{n_{p}(t)}{n_{p f}}
$$

to reach $63 \%$ of lts maximum value, at which time the grosis electric power of the reactor $(0.4$ of that at [u1] power) should be just suffictent to take over and power the neutral beams [or a zero net power $(Q \quad 1)$. DifEerent beam power tIme functions $\mathrm{P}_{\mathrm{b}}(\mathrm{t})$ may be consldered to minimize startup energy.

The rate equation for $n_{p}(t)$ is given by

$$
\begin{aligned}
& \frac{d n}{d t}=\frac{I_{b O}}{q V_{p}}\left\{1-\exp \left[-n_{p}\left(2 r_{p}\right) \sigma_{e r}\right]\right\} \\
& -\frac{n_{p}^{2}}{(n t)_{p}} \text {, }
\end{aligned}
$$

where $V_{p}=4 / 3 \pi r_{p}^{3}$ is the volume of the plug Iperhaps $r_{p}=r_{p}(t)$, but it might be taken constant wich certain profiles of target plastia and bearn injection] .

We assume that the incident beam current $I_{b U}$ may be approximated by a pencil beam aimed through the plasma diameter and that it is attenuated by an effective cross section $\sigma_{\text {eff }}=\frac{\sum\left\langle\sigma_{i} v\right\rangle}{v_{0}}$, which is nearly all Ionfation on deuterons at $E_{1 \mathbf{n} j}$ $=1.2 \mathrm{MeV}\left(\sigma_{\text {eff }} \approx 1 \times 10^{-16} \mathrm{~cm}^{2}\right.$ at 
1.2 MeV). Furthermore, we assume that the plasma confinement product (nt) ${ }_{p}$ is independent of density, as is appropriate for classical loss rates due to ion-ion scattering and electron drag. Since the IMR plasma energy balances for $T_{e}$ and $T_{i}$ are also independent of $n_{p}$ or $n_{c}$ as long as we keep $n_{p} / r_{c}$ constant, we can take $T_{e}$, $T_{i}$ and $\left(n^{\mathrm{C}} i\right)_{\mathrm{p}} \quad 6 \times 10^{9} \mathrm{E}_{\mathrm{inj}}^{3 / 2}=2.5$ $\times 10^{14} \mathrm{~cm}^{-3} \cdot \mathrm{s}$ constant to zero order.

When $n_{p}$ is small, the plasma is thin to the beam, and the loss term $n_{p}^{2} /(n T)_{p}$ can be neglected. Equation $(11-2)$ then gives

$$
\frac{d n_{p}}{d t}=\frac{I_{b 0}}{q^{V}}\left(n_{p}\right)\left(2 r_{p}\right)\left(\sigma_{e f f}\right) ;(11-3)
$$

that is, $n_{p}$ increases exponentially in time as

$$
n_{p}(t)=n_{p 0} \exp \left(t / \tau_{0}\right)
$$

with a time constant $\tau_{0}$ given by

$$
\tau_{0}=\frac{q V_{p}}{I_{b 0}\left(2 r_{p}\right) \sigma_{\text {eff }}}
$$

At high density, the plasma becomes thick to the beam, so that $\exp \left[-n_{p}\left(2 v_{p}\right) \sigma_{e f f}\right]=0$, and the loss term $n_{p}^{2} /(n \tau)_{p}$ begins to dominate. Equation (11-2) predicts that the density will saturate to a maximum value $n_{p f}$ at equilibrium $\left(\mathrm{dn}_{\mathrm{p}} / \mathrm{dt}=0\right)$ given by

$$
\frac{I_{b 0}}{q V_{p}}=\frac{n_{p f}^{2}}{(n \tau)_{p}}
$$

that is,

$n_{p f}=\left[\frac{I_{b 0}(n t)_{p}}{g V_{p}}\right]^{1 / 2}$.

Starting with $0.01 \mathrm{n}_{\mathrm{pf}}$ density in the thin-plasma $11 \mathrm{mit}$ and assuming constant $I_{b}, r_{p}$, and $\tau_{0}$, we can estimate the startup time for the density to exponentiate to $0.63 \mathrm{n}_{\mathrm{pf}}$

$$
t_{s}=\tau_{0} \ln 63=4 t t_{0}
$$

Let us conslder the case where all the beam current and power required to maintain the steady state at $n_{\mathrm{pf}}=8.6 \times 10^{14} \mathrm{~cm}^{-3}, \mathrm{r}_{\mathrm{p}}=48 \mathrm{~cm}$ at $\mathrm{E}_{i n j}=1.2 \mathrm{MeV}$, and ${ }_{\mathrm{n}}{ }_{\mathrm{P}}^{\mathrm{P}}=2.5 \times 10^{14}$ $\mathrm{cm}^{-3}$.s are switched onto the target at $t \quad 0$ and maintained constant during the bulldup. For these parameters, $\mathrm{Eq} \cdot(11-6)$ gives $\mathrm{I}_{\mathrm{b} 0}=219 \mathrm{~A}$ for all beam trapped and $I_{b 0}=244 \mathrm{~A}$ for $10 \%$ beam transmission in the steady state. Then $\mathrm{Eq}$. (11-5) gives an exponentiation time constant $\tau_{0}=32 \mathrm{~ms}$ and a startup time $t_{s}=0.13 \mathrm{~s}$. This is a very short time. The beam energy consumed during this time is

$$
\begin{aligned}
w_{0}=(2)(244 \text { A })\left(1.2 \times 10^{6}\right) & \\
(0.13) & =76 \mathrm{MJ} .
\end{aligned}
$$

This energy is within the range of energy that can be stored in devices such as batteries or homopolar generators. In fact, however, $t_{s}=0.13 \mathrm{~s}$ 
is too short for reactor startup

because the characteristic time constant for hot alpha particles and electrons to heat solenoid ions is $n \mathrm{drag}^{/ \mathrm{n}} \mathrm{e}=\left(2.7 \times 10^{14} \mathrm{~cm}^{3} / \mathrm{s}\right) / 10^{14} \mathrm{~cm}^{-3}$ $=2.74 \mathrm{~s}$. Thus, fusion power will not be generated until several seconds after the plug plasmas have been built up.

The thermal time constant for the blanket is much larger:

tolanket

$$
\begin{gathered}
\approx \frac{\left(10^{6} \mathrm{~cm}^{3}\right)\left(500^{\circ} \mathrm{C}\right)\left(4 \frac{\mathrm{J}}{\mathrm{cm}^{3} \cdot{ }^{\circ} \mathrm{C}}\right)}{2 \times 10^{6} \mathrm{~W} / \mathrm{m}^{2}} \\
=10^{3} \mathrm{~s} .
\end{gathered}
$$

Most of the neutral-beam power can be supplied by the direct converter once the plasma starts to burn (i.e., after a few seconds), so that the power that must be taken off the local grid can be a small fraction ( $(25 \%)$ of the net final power put into the grid.

THE STARTUP SEQUENCE

If we assume that we shall achleve a steady-state power of $1000 \mathrm{MW}(\mathrm{e})$ with the TMR, the startup sequence would be as follows:

1. The magnet is cooled down and the field is generated.

2. The blanket and the thermal conversion part of the direct converter are warmed up by circulating helium, which is heated externally. Assume this requires $25 \mathrm{Mh}$.

3. The cryogenic magnet is energized; chis requires about $25 \mathrm{~kW}$ of refrigeration power. A rough estimate for the energizing time is $10 \mathrm{~s}$.

4. A target plasma is created from energy stored in a capacitur bank.

5. The neutral-beam modules are turned on in the plugs; this consumes 734 MW (e).

6. The plug plasma builds up to [u1] density, and the plasma becomes steady state with $90 \%$ beam attenuation after $0.1 \mathrm{~s}$.

7. The direct converter then begins to recover the injected, trapped beam power. This is $320 \mathrm{MW}$ from the direct converter plus $85 \mathrm{MW}$ from the thermal bottoming cycle.

8. After $3 \mathrm{~s}$, the center-cell plasma reaches its steady-state density and temperature. (Because we assume a D-D mixture in the center cell, the fusion power will be low.)

9. The mixture is changed in about 10 minutes to a 50-50 D-T mixture so as to keep the power transient in the thermal conversion system less than $5 \%$ per minute, which is standard power plant operation.

Figure 11-1 shows the power that must be supplied versus time during startup of the TMR. Note that $800 \mathrm{MW}$ is supplied for $0.1 \mathrm{~s}$ and $400 \mathrm{MW}$ for a few minutes. 


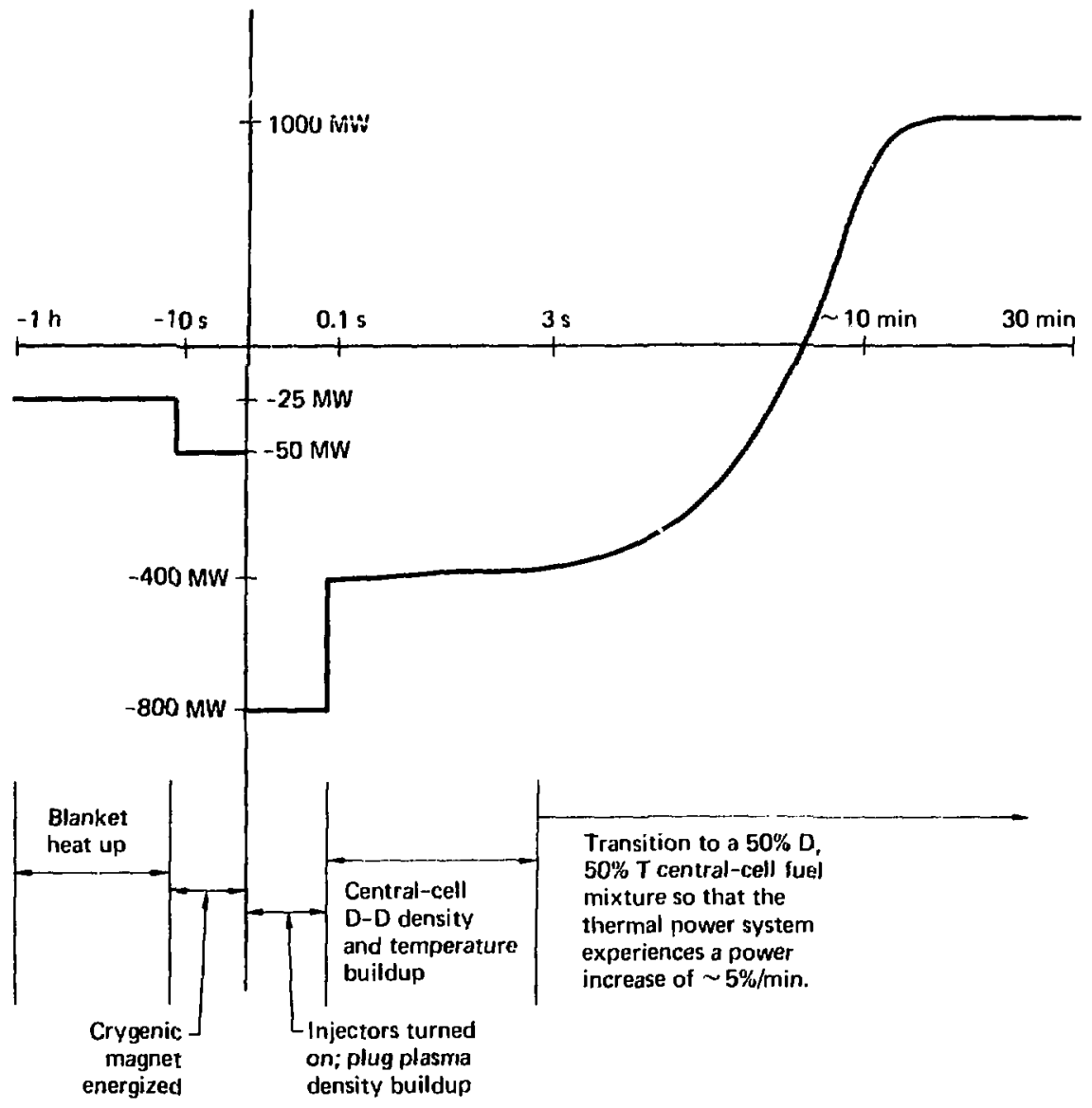

Fig. 11-1. Net electrical power from TMR during the startup sequence.

It should be emphasized that startup months. It may be possible to start is an event that can be scheduled for up with less than full power in the times when excess capacity from the beams and thus reduce the 800-MW and grid is avallable. Also after startup 400-MW power requirements.

the reactor will run continuously In the next study on the TMR, the unt11 a scheduled maintenance or un- question of startup will be examined planned outage occurs; that could be more carefully in a systems context. 
We sha11 treat questions such as the best ways to store energy during plasma buildup, the fraction of full load that can be sustained, the factors affecting load-following characteristics.

tromsicht power loading (i.e., how fast can we sof from the power-consuming phise to the power-output phase), and nd can he sustained, the factors afrecting loan-following characturistics. 


\section{CHAPTER 12. ASSESSMENT OF NEEDED TECHNOLOGY}

\section{P. W. Moir}

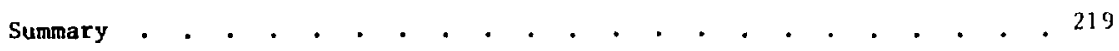

Technology Representing State-of-the-Art or Being Developes. . . . . 219

Technology Needing Special Development Programs . . . . . . . . . 219

References . . . . . . . . . . . . . . . . . . . . . 220 
SUMPARY

Much of the technology needed fo: the Tandem Mirror Reactor (TMR) is either scate-ot-the-art or is alleady being developed for uther fusion reactor designs. We have proposed spectal development programs for areas of cechnology not falling into vither of these categories.

TECHNOLOGY RTPRJ:SFETING:

STATT:OF-THE-ART' OR BETNG DEVELOPED

\section{Brianket}

The blanket in the lMR hits al simple cylindrical geometry and modest $\left(2 M \cdot \mathrm{m}^{-2}\right)$ wall loitling. Therclore, the naterial requitrements and first-wall design are similiar lo if not atsier to fulfill than those In other fusion reactor designs.

\section{Contri1-Coll Magnet}

The central-cell magnet is a $\mathrm{Nb}-\mathrm{l} t$, 2.5-1, dc supercondact Ing coil. that could use state-of-the-irt tecinology.

Superconducting Magnet for the lind Plug

The superconducting magnet in each end plug is constructed rrom $\mathrm{Nb}_{3}$, in and has a $17.3-' l$ fileld at the winding. Because this magnet is a simple solenoidal palr and has a simply curved, winding pattern with a 4- to 5-m radius of curvature, there are no sperefal problams due co peometry. The combluctor is now belng developed and will probably be available within 5 yeirs.

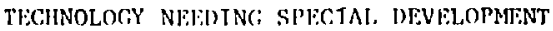
PROCIRAMS

Cryogenic Magnet ror the lind Plug

'l'he cryogen ic Yin-Yang magnet used in each end plug is made of aluminum, produces an furremental 1-T field superimposed on the 17.3-7 fleld of tha solenoldil palr, and ts about $3 \mathrm{~m}$ in diameter. This coll represents a nodest extension of stace-of-the-art teclmology and could probably be buit in 10 years. See Rer. 12-1 for the magnet devolopment prosiam plan.

Fond-lys Injocent

A high-onergy $(120 i)-k e V)$ high-

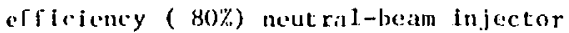
Is used for the and plugsi. 'Jiac' negative-ion technology that ls the bals is for this infection system does not now exist, and only a small development progratn ls underway. However, the basic processes are we 11 known and each Individual step has been demonstrated. Rapld progress is likely once a sizable effort is nounted. $\Lambda$ program plan for the development of a neutr:1-beam injector whose design is basod on the production of negative-ion beams is discussed elsewhere. ${ }^{12-2}$ 
The direct converter on each end of the TMR is beyond the state of the art. Smal1-scale experiments at $100 \mathrm{keV}$ are underway that are relevant to the $300-$ to $400-\mathrm{keV}$ conditions In TMR. Also, we plan to mount a small plasma direct converter on each end of the Tandem Mirror Experimert (TMX). The development plans for direct energy conversion are discussed in a drait program plan for direct conversion. $12-3$

\section{Plasma Production and Control}

A great deal of experimental information is needed on techniques for plasma production, impurity control. pumping, etc. It is partially in response to this need that we have initiated the TMX. 12-4

12-1. Frogram for vevezopment of Wigh-iield Supenoomiuating saynets jof Fuzion Feseapch, Lawrence Livermore laboratory, Rept. Misc-2007 (1975).

12-2. F. B. Hooper and R. V. Pyle, Negative Iom Progrom flan, Lawrence Livermore Laboratory, Rept. (in preparation).

12-3. R. W. Moir, G. W. Hamilton, and W. L. Barr, Ppetiminary Trogram I'zan for trirect Energy Convergion, Lawrence Livermore Jaboratory, Rept * UCRL-52141 (in preparation).

12-4. G. H. Coensgen, Project Leader, TMX Majox Project Proposal, Lawrence Livermore Laboratory Rept. LLL-Prop-148 (1977). 